\title{
Managing risks of violence in decriminalised street-based sex work: a feminist (sex worker rights) perspective
}

By

Lynzi Armstrong

A thesis

Submitted to the Victoria University of Wellington in fulfilment of the requirements for the degree of Doctor of Philosophy in Criminology

Victoria University of Wellington 


\begin{abstract}
It is widely understood that street-based sex workers are vulnerable to experiencing violence in their work. The Prostitution Reform Act (PRA) was passed in New Zealand in 2003, decriminalising sex work with the intention of supporting the health, safety, and human rights of sex workers. This thesis explores strategies to manage risks of violence amongst women working on the streets in New Zealand, considering how the law change has impacted on the management of these risks, and whether further change is required to better support the safety of street-based sex workers.

Drawing from the perspectives of women working on the streets, this thesis challenges portrayals of street-based sex workers as passive recipients of violence. The experiences and perceptions of these women highlight the diverse violencerelated risks they managed from a range of potential perpetrators, including passersby, individuals approaching as clients, other sex workers, and minders. The shift to decriminalisation has not eliminated violence. However, the findings suggest that the law change has provided a framework that better supports existing risk management strategies. For instance, in removing the possibility of arrest for soliciting, the PRA has provided an environment in which these women have sufficient time to screen potential clients on the street. Moreover, the perceptions of these women suggest that the law change has to some extent improved the relationship between police and street-based sex workers. Nevertheless, whilst decriminalisation has created an environment more conducive to sex worker safety, it is clear that challenges remain in addressing violence against sex workers. Since the sex industry does not operate in social and political isolation, moral discourses continue to stigmatise and threaten the wellbeing of street-based sex workers.
\end{abstract}

The overall conclusion of this thesis is that whilst decriminalisation was an important first step, moving forward to proactively challenge violence against street-based sex workers requires a paradigm shift away from discourses that support violence, to a more positive acceptance of street-based sex work in New Zealand society. 


\section{Acknowledgements}

There are many people who have supported and inspired me throughout the past three and a half years spent working on this thesis, which has been for me not just another academic pursuit but also a significant personal journey.

Firstly, I want to sincerely thank the women who took time out of their lives to be interviewed for this research. Thank you for trusting me with your stories. I hope that this thesis represents with fairness and accuracy, the experiences that you so generously shared with me. I would also like to thank other sex workers who were not formally interviewed but who made me feel welcome, and also provided informally some valuable insights from time to time.

I also wish to thank all of the individuals who participated in key informant interviews. Thank you for taking the time to share your views with me. Your helpful insights are all appreciated greatly.

This thesis would not have been completed without the involvement of my supervisors, Dr Jan Jordan and Dr. Elaine Mossman. I sincerely thank both of you for the invaluable support and guidance you provided throughout the entire process. Jan thank you for continually inspiring me, challenging my thinking, and helping me understand some of the complexities of research (and of life in general!) Elaine thank you for teaching me essential research skills, sharing your technological expertise, and keeping me organised through to the final stages of writing up. Thank you both for your wisdom, patience, and encouragement. I could not have wanted for better supervision.

The support and guidance provided by NZPC was also instrumental in ensuring the completion of this research. I particularly want to thank two truly inspiring women, Catherine Healy - National Coordinator and Anna Reed - Regional Coordinator of the Christchurch branch. Catherine - thank you sincerely for your expert guidance, honest feedback, encouragement, and also tolerance (particularly early on in the research process when I was still finding my way). Anna - thank you for supporting the fieldwork in Christchurch, and for your kindness, guidance and encouragement. I have learned so much from both of you. Thanks also to others from NZPC who welcomed me and shared extremely useful insights from time to time. Specifically I'd 
like to thank - Calum, Rochelle, Hannah, Chanel, Jasmine, Suzy, Tracey, Sue and Jo along with others I have met briefly over the years. I truly appreciate how welcoming you all were to me whilst doing this research.

I wish to thank Wendy Barney from the Salvation Army for allowing me to be involved in the services for street-workers and supporting me throughout the fieldwork in Christchurch. Thank you sincerely for your kindness. Furthermore, I'd like to thank the many volunteers in the drop-in centre and outreach van for allowing me to accompany them. Particular thanks to Sue who gave me frequent rides home and was great company into the early hours.

Thanks also to Kim Boyce from Youth Cultural Development for supporting the research by allowing me to attend the drop-in and for helping recruit women to take part in the research. Your assistance was greatly appreciated.

I would like to acknowledge Brenda Watson for transcribing 12 of the interviews and also Cara Gledhill, Hollie Doar, Jamie Armstrong, and Kim Dobson for kindly assisting with final proofreading.

I have been very fortunate to have the support of family, friends and partners during the past three and half years. Sincere thanks to my parents for supporting me throughout my life and believing in my personal goals. Thanks to all of the friends who have been there helping me remain smiling (and sane!) at various stages throughout my years spent in New Zealand working on this thesis - particularly Kim, Hollie, Phil, Jemima, Cara, Aura, Lana, Shona, Sophie and Alex. I'd also like to acknowledge Sarah and Dom who were excellent flatmates putting up with me in the final months of writing my thesis when my stress levels were increasing significantly!

Thanks also to others who helped support my $\mathrm{PhD}$ journey in other ways throughout the three and a half years, though particularly in the final stages - through selfdevelopment, personal reflection, and 'fun'. Without your support this thesis may not have been completed. You know who you are.

Final thanks to Victoria University for providing funding to support this research for three years and in the final writing up stages - I appreciate greatly the support that has been given in helping me to complete this thesis. 


\section{Table of Contents}

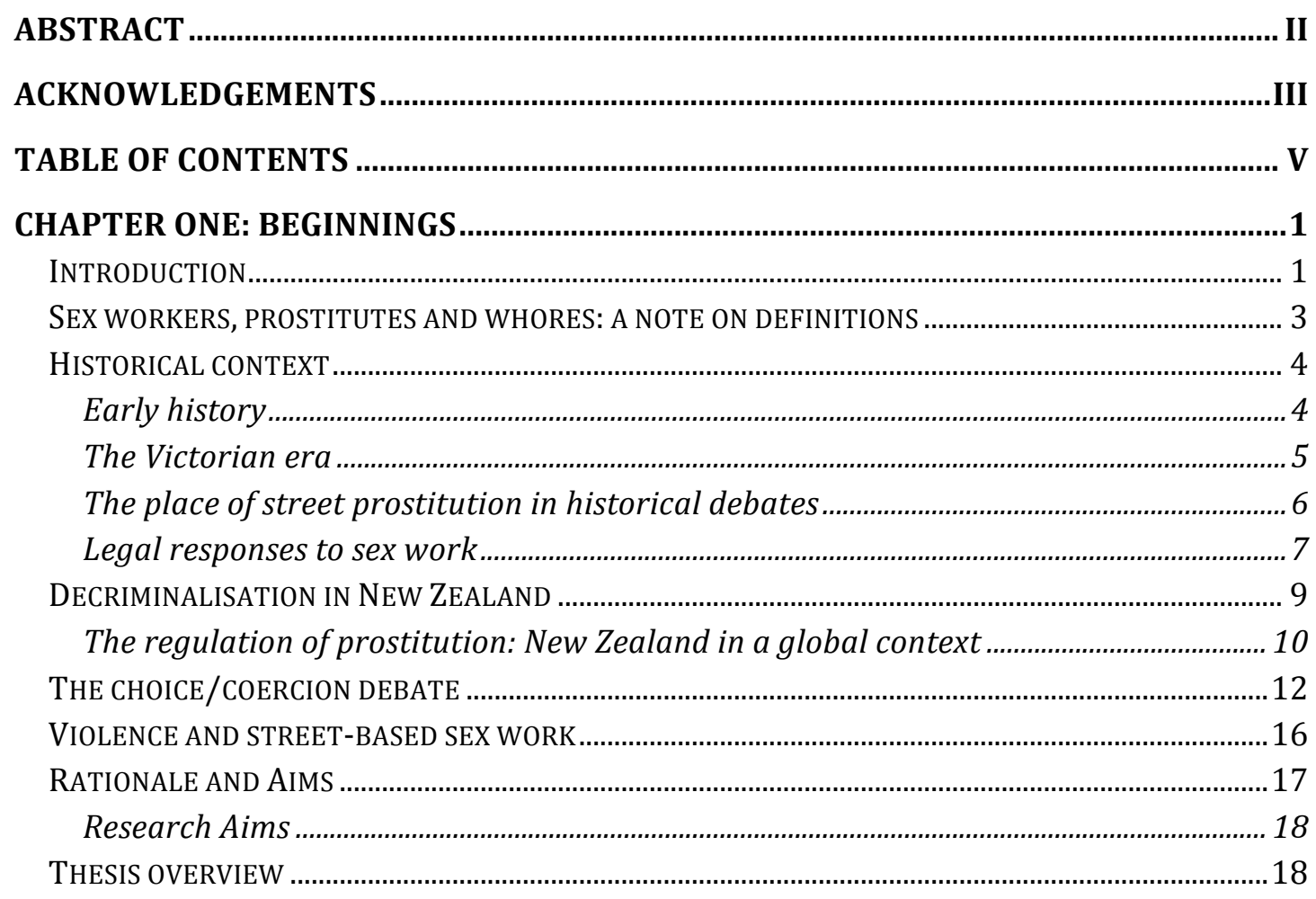

CHAPTER TWO: VIOLENCE AND THE MARGINALISED STATUS OF STREET-BASED

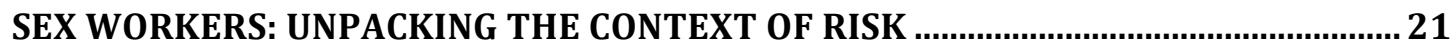

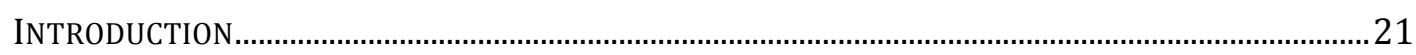

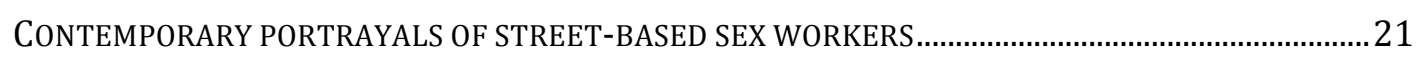

Street-based sex workers as deviants.................................................................................... 22

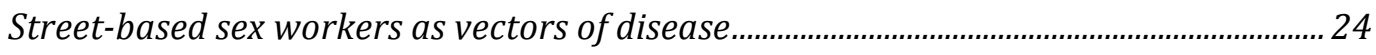

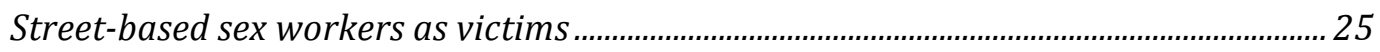

Contemporary constructions: unpacking the context of violence ....................................... 27

THE NATURE AND PREVALENCE OF VIOLENCE IN STREET-BASED SEX WORK........................................29

Who perpetrates violence against sex workers? .............................................................. 30

The nature of violence ........................................................................................................... 32

The prevalence of violence in street-based sex work …………............................................... 33

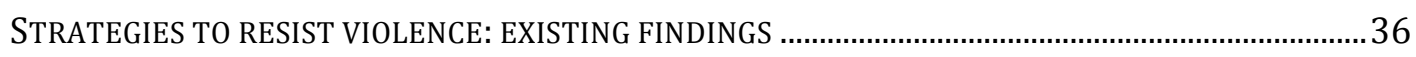

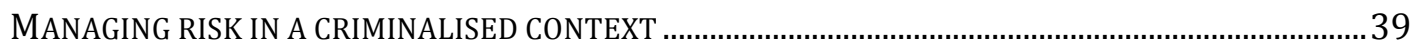

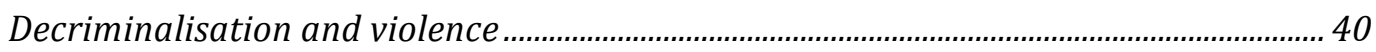

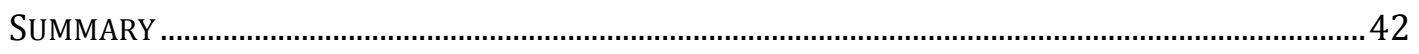


CHAPTER THREE: METHODOLOGY

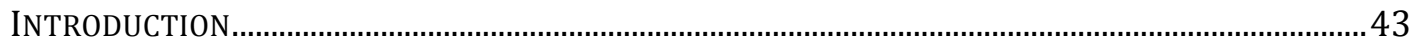

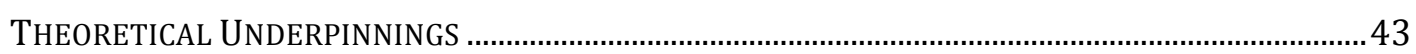

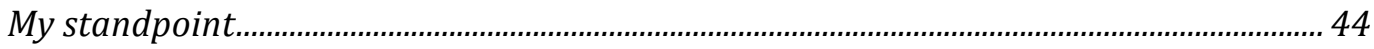

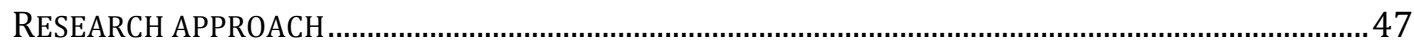

SELECTING METHODS AND PLANNING THE DATA COLLECTION ...................................................... 48

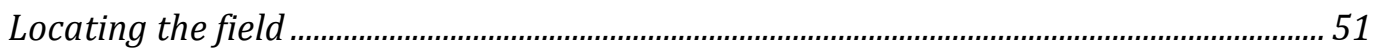

AN OPEN AND CLOSED ENVIRONMENT: FACILITATING ACCESS IN THE DECRIMINALISED CONTEXT 52

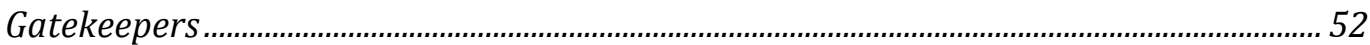

Recruiting participants: the field in Christchurch.............................................................. 54

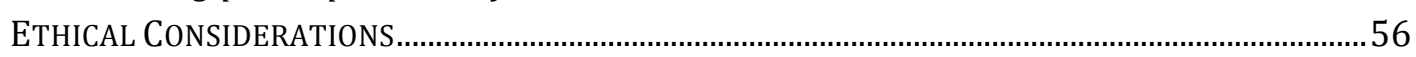

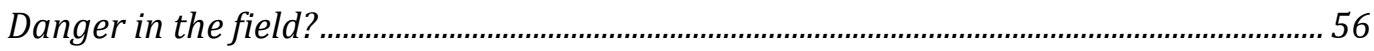

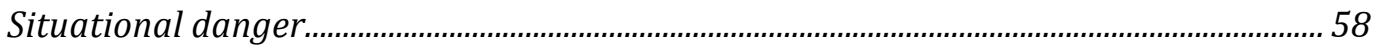

ETHICAL RESEARCH IN PRACTICE ………............................................................................ 58

Obtaining informed consent and ensuring privacy............................................................. 59

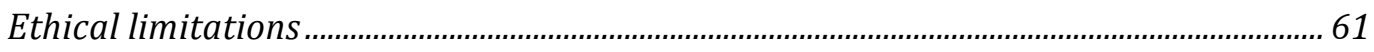

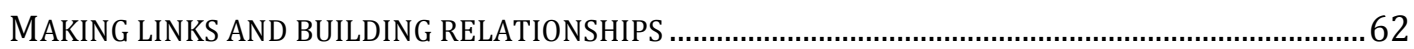

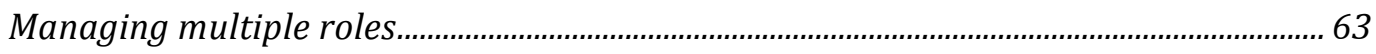

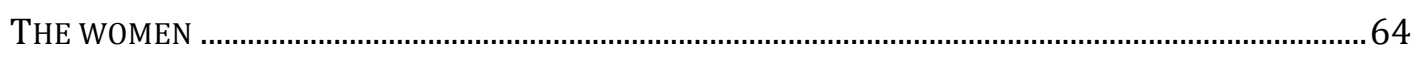

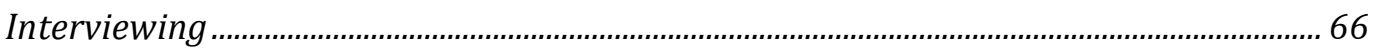

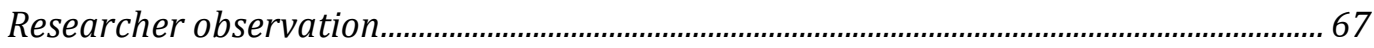

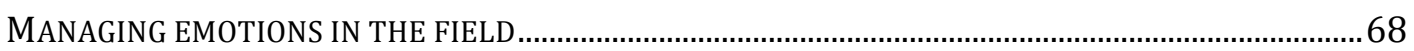

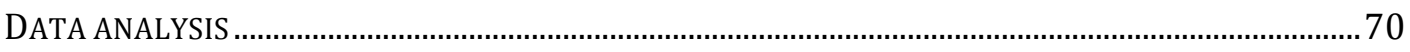

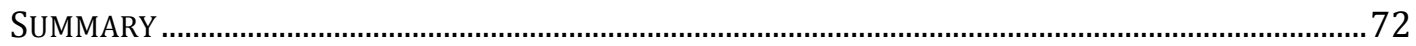

CHAPTER FOUR: PERCEPTIONS AND EXPERIENCES OF VIOLENCE.............................. 73

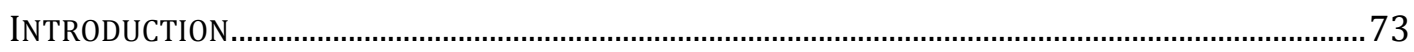

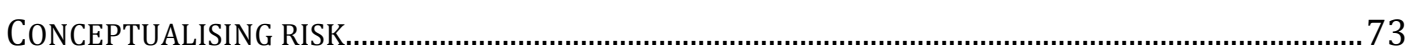

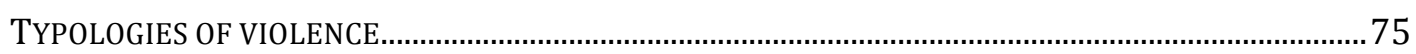

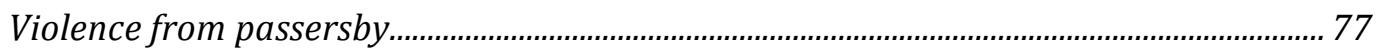

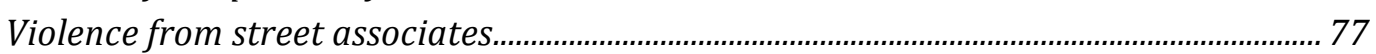

Violence between sex workers................................................................................................... 78

Risks of violence from clients: the good, the bad, and the ugly........................................ 79

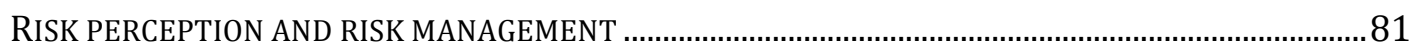

PERCEPTIONS OF VIOLENCE IN THE STREET CONTEXT ………........................................................ 84

THE EXPERIENCE OF VIOLENCE AND PERCEPTIONS OF RISK...............................................................89

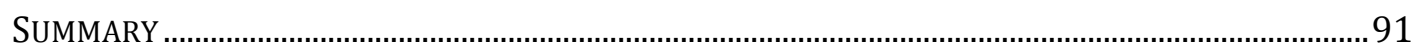

CHAPTER FIVE: ASSESSING RISK: SCREENING CLIENTS IN THE DECRIMINALISED CONTEXT

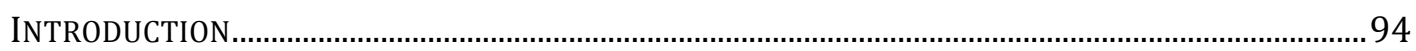

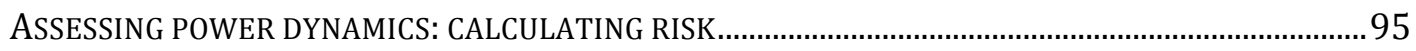

READING THE CLIENT: BODY LANGUAGE AND EYE CONTACT .............................................................96

AGE AND ATTITUDE

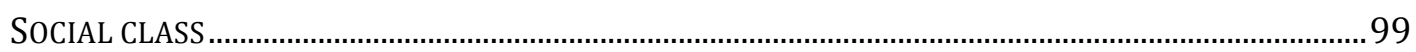

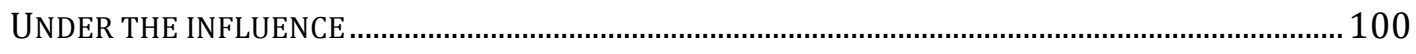

PREDICTING COMPLIANCE: SETTING THE TERMS OF THE ENCOUNTER........................................... 104

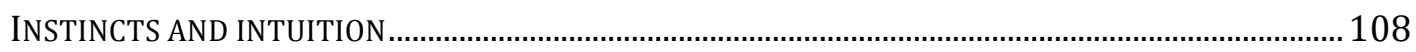


COMPLETING THE SCREENING PROCESS: CHECKING AROUND THE CAR .......................................... 109

SCREENING IN A DECRIMINALISED ENVIRONMENT ................................................................... 110

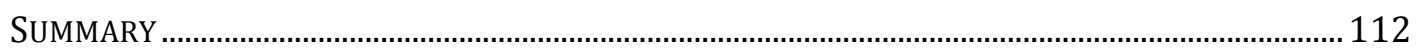

CHAPTER SIX: BOUNDARIES, RULES, AND TENSIONS: MANAGING RISKS OF

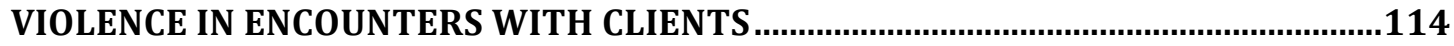

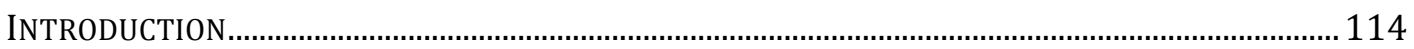

POWER, CONTROL AND VIOLENCE IN SEX WORK …………......................................................... 114

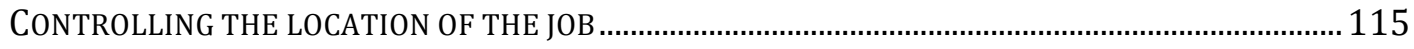

RISK AND TRUST: STRATEGIES TO EXIT SAFELY AND INHERENT TENSIONS ....................................119

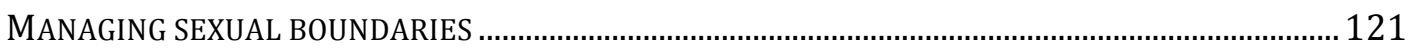

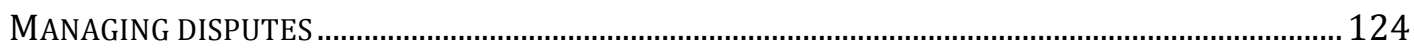

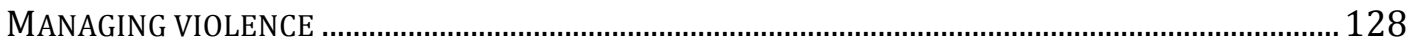

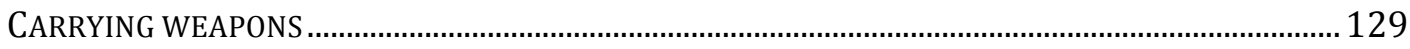

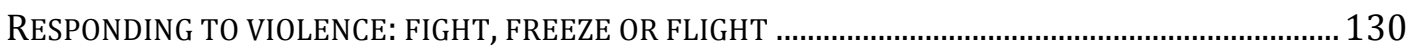

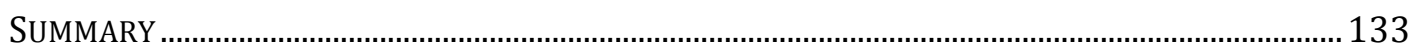

CHAPTER SEVEN: 'WHO'S THE SLUT, WHO'S THE WHORE?': THE EXPERIENCE AND

MANAGEMENT OF VIOLENCE FROM PASSERSBY ......................................................135

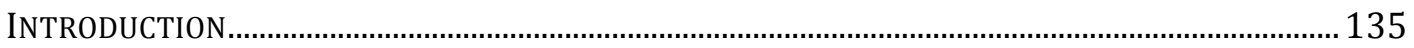

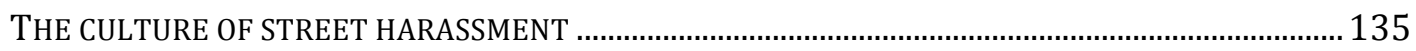

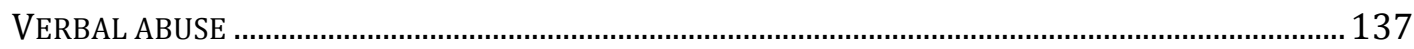

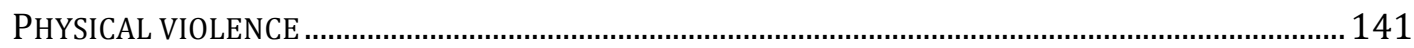

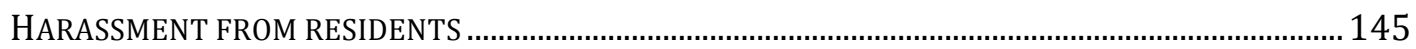

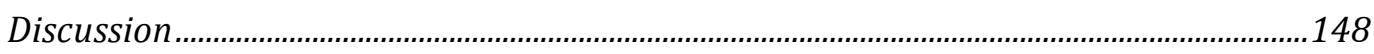

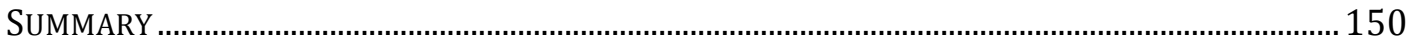

CHAPTER EIGHT: BEYOND INDIVIDUAL ACTIONS: COLLECTIVE STRATEGIES TO

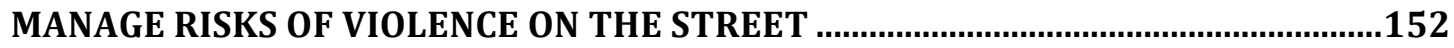

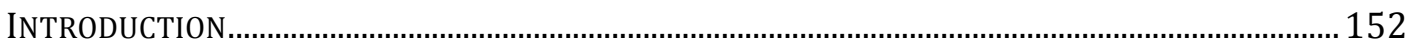

PEER SUPPORT AND SAFETY: FRIENDSHIP, CONFLICT AND THE MANAGEMENT OF RISK..................152

Sharing information to prevent violence..........................................................................153

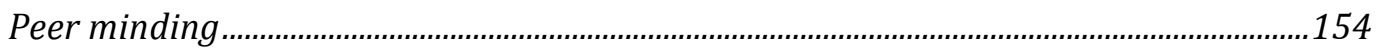

Providing 'back up'? Challenges and contradictions..........................................................155

THE ROLE OF MINDERS ON THE STREET: SUPPORTING SAFETY OR SUPPORTING EXPLOITATION? 159

THE ROLE OF THE POLICE IN A DECRIMINALISED CONTEXT …………………………….................. 166

From law enforcement to protection ...............................................................................167

The role of the police post-decriminalisation: police perceptions......................................169

The role of the police: sex workers' perceptions..................................................................170

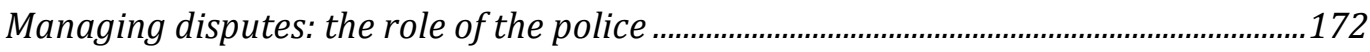

Supporting sex worker safety: barriers and tensions .......................................................174

Additional challenges............................................................................................................175

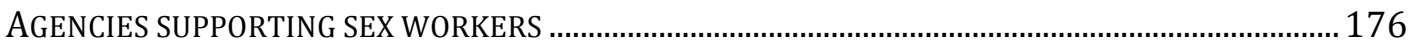

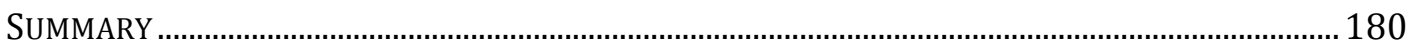

CHAPTER NINE: MOVING FORWARD: RISK MANAGEMENT STRATEGIES IN

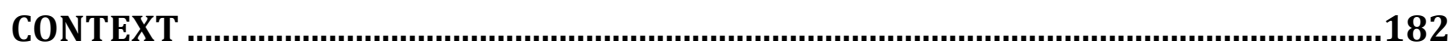

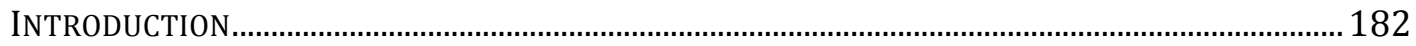

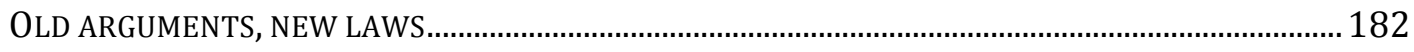




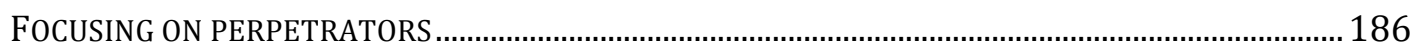

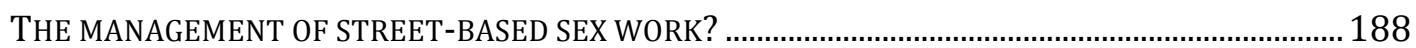

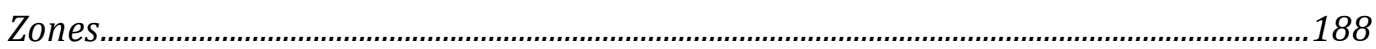

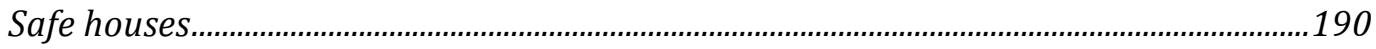

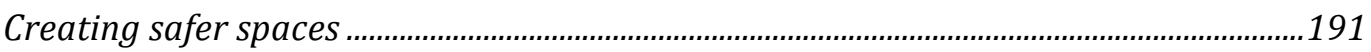

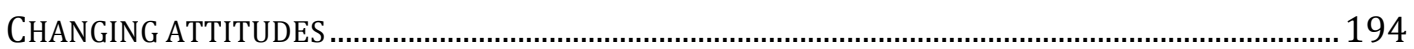

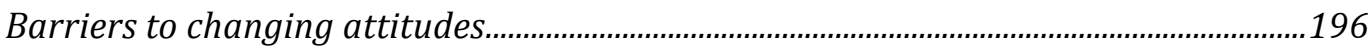

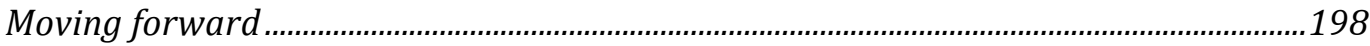

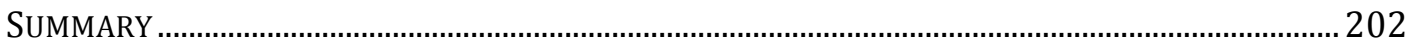

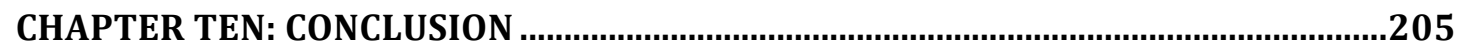

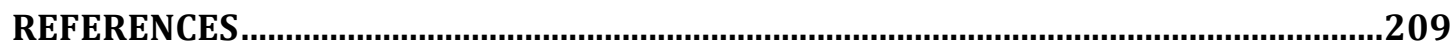

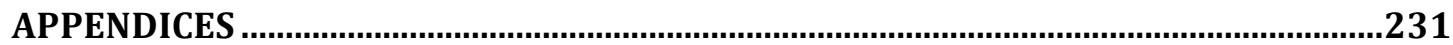

APPENDIX A: STREET BASED SEX WORKER INTERVIEW GUIDE ...................................................... 231

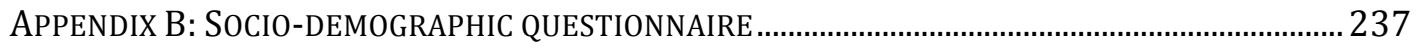

APPENDIX C: KEY INFORMANT INTERVIEW GUIDE ................................................................... 241

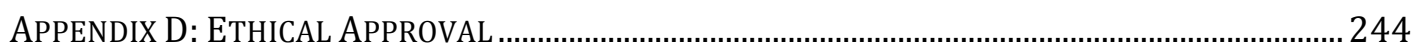

APPENDIX E: SEX WORKER PARTICIPANT INFORMATION SHEET .................................................. 245

APPENDIX F: KEY INFORMANT PARTICIPANT INFORMATION SHEET ................................................ 247

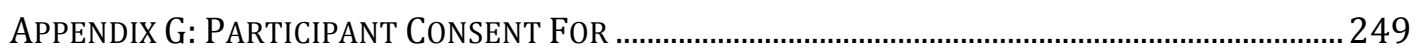





\section{Chapter One: Beginnings}

Punishing the prostitute promotes the rape of all women. When prostitution is a crime, the message conveyed is that women who are sexual are "bad", and therefore legitimate victims of sexual assault. Sex becomes a weapon to be used by men.

(Margo St. James, 1979) ${ }^{1}$

\section{Introduction}

For centuries the patriarchal legacy has ensured that sex workers are stigmatised and marginalised in society. This is reflected in the widespread criminalisation of sex workers globally and the denial of labour rights for those involved in sex work. Over 40 years have passed since sex workers (such as Margo St. James quoted above) began organising on an international scale against the criminalisation of sex workers and its relationship to the incidence of violence in the sex industry. Yet sex workers (and particularly street-based sex workers) continue to be criminalised in most parts of the world, and violence remains a key risk managed by sex workers globally. In recent years, a dramatic policy shift has set New Zealand apart from other nations in decriminalising all forms of adult sex work on a national level. This thesis explores strategies used by female street-based sex workers to manage risks of violence whilst working in the decriminalised New Zealand context.

This introductory chapter will contextualise the research and outline the research aims. This chapter begins with a brief background to my interest in this topic and an overview of key terms and definitions, following with an introduction to the historical context surrounding the research. The rationale for undertaking this research in New Zealand will be summarised. Key discourses that permeate dominant debates on sex work are then discussed, to highlight the foundations of my interest in the management of violence in the decriminalised street context. The research aims are then outlined. This chapter concludes with an overview of the structure of this thesis.

\section{Background}

My specific interest in the management of violence in sex work, and how this relates to the overarching legislative framework, was sparked in 2006 whilst observing media

\footnotetext{
${ }^{1}$ Margo St James was the founder of COYOTE (Call Off Your Old Tired Ethics), one of the world's first sex worker rights organisations, based in San Francisco.
} 
coverage of the murders of five women who worked as street-based sex workers in Ipswich in the United Kingdom (UK). Through this media coverage, I become more aware of the legal framework surrounding prostitution in the UK and how this impacts on street-based sex workers. I also developed an awareness of the dominant 'social nuisance' discourse surrounding street-based prostitution. In one news article, for instance, street-based sex work was described as "demeaning, disease ridden and dangerous... a public nuisance, a public health hazard and threatening to residents". In the same article the clients of street-based sex workers were referred to as "dirty, furtive strangers" and the stigma attached to street-based sex work was stated as a necessary "clear and harsh warning to others". The author concluded that the laws surrounding sex work should be revised, but only in relation to indoor sex work, so that street-based sex workers may move indoors (Marrin, 2006). Another commentator suggested that society bore no responsibility for the safety of sex workers and that the murder of sex workers on the street represented an “occupational hazard" (Littlejohn, 2006). Having already developed an interest in the laws surrounding sex work in the UK, I was aware of the transition to decriminalisation that had occurred in New Zealand in 2003. I was interested in how such a change may have impacted on those working on the street as sex workers, and was curious about how this framework might translate in the UK context. However, I could find no evidence documenting the effects of this change on the safety and wellbeing of street-based sex workers in New Zealand. Whilst researchers have called attention to the negative impacts of criminalisation on the capacity of sex workers to manage violence-related risks, there appeared to be a paucity of research exploring how the decriminalisation of prostitution impacts on violence risk management. At this time, in 2006, research exploring the impacts of the Prostitution Reform Act in New Zealand was ongoing and the findings were yet to be released (Abel, Fitzgerald \& Brunton, 2007; Mossman \& Mayhew, 2008; Prostitution Law Review Committee (PLRC), 2008). My interest in doing this research was, therefore, influenced by my curiosity about the potential impacts of the decriminalised framework on sex worker safety. The next sections further contextualise my research, starting with a brief overview of terms used in this thesis. 


\section{Sex workers, prostitutes and whores: a note on definitions}

In previous research on the sex industry various terms have been used to describe those selling sexual services and the terms used are important and relevant, because they infer an overarching perspective on the selling of sex. 'Prostituted woman' for instance is generally used to construct those who sell sex as devoid of agency since prostitution is not considered to be something that has been chosen but something that has happened to women (Rosen \& Venkatesh, 2008; Weitzer, 2006). The term 'sex worker' is a relatively recent term and reflects a recognition that selling sex is a form of labour (Kempadoo \& Dozema, 1998; Kinnell, 2008; Prestage \& Perkins, 1994). The term sex worker was first used by Carol Leigh, a sex worker rights activist also known as 'Scarlot Harlot' (Leigh, 1997). Sex worker is considered a more inclusive term that better reflects the experiences of the majority of service providers in the sex industry. Basu and Dutta (2008) note:

The term sex worker has gained precedence over the term prostitute because people involved in the profession view it as less stigmatising and better descriptive of their work and life experience. (p.107)

In this thesis the term sex worker is used predominantly since this is more representative. However, it should be noted that the women interviewed for this research used a range of terms to describe their work - including sex worker, prostitute, hooker, working girl, and whore. Whilst some of the women did not describe themselves as sex workers, this term better reflects their experiences overall. The constructing of selling sex as a form of labour is encompassed in the language used by sex workers (Jeffreys, 2005). Furthermore, Perkins (1991) explains:

They refer to themselves as "working girls" or simply "workers". The men who visit them are called "customers" or, more often "clients", and their payment is called a "fee" or "pay"...time spent with a client is known as "a job", or "a session", and the period involved is referred to as the prostitute's "time”. (pp.10-11)

The women involved in this research also used language frequently that defined their role on the street as a job, as a form of labour. Thus, the term sex worker is the most inclusive term, whilst acknowledging that many of the woman used less mainstream terms to describe their occupation. The term 'prostitute' is used when outlining historical debates in order to reflect the time period in which this word was predominantly used, and the fact that the term sex worker has only emerged in the 
past 20 years as a descriptor for service providers (Harris, Nilan \& Kirby, 2011). On occasion the word 'whore' is used in recognition of efforts to reclaim this word (Nagle, 1997; Pheterson, 1989; Roberts, 1992), and to reflect my commitment to destigmatise terms that have been used to disparage sex workers. The next section outlines the historical context surrounding the research.

\section{Historical context}

Locating my own research within a historical context is useful in providing a framework for analysis. Many parallels can be made between the way in which prostitution is understood in contemporary society, to how it was conceptualised in previous centuries, and to early biblical understandings of gender and sexual behaviour. To provide a full account of this is beyond the scope of a thesis of this type, and the following discussion will only touch on specific aspects of the history surrounding female sex work. This section will provide a historical account of the origins of social constructions of sex work, locating this in the New Zealand and also global context.

\section{Early history}

Throughout history, prostitution has been surrounded by myths and stereotypes (Walkowitz, 1980). It has been argued, however, that female prostitutes have not always been stigmatised; in pre-history (or what Roberts (1992) more aptly terms prepatriarchy), female prostitutes were temple goddesses, all-powerful, and considered very much in control of their sexuality. As Rindal (2004) notes, these women provided far more than just a "quick screw". Headed by Ishtar, Babylonian goddess of love and war, they "educated the savage” (p.p 10-11). There has been some debate regarding the existence of 'sacred' prostitution carried out by temple women (Roth 2005), arguing that some women who were portrayed as prostitutes were in fact often just women who were sexually available outside marriage (McClure, 2005). However, Roberts (1992) notes that the sexual divisions between groups of women are only as old as patriarchal society. These divisions are reflected in early Christian ideas regarding the position of women in society.

According to Bullough and Bullough (1987), patriarchal thinking infuses Christianity; in the Bible women are clearly set apart to live up to different sexual standards to 
men. In relation to this they note that in Mosaic law sexual purity was rigidly expected of the bride, but not specifically of the bride groom. Thus, Christianity essentially disapproved of the existence of women as sexual beings (Philip, 1991). Early Christian ideas, based on the story of Adam and Eve in the book of Genesis, equate women with dangerous sexual temptation, representing a risk to men. Sex is therefore the 'original sin' and women are the ultimate sinners (Hawkes, 2005). Further, the contrasting images of the Madonna (the pure virginal woman) and Mary Magdalene (the whore-saint) led to a portrayal of female prostitutes by gospel writers as "poor and exploited women, more to be pitied than condemned" (Bullough \& Bullough, 1987, p. 63). However, although prostitution was considered immoral, early Christian doctrines also defined the sale and purchase of sex as a necessary social evil. As Saint Augustine proclaimed: "Remove prostitutes from human societies and you will throw everything into confusion through lusts" (McGinn, 2004, p. 100). This has been interpreted to have several meanings, however it can be taken to reflect an idea that prostitutes were necessary in order to protect the 'Madonnas' of society, and defend the institution of marriage. This construction of prostitution as an immoral but necessary activity was hugely influential and continued onwards into Victorian society where the added influence of a rigid class structure cemented the perception of a divide between good women (wives and virgins) and unfortunate, foolish, or fallen women ('whores') (Roberts, 1992).

\section{The Victorian era}

Patriarchy essentially defined the structure of Victorian society and great emphasis was placed on the chastity of women: "Literally every women who yields to her passions and loses her virtue is a prostitute" (Hemynge, 1967, p. 215). Indeed, the $19^{\text {th }}$ century may be considered a fundamental point at which stigma built up against female prostitutes. This arose through the clear divisions that were drawn to divide women in general, with overwhelming anxiety of a perceived threat posed by female sexuality (Robinson, 1983). However, the oppressive and patriarchal nature of early Victorian society also fostered an expectation that prostitutes would attend to the sexual needs of men that their wives could not (Eldred-Grigg, 1984). In this period, prostitutes were thus considered "necessary and disgusting; an ambiguous mixture of sacred defender of the family and obscene cesspit" (Roberts, 1992, p. 223). In the patriarchal context, prostitutes in New Zealand were of considerable importance: the 
relatively low female population in colonial New Zealand deprived some men of the existence of a wife to address their sexual needs (Eldred-Grigg, 1984). Nevertheless, despite this earlier partial acceptance of prostitution as a social necessity, by the $1850 \mathrm{~s}$ the selling of sex was more commonly considered a social evil (Walkowitz, 1977, 1980). During this time, prostitution became constructed as closely associated with urban disorder; a clear distinction was drawn between 'good' middle class women and 'bad' working class women. Prostitutes who worked from the streets were thought to pose a grave threat to bourgeois social order (Scott, 2005). At this time female street workers were not considered so much potential victims of violence, but as possible perpetrators (Eldred-Grigg, 1984, 2008; Hemynge, 1967). The specific historical constructing of street-based sex workers will now be outlined.

\section{The place of street prostitution in historical debates}

Within debates surrounding the public acceptability of prostitution, street-based prostitutes have often been particularly singled out as problematic and threatening. Although the stigmatising of street-based prostitutes perhaps intensified in the early $20^{\text {th }}$ century, the 'othering' of street workers dates back to ancient Greece in which the term Zonah came to be applied to women who were paid for sex on the streets, and these women were unanimously considered social outcasts (McClure, 2005). In this period, clear divisions were drawn between prostitutes: with those who worked on the street considered a lower class of women, seeing large numbers of clients compared to those who worked in more discreet indoor settings (Skinner, 2005). The marginalisation of street-based prostitutes continued on right into the $19^{\text {th }}$ century period (Roberts, 1992). In this period street-based prostitutes were set apart from women working indoors since only indoor, discreet prostitution was considered tolerable (Robinson, 1983). Prostitution on the street was considered unacceptable in mainstream society and some individuals persistently called for the removal of prostitutes from the streets (Bartley, 2000). This linked in part to a perception that this visibility rendered areas where prostitutes were known to work inappropriate for any 'respectable' women to frequent and walk through (Bartley, 2000; Robinson, 1983), and in part to a belief that the visibility of female prostitutes may serve to tempt young men to engage sexually with them (Mahood, 1990). The emphasis on condemning a visible sex industry rendered street-based workers in the position of an outcast group, at increased risk of criminalisation, due to their defiance of the middle 
class expectation that prostitution should remain in the shadows. The next section overviews early legislative approaches to the sex industry in New Zealand, demonstrating how some of these responses were specifically aimed at curtailing street prostitution.

\section{Legal responses to sex work}

Historical legislation to regulate the sex industry in New Zealand was based largely on the example of legislation passed in Britain (Eldred-Grigg, 1984). In line with the constructing of prostitution as a threat to moral order, legislation was passed in New Zealand in the form of the Vagrancy Act 1866 under which a 'common prostitute' who behaved publicly in a 'riotous or indecent manner' could be considered an 'idle and disorderly person' and face imprisonment (Eldred-Grigg, 1984). This was modelled on the 1824 English Vagrancy Act and clearly singled out street prostitution as a specific threat to public morality. This legislation was replaced with the Police Offences Act (1884) which outlawed the propositioning of passing members of the public by 'common prostitutes', thereby reflecting ongoing disdain for street prostitution (PLRC, 2008).

Legislative responses to prostitution in New Zealand were not only framed by concerns about morality, however, but also by a perceived threat to public health. This development was directly linked to the panic surrounding the infectious disease syphilis, and a belief that the disease represented a serious threat to public health, transmitted via "promiscuous sexual contact with diseased prostitutes" (Walkowitz, 1980, p. 48). In the late 1800s Contagious Diseases Acts were passed in New Zealand, Britain and Australia in response to these concerns about the potential impacts of prostitution (Ryan, 2005). Initially the Contagious Diseases Act was passed in 1864 in Britain, and was followed thereafter by New Zealand in 1869. The legislation defined venereal disease (syphilis) as a threat posed by prostitutes to the health of those serving in the armed forces. This afforded police and medical professionals the power to alert a justice of the peace to a woman suspected of being a 'common prostitute'. The Act gave these individuals the authority to take women to a lock hospital, forcibly if necessary, to be examined and she could be detained in the hospital for up to three months (Ryan, 2005). This approach obviously rendered street prostitutes, again, more vulnerable to criminalisation due to their visibility. Although portrayed as 
a measure to protect wider public health, essentially the legislation was an attempt to socially isolate prostitutes from others living in poverty, to be designated members of the 'unrespectable' poor (Walkowitz, 1977). The contagious diseases legislation and the vagrancy legislation represented the first significant legislation passed directly in relation to prostitution in New Zealand (Jordan, 2005), and essentially set the scene for a legacy of understanding prostitutes as dirty, diseased and dangerous.

Prostitutes were not, however, all considered equally deserving of punishment; by the late $19^{\text {th }}$ century there was also a considerable split between perceptions of 'repentant' women who were considered in need of care and protection and 'unrepentant' whores who required sanctions to control their behaviour (Bartley, 2000). By the mid $20^{\text {th }}$ century the perception of prostitutes as victims had intensified and those involved in prostitution were regarded as fallen women, coerced and trapped in the sex industry as the inevitable result of financial desperation (Scott, 2005). At this time, there was also a considerable shift to pass judgement on men who buy sex and the general consensus was of clients as abnormal men incapable of achieving sexual satisfaction through 'normal' sexual practices (Scott, 2005). Nevertheless, prostitutes were still criminalised and legislative efforts thereafter began to focus on regulating the industry to limit its operation.

In the latter part of the $20^{\text {th }}$ century working as a prostitute in New Zealand was essentially not illegal, however prostitutes could be criminalised on the basis of related offences, such as soliciting (offering sexual services to another person in a public place) which was encompassed in the Summary of Offences Act 1981 (Robinson, 1987). Within this context street-based prostitution was heavily policed due to the perception of street work as a public nuisance, representing a threat to social order and morality (Robinson, 1987). Other legislation included the Crimes Act 1961 (Section 147) which prohibited brothel keeping, the Crimes Act 1961 (Section 148 (a)) which outlawed living on the earnings of the prostitution of another person, and the Crimes Act 1961 (Section 149) which prohibited the procuring for financial gain a woman or girl to have sex with a man who was not her husband (Robinson, 1987). In addition charges could be brought against those operating covertly as prostitutes within massage parlours under the Massage Parlours Act 1978 (Robinson, 1987). Therefore, it was not illegal to work as a sex worker; however it was impossible to work legally due to this related legislation. If charged under the 
Summary of Offences Act 1981 (Section 26) a maximum penalty of a \$200 fine was imposed, while the other offences could carry up to a five-year jail term (Robinson, 1987). Sex workers who were convicted under the Massage Parlours Act 1978 were also subsequently banned from working in massage parlours again and, as a result, were forced to work on the street if they wished or needed to continue working. This legislation sent out a clear message that sex work was not considered a legitimate occupation and continued to project the perception that sex workers were outside the realm of mainstream society. This demonstrated a continued commitment to set sex workers apart as different from others in society, particularly street-based sex workers. However, despite this history of criminalising sex workers in New Zealand, in 2003 the Prostitution Reform Act was passed decriminalising sex workers in the indoor and outdoor sectors. The next section outlines the shift to decriminalisation and the relevance of this change in the global context.

\section{Decriminalisation in New Zealand}

In 2003 the Prostitution Reform Act (PRA) was passed in New Zealand. Through this, New Zealand became the world's first country to decriminalise indoor and outdoor sex work. The decriminalisation of sex work in New Zealand was significant on a global level since prostitution is more commonly criminalised and as a consequence, very little is known about the potential impacts of decriminalisation. Currently, sex work is decriminalised in only New South Wales in Australia and in New Zealand (Mossman, 2008). In September 2010, Canada also appeared to be transitioning towards full decriminalisation after Justice Susan Himel declared in Ontario that the laws criminalising sex workers were unconstitutional, following a legal challenge led by two former sex workers. However, in May 2011 this decision was in the process of being challenged by the federal and Ontario governments and the ruling only applied in Ontario with no specific decriminalised framework in place (Jones, 2011). At the time of writing this thesis, New Zealand was therefore the only country to have completely decriminalised sex work.

The decriminalisation of street-based sex work in New Zealand represented a distinct change since this sector has been so highly criminalised and stigmatised throughout history. Although street work is decriminalised in the Australian state of New South Wales, sex workers are only permitted to work on the street within specific 
boundaries after changes to the law were enacted in 1988 that prohibited sex workers from soliciting in residential areas (Perkins, 1993; Quadara, 2008; Sullivan, 2008). In New Zealand, street-based sex work is essentially unregulated and sex workers can freely work on the streets with very few restrictions. This context is therefore particularly unique on a global scale.

The shift to decriminalisation was not an organic change but emerged from years of work by the national sex worker organisation, the New Zealand Prostitutes' Collective (NZPC), and a diverse array of supporters. Perhaps reflecting the historical propensity to criminalise sex workers, the PRA was opposed vigorously by specific groups, typically fundamentalist Christian organisations and some feminists who argued that decriminalisation would result in an increase in sex worker populations, more violence, coercion, and child abuse (Barnett, Healy, Reed \& Bennachie, 2010). However, regardless of this opposition the PRA was passed on the $25^{\text {th }}$ of June 2003 by one vote. The shift to decriminalisation in 2003 set New Zealand apart from other countries that have taken less liberal approaches in the development of prostitution policy.

\section{The regulation of prostitution: New Zealand in a global context}

Different rationales result in diverse approaches to all forms of legislation. In relation to the sex industry, legislation is often directed by concerns about morality and social order and this is particularly evident in countries where sex work is legalised and strictly regulated by the state (Mossman, 2008). Since the state controls the sex industry and dictates where it takes place, legalised regimes can result in a two-tiered industry where some prostitution is legal, whilst some is not, and those working in illegal sectors are criminalised (O’Neill, 2001; Sullivan, 2010).

Legal frameworks surrounding prostitution are often highly complex. In the UK for instance, it is not illegal to sell sex however related offences render it impossible for sex workers to work within the law unless they work alone indoors without the protection of others (Hubbard, 2004; Phoenix, 1999). Prostitution policy in the UK is clearly driven by a commitment to a public nuisance discourse within which policy aims to limit sex work and placate some members of the community, rather than seeking to support sex workers themselves (Boynton \& Cusick, 2006; O’Neill, Campbell, Hubbard, Pitcher \& Scoular, 2008; Phoenix, 2008a). This social nuisance 
framework to 'manage' prostitution evolved further following the 1957 Wolfenden Report, after which there was a demonstrated commitment to respond to street prostitution as representing a specific affront to public morality (O'Neill, 2010; Phoenix, 2006). In Sweden, the voices of sex workers were excluded from the policy making process which reflected the government's radical feminist rationale that drove the introduction of the 1998 law prohibiting the purchase of sexual services, whilst defining sex work as a form of violence and criminalising clients as a result (Östergren, 2004). In New Zealand, the PRA represented a unique approach to policy making since the law was written with the input of sex workers themselves and prioritised their safety and wellbeing. The PRA is understood as a human rightsbased approach that was underpinned by a commitment to minimise harm in the sex industry (Abel \& Fitzgerald, 2010a). As stated in part one (section three), the purpose of the PRA was to decriminalise prostitution (while not endorsing or morally sanctioning prostitution or its use) and to create a framework that:

a) safeguards the human rights of sex workers and protects them from exploitation;

b) promotes the welfare and occupational health and safety of sex workers;

c) is conducive to public health;

d) prohibits the use in prostitution of persons under 18 years of age; ${ }^{2}$

e) implements certain other related reforms (PRA, 2003).

The PRA intended to strengthen the legal capacity of sex workers to challenge exploitation in the sex industry. The rights provided under the PRA permit sex workers to work together on the street whilst also allowing up to four sex workers to

\footnotetext{
${ }^{2}$ Young people who become involved in the sex industry are not criminalised. The use of a young person in prostitution attracts a prison sentence of up to seven years.
} 
work together indoors without someone in a management role (Abel, Healy, Bennachie \& Reed, 2010).

Also encompassed by the PRA are provisions to target exploitative practices in the sex industry. For instance, under the PRA it is an offence to induce or compel another person to provide sexual service, which prohibits others from threatening or blackmailing individuals into providing sexual services (Abel et al., 2010). In addition, the PRA also empowers sex workers in their interactions with clients through the provision of rights to withdraw consent to sexual acts and to refuse to provide services to clients for any reason (Abel et al., 2010).

Importantly, the PRA legislated for the creation of a Review Committee to evaluate the law change five years after it was enacted, to consider the impacts of the Act and whether any future amendments were necessary (Abel, 2010). The Prostitution Law Review Committee (PLRC) was composed of 11 members from diverse backgrounds, including a former police commissioner, a formal brothel operator, an academic, and a nun. ${ }^{3}$

Decriminalising sex work across all sectors is, therefore, a unique approach that set New Zealand apart from other countries that continue to criminalise sex workers or have legalised frameworks in place. My interest in this framework partly shaped my interest in doing this research in New Zealand. However, the specific focus of this thesis also emerged from my interest in broader debates on sex work that have impacted on responses to violence against sex workers. The next section provides an introduction to these debates.

\section{The choice/coercion debate}

Debates on the legal regulation of sex work are commonly underlined by discourses that focus on issues of choice and coercion in sex work. The initial development of this thesis topic also emerged from my interest in these competing discourses and how they, to some extent, inform conceptualisations of violence in sex work and influence the societal response to it. Due to the intensity of this debate, a full analysis of this is

\footnotetext{
${ }^{3}$ For further details refer to http://www.justice.govt.nz/policy/commercial-property-andregulatory/prostitution/prostitution-law-review-committee/publications/plrc-report/appendix-1prostitution-law-review-committee-members
} 
beyond the scope of this thesis. However, this section provides an initial overview into these debates surrounding sex work and how this influenced the development of my specific research interest.

The issue that has resulted in considerable divisions in sex work debate, particularly amongst feminists, is the extent to which women make a conscious choice to enter the sex industry (Edwards, 1997; Kesler, 2002; O’Neill, 2008). ${ }^{4}$ Proponents of the abolitionist feminist perspective on prostitution have most vigorously canvassed the contention that no woman chooses sex work (Barry, 1984; Farley, 2004; Farley, Baral, Merab \& Sezgin, 1998; Jeffreys, 1997; McKinnon, 1993; Raphael \& Shapiro, 2004; Raymond, 1998, 2004; Sullivan, 2007). Weitzer (2010) refers to this perspective as "the oppression paradigm" (p. 15). In this paradigm, all sex workers are defined as victims. Farley and Kelly (2000) for instance argue that, "To the extent that any woman is assumed to have freely chosen prostitution, then it follows that enjoyment of domination and rape are in her nature” (p. 30). The contention that sex work can never be chosen has, however, been critiqued by sex worker rights advocates, and other researchers with a more nuanced stance on sex work (Bennachie and Marie, 2011; Brooks-Gordon, 2006; Kinnell, 2008; Morgan Thomas, 2009; O’Connell Davidson, 1998; Queen, 1997; Sullivan, 2004; Weitzer, 2005a, 2007). Central to this critique is the contention that defining all sex workers as victims who are forced to sell sex is an overly simplistic analysis that denies women agency and ignores the complexities of individual choice making (Scoular, 2004). In reference to this Wahab and Sloan (2004) note that:

Portraying all sex workers as victims or deviants obscures issues of agency (personal will and ability to act) and sex work as legitimate work...By continuously portraying and constructing sex workers as victims, researchers do not leave space for the possibility that sex work may be empowering for some, disempowering for others, that individuals may freely choose sex work, nor does the limited lens leave space for multiple and contradictory experiences. (p. 4)

The contention that all sex work is coercive denies the complexities in the lives of female sex workers, and dismisses all women who work in the sex industry as inherently oppressed and without agency. Thus, in this paradigm all women who work

\footnotetext{
${ }^{4}$ This debate has been focused on women, despite the fact that people of all genders are engaged in the provision of sexual services for profit.
} 
in the sex industry are defined as victims, since choosing sex work is considered implausible. Weitzer (2006) notes:

Activists use the terms "prostituted women" and "sexual slavery" to drive home the idea that prostitution is something done to women, not something that can be chosen. It is simply impossible that anyone would decide to be "used" in this way. (p. 34)

Sympathisers with the 'sex workers as victims' paradigm, however, do recognise that some women report choosing to enter the sex industry. These women are dismissed as victims of 'false consciousness' who suppress their true victimised status as a coping strategy. Whilst these women may think that they are choosing to sell sex, it is argued that this represents a mere psychological coping strategy to deflect from the reality of their situation. According to Barry (1984):

Agreeing to go with a customer, taking his money, and agreeing to and performing specific acts appear to be choices. The appearance of choice is especially necessary for prostitute women for without it they could, in this stage of prostitution, lose their selves entirely. (p. 33)

The concept of false consciousness has been endorsed in the development of public policy in the UK. For instance in the 2004 consultation document Paying the Price, it is stated that whilst sex workers claim to choose their work, this is likely the consequence of fear, shame or a internalised normalisation of prostitution (Home Office, 2004). Those questioning these assumptions by suggesting that sex work can be a conscious choice are accused of using a technique to downplay what is considered to be the destructive reality of prostitution. Jeffreys (1997) refers to this as a 'neutralising technique' arguing that, "The idea that prostitution is freely chosen is such a technique. When pro-prostitution activists and theorists employ the idea of choice, they incorporate the dehumanisation of prostitution into the identity of prostituted women" (pp. 137-138). It is important to highlight, however, that there are considerably varied perspectives within the feminist movement on the sale and purchase of sex (Matthews \& O’Neill, 2003; O’Neill, 2009, 2010; Sullivan, 1991). Thus, O'Neill (1997) suggests that it is overly simplistic to reduce feminist perspectives on prostitution to only two opposing paradigms. As Sullivan (1991) notes, "Some feminists would look to the long-term abolition of the sex industry, whereas others would say that it might be possible to create a less oppressive prostitution" (p. 11). It is also important to note that feminists and sex workers are not 
necessarily distinct groups and indeed, there are sex-working feminists who have been excluded from feminist spaces for failing to embrace the abolitionist and victimcentred construction of sex work (Fawkes, 2005; Kesler, 2002). An alternative perspective advocated by feminists, sex workers, and researchers is that sex work represents a form of labour and, in this paradigm, the providers of sexual services are conceptualised as workers (Brewis \& Linstad, 2000; Chapkis, 1997; Jordan, 1991; Perkins, 1991; Pheterson, 1989). Proponents of this perspective do not deny the exploitation and coercion that can occur in sex work; instead arguing that labour rights for sex workers would assist in reducing scope for coercion and would increase choices and options for sex workers (Lopes, 2006; West, 2000). O'Neill (2010) argues that these conflicting perspectives within the feminist movement have subsequently led to a "paralysis" that has constrained progressive thinking on sex work issues. Accordingly, O'Neill suggests that that moving forward to ensure positive change with sex workers requires a shift away from these "binaries" of prosex work and anti-sex work (pp. 219-220).

It has been argued that it is critical to recognise the nuances of choice and coercion in individual decision making and other academics have argued that structural conditions can coerce some women to remain in prostitution and, as a result of this, their involvement in the industry may be understood as choice made within the context of these circumstances (Matthews, 2008; Phoenix, 2000, 2006). In relation to streetbased sex work in particular Phoenix (2006) notes that:

Ordinary women whose lives are largely unremarkable and mundane experience social and economic dependency on men who may, or may not, let them down, leave them or abuse them, or from whom they may be desperate to escape. Such women find themselves in a struggle to survive on meagre incomes or social security benefits...Time and time again empirical studies confirm that women working from the streets have such backgrounds. They are like many other working class women in that they face risks of violence and poverty and make choices in their struggle to survive. Some of the choices are commonplace, such as claiming benefits, whereas others are more extraordinary, such as engaging in prostitution. (pp. 78-79)

Thus, for some women it is argued that the choice to enter sex work is taken in the context of structural constraints that mean sex work is the most attractive option of all other options that are available (Rosen \& Venkatesh, 2008). Even in the context of extreme structural oppression, engaging in sex work may represent a form of 
resistance to these conditions. For instance, in research conducted in Uganda, women described choosing to enter the sex industry to gain independence from violent partners and the patriarchal expectations of marriage that render women financially dependent on, and subservient, to men (Gysels, Pool \& Nnalusiba, 2002). Moreover, some findings suggest that women who enter the sex industry in the context of extreme structural oppression reject the rhetoric of coercion and victimhood (Harding \& Hamilton, 2008). Entry into sex work can therefore represent, for some women, a choice made in response to violence and structural oppression as a means of facilitating personal and financial autonomy. It has therefore been argued that women's decisions to enter the sex industry are made within variable circumstances that influence, but do not ultimately determine, their choice to sell sexual services. Additionally, some women choose to enter the sex industry without the influence of such constraints. Accordingly, Scrambler (1997) argues that:

There can be no question that even women confronted with relative poverty, primed by their personal biographies and with peers in sex work can take conscious decisions to enter or not enter the sex industry; and some women decide to engage in sex work outside the sway of all such influences. (p. 113)

The divisive nature of these debates on choice and coercion shaped the development of my research interests. I was curious about these perspectives, particularly those perspectives that have been critiqued for obscuring the voices of those directly involved in sex work. However, the specific focus of this thesis also emerged from my interest in the incidence of violence in the street-based sex industry and how the resulting legal responses to it intersect with the broader debates on choice and coercion described above. The next section introduces some key debates on risk and violence in the street context and the relevance of this in shaping the focus of my research.

\section{Violence and street-based sex work}

This chapter has, so far, demonstrated how street-based sex workers have been marginalised both in discourse surrounding sex work and in the legislative response to prostitution. Historically, female street-based sex workers have been defined as an outcast group in public debate and in law. It is perhaps then not surprising that women working on the streets have also been singled out in debates concerning the risks of violence in sex work. Violence has been highlighted as a key risk managed by sex 
workers globally, and it has been found that those working on the street are more likely to be offended against than those working indoors (Abel, 2010; Church, Henderson, Barnard \& Hart, 2001). A wealth of research has explored the prevalence of violence in street-based sex work, whilst far less research has explored the ways in which women manage and negotiate the risks of working on the street, in the context of their marginalised status and the stigma surrounding their work (Barnard, 1993; Benson, 1998; Miller, 1993; Pyett \& Warr, 1999; Sanders, 2001; 2004a; Williamson \& Folaron, 2001). Researchers and advocates of sex worker rights have called attention to the impact of criminalisation on the capacity to manage risk in the streetbased sector, and it has been suggested that criminalisation increases risk for sex workers on the street (Campbell \& Kinnell, 2000; Chapkis, 2000; Hubbard \& Sanders, 2003; Kinnell, 2006a; Morgan Thomas, 2009; Sanders, 2004a; Sanders \& Campbell, 2007; Scotpep, 2007; Shannon et al., 2009).

\section{Rationale and Aims}

The origins of this research are thus embedded in my interest in dominant discourses that underline debates concerning the incidence of violence in street-based sex work, and the legal frameworks surrounding prostitution. Given that criminalisation is thought to increase the vulnerability of sex workers on the street and undermine their personal safety strategies, there is a pressing need for more research documenting how decriminalisation can impact on the personal safety of street-based sex workers.

One piece of research has explored violence in the New Zealand street sector since the law change, with a focus on perceptions of violence and the prevalence of violence amongst sex workers in the indoor and outdoor sectors. This work highlighted strategies to manage risks of violence amongst street-based workers, including screening clients, peer support, and reporting violence (Abel, 2010). However, this formed part of a far broader study focusing on indoor and outdoor sex work covering a range of themes on the impacts of the PRA. There is no existing research focusing exclusively on the experiences of street-based sex workers managing risks of violence since the law change.

My research, therefore, represents a unique contribution to existing research findings on the management of violence-related risks in street-based sex work and provides new insights into the impacts of decriminalisation. This research addresses an 
important gap in knowledge with regards the alternatives to criminalisation that could inform the development of policy responses to street-based sex work elsewhere. Furthermore, this research presents a progressive account of the experiences of individual street-based sex workers in-depth, which challenges some existing stereotypes. The next section outlines the research aims.

\section{Research Aims}

The broad aim of this research was to explore strategies used by women working on the street to manage and negotiate risks of violence in the decriminalised context. As a feminist researcher, I wanted to explore the nuances of these issues from the perspective of women directly involved in street-based sex work. The specific aims of the research were:

- To consider perceptions of the risks of violence amongst women working on the streets as sex workers.

- To explore strategies to manage risks of violence amongst these women.

- To provide an analysis that locates these findings in the context of decriminalised street-based sex work.

- To consider what more could change to better support these women in their management of violence-related risks.

\section{Thesis overview}

This thesis consists of ten chapters in total, starting with this introductory chapter. Chapter two reviews the body of literature considered most relevant to the central focus of this thesis. Undertaking a review of the relevant literature that was comprehensive whilst also suitably succinct and appropriately focused was a challenging task. Prostitution is a contentious and widely debated topic that encompasses a range of sub-themes and historical debates including sexuality, law, religion, economics, sexual health, substance use, human rights, violence and feminism. This chapter brings together the most relevant themes and debates, exploring existing findings on the social positioning of street-based sex workers, the incidence of violence, the management of violence-related risks, and the impact of legislative frameworks, to appropriately contextualise my own research on strategies to manage risks of violence amongst women working on the street in a decriminalised 
context. Chapter three outlines the methodology and related theoretical framework used. This chapter provides a reflexive account of my approach to the research and the methodology used, along with a discussion of the ethical issues negotiated and insights into the experience of conducting this research in practice. Chapter four presents findings on the nature of violence in street-based sex work. Drawing from the perspectives and experiences of the women interviewed, this chapter highlights diverse perceptions of risk and how these perceptions are influenced by a range of factors, such as the experience of violence. This chapter provides a nuanced insight into the different types of violence that can be encountered in street-based sex work, arguing that it is important to distinguish between genuine clients and violent offenders. Subsequent chapters explore how the women reported strategising against these types of violence. Chapter five presents an account of screening strategies to assess risks of violence from those approaching as clients, and considers the relevance of these findings in the context of decriminalisation. This chapter demonstrates how the women strategised to screen out potentially violent clients, and how the law change simplified the process of screening clients as a risk management strategy. In chapter six, strategies to manage risks of violence in encounters with clients are explored. Focusing on themes of power and control as fundamental to these encounters, this chapter explores how these women strategised against the possibility of violence and in the event of violence. This chapter highlights the reality that preventing violence is not always possible, and that violence continues to occur in the decriminalised context. However, this chapter shows how these women resisted the victim label by continuing to strategise against the possibility of violence, and that the law change had enabled these strategies without the risk of entrapment. Chapter seven explores the experience of violence and abuse from passersby on the street and the strategies the women used to manage this. This chapter highlights how the construction of street-based sex workers as a social nuisance has resulted in their marginalisation and casual violence from passersby has been supported in this context. The focus shifts in chapter eight to examine collective strategies to manage violence-related risks whilst working on the street. This chapter considers how relationships between the women and others on the street - specifically minders, other sex workers, police and support agencies, functioned as strategies to manage risks of violence. This chapter explores the complexities in these relationships, moving beyond the management of violence from potential clients to also consider the 
additional risk of violence from other sex workers and minders. The chapter shows that whilst there are some outstanding issues, the change in law has provided a framework in which the safety of sex workers on the street can be better supported. Chapter nine discusses these findings in the context of decriminalised street-based sex work to consider options for moving forward beyond decriminalisation to provide a more positive environment for sex workers. Specifically this chapter considers some remaining challenges and explores how these challenges may be addressed in the context of decriminalised street-based sex work. The implication of these findings suggests that at the core of challenging violence is changing attitudes that are supportive of violence towards sex workers, and a broader acceptance of sex workers as part of public spaces. Chapter ten concludes on these findings and I outline recommendations for public policy, police, support organisations and broader society. The overall conclusion acknowledges that decriminalisation was a significant first step that better supports the safety strategies of street-based sex workers, but that a broader paradigm shift is necessary to provide fair and reasonable protection from violence for those working on the street as sex workers. 


\section{Chapter Two: Violence and the marginalised status of street-based sex workers: unpacking the context of risk}

\section{Introduction}

Research on sex work is diverse, contentious, and contradictory. The considerable amount of research focusing on violence in street-based sex work reflects the extent of social interest and debate on these issues. This chapter comprises a review of the literature surrounding the incidence of violence in street-based sex work in order to place in context my own research with street-based sex workers in New Zealand.

First, I explore findings, which illustrate the ways in which female street-based sex workers have been constructed in the contemporary context, discussing how these portrayals have influenced responses to street-based sex work. The next section explores the nature of violence in street-based sex work and competing perspectives on this. Findings on who perpetrates violence against sex workers on the street are then discussed. I then move on to consider the prevalence of violence in street-based sex work and outline some of the barriers identified to measuring the true prevalence of violence against women working on the street. Existing findings on the strategies used by street-based sex workers to manage these risks of violence are then explored, followed by a discussion of the impacts of legislative frameworks surrounding prostitution and the management of these risks. The final section overviews research findings and theory on the ways in which decriminalisation can impact on the personal safety of sex workers on the street in the context of ongoing risks of violence.

This chapter concludes by outlining gaps in research on the relationship between legislative frameworks and the management of violence-related risks in street-based sex work. The main gap identified is the lack of data on how risks of violence are managed in the decriminalised context.

\section{Contemporary portrayals of street-based sex workers}

The ways in which female street-based sex workers have been constructed in the public domain is connected to the ways in which violence against sex workers is conceptualised and responded to. This section outlines contemporary constructions of 
street-based sex workers, tracing the connection between these portrayals and the management of violence on the street.

\section{Street-based sex workers as deviants}

Sex workers are considered to behave in ways that are far beyond patriarchal norms of female sexual behaviour, and as such they are seen as the 'bad girls' of the sisterhood (Barnard, 1993; Sanders, 2004a). Becker (1963) states that those who transgress prescribed social norms may then be considered 'deviant' by those who conform to and support the particular set of norms in question. By charging for sexual services, female sex workers defy the patriarchal expectation of sexual passivity, and are accordingly considered deviant women. In response to the deviant positioning of female sex workers, Kinnell (2008) argues that they have been, "portrayed as hate figures, social outcasts who deserve public humiliation and punishment for the social and environmental pollution they are deemed to cause" (p. 90). Constructed as deviants, female sex workers are 'othered' from individuals working in alternative public service industries and, as a consequence of this 'othering', stigma is attached to their work. As O'Connell Davidson (1998) notes, “there is no popular moral doctrine which tolerates hostility towards 'dirty plumbers' only 'dirty whores',' (p. 64).

In soliciting for sex in the public space, female street-based sex workers have been considered particularly deviant. Women working on the street are distinguished from indoor workers as representing the deviant and dangerous 'coalface' of prostitution (Hubbard \& Sanders, 2003; Kantola \& Squires, 2004; O’Neill, 2008; Sanders \& Campbell, 2007). Street-based sex workers are considered deviant on two levels in not only charging for sexual services, but also for defying the expectation of discreet sex work by openly flaunting their work in the public domain. As Pheterson (1996) notes, "Street prostitutes depend on whorespeech, appearance, and attitude as advertisement. They are 'public' women who show too much, say too much, know too much and do too much. Too much of anything is unchaste for women" (p. 165). In bringing a private act into the public space, street-based sex workers threaten not only the gender expectations of female sexual behaviour, but also the moral make-up of society. As such they represent a threat to narrow understandings of 'family values' and moral order (Kantola \& Squires, 2004; Sanders, 2004a). Hubbard and Sanders (2003) state that, "Within a rational and heterosexually-ordered city, street 
prostitution is seen as polluting because it challenges the notion that a woman can express her sexuality only in the confines of the home" (p. 82). Thus, through refusing to adhere to these norms, Pheterson (1987) argues that street workers are considered to represent "models of female unchasity" (p. 225). In 'polluting' the urban landscape, street-based sex workers have been 'othered' to a greater extent than indoor sex workers and subsequently are the most stigmatised group (Weitzer, 2005b). Moreover, they have subsequently been portrayed as symbolic of negative stereotypes and have been constructed as unwelcome in the public space. As Sanders and Campbell (2007) note:

The cultural message about women who work on the street is that they will not be missed, as they are not valid citizens. In media, policy and amongst men who buy sex, off street sex workers are not to the same extent constructed as desperate, dirty, addicted individuals conforming to the 'junkie whore' stereotype (p.15).

The constructing of female street-based sex workers as deviants has influenced policy responses to this group of women. Positioned as the polluters of public space by behaving as unchaste and immoral women, female street-based sex workers have been portrayed as a social nuisance (Hallgrimsdottir, Phillips \& Benoit, 2006; Hubbard, 1998; Kantola \& Squires, 2004; McKeganey \& Barnard, 1996; Phoenix, 2006, 2008a). Accordingly, there has been a tendency for policy to attempt to disrupt and subsequently contain or control street-based sex work (Hubbard, 1998; Hubbard \& Scoular, 2009). This has been reflected particularly in the UK context where, in recent years, Anti Social Behaviour Orders (ASBOS) have been used to ban sex workers from specific areas of open space (Day \& Ward, 2007; Hubbard, 2004; Phoenix, 2008b; Sagar, 2007; Sanders, 2004a). Moreover, the proposed introduction of Compulsory Rehabilitation Orders under the Criminal Justice and Immigration Bill 2007 in the UK reflected the desire to, as Sanders (2009) argues, "make 'bad women' into 'good women' by assisting them to desist from their sexual deviancy through reeducation, retraining and re-socialisation" (p. 988).

The construction of street-based sex workers as deviants has been fuelled by inaccurate media accounts of street sex workers that serve to increase stigma and influence public opinion (Hallgrimsdottir et al., 2006; Kantola \& Squires, 2004). For instance, Wagenaar and Altink (2009) argue that the media were instrumental in driving public opinion of Dutch Tipplezones (areas in which street sex work was 
permitted to take place), by constructing areas of street sex work as symbolic spaces representative of certain behaviours, portraying "lurid images of men soliciting sex services from scantily clad women, drunken behaviour, addicted derelict women and the odd flamboyant transgender". They argue that, as a consequence of this, these areas of street sex work became "a moral spectacle to a gullible uninitiated audience which is simultaneously repelled and attracted" (p. 157). Furthermore, some researchers have perpetuated the portrayal of street-based sex work as unpalatable, arguing that the removal of street-based sex workers would benefit communities and sex workers themselves (Matthews, 2008). However, street-based sex workers have not only been considered a threat to moral order, they have also been portrayed as a posing a threat to public health.

\section{Street-based sex workers as vectors of disease}

The portrayal of female street sex workers as a deviant, outcast group is reminiscent of the ways in which street workers have been perceived historically, as outlined in chapter one. Similarly, in the contemporary context female street-based sex workers have been considered to pose a threat to wider public health, reminiscent of the concerns over the spread of syphilis described in chapter one, which resulted in efforts to control sex workers. In the past three decades, concerns have been largely centred on the perceived links between injecting drug use, HIV, and street sex work. The public health risk that female street workers have been charged with, regards the assumed likelihood that this group will spread HIV/AIDS to the broader population (Hubbard, 1998; Faugier \& Sargeant, 1997; Maher, 1997; Phoenix, 2006). Following the 1980s AIDS pandemic, Phoenix (2006) notes that:

Popular media and public discussion drew on the stereotype of a 'junkie whore' - a syringe-using, drug-addicted woman selling sex from the streets. These women were seen as reservoirs of sexual disease. (p. 85)

Such accounts, it can be argued, have resulted in the direct conflation of street sex work with problem drug use. Accordingly, the practice of street-based sex work has been conceptualised as inextricably linked with problem drug use, and this has fuelled the construction of street-based sex work as a threat to community cohesion and safety (Hubbard, 1998; Melrose, 2007, 2009; Sanders, 2009). This, it is argued, has contributed to the stigmatised image of the street 'crack whore', the drug-using sex worker, who is afforded the lowest status (Maher, 1997; McKeganey \& Barnard, 
1992). Drug-using street-based sex workers are, thus, positioned "low on the hierarchy of women" (Lees 1997, p.82). Since drug users are also marginalised, the conflation of drug use with street-based sex work means that all of those who work from the street have been doubly stigmatised (Efthimiou-Mordaunt, 2002; Erickson, Butters, McGillicuddy \& Hallgren, 2000). The conflation of street sex work with injecting drug use has, thus, led to a moral panic over the perceived health risks posed by these women, and has increased the stigma attached to street work as a result. Divisions are drawn between and within different sectors of sex work, with streetbased sex workers who use drugs being afforded the lowest status. Sterk (2000) notes that:

"Call girls" often achieve a higher occupational status than women who work in brothels or sex clubs, who, by comparison still command more prestige than street prostitutes. Among the latter group, non-drug using women are accorded higher status than women who use drugs. (p. 44)

This positioning of street-based sex workers as a threat to public health representing a risk to others has been accompanied by a construction of street sex workers as victims, which has also influenced policy responses. The portrayal of street sex workers as victims will now be outlined.

\section{Street-based sex workers as victims}

In line with historical positioning of street-based sex workers, in the modern context women working on the street have been responded to not only as deviants posing a risk to moral order and public health, but also as victims. As Sanders (2009) notes:

The lessons from history show very clearly that now in the twenty-first century the identity of the 'prostitute' is still fixed along a victim trajectory supported by discourses of sex and sin. (p. 122)

The victim label has been particularly afforded to those who work on the streets, which has arguably been used in the UK context to disrupt street-based sex work (Phoenix, 2008a). Reminiscent of divisions drawn historically between repentant and unrepentant whores, those who accept the victim status are offered assistance, whilst those who reject assistance are punished (Scoular \& O’Neill, 2010). As Phoenix (2008a) explains, “the 'unwitting' victims of prostitution are compelled to seek help and the voluntarily engaged are given the choice to have help to leave or face harsher punishments" (p. 40). The sex workers as victims paradigm has been influential in 
driving more recent policy in the UK and Sweden that has sought to 'save' women involved in sex work and criminalise the purchasers of their services (Morgan Thomas, 2009; O’Neill, 2010; Scoular \& O’Neill, 2008). The construction of streetbased sex workers as victims has subsequently been accompanied by an increase in the stigma attached to the purchase of sexual services, in that clients of sex workers have been portrayed as abusers and exploiters (Brooks Gordon, 2010; Kingston, 2009; Kinnell, 2006b). The media has also been influential in promoting the victim paradigm, as Day and Ward (2007) state, in reporting on "drug abused victims from broken families forced to expose themselves to madmen on the streets" (p. 187), whilst ignoring the ways in which sex workers manage and resist oppressive ideas and actions in the course of their work.

The identification of sex work as a form of victimisation has been influenced by abolitionist ideology discussed in chapter one as integral to the choice/coercion debate. From this perspective, sex work cannot be chosen because the act of being paid for sex is defined as a form of violence (Barry, 1984, Ekberg, 2004; Farley, 2004; Farley \& Barkan, 1998; Jeffreys; 1997; Raphael \& Shapiro, 2004; Raymond, 1998, 2004; Sullivan, 2007). The relevance and impact of this perspective in problematising the definition of violence in sex work, and responses to it, will be discussed in subsequent sections of this chapter.

Contemporary portrayals of female street sex workers have, therefore, been characterised by representations of this group of women as either offenders posing a risk to moral order and public health, or victims in need of rescue from the sex industry. Women working on the streets are thus conceptualised as "amoral, conspicuously vulgar and indiscriminate", whilst concurrently portrayed as "lost and hopeless victim of abusers and manipulators" (Scrambler, 1997, p. 105). Reflecting on the treatment of street-based sex workers throughout history covered in chapter one, these findings suggest that not much has changed. Female street-based sex workers are still largely constructed and responded to as offenders or victims, and policy responses generally focus on a need to either 'rescue or punish' those engaged in sex work on the street. It is only in New Zealand that there has been a national level policy shift away from the commitment to curtail street-based sex work. The next section discusses theory and findings on the relationship between these 
(mis)representations of street-based sex workers and the incidence of violence in street-based sex work.

\section{Contemporary constructions: unpacking the context of violence}

These constructions of street-based sex workers in the public sphere can be related to the incidence of violence against sex workers and the societal response to it. This section reviews findings, which suggest a link between the portrayal of sex workers as deviants or victims and the context of violence.

In defining the identity of women working on the street as deviant and responding to street-based sex work as criminal behaviour, or social nuisance, female street-based sex workers have been constructed as sexual minorities. In the context of victimisation, sexual minorities, according to Richardson and May (1999), are considered deserving victims, especially if they bring private and taboo behaviour into the public sphere. Overwhelmingly efforts to prevent violence against women outside of the home have emphasised that women are expected to manage risks themselves to 'avoid' being victimised (Carmody, 2006). In relation to this, Malloch (2004) notes that:

Certain victims are viewed as possessing some level of behavioural responsibility and are expected to employ a range of avoidance strategies to minimise the risk of violence they may be subject to. Behaviour which is deemed 'problematic' (sex work, gay sex, intravenous drug use) subsequently denies those who participate the status of the 'innocent victim' (p. 113)

The Madonna/whore dichotomy dictates that women who deviate from expectations of 'good' and 'decent' female behaviour are deserving of violence and only those who conform are considered genuine victims (Russell, 1984; Stanko, 1985). Thus, portrayed as particularly deviant women, violence against street-based sex workers may be trivialised in comparison to violence against other women who do not sell sex. Indeed, in one Australian court case a judge noted:

It seems to me that the crime when committed against prostitutes, at all events in the circumstances of the case, is not as heinous as when committed, say, on a happily married woman living in a flat in the absence of her husband when the miscreant breaks in and commits rape on her. (R V Harris, cited in Scutt, 1992, p. 348)

Indeed, in apparently deviating to such an extent from the expectation that women will practice risk avoidance, female street-based sex workers have been construed as 
the ultimate example of 'asking for it'. As Pheterson (1987) notes, "as sexual solicitors they are assumed to invite male violence" (p. 225). Portrayals of streetbased sex workers as deviant women has resulted in the suggestion that they are to blame for any violence they experience at work for putting themselves in what has been constructed as a position of significant danger (Canter, Ioannou \& Youngs, 2009; Levi-Minzi \& Shields, 2007; Sanders \& Campbell, 2007). In relation to this Levi-Minzi and Shields (2007) argue that:

Most people believe that prostitutes deserve the crimes that are perpetrated against them and that it does not matter when a prostitute is hurt or killed; they are invisible, a facet of society that is not afforded the same basic rights granted to all people. (p. 77)

The perception that street workers invite violence was reflected in the police, media and public response to the 'Yorkshire Ripper' murders, in which distinctions were drawn between sex workers who were targeted, and the targeting of 'innocent' and 'respectable' women (Bland, 1992). More recently this attitude has been reflected in the trial in the UK of serial murderer Steve Wright, where the defence argued that his actions had been provoked by the drug-using street workers in the vicinity (Kinnell, 2008). The labelling of street-based sex workers as deviants has therefore promoted the idea that violence towards these women should be expected. This in turn, may be seen to support the actions of those offenders who wish to target sex workers with violence. For instance, Lowman (2000) has argued that media accounts of attempts to 'get rid' of street-based sex workers amongst resident groups, politicians and police represents a "discourse of disposal", and Lowman suggested that this contributed to an increase in murders of street-based sex workers in Canada (p. 988). As such, defining street-based sex workers as the lowest common denominator has resulted in a dominant discourse that is supportive of violence towards them. Furthermore, perhaps linked to the negative positioning of female sex workers in the public sphere, it has been found that sex workers are unlikely to report violence to the police as a consequence of previous adverse experiences being harassed by police at work, or because they believe the police will blame them for the attack (Abel, 2010; Dalla, Xia \& Kennedy, 2003; Delacoste \& Alexander, 1988; Downe, 1999; Harris et al., 2011; Silbert, 1981). Some findings suggest that reluctance to report violence is particularly pronounced for street-based sex workers (Campbell \& Kinnell, 2000; Silbert \& Pines, 1982; Woodward, Fischer, Najman \& Dunne, 2004). 
The social positioning of street-based sex workers as deviant women has, therefore, contributed to the creation of an environment in which violence towards them is supported. This arguably represents a barrier to ensuring effective and appropriate responses to violence experienced by this group of women. This is complicated further by the dual portrayal of street sex workers as victims, as a direct result of their involvement in selling sex. This will now be discussed in relation to findings, which highlight the complex issue of defining violence against sex workers.

\section{The nature and prevalence of violence in street-based sex work}

Perhaps the most intensely debated discourse relating to definitions of violence against sex workers is the abolitionist feminist perspective that the act of being paid for sex is in itself a form of violence (Barry, 1984, Ekberg, 2004; Farley, 2004; Farley et al, 1998; Jeffreys; 1997; Raphael \& Shapiro, 2004; Raymond, 1998, 2004; Sullivan, 2007). Within this perspective, the violence sex workers experience is defined as the sexual acts they are paid to perform. As Jeffreys (1997) notes, "the acts carried out on and in the bodies of prostituted women are in themselves sexual violence” (p. 242). From this perspective, all sex workers are conceptualised as victims (Farley 2004). In this paradigm, all clients of sex workers are subsequently defined as perpetrators of violence. As Dworkin (1997) notes, "When men use women in prostitution, they are expressing a pure hatred for the female body” (p. 145). Thus, the sex industry is discussed as a particularly high-risk environment. Dalla et al. (2003) describe the sex industry as an environment "characterised by crime and destruction", and argue that it "breeds violence and victimisation" (p. 1380). The abolitionist feminist perspective is particularly worthy of discussion, as despite the widespread critique of these arguments, this perspective has been influential in shaping sex work policy in countries such as the UK and Sweden (Gould, 2001; Kingston, 2010; Scoular, 2010; Scoular and O'Neill, 2008). Referring to the Swedish model that criminalised purchasers of sexual services, Ekberg (2004) notes that:

In Sweden prostitution is officially acknowledged as a form of male sexual violence against women and children...Prostitution is a serious problem that is harmful, in particular not only to the prostituted woman or child but also to society at large. Therefore, prostituted women and children are seen as victims of male violence. (p. 1189) 
The abolitionist feminist perspective has been critiqued by several scholars as highly simplistic and problematic in failing to distinguish between acts of violence and consensual acts between sex workers and clients (Bennachie \& Marie, 2010; Kinnell, 2008; Morgan Thomas, 2009; Scoular \& O’Neill, 2008; Sullivan, 2004). In relation to this Kinnell (2008) notes that:

It is important to realise that 'violence' in the radical feminist discourse does not mean the beatings, rapes and murders inflicted on sex workers. Instead the commodification of women's bodies through charging for sexual acts...is deemed the essential harm, the 'violence' which damages women. (pp. 27-28)

Brooks-Gordon (2006) argues that the influence of the abolitionist perspective on the development of public policy is particularly concerning in that it obscures the actual violence that sex workers experience, stating that:

Also worrying is the ease with which these beliefs about prostitution elide with repressive state policies towards sex workers, and with punitive religious views on sexual morality. Proposals to improve sex workers' safety by legitimising their working situations are rejected as legitimising violence against women, since sex work itself is deemed violence. Alternatively, such measures are rejected lest they 'encourage' women to enter or remain in prostitution, by making it safer and therefore more attractive. (p. 186)

Alternative perspectives have therefore sought to challenge the contention that sex work is a form of violence against women through highlighting the actual violence that sex workers experience, whilst aiming to decrease stigma and increase labour rights for sex workers (Goodyear, 2008; Hubbard \& Scoular, 2009; Jordan, 1991; Kinnell, 2008; Phoenix, 2009; Sanders, O’Neill \& Pitcher, 2009; Scoular, Pitcher, Campbell, Hubbard \& O’Neil, 2007; Shannon et al., 2009). Proponents of this perspective argue for a more balanced discussion of violence that better reflects the diverse experiences of sex workers. In this regard, Morgan Thomas (2009) notes that, "Prostitution is not inherently violent and abusive; nor is it inherently empowering" (p. 151). The next section reviews findings on the types of violence that are experienced by street sex workers, starting with a discussion of what is known about the perpetrators.

\section{Who perpetrates violence against sex workers?}

In order to fully explore the types of violence against sex workers, it is important to consider the identity of offenders and offender motivations (Brooks-Gordon, 2006; 
Kinnell, 2008). It has been found that street-based sex workers experience violence from a range of sources including police, 'clients', pimps, partners, other sex workers and community protestors (Dalla et al., 2003; Hubbard, 2004; Kinnell, 2008; Nixon et al., 2002; Pearce, 1999; Plumridge, 2001; Sanders, 2004a; Simić \& Rhodes, 2009). In addition, those who work from the street have been found to experience frequent violence from passersby (Day, Ward \& Boynton, 2001; Kinnell, 2006a; Nixon et al., 2002; PLRC, 2008; Sanders, 2004a). A large proportion of research has concluded that clients perpetrate most of the violence encountered by sex workers (Benoit \& Millar, 2001; Hoigard \& Finstad, 1992; Matthews, 2008; Raphael \& Shapiro, 2004; Shannon et al., 2009, Valera, Sawyer \& Schiraldi, 2001). However, Kinnell (2008) states that this is a flawed conclusion, arguing that on closer examination some findings suggest that most of those who attack sex workers are not clients. Instead, Kinnell suggests that these perpetrators merely approached under the pretence of being a client and then attacked the sex worker instead (Kinnell, 2008). Other findings have confirmed this, finding that a large proportion of violence from those assumed to be clients occurred before payment had been made (Williamson and Folaron, 2001).

Lowman (2000) argues that 'clients' (or rather those who have approached as clients) who attack street-based sex workers can be considered in two categories - situational and predatory. Lowman explains that situational violence occurs following a dispute over issues such as payment or services provided, which the client attempts to resolve with violence. Describing these incidents as situational is attributed to the apparent lack of motive - these incidents do not appear to be premeditated. Conversely, predatory violence is considered premeditated, as the offender approaches the sex worker not with the intention of paying for sex, but with the express intention of perpetrating violence (Lowman, 2000). In agreement with this, Kinnell (2008) argues that it is critical to distinguish between 'genuine clients' (those who pay for sex and complete the transaction without incident); 'bad clients' (those who resist the client role by bartering prices, pushing boundaries and respond with violence to resolve disputes with sex workers); and 'bogus clients' (those who mimic client behaviour in an attempt to lure sex workers into situations with the intention of perpetrating violence). Kinnell also calls attention to another category of opportunistic offenders who do not approach under the pretence of being clients, but rather "seem to target sex workers only because they are easy to attack” (p. 65). 
These findings therefore suggest that street sex workers are vulnerable to experiencing violence from a range of sources. Furthermore, the different types of violence experienced by sex workers on the street are diverse. The next section explores findings on the nature of violence experienced by sex workers on the street.

\section{The nature of violence}

Street-based sex workers have been found to experience many types of violence, which include rape, physical assault, robbery and abduction (Kinnell, 2008; O’Neill \& Barberet, 2000; Sanders, 2004a; Willamson \& Folaron, 2001). Violence may also include harassment from community protestors who harass street-based sex workers in an attempt to drive them out of the area (Morgan Thomas, 2009; Sanders, 2004a; Sagar, 2005; Williams, 2008). Street-based sex workers have been found to experience frequent verbal abuse from passersby (Day et al., 2001; Miller \& Schwartz, 1995; Nixon et al., 2002; Pitcher et al., 2006; PLRC, 2008; Sharpe, 1998). Street sex workers are vulnerable to physical violence, robbery, rape and murder from those who approach them as clients (Kinnell, 2008; Lowman, 2000). Findings suggest that violence from 'bad clients' includes coercion to perform sex acts that were not pre-negotiated, covert removal of the condom, verbal abuse and being 'ripped off' (Nixon et al., 2002; Sanders \& Campbell, 2007). Individuals outside of the sex industry may consider some of these actions relatively mundane, however Kinnell (2008) states that these acts are particularly violating in the context of commercial sex, noting:

Violation of the accepted conventions may be flagrant and obvious acts of aggression, or may appear relatively insignificant to outsiders, though regarded very seriously by sex workers themselves, both because disregard of the conventions may breach the emotional and practical boundaries which separate sex work from other kinds of relationships and because it can indicate potential for committing serious harm. (p. 59)

It has been argued that the broad range of violence experienced by sex workers highlights a need for a more holistic understanding of what constitutes violence against sex workers (Kinnell, 2008). Accordingly, Kinnell explains:

Understanding 'violence' as including acts that cause fear, humiliation, manhandling, or exposure to danger, many non-criminal acts might be classed as violence, including immigration raids and deportations, policing operations, community actions against street sex workers, evictions, 
politicians' statements and media exposes of sex workers. Such events are always presented as legitimate means to achieve socially desirable outcomes, uncover serious offences, 'rescue victims' or expose moral turpitude, but their intrinsically violent or abusive nature is usually ignored. (p. 31)

Thus, these findings show that sex workers on the street experience and manage a broad range of violence in the course of their work. The nature of violence is therefore highly complex encompassing a range of potential perpetrators. Attempting to evaluate the prevalence of violence in street-based sex work is also problematic, and the next section considers existing findings that explore the extent of violence against street-based sex workers.

\section{The prevalence of violence in street-based sex work}

There are several barriers to effectively measuring the prevalence of violence towards sex workers. First, sex workers are considered to be a 'hidden' population, and as such there can be difficulties obtaining representative data (Brooks-Gordon, 2006). The difficulties measuring prevalence are also hindered in part by some of the perspectives discussed earlier, such as the contention that the selling of sex is in itself a form of violence. If sex work is considered to be in itself a form of violence, the prevalence of violence in sex work will be considered widespread. Writing from an abolitionist perspective, Raphael and Shapiro (2004) for instance describe the prevalence of violence in sex work as 'unimaginable', inferring that rates of violence against this group of women are inexplicably high. Measuring the prevalence of violence against those working on the street is, therefore, complicated by the propensity of some researchers to include the sexual transaction itself as a form of violence.

Despite these challenges, a number of studies have attempted to evaluate the extent of violence in street-based sex work. Rates of violence in the on-street and off-street sectors have been compared, leading to the overwhelming agreement that street-based sex workers are particularly vulnerable to experiencing violence in their work (Abel, 2010; Benoit \& Millar, 2001; Busch, Bell, Hotaling \& Monto, 2002; Farley et al., 1998; Farley \& Kelly, 2000; Kinnell, 2006a, 2008; Lowman, 2000; Miller, 1993; O’Neill, 1996; Phoenix, 1999; Plumridge \& Abel, 2001; Pyett \& Warr, 1997; Rhodes, Simić, Baroš, Platt \& Žikić, 2008; Sanders, 2004a; Silbert \& Pines; 1982; Valera et al., 2001; Vanwesenbeek, 2001; Williamson \& Folaron; 2001). One UK study which 
compared the experiences of on-street and off-street sex workers found that 81 percent of the 115 on-street sex workers surveyed had experienced violence compared to 45 percent of 125 sex workers based in indoor venues (Church et al., 2001). This research was, however, critiqued for overtly focusing on risks of violence from clients, when street sex workers manage diverse violence-related risks (Day, Ward \& Boyton, 2001). In another study, higher fear of violence and higher incidence of violence were reported by street-based workers by comparison to indoor sex workers (Pyett \& Warr, 1999). Research conducted in New Zealand revealed that $41 \%$ of street-based sex workers had experienced violence, compared with $21 \%$ of indoor workers (Plumridge \& Abel, 2001). More recent findings on the impacts of the PRA in New Zealand revealed that street-based sex workers were more likely than those working in the indoor and managed sectors to experience violence. However, rates of violence from clients were only marginally different for indoor managed and streetbased sex workers. A total of 13.4 percent of street-based workers reported that they had been physically assaulted by a client in the past twelve months, compared to 10.4 percent of managed indoor workers and 7.3 percent of private indoor workers. However, a total of 39.5 percent of outdoor workers reported being threatened with violence by someone at work, compared with just 9.3 percent of managed workers and 16.3 percent of private indoor workers (Abel et al., 2007). This perhaps reflects the broader range of violence-related risks managed by street-based sex workers. Thus, on a global scale the indoor sector is considered an infinitely safer work environment. However it is important to acknowledge that there is conflicting evidence on safety and working conditions for indoor workers (Sanders \& Campbell, 2007; Hubbard \& Scoular, 2009).

Findings on the prevalence of violence in street-based sex work specifically are variable, but overall suggest a high incidence of violence in the street sector, estimating that between 50 percent and 100 percent of street-based sex workers experience violence in their work (Kurtz, Surratt, Inciardi \& Kiley, 2004; Lowman, 2000; Miller \& Schwartz, 1995; Nixon et al., 2002; Pauw \& Brener, 2003; Pyett \& Warr, 1997; Sanders \& Campbell, 2007; Silbert \& Pines, 1981; Williamson \& Folaron, 2001). In Canada, between 1992 and 1998 it was reported that at least 86 women were murdered who had been working on the street as sex workers (Lowman, 2000). A UK study found that 14 out of a total of 40 women interviewed had been 
physically attacked by someone who had approached as a client whilst they were working on the street (Sharpe, 1998). A study conducted in the United States found that 12 out of 13 women interviewed had experienced violence from a customer (Williamson \& Folaron, 2001). Overwhelmingly, these findings suggest that those working on the street who have not experienced violence are in the minority and that most street-based sex workers are likely to experience violence at some point in their working lives (Phoenix, 1999; Salfati, James, \& Ferguson, 2008; Sanders, 2001; Shannon et al., 2009).

The findings of research globally, therefore, suggest that violence against sex workers is commonplace. However, such findings must be interpreted carefully. In one study it was found that the majority of individuals interviewed had experienced violence from a client at least once - seven had been raped, fourteen had been beaten, five had been robbed at knife point, three had been held against their will or abducted, three had been robbed at gunpoint and two had been drugged by a client. However, despite this, it is stated that the majority of contacts sex workers have with clients are not violent (Sanders, 2004a). Further, it was found that 19 out of 26 women interviewed for Hoigard and Finstad's (1997) research had experienced violence on at least one occasion. Nevertheless, it was emphasised that the majority of clients these sex workers had encountered were not violent. Thus, whilst the level of violence experienced is entirely unacceptable, these experiences do not suggest that the majority of those who pay for sex are violent. On this basis, it has been suggested that a small proportion of those who approach as clients, are likely to be responsible for a large proportion of violence (Barnard, 1993; Benoit \& Shaver, 2006; Kinnell, 2006a; Monto, 2000; Morgan Thomas, 2009; Weitzer, 2000). Thus, whilst most clients are not violent, in each encounter there is potential for violence to occur (Sanders, 2004a).

This section has shown how a range of previous findings have documented the position of street-based sex workers as the most criminalised, stigmatised and marginalised group in the sex industry. The wide range of violence street-based sex workers are exposed to has been highlighted, whilst exploring some of the difficulties defining and quantifying violence against sex workers. It has been commonly found that street-based sex workers experience violence more frequently than indoor sex workers. Despite this, there has been an expectation that sex workers will take responsibility for their own safety whilst working on the street. Some researchers 
have, therefore, explored the management of these risks of violence with street-based sex workers. This chapter will now progress to explore these existing findings on strategies to manage the risks of violence amongst female street-based sex workers.

\section{Strategies to resist violence: existing findings}

As discussed earlier in this chapter, debates on the risk of violence in sex work have been overshadowed by a propensity to criminalise and stigmatise street-based sex workers and clients. It is, perhaps, a direct consequence of this that street-based sex workers have been expected to take responsibility for preventing their own victimisation (Sanders \& Campbell, 2007). Thus it has been found that some women working on the street have developed strategies to manage and negotiate the risks of violence (Barnard, 1993; Benson, 1998; Dalla et al., 2003; Miller, 1993; Nixon et al., 2002; O’Neill \& Barberet, 2000; Pyett \& Warr, 1999; Sanders, 2001, 2004a; Williamson \& Folaron, 2001). Whilst there has been an overwhelming focus on labelling street-based sex workers as either victims or deviants in the general public sphere, some research on risk management strategies has moved beyond this to highlight the agency some women exercise in their management of risk, and over their involvement in sex work. For instance, Sanders (2001) explains that:

Protection strategies, in their creativity and initiative highlight how the street workers use their agency and are making decisions that remove them from the state of passive victim... When understanding street prostitution, using a dichotomy of either victim or survivor does not address the full range of street workers' experiences...to understand street sex workers as only victims would be to ignore the agency they exercise, to some extent, over their involvement in prostitution. (p. 16)

Indeed, contrary to the assumption that sex workers have no agency in their encounters with clients, some findings suggest that women carefully choose clients, and central to this is the process of screening clients to assess risk (Sanders, 2001; Williamson \& Folaron, 2001). Through the screening of clients it has been suggested that sex workers develop a 'dangerous date profile', against which they evaluate the client in order to approximate the extent to which they can be considered safe or potentially unsafe (Williamson \& Forlaron, 2001). It has been found that street-based sex workers apply a series of rules including preferences for age, ethnicity, dress, accent, general appearance and the vehicle driven (Nixon et al., 2002; Sanders, 2004b; Williamson \& Folaron, 2001). In one Australian study, street workers reported 
avoiding hire cars or cars with interstate registration plates (Pyett \& Warr, 1999). However, screening has been found to be far broader than evaluating aspects of the client's physical appearance and initial impressions of the vehicle. Kinnell (2008) notes that central to assessing risk is also establishing the extent to which the client is likely to resist the client role - for instance, by attempting to barter the required payment or push for sexual services that have not been agreed on. Essentially, sex workers screen clients to assess whether or not they are first and foremost genuine, and second that they are likely to follow the rules. In relation to this Kinnell notes that:

Agreement must be reached about where the sexual interaction will take place and how much time the client is buying...the sex worker's aim is to arrange a place where she feels safe, however marginal this perceived safety may be. A 'genuine' client accepts the sex worker's choice of venue without dispute and any quibbling may indicate trouble ahead. (p. 57).

Thus sex workers have been said to screen clients in an attempt to identify clients who may not be genuine and are instead mimicking client behaviour (Sanders, 2005; Williamson \& Folaron, 2001). For instance, in one study a street-based sex worker described initially refusing all clients to gauge their reaction. Clients who reacted with verbal abuse were not given a second chance, but those who were polite and returned to try again were accepted (Sanders, 2005). Street workers have also been found to strategise against the possibility of violence by refusing to get in cars with more than one person inside (Nixon et al., 2002; Pyett \& Warr, 1999). Furthermore, it has been found that street workers insist on choosing the location of the job, and choose to work in locations where they feel safe that provide increased scope to call for help or to escape in the event of an attack (Miller, 1993; Nixon et al., 2002; Pyett \& Warr, 1999; Sanders, 2004a). Essentially, street workers have been found to strategise in such a way that intends to increase their power and control over services provided, time spent, and the location in which the job takes place (Miller, 1993; Sanders, 2004a).

Some findings also suggest that sex workers on the street may initially rely on gut instincts to evaluate risk (Barnard, 1993; Dalla et al., 2003; Nixon et al., 2002; Williamson \& Folaron, 2001; 2003). Once established as a sex worker with a regular client base, some street-based sex workers have been found to aim to see only regular 
clients who have been pre-screened and are considered far less likely to be problematic (Barnard, 1993; Salfati et al., 2008; Williamson \& Folaron, 2001). The evaluation of clients via screening is not an entirely individual process, and sex workers on the street have been found to work together to warn about potentially problematic clients (Abel, 2010; Miller, 1993; Nixon et al., 2002; PLRC, 2008; Sanders, 2001). Sex workers may also screen out clients they have been alerted to via 'Ugly Mugs' listings provided by local support agencies that document potentially violent clients in the area (Kinnell, 2008; Sanders, 2001).

In addition to strategising to prevent violence, street-based sex workers have also been found to manage the environment in ways that will assist in identifying offenders should they be attacked. One study found that some sex workers worked close to CCTV cameras, thus enabling the identification of vehicles they leave the street in (Sanders, 2001). In another study, street-based sex workers reported utilising environmental strategies, such as working in safer spaces where there was more lighting and where others were close by (O’Neill \& Barberet, 2000).

It has been found that some sex workers carry weapons to use in the event of violence (Barnard, 1993; Dalla et al., 2003; Nixon et al., 2002; Williamson \& Folaron, 2003). In one study a sex worker recalled hiding a metal bar in the bushes at her regular work site to use in the event of an attack (Sanders, 2004a). Indeed, some findings indicate that some sex workers on the street feel prepared to fight back in the event of violence, and women reported fighting with men and jumping from moving vehicles to escape from violence (Dalla et al., 2003; Miller, 1993; Sanders, 2004a).

Some proponents of the abolitionist feminist perspective, which was discussed earlier in this chapter, have critiqued research that highlights the risk management strategies employed by female sex workers. For instance, Farley et al. (1998) argue that "Apologists for prostitution legitimise it as a freely made and glamorous career choice. We are told that people in prostitution choose their customers as well as the type of sex acts in which they engage” (p. 421). An alternative perspective is that rather than glamorising sex work, discussions that acknowledge the strategies used to select clients highlight the risks managed in sex work whilst also recognising the agency some women use, despite the broader constraints in their lives. Roche, Neaigus \& Miller (2005) state that: 
These women have few resources and severe poverty, homelessness, and the absence of opportunity mark their lives. Yet, these women manage to demonstrate power and decision making in critical ways. How they evaluate risks is one way in which they exercise choice, even if that choice opens them up to other situations of risk. (Roche et al., 2005, p. 152)

It is clear from the findings highlighted in this chapter that street-based sex workers are vulnerable to experiencing violence. This vulnerability transgresses a range of legislative environments, including the decriminalised context in New Zealand. However, the findings described above also show the ways in which sex workers on the street actively resist the risk of violence in the course of their work. The next section overviews existing findings on the ways in which the legislative context can impact on the management of violence-related risks, followed by an overview of findings on the impact of the decriminalised framework in New Zealand in relation to the incidence of violence.

\section{Managing risk in a criminalised context}

Existing findings overviewed in the previous section of this chapter suggest that sex workers do not passively accept violence and actively resist these risks. However, this research has been conducted almost entirely in contexts where street-based sex workers are criminalised. It has been argued that criminalised frameworks undermine street sex worker's strategies to manage risks of violence in their work (Kinnell, 2006a; Shannon et al., 2009). This section reviews findings and commentary on the impact of criminalisation on the management of violence-related risks on the street.

It is argued that criminalised frameworks impede the use of safety strategies amongst individual sex workers through presenting an additional risk to the already substantial hierarchy of risks managed whilst working on the street (Sanders, 2004b). In criminalised contexts the policing of street sex work is highly variable between different areas and cities (Hubbard, 2006). However it is clear that some police do proactively pursue sex workers on the street with an aim to arrest them (Benson and Matthews, 2000; Brents \& Sanders, 2010; Hubbard, 2004; Rosen \& Venkatesh, 2008; Sagar, 2007; Sanders, 2004a; Sullivan, 2008; Wotton, 2005). Avoiding the police is, therefore, an additional daily hazard for street workers working in this environment. The significance of this risk is reflected in research findings. In one UK study, amongst 15 women interviewed, eight had between one and five prostitution related 
convictions and others had been arrested and fined between 20 and 30 times within a period of one year. A further 19 women in the area in which the study took place had been issued with ASBOs which prevented them from entering certain areas (Sanders, 2004a). The possibility of being arrested is, therefore, a very concrete risk. It has been argued that as a consequence of this risk, sex workers must work quickly and position themselves discreetly in order to avoid the gaze of authorities (Chapkis, 2000; Hubbard \& Sanders, 2003; Kinnell, 2006a). Legal frameworks that prohibit streetbased sex work are therefore thought to hinder the screening process to assess risk with potential clients by minimising the amount of time that can be spent assessing risk on the street (Barnard, 1993). It is therefore suggested that criminalisation of street-based sex work and a policy of zero tolerance increases risks of violence by hindering the full use of safety strategies (Campbell \& Kinnell, 2000; O’Neill, 2009; Wotton, 2005). In reference to the UK context Kinnell (2006a) notes:

These approaches to reducing street sex work increases the dangers for street sex workers. The threat of arrest and of ASBOs increases the incentive to avoid being seen by police or CCTV cameras, so women take less time to assess potential customers and work later at night, in darker and more isolated areas. Enforcement directed at kerb crawlers means fewer customers, so women have to work longer hours in dangerous environments to make their money. (p. 147)

A number of researchers subsequently argue that decriminalisation of sex work would better support the safety of sex workers (Brooks-Gordon, 2008; Day \& Ward, 2007;

Goodyear \& Cusick, 2007; Jeffrey \& Sullivan, 2009; Pyett \& Warr, 1999; Scrambler, 1997; West, 2000). The next section explores the impact of the decriminalised framework in New Zealand on the incidence and management of violence in streetbased sex work.

\section{Decriminalisation and violence}

Existing findings highlighting the impacts of the law change indicate broad positive impacts for sex workers in all sectors of the industry (Abel et al., 2007; Mossman \& Mayhew, 2008; PLRC 2008), This research was conducted by researchers from the Christchurch School of Medicine, led by Gillian Abel, and the Crime and Justice Research Centre at Victoria University of Wellington, along with a report produced by the Prostitution Law Review Committee. Findings specifically outlining the incidence of violence in the decriminalised context are reviewed in Abel's $\mathrm{PhD}$ 
published in 2010. This section explores these findings to demonstrate existing knowledge on the incidence of violence in New Zealand since the law change.

The absence of data collected before the law change means that it is impossible to conclude on whether there has been a decrease or an increase in violence since the PRA was passed. However, what is clear is that violence is still a considerable risk managed by street-based sex workers in New Zealand. Findings suggest that streetbased sex workers are, overall, more likely to experience violence than those working in the indoor sectors of the sex industry (Abel, 2010). Responses from the qualitative interviews revealed that street-based workers managed risks of violence from a range of sources, such as passersby and other sex workers, in addition to potential clients. The diverse range of potential perpetrators perhaps explains the high rate of threatened violence against participants working in the street-based sector. Despite feeling that the law change had improved police perceptions towards them, the findings showed that there was still reluctance amongst street-based sex workers to report experiences of violence to the police.

In the context of these ongoing violence-related risks, street-based sex workers described controlling where they stood on the street as a risk management strategy. Furthermore, street-based participants described drawing from their instincts when screening clients, with $81 \%$ of street-based sex workers reporting refusing to 'do' a client on this basis in the past 12 months. Street-based participants were more likely than participants in other sectors to report refusing a job with a client because they had heard that the client was dangerous, which perhaps reflects the culture of peer support and information sharing practices described by some of these participants (Abel, 2010).

These findings highlight the ongoing risks of violence managed by street-based sex workers since the law has changed. My research, therefore, builds on these findings by exploring in-depth the individual experiences of street-based sex workers managing risks of violence since the law has changed. Thus, my research represents a significant contribution to existing findings by exploring the ways in which risks are managed by sex workers in a decriminalised context and considering the extent to which the law change has impacted on the management of violence-related risks. Furthermore, this research helps address a gap in knowledge on the impacts of 
decriminalisation on street-based sex workers, specifically in relation to the experience and management of violence.

\section{Summary}

In this chapter findings on street-based sex work and violence have been reviewed demonstrating how street-based sex workers have been the most marginalised, criminalised and stigmatised group of sex workers and how this has continued into the contemporary context. Whilst street-based sex workers have been frequently cast as victims, deviants or survivors, some research has moved beyond these portrayals to explore violence risk management with street-based sex workers. This research has highlighted the agency of street-based sex workers, whilst arguing that the strategising of these women may be undermined by policies that criminalise them. However, there is a lack of research documenting violence risk management specifically amongst female street-based sex workers in decriminalised contexts. This thesis therefore aims to address this gap by exploring violence risk management with female street-based sex workers in a decriminalised context, considering what more could change for street-based sex workers to support them in their management of risk. 


\section{Chapter Three: Methodology}

\section{Introduction}

This chapter outlines the methods used for data collection, and the theories underpinning the methodological approach, providing an insight into the data gathering process. As noted in chapter one, the research aims were:

- To consider perceptions of the risks of violence amongst women working on the streets as sex workers.

- To explore strategies to manage risks of violence amongst these women.

- To provide an analysis that locates these findings in the context of decriminalised street-based sex work.

- To consider what more could change to better support these women in their management of violence-related risks.

In this chapter I overview the approach employed to address these aims through the research process. The first part of this chapter explores the theoretical perspective, before detailing the methods selected as relevant to the research aims and the theoretical underpinnings. The next section discusses the ethical issues considered prior to entering the field, and how these relate to mainstream conceptualisations of the nature of sex work. The chapter ends with a detailed insight into the process of undertaking fieldwork, and the resulting data analysis process.

\section{Theoretical Underpinnings}

Theoretically, this research is based on an interpretivist approach centred within a feminist epistemological framework. Feminist epistemologies were developed partly in response to a frustration with the inadequacies of traditional positivist epistemology in representing the experiences of women (Brooks, 2007; Chase, 2005; Cotterill, 1992; Harding, 1998; Kitzinger, 2004). However, feminist research is not simply research 'by', 'for' and 'about' women (Alice, 2003; Glucksman, 1994). Rather what makes research 'feminist' lies more within the way in which the research is carried out, and the particular way in which methods are used (Brooks, 2007; Code, 1991, 1995; Harding, 1993, 1998; Kelly, Burton, \& Regan, 1994; Maynard, 1994).

The theoretical framework which explicitly informed this research is feminist standpoint 
epistemology, within which social phenomena are explored from the point of view of an individual who has been culturally and historically defined for the reader (Schwandt, 2000). Sanders et al. (2009) comment that, "central to much feminist research methodology is an acknowledgement of the location of the researcher as part of and influencing the research process" (p. 168). In conducting this research I felt it was important to make explicit my own political and moral standpoint on sex work, and thus feminist standpoint epistemology seemed appropriate. As Letherby (2003) explains:

All research is ideological because no one can separate themselves from the world - from their values and opinions, from books they read, from the people they have spoken to and so on. (pp. 5-6)

In agreement with this, I think it is fair to suggest that very few people can claim to have no opinion on prostitution. Therefore, to make claims of absolute 'objectivity' in research on the sex industry would indicate a flawed approach. Stating my own personal standpoint, and making explicit factors which may have underpinned my decision-making processes in the course of planning and carrying out the research, is an attempt to minimise the impact of any bias. The purpose of specifically stating my standpoint is to make clear that I have been consistently aware of my own biases throughout, and to argue that this awareness has facilitated my flexibility to consider alternative points of view. Engaging my own standpoint has perhaps increased validity of the findings through my own disclosure and self-reflexivity (Code, 1991).

Feminist standpoint epistemologies have been critiqued as based on narrow understandings of power and domination that focus on patriarchal oppression whilst failing to acknowledge the power differentials that exist between women (Sanders et al., 2009). In recognition of this, my use of feminist standpoint epistemology in this thesis encapsulates my belief that research is grounded in experience, but also in the need to make explicit my own position of privilege in the research process. I will now briefly outline the origins of my interest in carrying out this research, and how this has influenced my own standpoint on sex work.

\section{My standpoint}

My positioning in this research is complex and multi-faceted which reflects the nature of my interest in sex work on various levels that has shifted over time throughout the process of undertaking this research. 
I was brought up in a small town in the East of Scotland by hard working parents who had elevated themselves to middle class by my early childhood years. I had a troubled adolescence, from which I developed a fractured sense of self, but also resilience, an open-minded outlook on life, and a curious nature to take risks in the pursuit of knowledge and self-exploration. I left my hometown at 18 to study at the University of Glasgow and developed an interest in social justice and social research. I was intensely curious about the sex industry for several years, but it was not until the final year of my degree that I began exploring some academic literature on prostitution. What I read was at odds with what I had gleaned in my previous explorations, and focused on drug addiction, violence, and homelessness in street prostitution. At the age of 21 , I had no appreciation of the turbulent history of debates on sex work in the academic sphere, or the nuances in individual experiences, and naively dismissed the women I read about as victims, whilst wondering what sort of men would pay for sex with them. My earliest academic interest in sex work therefore reflected an elitist and privileged attitude.

Moving to London after graduating in 2006, my curiosity about sex work continued. I became interested in the laws in the UK that I had been confused about for some time. Through media coverage of the tragic murders of five women working on the street in Ipswich, and through informal research, I became more aware of the risks of violence in sex work and how this related to legislative frameworks that criminalised sex workers globally. Learning about the shift to decriminalisation in New Zealand in 2003, and having recently considered returning to do further study, I made contact with an academic at Victoria University to discuss fledgling research ideas with little expectation that this would come to anything. However, further to writing an initial research proposal and the great surprise of receiving funding, I moved to New Zealand at the end of 2007 to start the research.

Coming to New Zealand to do this research therefore emerged from an academic interest in the decriminalisation of sex work but also represented part of my own broader interest in sex work. My standpoint on sex work is inevitably influenced by the prior assumptions I had made about the nature of the sex industry, my impressions of those involved in it, and my personal interest and curiosity in sex work. My perspective has shifted over time as I have progressed with this research and had some of my own preconceived ideas challenged. Miller (1997) notes that "With the passage 
of time, our perspectives develop in new ways and we can become more explicitly aware of the frames of reference that shaped us previously" (p. 161). At times throughout the research I struggled with understanding the origins of my own standpoint and in locating myself in the research. I came to realise that this was partly because this is not a fixed process but something that develops and progresses over time.

I self-identify as a feminist and, as such, I believe in challenging the oppression of women, and the gender stereotypes that impact on both men and women in society. Central to my feminist principles is a belief that women should be able to do as they wish with their own bodies without judgement from others. Fundamental to this is my belief that individuals working in the global sex industry should have appropriate rights to challenge violence and exploitation. I therefore approached this research from a feminist, sex worker rights perspective.

As already noted, however, my positioning on these issues is complex and multidimensional, and thus is also heavily influenced by my own privilege as a researcher and as an individual. I am white, able bodied, literate, and with sufficient formal and informal education to support myself independently wherever I choose to live. I recognise that individuals make choices within the constraints of structural oppression that impacts on their lives and that for some women involved in sex work, choices are limited significantly. However, I argue that all forms of labour are performed within individual personal constraints and I am reluctant to make generalisations about the capacity to choose to do sex work, or any other job. I believe individuals have a right to define this for themselves and that there is too much diversity to generalise. Regardless, I recognise and have remained aware of the fact that I have considerable privilege and have been exposed to far broader opportunities than most of the women who took part in this research.

In locating myself in the research process and making clear the origins and nature of my personal standpoint, I hope to have provided greater clarity with regards the lens through which I have interpreted the data that forms the basis of this thesis. 


\section{Research approach}

Fundamental to this research was exploring the experiences of women working on the streets in-depth, in relation to their personal safety strategies. Sex work is not limited to just women, but I chose to focus this research on the experiences of women since this group form the majority of the sex worker population (Perkins and Bennett, 1985; Sterk, 2000) but also because I was interested in how debates on violence, risk and sex work may intersect with the tenets of patriarchal society and broader debates on violence against women. It should be noted that as a consequence this research only includes the experiences of 'cisgender' women. ${ }^{5}$ Transgendered women and men who work on the streets are arguably particularly marginalised and vulnerable to experiencing violence. A limitation of this study is that it does not encompass these experiences, and I recognise that further research with a specific focus on this group is critical.

This research incorporates the experiences of Pakeha and Māori women. A further limitation of the research approach is that there is no analysis of the women's experiences in relation to ethnicity. My identity as a white, female researcher from the UK reflects the lens through which I have interpreted the women's experiences and as such I felt unqualified to undertake an analysis of this type. I recognise this is a considerable limitation and this could be addressed in future research by recruiting a Maori researcher or advisor.

This research is therefore limited to exploring experiences and perceptions of a particular group of women who work on the streets as sex workers. However, it was never my intention to generalise, but to offer an insight into the diverse realities of these women, utilising this thesis as a vehicle through which their voices could be heard. My approach was focused on "accepting the essential validity of other people's experiences", underpinned by a belief that "Feminists...shouldn't tell other women what to be, how to be, how to behave" (Stanley \& Wise, 1983, p. 8). I wanted the research to reflect as accurately as possible these individual experiences, to avoid making judgements on the choices the women had made throughout their lives, and their current circumstances.

My approach was therefore in contrast to positivist epistemology in which the researcher

\footnotetext{
${ }^{5}$ Cisgender woman are those women who identify with the gender assigned to them at birth.
} 
is expected to remain as an outsider, carrying out research 'on' foreign, and alien 'subjects' (Denzin \& Lincoln, 2003). Locating the research within the interpretive paradigm of data gathering and analysis, utilising self-reflection, and drawing from the principles of feminist standpoint epistemology sets my approach apart from the positivist tradition. The positive approach is, as Stanley and Wise (1983) note, expected to remain "hygienic", carried out in the absence of emotion, therefore constituting "research as it is described, not research as it is experienced" (p. 153). I cannot make claims of emotional disconnection or argue that the research findings are 'value free' as with positivist empirical research (Code, 1995). Further, in contrast with positivist and post-positivist paradigms, it was not of interest to me to find one particular 'truth' and generalise it as applicable to a wider group. There was no one single 'reality' out there on female streetbased sex work that I wished to 'study', or one I felt may be approximated (Denzin \& Lincoln, 2003). I was interested in gathering perspectives as opposed to seeking to locate universal truths (Gray, 2004).

The wider interpretivist approach I opted for drew from the social constructionist view that the 'realities' we are familiar with are socially situated (Willis, 2007). Specifically, that meaning is located not within an external and detached reality, but within the context of individual experiences and interactions in the social world (Gray, 2004). Analytically, my approach to the research was therefore phenomenological in nature, in seeking opinions, subjective experiences, and interpretations of participants. This required taking an inductive approach to construct theory from the data collected, in contrast to a positive approach that seeks to test theory (Gray, 2004).

I opted for qualitative methods to complement the theoretical perspective, and the emergent nature of the data I wished to gather. The next section of this chapter details the methods selected and how these related to the over-arching theoretical underpinnings and research aims.

\section{Selecting methods and planning the data collection}

The qualitative approach adopted was considered appropriate due to the nature of the information I was seeking. I wanted a genuine insight into the experiences of women working on the streets and qualitative methods were most appropriate given this, to ensure an inductive approach to the development of theory. I felt that using survey methods would be more appropriate for testing theory from a positivist perspective and could 
potentially obscure the complexities and nuances of these individual experiences. Fundamental to what I wanted to do was to really hear these experiences as individuals perceived them, and to avoid making judgments. Believing there to be multiple realities, and that positive and negative experiences could actually coexist, it was not of interest to me to gather information which would confirm street sex work as either 'good' or 'bad'. I was interested in all kinds of experiences and views, which may challenge or confirm dominant perceptions of the street sex work sector.

The primary method I felt appropriate was in-depth qualitative interviewing with women working on the streets as sex workers. Since the issues I wanted to explore were deeply personal, it was important not to rush participants. Exploring experiences in-depth, it was hoped, would ensure participants could open up at their own pace. Furthermore, this would mean I would gain a deeper insight into these issues. Semi-structured interviews were most appropriate to ensure the interview was focused but flexible, again allowing participants to take the interview in the direction which most suited them. I also felt it would be ideal to interview women on more than one occasion to allow further flexibility to explore issues at their own pace. This could also facilitate follow up on issues emerging from the first interview, which may have only been glossed over initially.

In-depth, qualitative interviewing was also felt to be the most appropriate method in light of the feminist approach to carrying out the research. I was acutely aware that the women I hoped to interview were human beings, as opposed to simply objects being studied (Maynard, 1994). The relationship between researcher and 'researched individuals' is classically understood as being unavoidably unequal. However, I felt that in-depth qualitative interviews provided an opportunity to address the power imbalance as much as possible by allowing scope for my own personal disclosure and openness with participants (Cotterill, 1992; Oakley, 1981).

I felt it was important that I was open to sharing some of my own views and experiences with the women, given that I was asking them to share with me a deeply personal aspect of their lives. Such disclosure would be more appropriate and natural in an in-depth semistructured interview, as opposed to in a more structured, closed survey environment in which personal disclosure may be very contrived. I did not intend to tell every respondent my life story, but wanted to have an environment in which they might feel freer to ask questions about myself, and therefore perhaps feel more empowered in the research 
process.

I originally anticipated interviewing 25 women at least once, but ended up doing 34 interviews with 28 women who were currently working on the street, or had done previously. In total, four of the 28 women had stopped working within the past two years, although two of these women alluded to still working occasionally to generate income to meet unexpected household expenses or personal entertainment costs. The sample size was relatively small to enable women to be interviewed more than once if possible. Repeat interviews were planned once the interview was transcribed and reviewed for any issues to follow up on, such as particular points that were of interest to explore further. All of the women who were approached for a second interview were happy to do so. One woman could not be contacted for a second interview as she had started a residential rehabilitation programme for drug users, and another was experiencing personal issues so it was decided that it would be inappropriate to approach her for an interview at that time. These methods facilitated an in-depth insight into these women's experiences, which was most appropriate as it was not the intention to generalise across the sex worker population in New Zealand, but to provide an insight into individual experiences.

However, I also wanted to go beyond hearing people's experiences, and to live and understand it myself as much as was practically possible. I wanted to gain a realistic insight into being part of that world as far as I could, to enrich my own understanding into the street sex work culture, and to avoid drawing on already overused stereotypes. The data from the interviews with sex workers was therefore supplemented by observational data of my experience in the field as an observer on street outreach and in the drop-in centre, which I regularly recorded in a fieldwork journal. In addition, 16 interviews were carried out with 17 key informants with an interest in street sex work. Key informant interviews were undertaken initially with two staff from NZPC in Wellington in late 2008. In Christchurch, key informant interviews were carried out between February 2009 and July 2009. Two key informants were interviewed from NZPC, four from the Christchurch Police, two from a drug harm minimisation organisation, three from a social service organisation, one from the Christchurch City Council, one from a local church, and two from a youth organisation. Individuals and organisations were invited to take part in interviews based on their interest or contact with the street-based sex industry in the course of their work. The inclusion of these key informant interviews increased my understanding of the broader context surrounding the street sector in New Zealand. 


\section{Locating the field}

The decision to focus a large proportion of the fieldwork in Christchurch and to carry out fewer interviews in Wellington was taken for specific reasons. Christchurch has the highest population of street workers in New Zealand as a proportion of all sex workers, $26 \%$ compared to $13 \%$ in Wellington and $11 \%$ in Auckland (Abel, et al., 2007). Three street-based sex workers have been murdered in the city since 2005, and subsequently there has been much debate in Christchurch regarding sex worker safety. A number of preventative initiatives have been developed by the NZPC, and relationship building has reportedly taken place between police and street-based sex workers in the city. Importantly, the support and social agency infrastructure available in Christchurch is very strong, which it was hoped would facilitate the fieldwork. Christchurch therefore provided an ideal site for the bulk of the fieldwork to take place. Wellington has a relatively low number of female street-based sex workers and my initial base at Victoria University meant that the city provided an appropriate site for initial consultation with sex workers.

Consideration was given to Auckland since the city has central hubs where street sex work is practised, such as Karangahape Road and Hunters Corner. However, the city comprises multiple sites that are geographically disparate, and focusing some of the fieldwork here in addition to Wellington and Christchurch proved prohibitive due to resource constraints. In the course of carrying out this research in Wellington and Christchurch, some significant issues emerged detailing ongoing violent conflict between a South Auckland vigilante community group and street-based sex workers. So although it was not practically possible to do fieldwork in Auckland, the issues unfolding in South Auckland have been discussed in this thesis in the context of media commentary and discussions with key informants such as NZPC.

The methods selected for the data collection consisted of three strands: 34 in-depth semistructured interviews with 28 women working on the streets as sex workers, 16 semistructured interviews with a number of key informants, and researcher observation. Interviews with the women were focused on entry into sex work, perceptions of risk and vulnerability, feelings of safety, and strategies to manage risks. The interview guide was developed following an initial review of existing research on violence risk management in the street sector and three members of staff from NZPC were consulted on the content before it was finalised. A copy of the interview guide can be found in Appendix A. The 
women also completed a socio-demographic questionnaire, which included questions on age, ethnicity, work history, and family responsibilities (see Appendix B). The questionnaire was based on part of a survey used for the CSOM research, which evaluated the impacts of the PRA (Abel et al., 2007). Key informant interviews were included to broaden the range of perspectives and to supplement the interviews with sex workers. Key informants were selected from organisations with an interest in sex worker safety and in the case of NZPC, their expert knowledge of the sex industry. These interviews explored perceptions of sex work and risk in the street sector and strategies to support the safety of street-based sex workers (see Appendix C).

In combining these three strands of data collection, the approach may be understood as a broad qualitative approach, drawing from principles of ethnographic research to provide a multi-dimensional perspective. The next part of this chapter provides an insight into the setting up and planning of the research further to selecting methods.

\section{An open and closed environment: facilitating access in the decriminalised context}

Due to the extent of stigma shrouding the sex industry, sex workers are considered a hard to reach population. Female street-based sex workers are considered a particularly hard to reach group, due to their criminalised status (Barnard, 1992). Researching street-based sex work in New Zealand is a very unique opportunity since sex workers can work on the street without the ongoing threat of arrest. Unfortunately this is not to say that street-based sex work is not still considered a clandestine activity in mainstream New Zealand society. It is therefore fair to assume that many of those working in the industry on the street are unlikely to be trusting of unknown researchers with no links to friends and allies. Therefore, as other researchers have also commented, I found it was of great importance to work with gatekeepers already involved in the sex industry (McKeganey \& Barnard, 1996; O’Neill, 2001; Sanders, 2006a; Wahab, 2003).

\section{Gatekeepers}

The most appropriate point of contact was the national sex worker rights organisation, the NZPC. I first met with NZPC in December 2007 to discuss the research proposal I had developed and to get their feedback. Hubbard (1999) has outlined four basic principles which would be typically expected by gatekeepers in the sex industry before giving support and introducing researchers to potential participants: (1) that the research must be 
capable of producing knowledge which would reduce stigma surrounding sex work, (2) that the researcher has an understanding of the realities of sex work, (3) that sex work is understood by the researcher as a legitimate form of work, and; (4) that the researcher believes in the minimisation of health and safety risks for sex workers in their work.

These were principles that were important to the staff and volunteers I met with at the Prostitute's Collective, and was, from my perspective, underpinned by a broader desire to shield sex workers from researchers who may reinforce stigma attached to their work. I was nervous at this initial meeting. I was completely unknown to them and therefore an outsider, but at the same time I hoped that I shared common views on sex work, and therefore hoped that would mean I'd be more readily accepted.

Being an outsider in the crude sense that I was from the other side of the world, whilst having an interest in sex worker rights, was perhaps an advantage. Had I only read the perceptions of other postgraduate researchers, I may have felt overwhelmed by the political standpoint and experience of NZPC. Eden (1997) reported feeling restricted in what he could and could not express, feeling that "If I could contribute to their work in a useful way, well and good, but if I was potentially going to be detrimental, I would have to be monitored" (p. 18). Although nervous, I had few preconceptions, and little idea of what to expect which arguably meant I was not too overwhelmed by preconceived ideas about the organisation. I still had to work hard to gain trust. Like Sanders (2006b), I had to convince frontline staff in the organisation that I would not be problematic to have around, that I would not embarrass them and jeopardise their relationships with individuals and organisations by behaving inappropriately, or harass and have an adverse impact on sex workers.

At this first meeting I expressed an interest in becoming a volunteer with NZPC for the duration of the research. The purpose of this was threefold. In line with the feminist approach ensuring reciprocity was a priority (Skeggs, 1994), I felt that working as a volunteer would provide that opportunity. I also recognised the value of volunteering in that I would be likely to learn a great deal about the broader sex industry in New Zealand and perhaps make connections with other interesting people in the course of this. Finally, I also genuinely wanted to be involved in NZPC because I admired the work invested by them to achieve the law change in 2003, and had a genuine interest in sex work beyond the research. They were supportive, and I started working with them as a volunteer 
providing administration support at the beginning of March 2008. This also facilitated my initial contact with potential participants in Wellington. Seven interviews were completed in Wellington in total, two with NZPC staff and five with sex workers. These interviews were completed between October and December 2008. All five of the interviews in Wellington took place in the NZPC national office. Four of these participants were approached by the National Coordinator of NZPC, and one participant was recruited by another woman interviewed previously. However, most of the fieldwork was carried out in Christchurch where there is a higher population of street-based sex workers and a range of organisations with an interest in this sector. This chapter will now move on to introduce the field in Christchurch and strategies to make contact with women working on the street there.

\section{Recruiting participants: the field in Christchurch}

In Christchurch the situation was slightly different since NZPC is not the only organisation in the city extensively in contact with street-based sex workers. Owing to the higher street-based sex worker population than in Wellington, services including outreach and drop-in centres are provided by NZPC, the Salvation Army, and Youth Cultural Development (YCD). NZPC provide street outreach one night per week and a drop-in from their base five days per week for all sex workers, in addition to sexual health services. The Salvation Army offer an evening drop-in centre providing food and hot drinks for street-based sex workers three nights per week, and an outreach van three nights per week when the drop-in centre is closed. YCD run a project for young people who have been involved, or are perceived to be at risk of becoming involved in sex work on the streets, and do street outreach three nights per week. In addition they run a weekly drop-in one night per week where young people can come along for a meal to socialise and access washing facilities and other assistance from youth workers.

Therefore, to get a broad insight into the street-sex work scene in Christchurch and introductions to as many women as possible, it was important to work with all three of these organisations. Making links with the NZPC was the most straightforward since I had been volunteering in the Wellington base for almost a year and had already met with the Regional Coordinator and some of the Christchurch staff. However, I did still have to work hard at building relationships with the NZPC in Christchurch, and support for the research developed over time as I progressed with it and built relationships with those 
working in this branch of the organisation.

Connecting with the Salvation Army was particularly important given the scope of the services they provided to street based sex workers in the city. I was aware that the evening drop-in centre could be an ideal place to make links with women working on the street and to carry out interviews. Likewise, I thought the street outreach van could be a useful way to carry out observation work on the street. However, making this connection was on a personal level more challenging than linking with NZPC. In contrast to my enthusiasm about the initial meeting with NZPC in Wellington, I was full of preconceptions before meeting with the person in charge of the Salvation Army project. The Salvation Army is a Christian organisation and has a history of coming from a different perspective on issues such as sex work. I was concerned about having religious perspectives pushed on me and was unsure how I should respond to this should it eventuate. I also wondered how open I could be with some of those involved in the sex worker project about my own perspectives and interest in sex work. Aware of my own judgmental view, I arranged a meeting with the coordinator of the services run for street-based sex workers at the end of January 2009 and I was offered the opportunity to spend time at the evening drop-in centre as a volunteer, and to experience the work of the outreach van. The drop-in centre then became my most important point of contact for making links with women working on the streets as sex workers in Christchurch. My experiences carrying out research in the drop-in centre, whilst also participating as a volunteer, will be discussed in more detail later in this chapter.

Through my connections with NZPC and the Salvation Army I met a youth worker from YCD in early April 2009. After this meeting I was invited to attend the evening drop-in regularly to meet with young people they were in contact with and to carry out interviews with some of these young people. Given the potential vulnerability of this particular group, I think it is unlikely that I would have been offered this opportunity had I not already developed close relationships with NZPC and the Salvation Army, organisations working closely with YCD.

Thus, gaining access to the field in Christchurch involved working with three very different organisations, therefore increasing the range of perspectives encompassed within this research. The field in Christchurch was complex and the range of agencies willing to involve me was instrumental in helping me gather a broad understanding of the street sex 
industry. In total, 23 women were interviewed in Christchurch. Five of these women were introduced by a youth worker at YCD, one by a staff member at NZPC, and the remaining 17 were contacted at the evening drop-in centre using a snowball approach. As the women were usually busy working in the evenings, some interviews were scheduled for during the day and NZPC generously provided a place for several of these interviews to take place.

The next part of this chapter provides an insight into my experience in the field, beginning with a discussion of the ethical issues considered and encountered from the very first stages of the research.

\section{Ethical Considerations}

Prior to starting the fieldwork ethical approval was sought from the appropriate Victoria University of Wellington Human Ethics Committee. Initial concerns were raised with regards to my own safety carrying out the research. The beginning of this section focuses on the issue of personal safety in relation to obtaining ethical approval for undertaking sex work research, and how this translates in the field in practice. The remainder of the discussion details the procedures to ensure the research was ethical and fair for all participants.

\section{Danger in the field?}

Any qualitative research on sensitive, personal topics carries with it a degree of physical and emotional risk (Lee-Treweek \& Linkogle, 2000), for both the researcher and participants. In New Zealand, concerns have been voiced about the importance of discouraging young female researchers from undertaking research in the sex industry (Snook, 2003). Judging on the basis of stereotypes, ethics committees often associate sex work as inextricably linked with criminal behaviour, drug taking, violent male pimps, and HIV. As such it is deemed imperative to shield young female research students from what is perceived as the 'seedy underworld' of prostitution (Sanders, 2006b). In line with these assumptions, questions were raised in response to my initial ethics application. Specific concerns were expressed about my own personal safety, despite having already made clear the steps I would take to protect myself, as I would had I been carrying out qualitative research with any population group. I was required to meet with the Committee Co-ordinator together with my supervisors to provide extra reassurance that I 
was personally equipped to carry out this research safely. A copy of the ethics approval is included in Appendix D.

I can recall feeling frustrated, as though I was being forced to buy into myths that construct street-based sex workers as deviant and dangerous. However, I also realised that any research carries with it a degree of risk and that danger can be inadvertently encountered. O’Neill (1996) for instance, had her car damaged before testifying in court about a violent attack on a street-based sex worker that she had witnessed whilst accompanying an outreach worker (O’Neill, 1996). Warr (2004) described fear of passersby who would throw eggs and buckets of water at sex workers on the street (Warr, 2004). Thus, however unlikely, the possibility of violence must be considered and planned for as much as possible. Central to this was making strategic decisions about the location of interviews, whilst also ensuring the women felt comfortable with these locations. This process will now be outlined.

The majority of the interviews were carried out in a private room at the evening drop-in centre, at the YCD drop-in, or during the day at NZPC. For interviews carried out in participants' homes, a contact from the NZPC was notified of my whereabouts before the interview took place, and when it was complete. Like sex workers described doing in their work, I also drew from my own instincts when deciding whether or not to go to people's houses to do interviews. In general, the interviews that did take place in participant's homes were actually the most relaxed and tended to go on for longer than interviews done in the premises of one of the gatekeeper organisations. However, during one of these interviews I did feel slightly nervous not because of the woman I was interviewing but because of the presence of her partner who had a history of violence and a houseguest who was experiencing withdrawal from drug use. I hadn't been aware that either of these men would be present during the interview and as a consequence had to manage the situation to the best of my ability. Despite this making it difficult to relax in the situation, the interview was completed successfully and the woman appeared in control throughout, at one point instructing the houseguest to leave the room. However this reminded me of the potential risks involved when entering private spaces, and the need to be prepared for the possibility that others will be present in this space unexpectedly.

I always ensured I carried a fully charged mobile phone, and only carried out observations on the street in the company of an outreach worker from NZPC or the Salvation Army. I 
kept regular contact with my supervisors by email and contacted them in the event of any concerns, however minor.

\section{Situational danger}

Despite my belief that doing the research would expose me to little risk, I did have one difficult experience conducting an interview with one woman who had heard about the research through people on the street. Initially this woman was friendly and keen to take part. However once the interview began she changed her tone and raced through the questions with profanities and impatient sighs advising me to 'just fucking get on with it'. The interview lasted less than 10 minutes before it had to be terminated, and I was required to hand over the koha that was intended to recognise the value of participation.

After this experience I consulted with staff and later discovered why the interview had taken such a hostile turn. I learned that this woman was not currently a sex worker but someone well known on the street for using stand over tactics to extort money from sex workers, often in the guise of 'minding' younger women.

Although this experience was quite unpleasant it constituted important data. Through my interaction with this woman I learned a little more about how stand over tactics work on the street. I got a deeper understanding of how unnerving it could be for some sex workers on the street when these individuals were present. It also gave me the knowledge that men do not exclusively perpetrate violence and coercion on the street.

This experience highlighted to me that whilst sex workers are ordinary people, and pose no greater risk than any other population, they are exposed to risks and these risks experience can be extended to researchers who become known in that scene. The possibility of this, however unlikely, is therefore important to consider.

\section{Ethical Research in Practice}

As discussed in the previous section, a number of steps were taken to protect my own safety whilst working in the field. Ensuring those who took part were treated fairly and protected from exposure was also of paramount importance. Sex workers are a diverse group, and usually have separate lives away from the street scene. As a result of the stigma attached to sex work, sex workers may keep their occupation a secret from close friends, family members, employers, and some government agencies. I was aware of this 
from the outset, and considered the integrity and privacy of the women taking part in the research a critical issue. For some women, being unintentionally 'outed' could mean the breakdown of personal relationships, so this was not an issue to be treated lightly.

\section{Obtaining informed consent and ensuring privacy}

All participants had the opportunity to read through an information sheet prior to being interviewed. This information was also summarised verbally before the consent form was signed and participants had the opportunity to ask any questions. The information sheets used are included in appendices $\mathrm{E}$ and $\mathrm{F}$. Before starting, all participants were required to sign the consent form to confirm they agreed to take part (see Appendix G). For the purpose of confidentiality, sex workers were given the opportunity to choose a pseudonym so they could identify themselves in the research, whilst still ensuring their responses remained private. The procedures to maintain confidentiality and obtain informed consent were the same for key informants, although it was asked if they would agree to comments being attributed to the organisation they worked for.

These procedures are common strategies used in qualitative research to ensure confidentiality. However, there were other subject and situation specific practicalities that I had to consider beyond these measures in the research process. For instance, if I saw a woman I had interviewed in the street or in a shop, should I say hello? If I was carrying out an interview in a public place or someone's home and a friend called round, who would I say I was and what would I say I was doing there?

I resolved to only talk to women outside of the field situation if they spoke to me first, and to not address them by their name in case I unintentionally used the wrong one. However the only time I saw a participant outside of the field situation was when a young woman yelled hello to me from a bus stop, thus sending a clear message that in this situation she was happy for me to acknowledge her. For one interview that took place in a woman's home I avoided giving any identifying information to an overly inquisitive taxi driver by simply saying I was going to visit a friend. Should any difficult situations occur in which it was clear I was a researcher, I resolved to say I was doing 'women's health research'. In another interview completed in the home of one of the women there were specific privacy issues. This woman had wanted to do the interview at home but did not want to answer any questions in front of her child who would return home from school in an hour. I therefore had to ensure that the interview was fully completed before her child returned 
home. However she was slightly earlier than expected and I was therefore introduced as a friend and had to make small talk before leaving.

These were all simple and common sense precautions, however, they were of great importance in respecting the rights of participants to not be identified, especially when exposure could have very serious consequences indeed. Just as sex work necessitates skills to think on your feet, so does sex work research given the situations that can arise that must be managed carefully when individuals have clear divisions between their work and private identities.

To facilitate a realistic portrayal of their experiences, participants were asked if they would allow me to record the interview using a digital voice recorder. All of the participants agreed to this, and I was surprised that there were no objections, and few concerns. All of the recordings were, however, kept in a password protected file and only I had access to them. I gave reassurances of this, which may have alleviated any initial concerns. These recordings will be destroyed within five years of the completion of the research.

It was made clear that the only limit to confidentiality was if a participant disclosed something that indicated that she, or another person, was at significant risk of imminent harm. This situation did not eventuate, however planning for it and communicating this to participants was of great importance given the focus on violence that was integral to the research.

All of the women who took part were provided with koha of $\$ 30$ for an interview of around one hour, which was comparable with what had been provided in a relatively recent national study on the impacts of the PRA (Abel et al, 2007). The use of a cash koha for participants in research is contested and on applying for funding I was advised that only vouchers would be considered appropriate. However, I felt strongly that the women I interviewed would benefit most from a cash koha since they could use this money to support their own specific needs or wants, rather than having these determined by the provision of a specific type of gift voucher. Cash incentives have been used in previous research on sex work: justified as a mark of respect for the expert input of sex workers; to differentiate the interview from formal unpleasant interviews with authorities; to recognise the potential harms of taking part in research; and to avoid using participants under the pretence that they will benefit in some broader way from the research findings 
(Sanders, 2001). Recognising that research findings generally take a long time to have any impact, and sometimes have very little tangible impact for participants, I felt it was important that the women received some immediate benefit from participating in the research, and also wanted to acknowledge the value of their input. The use of cash incentives in sex work research has been criticised on the basis that it mimics the sex worker client relationship since sex workers are sometimes paid by clients not just for sex but for conversation and companionship (Sanders, 2001). However, the koha provided was far less than sex workers would make seeing clients and thus did not represent financial compensation as such, but a personal thank you for their individual contribution.

Those who took part in interviews were also made aware that they had the right to withdraw from the research at any time. I hoped that making this explicit helped participants feel more at ease and empowered in the research process.

All participants were over the age of 16, and prior consideration was given to the law that prohibits clients from legitimately purchasing services from 16 and 17 year olds. However under $18 \mathrm{~s}$ do still get involved on the street, and it was important to also incorporate the experiences of younger and less experienced women.

Thus, in the planning stages and process of carrying out this research, a number of ethical issues were considered which influenced the way in which the research was carried out. A number of strategies were employed for the purpose of protecting my own safety, and the integrity and privacy of the people I interviewed. However, the process of carrying out research is rarely straightforward. The next section overviews an ethical limitation of the research.

\section{Ethical limitations}

In the ethics application I stated that I would not interview anyone who was visibly under the influence of alcohol or drugs. However it was not possible to adhere to this and on reflection it was a naïve and unfair assumption to have made. Although some of the participants were not drug users, or only used recreationally, a number of those I interviewed were habitual users. For these individuals it was unrealistic to expect that they would attend an interview without using beforehand, since using was something they currently did every day. However, all of these participants reported feeling 'on to it' before doing the interview, and engaged completely in the conversation. In one interview 
I had no idea that the participant had been using beforehand until she told me. She explained to me that what she was like after using was her 'normal', whereas to be 'straight' would be an alien, abnormal feeling. At this point I realised that insisting a participant be 'straight' for the interview would actually be a complete contradiction to the objectives of the research. If the objective really was to see the world through their eyes, their realities, their 'normal' then I had to accept drug use as part of that for some individuals. Through this I learned more about the complexities of conducting research in practice. The following sections provide a more in-depth insight into my experience carrying out the research, focusing on my relationships with organisations and participants.

\section{Making links and building relationships}

As discussed earlier in this chapter, in the course of planning and carrying out this research I developed a working relationship with the New Zealand sex worker organisation, NZPC. The first part of this section details the role of this relationship in the research process.

The voluntary work I did for the NZPC in Wellington in the first year of the research varied from answering phones to take messages, providing written input for submissions, helping to design an evaluation, and delivering condoms and lubricant to brothels. Initially, I felt like an outsider. On the first day I volunteered I worked in a back room on some computer-based work. However, I did not resent this and recognised that it was important to build trust and make clear that I would not jeopardise the privacy of anyone visiting the organisation.

As the months progressed, I spent more time at NZPC and felt the relationship I had with the organisation began to shift. I started to share more about myself with some staff I met at the collective and I began to consider them more as role models and confidants than 'key informants'. I enjoyed spending time at NZPC as it provided an atmosphere in which sexuality was discussed openly and there was no judgment. Having been socialised in an environment in which prudery and judgments of female sexual behaviour prevail, NZPC is a refreshing environment in which there is no place for shame in discussions of sexuality. Thus it is perhaps not surprising that as a young woman in my early twenties who had become accustomed to censoring my own experiences and views on sexuality, NZPC became a place where I enjoyed spending time. It would be an untruth to suggest 
that I tried to distance myself from the NZPC in the research process.

In February 2009 I accepted a temporary paid position with the NZPC in Christchurch. I realised that this raised issues around my autonomy as a researcher, however by this point in the process, I felt it was unrealistic to consider myself an outsider given the relationship I had already developed with the organisation. The paid work I did over this period was of considerable benefit to the research, providing a regular opportunity to assist with street outreach work, furthering scope for chance meetings with women who may wish to take part, and enriching the observational component of the research. This work, in addition to the volunteer work I did for the Salvation Army, meant I became an active participant in the street scene, becoming completely immersed in the research environment. The women were always made aware of my identity as a researcher, and the nature of what I was researching, but as someone who also respected them as individuals and was prepared to contribute as a volunteer and assisting in outreach. On many occasions I filled in for absent volunteers at the Salvation Army drop-in centre so that the centre would not have to close that evening. Thus, although I was employed by NZPC during this time, I also volunteered my time in the evenings. I hoped that adopting these membership roles helped me become understood as someone who was not a threat. Outsiders typically can be seen as a threat, which supports the benefits of adopting these membership roles. However I was also conscious that my multiple roles could raise suspicions amongst the women that I may share details of our conversations, and they may not feel free to criticise the organisations I was working with. To avoid this as much as possible, I always reemphasised that the conversation was totally private and that they should feel free to say anything they felt was important. Indeed, adhering to strict confidentiality was a key issue in the delicate balancing act of managing my insider outsider status.

\section{Managing multiple roles}

Although having these multiple roles may have assisted me in some respects in the research process, they also created the possibility for 'role confusion'. Similar to my work with NZPC, Wahab (2003) built a relationship with the sex worker organisation COYOTE in the USA in the process of carrying out her research. She experienced similar role confusion in the research process, feeling she had the multiple identities of "social worker, voyeur, wanna-be-sex worker, advocate, friend, goodie-two-shoes...I constantly felt like an insider and an outsider while working with sex workers" (pp. 628-629). 
Sanders (2006b) also reported experiencing this role confusion whilst balancing the roles of researcher and sexual health outreach worker, becoming known in several sex work venues as the "condom lady" (pp. 459-460). I also struggled to balance diverse roles in the research process. At times I felt like part of the scene and had to remind myself of my primary purpose of being there. At other times I felt like an outsider, paranoid I was considered a snotty, middle class, white girl who wished to benefit personally by 'studying prostitution'. I constantly had to reflect on and negotiate these roles in the field and, like Sanders (2006b) I came to accept that the role of researcher in this setting is seldom clear-cut and limited to the mere gathering of information.

The management of these multiple roles was particularly relevant in specific situations. For instance, to facilitate the research I worked as a volunteer for the Salvation Army run drop-in centre and on the outreach van, however I did not share the perspective of some of those involved in these projects. I had to reflect on my own perceptions and boundaries to ensure I respected the staff and project, whilst remaining true to my own perspective. In one situation I was expected to participate in a prayer, which was uncomfortable for me, and though I managed to avoid participating, this raised an issue of how to respond in these situations. I also had difficulty with a lead volunteer insisting I wear a Salvation Army hat while accompanying them on the outreach van, which I was reluctant to do since I wished to emphasise my autonomy from the organisation. Whilst I felt comfortable being associated with the NZPC, I felt more ambivalent about my contact with the Salvation Army. At times I felt very conflicted. Thus it was important to learn how to participate in their work whilst doing the research, without being disrespectful to those in the organisation who had afforded me the privilege of being involved.

These multiple roles also had some impact on my interactions with sex workers. These experiences will now be discussed to provide an introduction to the women, and an insight into the interview process.

\section{The women}

A total of 28 women took part in in-depth interviews on their experiences working on the street. The women were aged between 17 years and 57 years. Thirteen of the women identified as New Zealand European, fourteen as Māori and one as Cook Island Māori . 
The length of time working in the sex industry varied between two months and 22 years. Five of the women had started working after the law reform, whilst the remaining 23 worked in the sex industry before the law change. This thesis therefore incorporates the perceptions of women with experience working pre- and post-law reform.

Sixteen of the women were unsure about how much longer they would work in the sex industry, whilst two thought they would continue for another one to two years. One woman expected to work for a further three to five years and four women reported that they would continue to work for more than five years. Four of the women had recently stopped working, although two of these women disclosed working occasionally to meet unexpected personal and household expenses. A few of the women described feeling satisfied working and had no desire to stop, whilst a few were very keen to stop and were proactively exploring options to leave the sex industry. There were also a number of individuals in between these two positions.

Ten of the women reported doing no other work outside of the sex industry in the course of their lives, whilst the remaining 18 had worked in other occupations previous or concurrent to working in the sex industry. Two women were also engaged in part-time paid employment outside of the sex industry at the time of the research. Five women were currently studying in full- or part-time education, whilst nine were full-time caregivers. Four women reported that they were currently involved in voluntary work.

The average age of entry to the sex industry was 20 years old. The range was broad however, and one woman had become involved in street prostitution at the age of 12 whilst another woman had started working at 45. A range of perspectives are therefore included in this thesis from women who had started selling sexual services at very different times in their lives and in variable circumstances.

Seventeen of the women had children. In some cases these children were grown up and therefore not dependent financially. In a few cases children had been taken into care. However, nine of the women were supporting children currently. Several of these women described working on the street solely for the economic benefits that this brought to their children, to provide necessities and luxuries that they had sometimes lacked in their own childhood. 
All of the women were given the opportunity to choose a pseudonym in order to facilitate identifying themselves in the research, and some were rather creative in their choice. For example, Alphadites explained that her name should be taken to mean goddess of shopping. A few of the women requested that a name be chosen on their behalf and this was respected. Care has been taken in the choosing of these pseudonyms to ensure the identity of all participants remains protected. The next section provides some insight into the interview process.

\section{Interviewing}

As discussed earlier in this chapter, in line with the feminist approach it was important to pay particular attention to the power balance with participants in interviews. In interviews with sex workers it soon became clear that most of these women would, in any case, not allow themselves to be disempowered. Although I was inevitably in a position of power as a researcher, it was simply not the case that I had all the power. In some situations, the women took control of the interview by asking me questions and letting me know their thoughts on the sorts of questions being asked. In some ways the way in which these women managed the power relationship in interviews perhaps reflected the skills they used in their sex work to retain control in encounters with clients. Many of these women were highly skilled communicators, which is undoubtedly reflected in the quality of the data throughout this thesis.

As outlined earlier in this chapter, interviews were semi-structured with scope for the participant to take the interview in the direction they wanted it to go. In practice, some of the most surprising and challenging responses were not in response to specific questions I asked, but when the person being interviewed had strayed from one of the questions, and explored a thought or a memory they had in the course of the interview. Often these moments came at the end of the interview as an aside or off the cuff remark. I learned to treat the interview guide more as a starting point for discussion as opposed to a predetermined structure of the discussion.

In the process of carrying out the interviews I too was asked questions by participants and, recognising the personal nature of the information I was asking them to reveal, I readily shared my own experiences with sex workers. Consistent with the experiences reported by other researchers, I found this to be a natural process often in response to curiosity of the participant, which helped build relationships and increase rapport (Liamputtong, 2007; 
Sanders, 2006b). It was important for me to be honest with the women, even though this was at times uncomfortable. For instance in my second interview with one woman, Sydney, I was asked whether I could ever see myself working on the street as a sex worker. I answered that I could not and Sydney pushed me to divulge the reasons why I did not think I could work on the street. Explaining that I would be afraid for my safety and would not have the skills to manage clients in such an uncontrolled environment, Sydney laughed and reassured me that if I ever did, she and the others would ensure I was safe, clearly emphasising her position of power as the holder of knowledge I was interested in.

In an interview with Justice, we discussed a similar experience of being raped as teenagers. After sharing my own experience, Justice talked in more detail about her own experience. In this situation I felt that this disclosure helped to balance the power relationship in the interview and the response from Justice suggested that my own disclosure helped her feel more at ease talking about the emotions that accompany such an intensely violating and deeply personal experience. However, I recognise that sharing such experiences risks emotionally burdening participants and thus it was important to ensure these situations were approached in a way that would support rather than hinder the participant.

This particular experience felt positive, although disclosure with participants and others in the field at times did cause me some concerns. Like Sanders (2006b), I also found on reflection that this made me feel vulnerable and I developed concerns about the need for my aspects of my life to remain detached from my fieldwork interactions. Although sharing parts of my own experiences with others in the field was not laborious and was something I often did without thinking, I developed an awareness that this required a delicate balancing of allowing myself to be vulnerable, but not too vulnerable (Angrosino \& Mays de Perez, 2000).

\section{Researcher observation}

Researcher observation was an ongoing process throughout the six-month fieldwork period in Christchurch. In the first two and a half months this involved volunteering at the Salvation Army run drop-in centre and on the street outreach van. In the final months of the research, I accompanied an NZPC outreach worker once a week on the street to distribute condoms. At the end of each evening, I typed up notes of these 
observations in order to increase my knowledge of the street sector. This research is not ethnographic and thus these notes were not intended to constitute data, but to increase my understanding of the broader context, and as a tool for reflecting on my experience whilst immersed in the research environment. Indeed, whilst undertaking the fieldwork and afterwards I experienced a range of emotions that I realised needed to be managed and reflected on. The next section outlines the emotional impacts I experienced whilst carrying out this research.

\section{Managing emotions in the field}

One of the less explored aspects of sex work research relates to the emotional impacts that can result from carrying out field research in this area (Melrose, 2002; Hammond, 2010). Melrose (2002) described experiencing 'labour pains' in the course of undertaking fieldwork on juvenile prostitution. During the data analysis process she reported experiencing a range of emotions, such as anger towards men who paid for sex with the young people she interviewed, concern for the ongoing wellbeing of participants, and sadness about the experiences of violence that were described during the interviews. Similarly, Hammond (2010) found herself experiencing emotions of sadness, anger, anxiety and fear in her field research with male clients of sex workers (Hammond, 2010). Managing emotional reactions in the research process was an issue for me throughout the research and was something I struggled with on multiple levels. In part, the emotional impact of the research was expected given that I was discussing experiences of violence with some of the women. Conversely, the majority of the interviews with sex workers involved a range of emotional responses and some of the interviews involved a lot of laughter. Indeed, the strongest emotional reactions I experienced were unexpected and related more to aspects of the research process.

One specific way in which I felt emotionally vulnerable related to my own experience and management of whore stigma. Liamputtong (2007) notes that researchers are vulnerable to social stigma and this became clear to me in some interactions I had outside of the fieldwork experience. As a researcher, and as a young woman, I became aware of how deeply ingrained and destructive whore stigma can be. Explaining the nature of my research to people often invoked two responses - giggling and questions around why I was interested 'in that' or furrowed brows and comments that it must have been rather saddening and frightening to do this sort of research. When I spoke about the women I 
had interviewed in a positive and respectful way, it felt as though some people could not handle this and would subsequently challenge this in an attempt to confirm their preconceived negative ideas about street-based sex workers. If I confirmed that some of the women had used drugs, for instance, it felt as though some individuals used this to dismiss the other skills the women had and the value of their rights working on the street. This ignorance was observed amongst a wide range of people with various levels of education. When tutoring a third year Criminology paper I had to engage with a Law student who passionately argued that the rape of a sex worker was best described as robbery. Whilst conducting research in the UK, Boynton (2002) reported experiencing similar reactions noting in her research diary:

I encountered negative feedback from academic colleagues, e.g. 'he [an academic colleague] laughed and said "whores can't be raped" [during a discussion about abuse of working women]. Later he told me "you'd better watch out now, if anything happens to you out there no one'll believe it wasn't your fault. You're one of them now". (p. 9)

In the course of carrying out this research I felt overwhelmed with frustration that I could not do more to challenge this stigma, and at times felt stigmatised myself. Like Warr (2004), I struggled with accepting the limitations of research to tangibly influence negative situations. At some points in the research process, this resulted in me feeling frustrated with myself for using my own power to do this research, when it felt as though I could do very little to influence social change in this respect. This self-questioning and critique has been highlighted by other researchers. Miller (1997) described feeling discomfort about her actions as a researcher after the fieldwork was completed. She notes:

When I think about my actions and my interest in the research, I'm not very comfortable with this aspect of it. Is it exploitative? Am I? How much does voyeurism play a part in any research? ...Although we are not dispassionate researchers who distance ourselves from our values and emotions, we continue to objectify our research subjects through the very power we employ as researchers. (p. 149)

Particularly during the data analysis process I struggled with similar feelings, in relation to my thoughts about what I could gain from the research, compared to any benefits for the participants. I eventually came to the understanding that accepting this, whilst uncomfortable, was necessary since there is a need to be realistic about the outcomes of research. Further, I came to an understanding that undertaking PhD 
research is a process of learning how to be a good researcher and thus reflection and learning should be seen as a positive rather than a negative dimension to this.

In the course of carrying out the research I also became familiar with the emotional impact of unexpected events in other people's lives whilst doing research. In the final stages of the fieldwork one of the women I had interviewed three weeks earlier, Lexi, committed suicide. This was very upsetting, particularly in the process of transcribing the interview. During the interview Lexi had described going back to work on the street having been excluded from the methadone programme for rule breaking. She still needed to work on the street despite feeling afraid after being attacked by someone who had approached her as a client several weeks earlier. Although it would be inappropriate to conclude on what led Lexi to commit suicide, I felt very angry that she had experienced such pressure because of punitive drug laws and I had to remain aware of my own emotional reactions whilst analysing her responses. In the event of such strong emotional responses it is important to reflect on these reactions in order to differentiate between personal feelings about situations and the experiences participants are actually describing from their perspectives (Warr, 2004). Managing and reflecting on my own emotions in this situation was critical and an important reminder that there are some events that cannot be controlled when researching people's lives.

\section{Data analysis}

As many interviews as possible were transcribed soon after the interview whilst the fieldwork was progressing. This allowed transcripts with sex workers to be reviewed and meant I could arrange second interviews with women where it would be useful to follow up on issues raised. Whilst transcribing the interviews, initial thoughts were recorded in a word document to begin some initial reflection on the data. I transcribed all 34 of the interviews with sex workers. In the process of transcribing the interviews I committed to not tidying up transcripts since such editing can result in deeper meanings being missed (Devault, 2002) and thus all interviews were transcribed verbatim. Notes were also made after each interview to review in the analysis process since I recognised, as Warr (2004) noted, that transcripts "are not facsimiles of research encounters".

Five of the key informant interviews were transcribed during the research process, however due to considerable time constraints the final twelve were undertaken by a 
professional transcriber after the completion of the fieldwork. Following a recommendation from the research supervisors, the transcriber was recruited as someone familiar and experienced with research on sensitive topics and privacy and confidentiality issues. The transcripts were reviewed for accuracy and were sent to participants who had requested copies. Once all interviews were compete and transcribed, the transcripts were saved in Nvivo. The possibility of using Nvivo to support the process of data analysis was considered after this was suggested by one of the research supervisors who had used it previously. Initially I was sceptical about using computer software for qualitative analysis. Unfamiliar with the software, I was concerned that this would somehow inhibit the depth of the analysis. However, on becoming familiar with Nvivo, I recognised that I could use it to effectively organise the large amounts of data I had from the interviews. As Richards writes:

Nvivo has tools for recording and linking ideas, and for searching and exploring the patterns of data and ideas. It is designed to remove rigid divisions between "data" and "interpretation" - if this is what the researcher wishes. It offers many ways of connecting the parts of a project, integrating reflection and recorded data. (Richards, 1999:4)

This facilitated an ongoing in-depth analysis process. Two Nvivo projects were created one for sex worker interviews and one for key informant interviews. Each interview transcript was then coded individually to identify themes. These themes were then analysed together to identify patterns. As Smyth (2000) notes, "Thematic analysis portrays the big picture. It is a starting point for qualitative research" (p. 16). In the process of constructing chapters based on these themes, drafts were reviewed by the supervisors to check the consistency and accuracy of interpretations. The data analysis process was challenging for me. At times I felt very overwhelmed by the large amounts of data I was trying to make sense of. Eventually, I learned to embrace the sense of confusion I had been experiencing, realising that the complexities, contradictions, surprises, and nuances were what enriched the findings. Once I had succumbed to the chaos, the analysis process became far more enjoyable and productive.

It should be noted that some of the quotations, particularly from sex workers, are written in the present tense and that this has not been altered. Although this is not consistent with the rest of the thesis, I felt it was important that these quotes remained as they were spoken at the time of the interview to better convey the overall meanings contained in these excerpts. In the final writing up process, some of the quotes were edited slightly to 
ensure ease of interpretation on behalf of the reader. The editing of quotes involved only adding punctuation and editing out instances where participants had said 'um' and 'you know' several times if this did not add to what was being said. Quotes were only edited when necessary, consistent with the overall aim to present participants' experiences and perceptions as they described them.

\section{Summary}

The purpose of this chapter was to detail the theoretical underpinnings and methods used in the process of doing this research. Further, I intended to provide some insight into how this translated in the field in practice, and how relationships in the field between gatekeeper organisations, individual participants, and myself developed over time. In this chapter I have highlighted some of the complexities of carrying out research in the streetbased sector whilst working with diverse organisations. The fieldwork represented not only the process through which I collected data but also a period of learning through which I came to appreciate the complexities between and within individual experiences. The next chapter begins to explore this, and introduces empirical data on the experience and perception of violence amongst the women. 


\section{Chapter Four: Perceptions and experiences of violence}

\section{Introduction}

The management of violence-related risks on the street invariably relates to individual perceptions of violence amongst street-based sex workers. This chapter presents perceptions and experiences of violence amongst street-based sex workers in Wellington and Christchurch. In addition the perspectives of key informants are included to provide a broader insight into understandings of violence-related risks amongst those familiar with the street sex work scene. This chapter begins with an overview of how risks of violence have been conceptualised and how the diversity of these risks is reflected in the perceptions and experiences of these women. Some complexities in how these risks were constructed and managed by the women are then explored, including perceptions of the street as a work environment. To conclude, I discuss how perceptions of risks of violence contribute to the development of risk management strategies.

\section{Conceptualising risk}

As a diverse population, it is likely that women working on the streets have varied perceptions of risk in their work, as shaped by their present and past life experiences. Sanders (2004b) notes that the concept of risk is both "an objective calculable event associated with certain actions, but relative to the individual and social circumstances" ( $p$ 558). A large amount of previous research has focused on the experience of violence in street-based sex work (Abel, 2010; Barnard, Hart \& Church, 2002; Benson, 1998; Church et al, 2001; Dalla et al, 2003; Kinnell, 2008; Lowman, 2000; Phoenix, 1999; Raphael \& Shapiro, 2004; Silbert \& Pines, 1982; Whittaker \& Hart, 1996; Willamson \& Folaron, 2001). To a lesser extent research has explored perceptions of the risks of violence in-depth amongst street workers (Plumridge, 2001; Pyett \& Warr, 1999).

Sex work is pre-defined as a risk behaviour in the mainstream and it has been noted that "the discourse of risk is applied to certain sexual behaviours and identities as a control mechanism to regulate those considered as 'Other'” (Sanders, 2006c, p. 96). Just as sex workers have been defined as 'at risk', so too have they been construed as a risk to broader society. Harris et al. (2011) note: 
Moreover, the social construction of sex work in medical, media, religious, and law and order discourses focuses on sex workers as both being at risk and posing a risk. The public risk discourse of sex work itself exposes sex workers to further risks, such as hate crime, and must certainly influence the ways in which they view themselves and their work practices as risks to be managed. (p. 388)

Indeed, the concept of risk in relation to street-based sex work is multi-faceted. On the one hand, street-based sex workers are considered at risk as potential victims of violence. One the other hand they are constructed as a risk to others - portrayed as "predatory, unruly, aggressive and threatening, disrupting the passage of their male victims" (Frances \& Gray, 2007, p. 318). Sex workers on the street are also portrayed as increasing risk for other non sex-working women, who may be mistaken for sex workers and propositioned (Bondi, 1998; Edwards, 1997; Kantola \& Squires, 2004; Matthews, 2008; Sharpe, 1998). For instance, in a study on community perceptions of street-based sex workers, some residents reported that the practice of street sex work made other women in the area more vulnerable. Pitcher et al. (2006) note:

Characteristically, men expressed less anxiety than women about walking along the street at night, but often stressed the 'dangers' faced by the women they knew. Some men reported that they would make sure to pick up their daughters and other female members of their family rather than let them walk around the neighbourhood after dark. (p. 18)

This dual construction of sex workers as both 'at risk' whilst also posing a risk to others can be considered linked to societal anxiety about women who defy expectations of the conventional female role. To manage risk, women are expected to practise risk avoidance (Walklate, 1997). This, in turn, has cemented divisions between sections of the population leading to an assumption that people can effectively 'avoid' being victimised should they try hard enough. Those who are not perceived as practising conventional risk avoidance are subsequently construed as bringing violence on themselves, commonly described as 'asking for it'. Lupton (2006) notes:

As discourses on risk proliferate, more and more risk-avoiding practices are required of the 'good citizen'. Risk avoidance has become a moral enterprise relating to issues of self-control, self-knowledge and self-improvement. It is deemed people's own responsibility to take note of risk warnings and act on them accordingly. The people who fail to engage in such behaviours may thus often find themselves stigmatised and subject to moral judgements. (Lupton, 2006, p. 14) 
Since street sex work is pre-defined as a risky behaviour, women involved in it are constructed as failing to practise risk avoidance, and are thus defined as risk takers engaging in an activity that assumed to be characterised by extreme danger. This may then impact directly on how risks are perceived by those working in this sector. As such:

The more stigmatised and dangerous the life situation, the more extreme an individual's perception of risk might be. Women who engage in sex work are compelled to identify and deal with the obvious and immediate physical threats and challenges involved in daily commercial transactions of sex for money. (Harris et al., 2011, p. 388)

In line with this, an overwhelming majority of the women interviewed in Wellington and Christchurch perceived violence as a risk of their work. It was clear that whilst individual women dealt with the presence of risk in different ways, all of the women were acutely aware of the risks of violence whilst working on the street. For instance, Alphadites noted:

I know in the back of my mind like any other working girl you put yourself in danger when you're out on the streets working...You're never safe. You never perceived yourself as being safe. You always think in the back of your mind you've got to be careful. You know, have your wits about you. You're never safe when you're out there. It's always there. You always worry about it. (Alphadites, Wellington)

Similarly Kay explained:

Of course! You could get murdered, what's more dangerous than that?...No I don't feel safe out there, I'm quite wary...Your life's on the line every night. You know, you're being picked up by strangers and who knows what they have in their car. (Kay, Christchurch)

These responses are in agreement with findings that suggest physical risk is identified as the main risk amongst street-based sex workers in New Zealand (Abel, 2010). Perceptions of violence-related risks, however, did not exclusively relate to risks of violence from those approaching as clients and reflected a range of potential perpetrators. The broad nature of violence-related risk will now be outlined.

\section{Typologies of violence}

As noted in chapter three, in recent years significant attention has been paid in academic research and media to the risk of violence from clients in street-based sex work. This can in part be linked to the murders of women working on the street in 
New Zealand and elsewhere, and subsequent increased interest in the risks of sex work. Attention afforded to the risk of violence from clients can also be linked to the legislative approach enacted in Sweden in 1998, which defined prostitution as a form of violence against women and criminalised clients of sex workers as a result (Ekberg, 2004). This approach, typically supported by those endorsing the abolitionist feminist perspective on sex work, it can be argued, has led to the construction of male clients as inherently violent and supported their criminalisation as a result (Scoular \& O'Neill, 2008). Women working on the streets have been considered the most vulnerable group, and as such, it is hardly surprising that their clients have subsequently been portrayed as sexually abusive, deviant, and potentially dangerous men. Clients have been defined as the main perpetrators of violence against sex workers (Abel et al., 2007; Benoit and Miller, 2001). Arguably, as a consequence of these combined factors, insufficient attention has been paid to the broad nature of violence-related risks in street-based sex work (Day et al., 2001). In her research on violence against sex workers in the UK, Kinnell (2008) highlighted the problematic nature of the focus on violence from clients. Kinnell provides a useful framework for understanding the diverse nature of violence against street-based sex workers by bringing attention to the range of violent acts sex workers experience - such as abuse and harassment from local residents and state violence that links to the criminalisation of sex workers. Other researchers have also called attention to the diverse perpetrators of violence against street-based sex workers, such as Sanders (2007) who notes that:

Perpetrators of violence are not only those men who pretend to be customers, or those men who break the commercial contract by not paying the agreed price, but also members of the community who direct their discontents to individual women through aggressive confrontation and sometimes collective vigilantism. The working environment has become increasingly hostile for sex workers as the police are encouraged to actively enforce the laws against sex workers as street prostitution becomes unacceptable, framed as problematic and uncivil. (pp. 791-792)

Whilst the women who took part in this research no longer managed the risk of state violence to the same extent due to the decriminalisation of prostitution in New Zealand, they continued to manage a range of violence-related risks. These typologies, which included violence from passersby, street associates, minders, other sex workers, and individuals who approach as clients, will now be outlined. 


\section{Violence from passersby}

Most commonly, the women described experiencing violence from passersby in the form of verbal abuse, missile throwing, and in some cases more explicit physical violence. Overwhelmingly, the women emphasised abuse from passersby was far more frequent than abuse from clients. Lisa-Lou described the verbal abuse she had experienced at work, explaining, "Actually you would get more abuse from ones that don't, you know that aint clients... well they yell things out like 'twenty cents' and stuff like that. It's really terrible". Shania explained that for her this was a particularly negative aspect of working on the street. She perceived the risk of violence from clients to be a lesser issue by comparison to the frequent violence from passersby:

The narrow mindedness, small mindedness of people in general in the community...Like you're out there and they go past and hurtling things at you and abusing you....not so much violence from clients, I struggle more with the taunting and shit from other people from society. (Shania, Christchurch)

Tessa noted that the perpetrators of this abuse could be males or females, noting, "Friday/Saturday nights a lot of the young ones drive up and down and they can't help themselves, they've got to wind down the window and the girls all have to yell 'slut',". Violence from passersby was perceived as a risk by all of the women and was highlighted by all of the key informants. Whilst conducting the research, I observed frequent instances of this type of violence towards women working on the street. However, whilst it was the most frequently discussed form of violence, it was not perceived as a particularly troubling risk. These issues will be explored in more detail in chapter seven.

\section{Violence from street associates}

Violence from street associates, including minders, was also perceived as a risk. Women and key informants described individuals who would attempt to 'stand over' sex workers for money whilst working on the street. This was perceived to be a risk more so for those who were inexperienced and new to the street environment. Again, perpetrators were not exclusively male and at the time of the research in Christchurch, women were considered to be the main perpetrators. One key informant described the perpetrators as “women who don't do sex work but want to benefit from somebody sex working”. This was considered a key risk factor for younger people who were present 
on the street. One key informant explained:

At the moment for instance we've got two women in particular who stand over the girls on the street and demand money by menace...So, so they do the tough tactics...And the sadness is they always target the younger people who are unsupported. They won't target anybody who's got support behind them. So they'll always...victimise victims. (Key informant, Youth)

Sex workers interviewed confirmed that this behaviour represented a risk for younger and more vulnerable women who may have fewer supports available to them. Chapter eight includes a fuller analysis of how this risk was managed.

\section{Violence between sex workers}

Violence between sex workers was also considered to be a risk. A hierarchy was described, and it was clear that those who were inexperienced were at risk of being victimised. Women who were new to the street scene were often perceived as a threat to the economic success of others. Alphadites explained:

If a new girl comes out on the corner and she wants to work. Just like anyone else she's got to go through the oldest one out there, and the second oldest, or the third oldest... And there's another thing. If a girl goes out there and she's doing a lot of jobs that just goes to show she's undercutting, you know? Because the older ones out there turn them [cheap clients] down. We send the new girls up the top to work at the beginning. The only time they can come down to us to work is if they been there longer than a couple of years, a year or so and they've started to get in with the older crowd...And usually the older ones can see who's been picking them up, you know. And then we call tell - oh she's cheap, she's taking the cheap ones. We've already turned them down and then they go up the top there and the girls are jumping in. Now this is where they've got to be taught a lesson - don't go cheap, it makes our street look cheap - you know? (Alphadites, Wellington)

Key informants also described violence between sex workers as a risk for those working on the street. One key informant noted, "Some of the violence meted out on the street is actually from other workers, females. Shouldn't always say 'he'”.

It should be highlighted that a strong ethos of peer support also existed on the street to protect from violence against outsiders; nonetheless relationships between the women were complex. However, it was clear that the women perceived violence from coworkers as a risk to be managed. The complexities within this will be explored in more detail in chapter eight. 


\section{Risks of violence from clients: the good, the bad, and the ugly}

Violence from individuals approaching as clients was perceived as a risk. However, 'clients' per se were not considered violent. Overall, the women described positive interactions with clients. This supports previous findings that suggest most contacts between sex workers and clients are incident free (Barnard, 1993). Hollie for instance explained "um nah the clients usually have a lot of respect". Shania also stressed that most clients did not threaten her wellbeing. She noted, "there's a lot of good guys out there. There's definitely a lot more good ones than bad'. Jane perceived violence from clients to be relatively uncommon. She explained, "you only get once in a blue moon where you get a real arsehole". The overall perception was that whilst there was the potential for violence in every encounter, clients were usually 'genuine' in that they wished to pay for pleasure. Jackie described interactions with some clients who had particularly good intentions and suggested that this had changed some of her impressions of men. She explained, "most guys pretty much are pretty cool....They might give you a massage, you know, and treat you like a goddess for a little while and it's like 'oh wow neat there's actually some real nice guys out there'". Key informants also suggested that most interactions between sex workers and clients were problem free. One police key informant noted:

I think in the five years that I have been here if you looked at the amount of violence associated with prostitutes as opposed to the number of prostitutes that are working and the hours that they are working out there I think you would find that it is a very small percentage. (Key informant, Police)

Another police key informant also suggested that the majority of interactions between sex workers and clients involved the exchange of money for services, rather than violence:

You've got a large amount of actions or transactions that are taking place where there's no violence. So it's easy to say, you know, it's violent because...there's going to be violence in amongst it all. It's very hard to measure and to say what the level is. It might be... actually be as low as 5\% or $10 \%$ but they don't report it so much. What we hear... when violence occurs it's likely to be at a high level of violence... ...there seems to be a lot of action where it's just simply a matter of engaging the sex, take them and come back in a 15 minute cycle. (Key informant, Police)

Other key informants from support and advocacy organisations also invoked this perception. One key informant noted, "I think the majority of the population using 
street workers are out there to seek a service. Because they are providing the service and things go fine and, you know, it's very seldom that they don't'. In contrast to the construction of clients as sexual abusers, neither sex workers nor key informants construed clients as inherently violent, but as purchasers in a market who were seeking a legitimate service. However, the violence inflicted on sex workers by individuals who initially approached as clients is well documented. The work of Hillary Kinnell (2008) provides an interesting analysis of this type of violence. In differentiating between 'good', 'bad' and 'bogus' clients, Kinnell provides a more accurate breakdown of the risk represented by those approaching as clients. She argues that although perpetrators may initially approach as clients, they generally do not pay for sex and instead inflict violence on the sex worker. As such, these individuals cannot be considered clients. Kinnell notes:

Attackers are nevertheless commonly described as 'clients', but examination of numerous reports of such attacks demonstrates that a high proportion of this violence comes from those who do not pay, and since the defining characteristic of a client is payment for sexual services, these attackers are therefore not clients, even though they may have approached as if they were clients. (p. 63)

Such individuals who approach as clients but perpetrate violence instead may then be understood as 'bogus' clients or 'ugly mugs'. A few of the women described experiencing violence from individuals who had initially approached as a client but seemingly had no intention to pay. Shannon explained, "He offered me seventy dollars for a sex job. So I said 'ok' so we went into somewhere round near Hagley Park and, um, he never paid me...He also took what money I had". Another sex worker, Claire, described an attempted attack by a man who had approached as a client:

I was asking for the money and he just like looked at me like "I've got nothing for you"...I had to tell him, you know, "This isn't right. You either give me the money or else I'm getting out of here". And he sort of went to like grab me and, you know, tried to overpower me. (Claire, Christchurch)

Vixen described being raped by an attacker who had initially claimed he wanted to pay for oral sex:

A guy just wanted a blow job and I was on Peterborough Street and just went behind the station and I bloody bent down to get a condom and next minute it just all happened so fast, he was on top of me and inside of me and then he was off. (Vixen, Christchurch) 
Some findings suggest that the behaviour of these offenders is complex. Kinnell (2008) notes that offenders may pay for sexual services and then demand money back or additional services using force to achieve this. In Christchurch, a few women described having experienced this. Lexi explained:

We did the job sort of thing and that's when it all started coming up that it was one of the better jobs that he'd had and um he'd been fucking ripped off before so he wanted more and he ripped the condom off and got something sharp and scratched my fingers. (Lexi, Christchurch)

The experiences of these women support the theory proposed by Kinnell (2008) that describing perpetrators as 'clients' is often inaccurate. These findings suggest that it is useful to consider those who approach as clients on a continuum of 'good', 'bad' and 'bogus' when reflecting on clients as potential perpetrators. Whilst these women stressed that they did not fear violence from clients per se, they had to consider the potential for violence since there was a continuous possibility that someone may approach who did not fit the genuine client profile, and could perpetrate extreme violence. In line with this, the possibility of being attacked by an individual who had approached as a client was positioned by the overwhelming majority of these women as the most concerning risk whilst working on the street. Kay explained:

Probably a client getting out of control would be the most freaky for me. I'm not too worried about being ripped off because hey you know you can always make the money back. But that's more a fear...the client freaking out, raping and murdering that kind of thing. (Kay, Christchurch)

The strategies employed by these women to manage and negotiate this possibility will be explored in chapter five. This chapter will now move on to consider how perceptions of risk were managed in the context of these broad risks of violence.

\section{Risk perception and risk management}

In light of these diverse risks of violence, all of the women interviewed were aware of the possibility of violence whilst working on the street. Despite these risks, a few of the women denied feeling afraid whilst working on the street. Pania explained:

No, I mean it doesn't scare me. I mean it's something that you can count on to happen really. I mean it's all with the job which is really sad but there's every chance it could happen you know? But it doesn't scare me. I mean so be it - if I die then it's meant to be. (Pania, Christchurch) 
In their research with female street-based sex workers, Pyett \& Warr (1999) argue that the risk of violence may be normalised to an extent for those working in an environment in which there is ongoing potential danger. Findings also suggest that feelings of safety may relate to the familiarity with the street environment, for those who have been involved in street sex work longer term (Abel, 2010). Pania's perspective that violence is to some extent inevitable may in part relate to a normalisation of violence, whilst also linking to her familiarity with the street scene. Some findings suggest that this results in a passive acceptance of violence amongst street-based sex workers, where the experience of violence is considered an 'occupational hazard' (El-Bassel, Witte, Wada, Gilbert \& Wallace, 2001; Gorry, Roen \& Reily, 2010: Phoenix, 1999). According to Harris et al. (2011):

In our data, the street was constructed as a dangerous place where the four street workers negotiated the service and the price, then with only their wits to protect them they climbed into the car of an unknown man...the street sex workers we interviewed constructed high personal risk of violence and infection to be unavoidable aspects of their daily work experiences that they managed as best they could. (p. 395)

In Wellington and Christchurch, however, the majority of the women did not appear to passively accept risks of violence in this way. In Christchurch, this may have reflected the context in which the fieldwork took place, months after a woman had been murdered whilst working on the street and the perpetrator was still at large. In the main, the women clearly recognised that the risk of violence was ongoing in the decriminalised context. For a few women, feelings of safety appeared to emerge from their sense of preparedness for what could eventuate if they encountered a violent client. Like women interviewed for Mullins' (2008) research, these women portrayed a street persona that was characterised by toughness, strength, and antithetical to conventional norms of femininity. This sort of response was most common amongst younger women who had essentially lived with adult responsibilities from a young age. Zoe for instance claimed "it doesn't phase me ay because I've seen a lot of shit in my life", positioning her perception in the context of her previous life experiences. One woman dismissed the possibility of being murdered whilst working on the street, by suggesting this was something she could control. Cindy noted, "I' $m$ not a silly bitch. I wouldn't get killed". Two of the women said they felt safe as long as they had their minder with them whilst working on the street. Sapphire explained, "I do feel pretty safe the majority of the time because I have a minder". These women therefore 
used perceptions of their circumstances and backgrounds to approximate the potential risks of violence in their work.

Douglas (1985) argues that risk perception is underpinned by a need to downplay the extent of actual risk involved in everyday activities. She argues:

Most common everyday dangers tend to be ignored. On the other end of the scale of probabilities, the most infrequent, low-probability dangers also tend to be played down. Putting these tendencies together, the individual seems to cut off his perceptions of highly probable risks so that his immediate world seems safer. (p. 30)

Plumridge (2001) argued that street-based sex workers acknowledged and yet simultaneously downplayed their own vulnerability:

They have an understanding of risk that on one reading is highly informed and realistic, but which on another reading can be seen to refuse acknowledgement of personal risk or risk-taking. The larger, structural constraints such as a dependence on alcohol and drugs, and inequalities of age and physical prowess vis-a'vis clients and other men which shape their risk exposure, are overridden in their accounts of themselves as expert and successful operators on the streets, experts at earning money in a world where money and expenditure comprise the meaning of existence. (p. 211)

Other findings contradict this suggestion, such as Sanders (2005) research with indoor and outdoor sex workers. In Sanders research, it was found that sex workers were skilled in their assessments of risk and reasonably precise in their perceptions of potential harm. Indeed, whilst a desire to distance from the realities of working in a risky environment may play a role in constructions of risk amongst some individuals, there are complexities within this and many additional factors. Specifically, distancing may not necessarily equal denial. One of the women interviewed in Christchurch, Sydney, expressed acute awareness of the risk of violence. However, despite this she described deliberately distancing from the risks of violence. She explained, "If you stress too much about it you won't go out, know what I mean? You have to get your head into a totally different zone to stand out there...If I worried about it I wouldn't be out there". Sydney did not deny the risks of violence, nor did she construct herself as a "fearless protagonist" (Plumridge, 2001, p. 210). Whilst acknowledging the risk, Sydney distanced herself from this not to deny the presence of the risk, but to protect her emotional self from constantly reflecting on this. Marie, a younger sex worker, explained that she was not concerned about the risks of violence because her partner 
worked as her minder, and she demonstrated limited awareness of how to manage risks whilst working on the street. At the same time she described a desire to distance from the potential for violence, explaining, "I try not to think about it too much because otherwise it just messes with my head". This highlights some of the complexity around how risk is constructed and how these perceptions and fears are subsequently managed in the context of street-based sex work. Furthermore, none of the women reported that they now felt 'safe' whilst working on the street since the law had changed, which is perhaps to be expected given that they continued to manage ongoing risks of violence. However, there was a sense that that PRA had represented for them, at least to some extent, a symbolic shift in recognising their human rights whilst working on the street. For instance, Shania explained:

I think now that the laws changed and that it's definitely made it...I don't know if it's made it safer. I'd say in a way it has to the point where it's accepted... Well the people haven't changed their small mindedness but ... it is allowed now, there's no hiding you know? It's out there so therefore people are more ... aware of it and it's not so scary and you're not such a freak ... Now that they changed the law it's taken away that shame ... out of the darkness and into a bit of light ... I'm not breaking the law and it's definitely made me feel that I matter, that I'm not in the darkness, a secret or like 'just forget about them and hope they'll go away'. Yeah definitely made me feel that I matter, that I am a human and that I have rights, even in the industry that I choose to work in, just like every other person. (Shania)

Thus, whilst the change in law had now removed the risk of violence, to Shania it had to some degree signalled that sex workers "matter" This research revealed several layers underpinning perceptions of the risk of violence amongst these women in the decriminalised context. Perceptions of violence-related risks also appeared to relate to how the women constructed the street as a working environment and to previous experiences of violence whilst at work. The following sections explore these factors.

\section{Perceptions of violence in the street context}

As noted in chapter three, previous findings indicate a higher incidence of violence in street-based sex work than in indoor settings. (Abel et al., 2007; Church et al., 2001, Whittaker \& Hart, 1996). The construction of the indoor sector as fundamentally safer raises questions about why some women continue to work on the street, particularly in a decriminalised context. Typically, it may be assumed that street-based sex workers have little choice over the location of their work and as a consequence they sacrifice 
their safety by working on the street as a survival strategy. However the women in this research overwhelmingly constructed their decision to work on the street as a personal choice made relative to their perceptions and experiences of the indoor sex industry. The central motivation for working on the street was autonomy, echoing previous findings in New Zealand and elsewhere (Abel, 2010; Rosen \& Venkatesh, 2008; O’Neill \& Pitcher, 2010; Pyett \& Warr, 1999). Amy constructed her decision to move into the street sector as driven by the flexibility this allowed, and her perception that comparable amounts of money could be made working on the street. She explained:

Flexibility really and...the client pays more at the parlour but you still end up with the same amount working on the street and you actually probably get more work out on the street though. But you can just go there do a job, leave, do another job and so like stay out three hours or something. (Amy, Christchurch)

Shania defined her experience of street work positively, explaining that it helped her avoid financial hardship, and had allowed her to remain in control of her work. She explained:

It definitely stopped me from doing a lot of criminal activity and kept me out of jail. And enabled me to support my children, you know, take care of my kids...And not that I'm passionate about this but I am really into the money...definitely made more money going to the street...Yeah and it was at my discretion, you know, I had a lot more control. Well I had all the control in the situation if you know what I mean? (Shania, Christchurch)

Shania, like the majority of these women, described her decision to work on the street as relating to flexible working hours, financial gain, and increased control over her work. Whilst the street-based sector is so frequently portrayed as out of control, these women's perceptions suggest that the decision to work on the street instead of indoors directly relates to a desire to be in control. For these women, street-based sex work provides more than other options available. As Rosen and Venkatesh (2008) note, "sex work offers just enough money and flexibility to make the job worthwhile, and just enough autonomy and professional satisfaction to make it more attractive than other options" (p.418). For instance, Tessa, who had worked in several other occupations prior to becoming a sex worker, felt that there was more honesty and empowerment in sex work than in her previous employment experiences. She explained: 
You don't wake up and think about it in the morning, you know? Yeah, it's job done. As soon as you get out of that car you don't have to think about that again... When I was younger I didn't comprehend that aspect of the professionalism of prostitution...I used to think it was really exploitative but it's not. I never imagined how empowering it can be and I know that's a strange thing to say about it but it is in some ways quite empowering. (Tessa, Christchurch)

In this research, however, is worth noting that not all of these women linked their involvement in street-based sex work solely to financial need or defined it as just a job. Deltah, for instance, described her work on the street as a fundamental part of her social life and sexuality, explaining "it's my social life and my sex life". She explained that she didn't go out to bars to socialise, but derived personal enjoyment from her time working on the street. When asked whether she had ever felt pressured to work on the street, Deltah explained "Nah. I'm just out there strutting my stuff" [laughs]. Deltah went on to note:

Yeah nah. I choose to [work on the street] because like I said I don't drink and I don't go out anywhere so that's my going out and that's my time away from the kids to just be an adult if you know what I mean. (Deltah, Christchurch)

This highlights the diversity within the street sex work population and the fundamental mismatch between the social construction of street sex workers as victims or deviants and the lived experiences of individual women. It is a myth that all women working on the street are coerced and make less money than those working indoors. Perkins notes:

...there are women who are stimulated by street work. They seem to enjoy the action and excitement and combine something of the exhibitionist and the voyeur in their approach to life on the streets. They have fun communicating with men and have the talent for a good sales pitch, which brings them a high number of jobs. (Perkins, 1991, p. 13)

Acknowledging the diverse ways that women construct their involvement in streetbased sex work does not deny the risks of violence; rather this contributes to a more nuanced understanding of the working lives of street-based sex workers.

The diverse ways in which these women described their involvement in the street sex industry was also related to their perceptions of violence in the sex industry, and their desire for autonomy was linked to this. Sex workers may move into the street sector in response to violence they have encountered in other work settings, viewing the street as safer because of the public setting and the presence of other sex workers (Day et 
al., 2001). Quantitative findings in the New Zealand context estimated that $78.8 \%$ of street-based sex workers started working initially from the street, although it is acknowledged that some sex workers work in more than sector (Abel, 2010). In Wellington and Christchurch, 16 of the 28 women had also worked indoors in brothels or in their own homes. The women overwhelmingly emphasised that the perception of increased autonomy made them feel less vulnerable, and suggested that this had shaped their decision to work on the street. A few of these women suggested that whilst working in an indoor setting they had felt disempowered in their management of risk. Sapphire explained why she preferred working on the street:

You don't have to be abused-you don't have to be downgraded and you don't have a madam trying to boss you around. Because I used to refuse to go out and see certain customers because I realised that they were just there to downgrade us. So I turned around and I said 'I'm not going out there' and she turned around and she said 'yes you are - this is what you're here for. If you don't get out there then you're not working here'....We're not there to be abused, we're there to provide a service, that's all. And abuse isn't part of it in any form, whether it's verbal or physical. (Sapphire, Christchurch)

A few of these women, therefore, felt that the street sector provided them with more autonomy and control over their work and reduced scope for exploitation. It has been argued that exploitation and coercion is more common in indoor sex work than street sex work in areas where there is no culture of 'pimping' (Abel, 2010). This may reflect the perceptions of these sex workers that working on the street provided them with increased scope to control their work and avoid being influenced by exploitative and coercive management. The experiences these women described in the indoor sector may, at least in part, reflect the context in which they had worked. Sapphire, for instance, had worked indoors prior to the law reform at a time when sex workers did not have the rights now available to them to challenge pushy and exploitative approaches to management in the indoor sector. These findings challenge assumptions about the reasons some women work in this sector and how these decisions relate to their awareness of and capacity to manage violence-related risks. One key informant for instance, who had limited knowledge of the outdoor sector, suggested that streetbased sex workers had little control in their work, noting:

I observe people on the street who have no business being in the industry, who appear to think that it's a joke...And I think that's partly why it's so dangerous...it's so out of control... The women I've met who work from home 
are incredibly careful and fussy...You can't pick and choose who's picking you up on the street. (Key informant, City Council)

Findings have shown, however, that some street-based sex workers prefer working from the street because they feel this provides more opportunity to screen clients and refuse those they do not feel comfortable with (Abel, 2010). One key informant echoed this complexity in how risks are perceived in relation to indoor environments:

These are environments that they sometimes are very scared in and other times they feel like that's the best environment for them and they feel they can control their clients and make more money and meet their friends. And it's where they feel safe...there will be street workers who would say that 'oh I wouldn't feel safe working indoors because I would never know who was going to come to my door and I don't have the opportunity to tell them to go away like I do on the street'. (Key informant, NZPC)

Some findings suggest that the managed indoor sector is the safest sector of the industry with the fewest incidents of violence (Pyett \& Warr, 1997, 1999; Sanders \& Campbell, 2007). However, a few women argued that, in their view, it was overly simplistic to consider indoor environments consistently safer when they perceived violence as a risk in both sectors. For instance, Kay explained:

Most people say it is safer but it's not really. Stuff can still happen because when you're in the room and stuff. People can't hear you scream and shit. I've had that happen to mates, you know, something's happened and no one could hear them. (Kay, Christchurch)

Pania felt that working on the street provided her with more options to escape in the event of violence. She explained:

I prefer to work on the street than in a parlour because in a parlour you've got four walls, a window and a door and you haven't got a lot of escape plans... [On the street] you've got lots of room to run. Yeah. Lots of room to run. (Pania, Christchurch)

Risk perception in the street environment was thus, in some cases, informed by the women's experiences of working both indoors and outdoors. However, these perceptions of risk were sometimes contradictory. The overwhelming majority of the women said that they would not encourage someone new to the sex industry to begin working on the street. Indoor environments, whilst constructed as inhibiting individual autonomy, were considered more appropriate environments to learn the tricks of the trade. Rose explained: "I always say to girls if they are interested in starting work go and work in a parlour first because it makes you familiar with 
clients...it's a good environment to learn in". These contradictory accounts may relate to the diverse risks of violence on the street and the level of skill required to manage these risks in terms of screening clients, establishing and retaining control in the sexual encounter, and negotiating the street environment whilst avoiding conflict with other women. Several women indicated that knowing how to manage the competitive street environment was a key part of violence risk management. Those who were poorly prepared for this were perceived as more at risk. Catherine for instance explained that the street was not an unfriendly environment "if you manage it the right way". Kay felt that for new workers it was important to initially "suss it out a little bit" so as to avoid tensions with already established sex workers. She explained, "it's best if you're like working for the first time not to just rock up to a corner and stand there it's best to suss it out a little bit".

The complexity of negotiating the street environment, coupled with the skills required to manage interactions with clients provides a possible explanation for the perception that street work was not as safe for inexperienced sex workers. These issues will be explored in more detail in subsequent chapters of this thesis. This chapter will now move on to consider how the experience of violence relates to perceptions of risk on the street.

\section{The experience of violence and perceptions of risk}

A further dimension to the development of risk perception is the experience of violence. Whilst this thesis is not focused on evaluating the prevalence of violence, the findings indicate that all of the women had experienced some form of abuse or violence whilst working on the street. Out of the 28 women, a total of 11 reported being taken somewhere they did not wish to go to with a client, whilst two reported a client had attempted this. One woman reported that she had been abducted then physically and sexually assaulted by a passerby. Nine of the women reported experiencing physical violence from someone who had approached as a client and seven had experienced sexual violence. One woman reported that she had been blackmailed by a police officer to provide sexual services for no payment. Fourteen of the women said that a client had attempted to covertly remove the condom during a sexual encounter. A total of 18 women said they had been robbed or ripped off at work. Most often these incidents were covert, with money being taken back when the 
sex worker was distracted. However, sometimes these incidents were also accompanied by overt violence. Whilst two of these incidents involved clients, a further six involved individuals who were not clients such as passersby, 'minders', and other sex workers. All of the women reported experiencing verbal abuse and missile throwing from members of the public whilst working on the street. The findings suggest that these women managed ongoing risks of violence from a number of different sources, and highlight the appalling types of violence directed at streetbased sex workers.

The experience of violence amongst a few of these women appeared to have a considerable impact on perceptions of risk. It has been argued that behaviours commonly considered 'risky' are likely to become normalised should no adverse experiences occur in the course of engaging in these behaviours (Rhodes, 1997). Perhaps not surprisingly then, the experience of violence resulted in increased feelings of vulnerability whilst working on the street. Amy described being attacked by a passerby whilst she was working on the street early in the morning. The offender was apprehended and jailed for two and half years. Despite the fact that this offender was not someone who had approached her as a client, Amy explained how the attack had a profound impact on her feelings of safety and her perception of risk on the street, “Because I'm from here I'd always say that it was safe... But then I got attacked and it changed my whole outlook on it, you know what I mean? Once I got attacked it changed everything and now I don't find it safe at all". Amy described how further to this attack she had reappraised her vulnerability whilst working on the street and had left her with a realisation that preventing violence is often impossible. She explained:

I never found out how old he was but I think he was 24, or 27 or something...He wasn't hideous...Just a yuppie spoiled little rich boy or whatever...There's no way I expected him to do that at all...Just because he could have picked up anybody, you know? He wasn't sleazy...Yeah that's what changed my mind is that I thought I was a good judge of character from working and you just kind of pick up how they are...And then yeah that changed my whole outlook completely (pause) You just don't know at all...that's what spins me out. Because I always thought being attacked you'd sort of have warning, like you'd know it's coming...But it was just so out of the blue and that's what spins me out. (Amy, Christchurch)

Another woman, Shania, described a similar impact on her perception of risk following an attack by someone who had approached as a client. She explained: 
I just didn't expect it...because he just seemed like a really nice kind of guy and just like snapped, you know? There was no warning, and that part was what freaked me the most because I had been with this person before and I'd done jobs with this person before and nothing like that had ever happened and I will had never felt in any way, shape or form [pause] like anything like that could happen... He just like snapped and I knew [pause] in the way that his voice changed and his demeanour changed and I just knew that I was in the shit...I think it was more [pause] the fact that it just came from nowhere... Like this guy well I'd been there before and there was nothing like that. So it made me doubt everything about me, you know what I mean? Because I thought I could tell. I thought I was a good judge of character and things like that. And that completely knocked me for a six and I realised how vulnerable I was. (Shania, Christchurch)

The experience of violence for these women had, therefore, significantly altered their perceptions of risk whilst working on the street and made them feel more vulnerable as a result. The experience of violence can be considered a further dimension that impacts on the development of risk perception.

\section{Summary}

In this Chapter I have explored perceptions and experiences of violence in streetbased sex work amongst the women and key informants interviewed for this research. There were differences and commonalities in how these women perceived the risks of violence in their work. All of the women acknowledged that the possibility of violence was a key risk of working on the street. However, although all of the women acknowledged the risk of violence, this risk was evaluated in diverse ways. A few women dismissed the risks as inevitable. Others identified as tough and street-wise, whilst a small number of women said they did not fear violence because they had a minder who watched out for them while they were working. For a few of the women, the worst possible risks were consciously minimised since constantly reflecting on these possibilities would be detrimental to their emotional wellbeing at work. However, there were several additional dimensions to these perceptions of risk.

Contrasting with social constructions of the street as a place of danger, there was a perception amongst some women that autonomy could make it safer to work on the street. It was felt that street work provided more control over their selection of clients. This contradicts portrayals of street-based sex work as always being characterised by desperation. Whilst the street may be portrayed as an inherently uncontrolled environment, for some of the women it was perceived as an environment in which 
they could exert greater control in their work. Key informants who had extensive contact with street-based sex workers were also aware that for some sex workers, whilst they may not always feel totally safe, the street was perceived as a safer environment as it gave them greater control over their work. Perceptions of risk were therefore linked to the way in which some women perceived the street environment in relation to the risk of violence.

However, whilst many of the women conceived the street environment as conducive to their safety to some extent, they also said that they would not recommend street work for people who were new to the industry. This, perhaps, relates to the multifaceted nature of risk in street-based sex work. The women managed risks of violence not only from those approaching as clients, but also from passersby, minders, and in some cases, other sex workers. The perception that street-based sex work was not a safe environment for those new to sex work may reflect a recognition that the management of these diverse risks required the skill and aptitude to manage harassment from passersby, the competitive environment, in addition to the potential risk from those approaching as clients. The ongoing risks of violence were clearly recognised by the overwhelming majority of these women, and none of the women felt that street-based sex work was risk free since the law had changed. However, the change in law had clearly had some impact in signifying recognition of street sex workers and their rights.

The multi-dimensional nature of violence-related risk in street-based sex work is relevant not only from a criminological perspective but also from a methodological perspective. The insights of these women, and the comments from key informants, suggest that perceptions of risk on the street are underpinned by the multi-faceted nature of risk. Whilst survey methodology is the most appropriate method to assess prevalence, questions must be carefully crafted to ascertain the true prevalence, which reflects the diverse nature of risk. Simply asking sex workers on the street questions such as 'do you feel safe?', 'have you experienced violence?' or 'have you been threatened with violence?' could lead to a misrepresentation of the risk of violence in street-based sex work, particularly if used to make inferences around the risk of violence posed by clients. Whilst some women may feel unsafe on the street because they fear violence from clients, others may feel unsafe because they are concerned about being stood over for their money, or they feel threatened by the carloads of 
people passing to verbally abuse and throw things at sex workers. A failure to distinguish between different types of violence not only misrepresents the reality of the nature of risk on the street but also has the potential to be highly problematic in driving misdirected efforts by well meaning outsiders hoping to address violence towards street-based sex workers.

Indeed the perceptions of those women who suggested they were not particularly afraid of violence from genuine clients may in part relate to the vast majority of their experiences with such clients having been non-violent. For outsiders, it is relatively easy to assume street-work is inherently dangerous and to dismiss women's claims to not feel particularly afraid as being the consequence of denial, ignorance, or a low sense of self worth. However, these women spoke of many of their clients positively and described the interactions they had with them as ordinary. Nevertheless, several women recounted disturbing experiences of violence from a range of perpetrators, including some offenders who had initially approached as clients. The fear of violence may be heightened for those who had experienced violence at work, and this was reflected in the narratives of two women in particular.

The focus on demonising genuine clients as the key source of risk in street-based sex work is problematic in removing the focus from the individuals who pose the most significant risk to sex workers on the street. The focus on 'clients' directs attention away from the most troubling perpetrators of violence against sex workers. These individuals use the client identity to target sex workers under the pretence of purchasing sexual services. Their real identity as violent offenders thereafter remains hidden in the context of a very public focus on the risks posed by 'clients'.

The next four chapters of this thesis explore sex workers' strategies to manage these broad typologies of violence identified. The next chapter focuses on strategies to assess risks of violence from those approaching as clients. 


\section{Chapter Five: Assessing risk: screening clients in the decriminalised context}

\section{Introduction}

This chapter explores strategies to assess risks of violence from those approaching as clients. The main aim of this chapter is to explore what factors influence sex workers' decisions regarding whether or not to accept potential clients as genuine and trustworthy. Further, this chapter considers whether the decriminalisation of streetbased sex work may impact on this process. This chapter considers the screening strategies used by street-based sex workers in the context of decriminalisation in which the additional risk of police arrest does not need to be managed. The findings reveal a number of factors are taken into account when deciding whether or not to accept a client.

\section{Assessing risk: screening for danger}

A central part of violence risk management on the street is the process of screening clients. As was noted in chapter four, not all of those who approach sex workers on the street are indeed genuine clients. The awareness of this amongst sex workers is illustrated in the screening process that sex workers engage in to assess individuals initially approaching as clients. Sanders (2005) terms this "the prostitution trust game" within which sex worker and client undertake initial negotiations whilst the sex worker ascertains whether the client is genuine. As Sanders notes:

The sex worker starts from a position of distrust until proven otherwise. The decision to accept or reject a client is based on a judgement of his genuineness or trustworthiness. This is not necessarily a moral judgement on his character but clarification that he has the qualities to fulfil the commercial contract $(\mathrm{p}$. 53)

Sex workers screen potential clients in an attempt to determine the likelihood that they will break or keep the agreed terms of the encounter, aiming to reject those who do not appear genuine. Individuals may break the client contract in several ways - for instance by demanding services not previously agreed to, by demanding money back after services have been provided or by perpetrating physical or sexual violence instead of engaging in the agreed transaction (Sanders, 2005). The screening process 
represents sex workers attempting to select only genuine clients who will not break the agreement in this way (Sanders, 2005). Sex workers are thus attempting to differentiate between what Kinnell (2008) terms as 'good', 'bad' and 'bogus' clients. However, this process is complicated by the propensity for bad and bogus clients to initially imitate good client behaviour in order to gain trust. In the process of screening clients, sex workers are therefore tasked with ascertaining which individuals are genuine clients as opposed to simply mimicking client behaviour. Sanders (2005) notes, "mimics are those who appear as good types but are really bad types aware of the signs that bad types display...The mimic is a customer who appears to be trustworthy but in fact has dangerous intentions" (p.54). Sex workers on the street, therefore, evaluate clients to ascertain whether or not they are genuine. This process is taken very seriously since there is always the potential for violence to eventuate. Williamson and Folaron (2001) explain that:

...each exchange encounter involves the skill of the sex worker both to read the potential of a date and make critical judgements regarding the customer's intent and, at the same time, to ultimately accept the element of chance from not knowing the customer's true intent. A mismatch between a worker's fundamental appraisal and the customer's true intent may result in a violent encounter. (p. 473)

The screening process is, therefore, an important time at which sex workers assess risks of violence and make critical decisions about the trustworthiness of individuals who approach as clients. The findings of this research suggest women draw on a range of strategies in the screening process. The next section considers some of the initial considerations in this process.

\section{Assessing power dynamics: calculating risk}

Consistent with other findings, one of the first considerations described by the women interviewed when a client initially approaches is whether or not more than one person is present in the vehicle (Nixon et al., 2002; Pyett and Warr, 1999). Kay noted:

...if a car comes up, straight away I'm looking to see 'oh does this person look dodgy or is it more than one person' you know? One or two people? Even if it's two sometimes I won't go up but if it's more than two I wouldn't go up to the car, I'd walk the other way. Just these days, you know, something could happen. (Kay, Christchurch) 
The overwhelming majority of women said that they would refuse to go alone with more than one person in the car. However, two women said that they could feel comfortable going on a job with more than one person, citing previous experiences as the justification. The majority of the women were only prepared to go with more than one person if it was a double booking with another sex worker. Jana explained, " $I$ never hop in a car with two men unless I'm going with another girl in the car. That's just a number one safety thing”. Going on a job alone with more than one person was constructed on the street as an unsafe working practice. This was a common norm shared by several women. Laura noted, "It's just a rule. You never get into the same car with more than one person if you're by yourself. If you're with another person and it's two people in the car, sweet. But no more than two". The reluctance to go with more than one client relates to perceptions of the dynamics of power and control in these encounters. It was felt that this would create an unequal power dynamic and as a consequence could increase risks of violence. Zoe explained:

I'd never go in a car with two guys and all the time they pull up ay and it's like 'keep moving through' because I'm not going to go in the car with two guys. Like even if one of them just stepped out to come forward to me it's like "nah you got another person in the car, I aint going with you"...Um girls can do that if they're desperate. If they really want the cash they'll jump in the car with two guys but that's their own risk and stuff...I know myself I would never do that. Even if I was really desperate I'd just wait and stand there and wait for the next one to come because I wouldn't go with two guys. Too dangerous. It's just too overpowering, ay. (Zoe, Christchurch)

The screening process therefore began with a consideration of whether there was only one person present in the car as part of an initial assessment of power dynamics with potential clients. This process continued in initial negotiations to ascertain whether or not the individual was likely to be problematic during the encounter.

\section{Reading the client: body language and eye contact}

As part of the process through which it was determined whether or not the client could be considered trustworthy, the women reported trying to evaluate the potential client. It has been noted that central to this is interpreting physical behaviour to look for positive and negative signals. As Sanders (2001) notes, "sex workers also interpreted the body language and mannerisms of the prospective client. Positive signals were assessed by eye contact and verbal communication. The decision to accept or reject a client is made on the streets within minutes" (p. 14). Through this 
process, women assess the potential client's behaviour against a 'dangerous date profile' (Williamson and Folaron, 2001). This was supported by women in this research who also described centring their initial screening on the body language displayed by the client and paid particular attention to eye contact. Judgments were based on perceptions of what constituted unsettling behaviour that could be indicative of potential danger. The most common concern was whether the individual appeared jumpy, nervous or agitated. Holly for instance noted that "biting their nails" could be considered unsafe body language whist Pania and Amy became concerned if a client appeared "fidgety". Similarly, Kay and Shania reported looking for signs the client was "agitated". Kay noted that a client might appear agitated "If their hands are clenched or sweaty or if they're constantly moving". These responses are particularly relevant in the context of decriminalised street-based sex work. In a criminalised context, this nervous behaviour could be misinterpreted as the individual being concerned about the possibility of being arrested. The decriminalisation of streetbased sex work may, therefore, simplify the screening process to some extent. Some individuals approaching as clients may exhibit anxious behaviour for other reasons, for instance, if they have social anxiety or another mental or physical health issue that manifests in this way. However, in removing the threat of arrest sex workers at least do not have to consider the possibility the client is nervous for this reason. The initial screening process is, therefore, less complex in a decriminalised context.

The women also reported paying close attention to the nature and frequency of eye contact in initial negotiations with potential clients. Holly noted "I read people through their eyes" whilst Laura explained "you can read a person like a book from their facial expression". Two women talked of specifically interpreting the eyes to measure risk. Sydney described how she felt uneasy with individuals who had what she described as "a hungry look...hungry for violence and to have control". Licious described how she interpreted eye contact before getting in the car. She explained:

I look at his eyes. That's the first thing that I do is look at the guys eyes. I look at the guys eyes to see if they are angry, have got angry eyes. If they've got angry eyes I won't go. (Licious, Christchurch)

Individuals who avoided making eye contact were also described as worrying. Shania reported feeling uneasy if "he just wouldn't look me in the eye when he was talking”. However one woman also described feeling concerned about individuals who made 
prolonged eye contact. Laura explained:

They tend to just can't stop staring at you. And just the more they stare at you the more you can feel, you know you can feel someone staring at you and you just wonder what's running through their head. (Laura, Christchurch)

One key informant also referred to the importance of eye contact, suggesting that the ability to screen clients on the street in this way, in some respects, simplified risk management by comparison to private indoor work:

...you don't know who's going to come in the door. Somebody may present on the phone rationally and turn up and be out of control... Whereas on the street you might see that in that person's eyes and not go with them. (Key informant, NZPC)

The mannerisms and eye contact exhibited by clients therefore comprised initial cues through which risk could be approximated. However, there were also additional considerations such as factors relating to the age group of potential clients.

\section{Age and attitude}

Overall, minimal consideration was given to the physical appearance of those approaching as clients. However, a few women reported gauging risk in relation to the age of clients. Alphadites, for instance, explained why she preferred older clients:

Nah. I take all the dull ones! The gentlemen who don't muck you around, who pay up, and even if they don't come they're like 'oh I'm sorry I'm a bit tired today. I'm like 'oh well that's a bit sad-never mind. Oh well maybe next time' (laughs) And then you just take the money and go. This is the reason why I like elderly gentlemen... That can't run, that are half dead. I know it's rude to say but they've got one foot in the grave. And then you feel a bit more safer when you pick someone up like that. (Alphadites, Wellington)

A preference for older clients was not only linked to a perception of decreased physical vulnerability. In line with the findings of other research that suggest younger men were seen as more representative of the "dangerous-date profile" (Sharpe, 1998; Williamson and Folaron, 2001, p. 468), a few of the women perceived younger men as more of a risk. Licious explained:

Honestly that depends on who they are...If they're real old guys that pick you up and you get in and the car they give you the power... When you get picked up by a young guy they have this ego thing going on like yeah I just picked up a girl and this is what she's going to do because I said so'. (Licious, Christchurch) 
Tessa expressed a similar view and also highlighted her perception of a sense of entitlement amongst some younger men. She explained:

Young, privileged boys are a nuisance... Oh [they think they] don't have to pay for it, especially the good looking ones. Oh they think you want to do it anyway - 'I'm doing you a favour' kind of thing. That they can take whatever they want, you know, do as much as they want because they're god's gift... I find them that little bit more dangerous than um say a lot of others. (Tessa, Christchurch)

Interestingly, the women did not base their decisions on perceptions of the affluence of the men who approached them. These perceptions appeared to be informed by previous experiences and will now be discussed with reference to a range of other factors involved.

\section{Social class}

When gauging risk it was clear that the women made judgments based on personal experience rather than perceptions of affluence. The women reflected that it was very difficult to gauge who might be dangerous on the basis of physical appearance alone. Shania noted, "there's no set box I could put them into". Vixen intuitively mused, "what does a rapist or a sexual predator look like?" highlighting the difficulties involved in identifying dangerous individuals. Distinctions were made, however on perceptions of social class and the women emphasised that it was important not to judge potential clients trustworthiness on the basis of perceived affluence. Jackie warned “don't ever judge a book by it's cover", explaining that the most dangerous individuals could be "a white collar, clean guy, all sorts". Above all the women perceived that clients who appeared affluent could be particularly problematic. Marie noted, "I've found the rougher looking guys are the more nicer ones though. The 'gentlemen' are arseholes". Lexi reported watching out for men dressed in business attire:

I do watch out for real suits, suits and good cars because they're pricks of clients. Yeah they can be. And they'll barter the prices and they'll, you know, just fucking arseholes and yet they're driving the latest Merc and whatever... I mean the men covered in all them tattoos are the best clients I've ever had (laughs) you know? Straight up with money, they do the job and it's a good time. (Lexi, Christchurch) 
Shannon agreed with this having been raped by a 'gentleman' several years earlier. She explained:

I have hopped into a car with a guy that you know, a suit and tie, and thought "oh yeah he's got a suit and tie", you know "I'm not going to have a problem with him". And you know - I did have a problem with him. (Shannon, Christchurch)

Decisions were thus underpinned not entirely by stereotyped ideas but by an analysis of how the individual would be likely to behave during the encounter. However, there were additional factors that were considered that could have an impact on individual behaviour. These factors will now be explored.

\section{Under the influence}

Violence from individuals approaching as clients can be considered strongly associated with alcohol use and accordingly sex workers attempt to screen out individuals who appear drunk or drugged (Harris et al., 2011; Nixon et al., 2002). In a New Zealand study it was found that two-thirds of street-based sex workers reported refusing a client who was visibly under the influence of alcohol or drugs, and assessing the client in this regard was a key part of the screening process (Abel, 2010). In line with these findings, all of the women interviewed in this research described individuals who were visibly under the influence of alcohol or drugs as being particularly high risk. This related to the perception that these individuals would be more impulsive and thus more likely to break the agreement that set the terms of the sexual encounter. Sapphire noted, "I don't go with them just because of the fact that they are pissed and unpredictable. Drunk guys are unpredictable”. Shannon felt that individuals who were heavily under the influence of alcohol were more likely to perpetrate physical violence. She explained, "I've never had that [been bashed by a client]. And normally it's the drunk ones that do that and I don't do drunk clients at all". A common experience described by almost all of the women was that individuals heavily under the influence of alcohol would be unable to 'come' within the pre-negotiated time limit. Some of these individuals were considered a high risk of perpetrating violence in this situation. The women therefore overwhelmingly avoided these individuals. Pania stated:

I won't do jobs with drunk people because they're convinced that they'll be able to come and you know that they're not going to be able to, and they get 
shitty because they can't [and] try and take the money. Yeah I just don't do jobs with drunk people. (Pania, Christchurch)

Kay described avoiding individuals who approached her "if their eyes are hard out dilated or if they look like they're frittered, ${ }^{6}$ you know their eyes are all over". The intentional avoidance of clients who appeared intoxicated represented a strategy to reduce the likelihood of getting into a potentially volatile situation in which violence could occur.

The use of drugs and alcohol also related to the screening process in other ways. The woman also discussed their assessment of risk in the context of their own personal use of alcohol and drugs. It should be noted that not all of those interviewed engaged in what could be described as problematic alcohol and drug use. It has however been found that excessive drug use increases vulnerability whilst working on the street by hindering screening strategies (McKeganey \& Barnard, 1996; Pearce, 1999; Williamson \& Folaron, 2001).

Williamson and Folaron note:

Being high often left prostitutes at increased risk for violence. Getting high whilst working hindered their ability to use instincts to read people...Coming to the realization while high that one's instinct is limited and judgement impaired contributes to increased paranoia and exaggerated use of other protection strategies. (Williamson and Folaron, 2001: 469)

In a previous study conducted in Christchurch, it was found that almost $40 \%$ of streetbased workers reported using drugs every time they worked, compared to $10 \%$ of indoor workers. However, the study did not provide a break down of the kinds of drugs used or the extent of drug used whilst at work (Plumridge \& Abel, 2001). It has been found that street sex workers attempt to minimise the use of substances as a strategy to retain control and awareness of violence-related risks (Nixon et al., 2002). In support of these findings, in this research, amongst those who did and also those who did not use drugs, there was a perception that excessive use of alcohol and illicit drugs was not conducive to assessing risk whilst working on the street. For instance, Rose noted:

Your barriers come down. You know? You're not as on to it. You know, you're more laid back... Well you don't feel anything, you just want to have a good

\footnotetext{
${ }^{6}$ Frittered' is a slang term for being heavily under the influence of Methamphetamine.
} 
time and make some money, you know what I mean? And all your safety things that you have put into action just go. Or your guard might be a little bit down and you think 'well it's never going to happen to me' but it might just be that time. (Rose, Wellington)

Similarly, Sydney described what advice she would give to less experienced street workers:

Don't go out there really off your face. You can do that at home, you know? You can go out there and still, you know, use drugs to keep you warm or whatever or have a drink to make you a bit merry but always have your wits about you cause your gut instinct's not going to kick in if you're wasted off your face. (Sydney, Christchurch)

Interestingly, drug use per se was not constructed as a risk, rather the quantity of the drug used. A key informant who had personal experience of using illicit drugs as a street-based sex worker explained how she perceived this:

I would say probably more the quantity...I myself am an ex worker, a street worker, and I used to go out on heroin and I used to find that totally fine but if I was to the point where I was nodding off then my instincts weren't as honed as they should have been. Cocaine and amphetamines if I had a little bit I was fine but if I had too much then I would be a little bit off the wall and so yeah it's more the quantity than the drug itself. (Key informant, Drug)

Limiting the use of substances was considered important in ensuring that strategies to assess risk were not undermined. Previous research has highlighted how streetworkers aim to limit the use of alcohol or illicit drugs in recognition of how this could impair judgment when screening potential clients (Nixon et al., 2002; O'Neill \& Barberet, 2000; Williamson \& Folaron, 2001). In line with this, these women felt that limiting the use of drugs and alcohol was important to maximise control in the encounter. For instance, Lisa-Lou explained, "I reckon I feel more in control when I'm straight because when I'm wasted I'm not in control'. However, whilst it was felt that excessive use of illicit drugs could result in a loss of control which could impact on screening strategies, so too could insufficient use of particular drugs. This was true for women who were dependent on particular drugs who may need to prioritise obtaining drugs. This was observed during the fieldwork amongst three women who had been forcibly withdrawn from methadone. The physical and mental impact of this was evident amongst these women, although it should be noted that none of the women explicitly stated that they would intentionally take risks when 'hanging out' for drugs. A few key informants, however, felt that the pressure to generate particular 
amounts of money in these circumstances could have an impact on the extent to which screening strategies could be prioritised. One key informant explained:

Definitely...when you're using drugs, depending on whether you are needing that drug or you're 'hanging out', you can sometimes make some wrong decisions because you're not feeling so great and you need that money to 'get on' and that sort of thing. (Key informant, Drug)

In the research carried out into the impact of the PRA, it was found that street-based sex workers were considerably more likely than private and managed indoor workers to report feeling as though they had to accept a client in the previous 12 months. It has been argued that this may relate to drug use amongst some street-based workers creating increased pressure to make money (Abel, 2010). It is possible that when withdrawing from drug use, some women may be pushed to take increased risks. In one study it was noted that:

A number of women observed their relative financial health at any given time drives their decision making as to whether to trust a particular date...Many women in the focus groups acknowledged poor control over their sex trades when they were "jonesing" (suffering drug withdrawal symptoms). At such times they would do just about anything with anyone for enough money to buy another rock of crack or bag of heroin. (Kurtz et al., 2004, p. 370)

It should be noted however that whilst dependency on drugs or alcohol may increase vulnerability by inhibiting the screening of clients, the use of drugs and alcohol is not the cause of violence that occurs in these circumstances. This is an important distinction. Kinnell (2008) notes:

Imagining that the drug use of victims 'causes' violence and murder not only absolves society from addressing sex workers' environmental vulnerability or the aggression of perpetrators, it also implicates the victims as responsible for their own victimisation. (p. 246)

It is clear that the excessive use of drugs and alcohol can increase personal vulnerability. However, the responsibility for violence exists only with the perpetrators who choose to exploit that vulnerability. In this research, the use of alcohol and illicit drugs appeared to relate to screening strategies in diverse ways. For the women, potential clients who were visibly under the influence of substances were considered a risk and thus were usually rejected for personal safety reasons. Excessive use of alcohol or drugs amongst sex workers on the street was also constructed as a risk that could undermine screening strategies. The different ways in which drug use 
was constructed in the context of violence and risk highlights the need to contextualise drug use in discussions of street-based sex work, as opposed to presenting drug-using sex workers as one homogenous group (Melrose, 2009). Limiting the use of drugs and alcohol was therefore constructed as a personal safety strategy and this was an expected working practice amongst the women. However it was clear that insufficient use of substances for those who were dependent could also represent a risk through pressure to make sufficient amounts of money to access drugs in an illegal market. Violence risk management therefore required the negotiation of these issues. Whilst these issues are complex, they are connected by the themes of power and control and the importance placed on having control in negotiations with clients in order to set the terms of the encounter. The process of establishing control in these negotiations will now be explored.

\section{Predicting compliance: setting the terms of the encounter}

A central part of the screening process involved setting the terms of the encounter and evaluating the extent to which potential clients were likely to comply. Sanders (2001) notes that the first conversation between sex worker and potential client provides an opportunity for the sex worker to ascertain the level of cooperation and the extent of bargaining expected. In addition sex workers set sexual boundaries to separate between their professional and private lives (Day, 2007).

In order to assess the likelihood of compliance, the women communicated what they expected and what the potential client could expect in return. The ways in which these women set in place and managed sexual boundaries in encounters with clients is at odds with the popular assumption that sex workers sell their bodies, or that sex work is akin to sexual abuse. The women described allowing clients conditional access to their bodies for the purpose of providing specific, pre-negotiated sexual services as opposed to allowing the client to do as he wished. Sullivan (2007) notes that sex workers often appear to demonstrate active engagement in communicating consent and non-consent to sexual acts compared to other adults in the course of sexual encounters. Consistent with this finding, the sexual acts to which the women were consenting to were defined before the job had started, so that both parties were clear about what could be expected. Achieving this before decriminalisation would have been difficult since women risked entrapment because police sometimes masqueraded 
as clients (Abel \& Fitzgerald, 2010a). In the decriminalised context, clearly establishing these sexual boundaries in the initial meeting was considered paramount. Zoe explained, 'I'd tell them from the start 'no'. I tell them from the start what they can and can't do really...they do listen to me. They do. They have no choice but to, you know?" In order to effectively communicate expectations and boundaries with individuals, the women described using assertiveness and a working persona. Assertiveness has been highlighted in previous research as an attribute used by sex workers to establish control in their interactions with clients (Barnard, 1993; Sanders, 2001; Miller, 1993; Pyett \& Warr, 1999). Sanders (2005) notes, "Sex workers adopt expressive equipment in the form of assertive personalities and brave, often boastful statements, express a fighting resilience” ( $\mathrm{p}$. 85). In this research, the women described communicating their position of dominance in the initial negotiations by telling potential clients what the rules were before starting the job. The reaction to these rules could be used to determine whether the individual would be likely to comply. This has been highlighted in previous research that has found sex workers set the terms of the encounter with potential clients to assess extent of risk. Barnard (1993) notes:

Prostitutes attempt to establish their contact with clients on a firmly commercial basis from the outset which entails that there be no such ambiguity as to the purposes of the meeting. Prostitutes appear to believe that if a client acquiesces to her terms of business there is less of a likelihood for trouble. In the context of prostitution, trouble can take the form of robbery or rape or physical attack or worse. (p. 691)

The women in this research described clearly setting the terms of the encounter during the screening process. Bianca explained 'well I just put the rules down straight away'. For the overwhelming majority of these women it was considered critical that the potential client was made aware that they expected to be in charge of the encounter. To achieve this, the women described communicating what the expectations should be on both sides. Kay explained:

Being in charge really. You're the one doing the job. You know? You're the boss. It's your body. Don't let them say 'oh I want this, I want that'. They can ask you but it doesn't mean they're going to get it...Tell them what's going to happen. Don't let them tell you what's going to happen. (Kay, Christchurch)

Shannon explained that she thought setting these rules and communicating them assertively was critical to ensure control. She explained: 
Oh they're definitely not in charge. I'm in charge... I just tell them how it is...you are the one that is in control because they are buying your service and the service you're providing is whatever it is you tell them and that's the only way you can stay in control I think. (Shannon, Christchurch)

All of the women described using a working persona that was in some cases considerably different to their own personality in the initial meeting with potential clients. Referring to the use of working personas amongst sex workers in the indoor and outdoor sectors, Abel (2011) notes that:

The street-based workers in this study were less able to maintain the separation of public and private roles and manage the emotional risks of their job than both the managed and private sex workers. They were less adept at "deep acting" and substances were used in an attempt to distance themselves from their public role. (p. 1183)

In contrast, the findings of this research suggest that these street workers used a working persona not only to separate their public and private selves but also to establish control whilst working on the street. Alphadites explained:

You have to change your attitude...my personality is a soft one, caring. But that goes out the window as soon as I get out on those streets. In comes the mean 'don't muck me around' sort of attitude. You have to when you get out there. And it's like you're a whole different person. (Alphadites, Wellington)

Pania identified as a caring and giving person in her private life, but explained that she didn't consider this appropriate whilst at work:

Pania: I am a nice person and people know that I will give... and they take advantage of that.

Lynzi: So what are you like at work, what sort of person?

Pania: I'm a very straightforward person. I tell a client what's happening and if they want the job done then they tell me what they want and I'll decide whether or not I'm going to do it. And if they don't like it then fuck them (laughs).

Vixen described her working persona:

I become more confident actually, yeah. Sort of become a different person... you know more forthcoming with talking to people and approaching people. And just the weird things that come out of my mouth too... and I just find myself in control, you know? I feel a bit of power too when I walk over to the guy. And in a way I like that. (Vixen, Christchurch)

Zoe advised using a working persona to manipulate potential clients into believing 
they would not be able to take control of the transaction. She explained:

...you know you might be scared inside but just try and act tough because if you act tough then clients are going to think 'sweet she's been here for a while, she knows what she's up to' you know? Whereas if you're just a new girl and you approach them as if you don't know what you're doing, they'll take advantage of you [and think]...' I wonder what I can get away with'. (Zoe, Christchurch)

The women therefore used their working persona to communicate rules and expectations to potential clients. Whilst this could function to establish control, it also represented a key part of the screening process through which the women attempted to predict whether individuals could be trusted to respect these boundaries. Individuals who did not appear agreeable were generally defined as potentially problematic. Such men may, for instance, request a discount on the quoted rate. Shania described feeling uneasy about potential clients, "trying to barter me down and trying to get more for less and stuff like that". Also concerning were individuals who appeared to have a sense of entitlement and self-importance in that they stated what they expected rather than listening to what services were available. Shannon defined men as having a 'bad attitude' if they tried making demands from the start. She noted, "they dictate right from the word go...they're dictating what they want, you know?" Kay described her concern about men who were "too demanding". These concerns were underpinned by a perception that this behaviour represented how the individual would likely be during the job. Accordingly, Amy stated, "if they seem to be really pushing then they're going to be that way anyway, you know?" Pushy behaviour was particularly viewed as concerning from a safety perspective. Sydney explained, "Um if they were pushy... sort of he wants you in that car no matter what so he'll agree to anything sort of thing... he wants you in there as fast as he can and out of the zone, you know? "Sydney's concern about individuals who appear pushy to get her in the car quickly is particularly relevant in the context of decriminalisation. It is thought that this behaviour is more difficult to recognise in contexts such as the UK where street-based sex work is criminalised:

To be told to get in the car quickly sounds reasonable if kerb-crawling measures are being enforced, instead of alerting the sex worker to potential trouble. A customer who is nervous, or looking over his shoulder, may also seem to be behaving reasonably under the circumstances. (Brooks-Gordon, 2006, p. 201) 
Abel and Fitzgerald (2010) note that prior to the enactment of the PRA sex workers risked entrapment on soliciting charges should they attempt to negotiate explicitly with clients over the services provided. Moreover, the change in law means that offenders can no longer take advantage of the need to negotiate particularly quickly to avoid being detected by authorities. Overly pushy behaviour is therefore interpreted more as a sign of potential danger. Therefore, the change in law may have simplified the screening process to some extent.

Setting sexual boundaries therefore was intended to set the tone for the encounter, but also represented a key part of the screening strategy through which potentially problematic men could be identified and rejected. This decision was underpinned by an evaluation of the possibility that the individual may breach the agreed terms of the encounter. This judgment was based on a number of combined factors predominantly, but not exclusively, focused on the overall demeanour of the potential client. However, some individuals were rejected at an even earlier stage on the basis of instinct before these factors were even considered. This will now be explored.

\section{Instincts and intuition}

Sex workers who work on the streets partly rely on gut instincts or a 'sixth sense' to negate risks of violence from individuals approaching as clients (Abel, 2010; Barnard, 1993; Dalla et al., 2003; Harris et al., 2011; Nixon et al., 2002; Pyett and Warr, 1999; Williamson \& Foloran, 2001, 2003). Williamson and Folaron (2001) note:

Instinct involves a complex set of impulses that serves as a gut-level feeling designed to predict the dangerousness of lethality of a potential exchange encounter. It is the feeling aspect of protection. Street workers are in tune with these gut-level instincts; with a highly audible gut-level voice, they listen and read their dates very quickly. (p. 470)

In line with this, the women in this research also reported drawing on their instincts when deciding whether or not to accept a client. Kay explained, "I go with my instincts, always with my instincts - it's a big thing ay?", whilst Delta noted, "gut instincts is your main priority out there". Several of the 28 women interviewed referred to negative feelings they would get from particular individuals and how this influenced their decision making over whether or not to do the job. Vixen noted ' $I$ don't get any signs it's usually just a feeling' whilst Tessa explained, “it's something within you, it can just be a little ping, you know? Or an itch or an 'I'll walk that way' 
feeling”. Lisa-Lou referred to these feelings as 'bad vibes', but combined this with other strategies she used to read the potential client. She explained:

I can feel bad vibes from somebody...so if a [client] would have stopped I go over [and] I'll take it from the way they talk, the way they present themselves. And like, if I don't like the way that they come across - because I'll get a bad vibe through me straight away, I won't bother to jump in. (Lisa-Lou, Wellington)

All of the women said that they would reject particular men if they had an instinctive bad feeling about them. Pania noted, "I'll walk away from a situation quite happily you know? If I get a bad vibe, I don't get into the vehicle. Any bad vibes I'll stay away". Similarly Rose explained, "You sort of try to use that intuition [and] listen to that inner voice. And if something tells me 'don't go there', I won't, I'll flag the client away". Alphadites described what advice she would offer those with less experience working on the streets:

Always trust your instincts, no matter how big or small it is, always trust your instinct because your body your mind is telling you something and you've got to listen so you don't get yourself into a bad situation. That's what I would say to any one of the girls - trust your instinct. You don't like the guy don't get in that car. (Alphadites, Wellington)

The importance placed on following gut instinct was clear when a few of the women reflected on previous bad experiences. Tessa, for instance, noted "whenever I haven't followed my instinct I've regretted it".

The women did not rely on gut instinct alone, though it clearly represented a factor that influenced whether or not they were prepared to accept an individual as a genuine client. However, these decisions were not only informed by perceptions of how the individual presented themselves, but also the physical environment in which they approached the sex worker.

\section{Completing the screening process: checking around the car}

Before leaving with the client, a few women also described paying close attention to the car as another strategy to assess risk. This has been highlighted in previous findings through which women recounted a series of rituals such as checking the door could be opened and checking for any concealed weapons in the car (Williamson \& Folaron, 2001). In this research, this strategy was used to gauge whether there was anything in the car that could be used to overpower them, such as a weapon or another 
person. Rose explained, "I normally look in the back seat of the car you know, look around see if they've got anything laying around". Similarly Bianca noted: "I look around, look in the back, I look in the vision mirror. I look on the floor [and] make sure there's no weapons, you know?" This strategy is arguably used to complement the other screening strategies described in an attempt to identify dangerous individuals who may successfully imitate good client behaviour. Zoe explained:

Like the first thing I think you know "ok sweet um when I meet you and I'm talking to you and you sound ok then yeah you're all good". But then I'll look at the other things like around him, what's his car like, what's he got kind of thing you know look around to see and if he's got lots of shit in his car then he might have a weapon around you know? (Zoe, Christchurch)

Screening the physical environment was therefore a useful strategy to use alongside the screening of the client described earlier in the chapter. When the most dangerous individuals may skilfully imitate the behaviour of good clients when approaching, it was clear that this necessitated broad screening strategies before sufficient trust could be established to accept potential clients as genuine.

\section{Screening in a decriminalised environment}

Interestingly, there was no sense of urgency when the women described these negotiations. In all of the women's descriptions of these initial encounters, it appeared that considerable time was taken to assess risk in these initial meetings. For instance Kay explained: “You stand outside the car and talk. Don't get in the car to talk - it's best to just get them to wind the window down, stand there, talk to them and judge them. Yeah". The decriminalisation of street-based sex work in New Zealand means that sex workers can spend as much time as they wish standing beside the car talking with potential clients before deciding whether or not to do the job. It is argued that the process of screening clients is complicated by the criminalisation of street-based sex workers in countries such as the UK, where sex workers manage the risks of violence concurrent with the risk of arrest of both worker and client (Sanders, 2004a). In this context, it is argued that sex workers must work quickly to avoid the gaze of authorities and this therefore limits the amount of time that can be spent screening clients (Barnard 1993; Brooks-Gordon, 2006; Gorry et al., 2010; Kinnell, 2006a). Much of the previous research documenting the management of violence-related risks amongst sex workers has been conducted in this context. As Sanders (2005) notes: 
"much of this research draws on the street market where there is distinct time pressure to attract a client and move away from the prying eye of the police and protestors as quickly as possible” (p. 52). In Sydney it was found that aggressive policing strategies meant that street-based sex workers were unable to spend sufficient time screening clients and reported getting into vehicles as quickly as possible so to avoid detection by authorities (Wotton, 2005). In agreement with this finding Sanders (2001) argues that in criminalised environments there is pressure on both sex workers and clients to negotiate quickly. The legal framework can therefore be seen to undermine screening strategies:

Sex workers taking their time in making a commitment to a transaction potentially agitate clients, as they too are vulnerable to arrest while negotiating a sexual encounter. Thus, the process of screening is jeopardised by the illegal nature of street prostitution. (p. 14)

Furthermore, Barnard (1993) notes:

Both prostitute and client are vulnerable to police arrest at the point at which they engage in negotiating the commercial sexual encounter. To avoid this eventuality negotiations are usually brief and hurried. Clearly the compressed time available does not assist with the process of deciding whether or not the client is safe to go away with. (pp. 700-701)

Decriminalisation can therefore be argued to simplify the screening process by reducing the number of risks sex workers must consider before deciding whether or not to accept a job. Individuals who may have untoward intentions cannot excuse their anxiety as concern over the possibility they may be arrested. In addition, sex workers themselves no longer have to fear entrapment and thus there is no need to be covert in their negotiations with clients. As a consequence, these negotiations can be conducted in more open spaces. This was evident in how some of the women described their experiences since the law had changed. For instance Claire noted that when the PRA was passed, "It changed because a lot of us had to hide before then". Describing what it was like to work on the street before the law change Claire noted "we were in like the darkest corners, ... Real shady". It was clear that the law change had decreased constraints on the locations in which initial negotiations could take place with potential clients. Laura for instance explained, "You can stand out there a lot more freely". Since the law had changed, it appeared that sex workers could complete negotiations with individuals who approached as clients away from darker corners of the public space. For instance Vixen explained: 
[There are] more people just walking up to you, and cars just pulling up... not like you'd have to watch where they'd go so you could see where they'd pulled up, you know? [It is] feeling a bit more freer I reckon. (Vixen)

The new freedom to work in less covert ways whilst on the street has conversely been constructed in the public domain as a negative consequence of decriminalisation. For instance, since the PRA was passed some authors have suggested that the law change has resulted in a stark increase in the numbers of sex workers on the streets (Farley, 2008; Espiner, 2005). These claims are contradicted by quantitative data that suggests very little change in the numbers of sex workers on the street since decriminalisation (Abel, Fitzgerald \& Brunton, 2009). It has been suggested that a media focus on moral discourses about street-based sex work, influenced public opinion and called attention to the visibility of street-based sex workers as a result (Fitzgerald \& Abel, 2010). This increased visibility may have contributed to a perception of a larger sex worker population. This may also suggest, as supported by the perceptions of the women in this research, that street-based sex workers have emerged out of the darkest corners since the law change and are now using the public space in ways that better support their safety and wellbeing (PLRC, 2008). From a sex worker rights perspective that prioritises safer working practices, the increased visibility of streetbased sex workers can be considered a positive impact of the PRA in that street-based sex workers can now interact with potential clients more freely with sufficient time to assess risk.

\section{Summary}

This chapter has overviewed the screening strategies used by these women in initial interactions with individuals approaching as clients. These strategies had two purposes. First, screening strategies functioned to assist the sex worker in ascertaining whether or not the individual had genuine intentions. Second, the process of screening represented an opportunity for sex workers to assess whether or not the individual would be likely to accept the terms of the encounter. In this way, screening strategies operated to initially assess dynamics of power and control with potential clients. In screening clients the women attempted to predict how these individuals would be likely to behave during the encounter.

The screening strategies highlighted in this chapter are relatively common strategies used by sex workers on the street to manage violence-related risks. For instance, 
paying close attention to verbal and non-verbal communication, listening to intuition and avoiding clients who appeared visibly under the influence of alcohol. However these findings contradict some popular assumptions about street-based sex workers. For instance, the assumption that street-based sex work is characterised by extreme desperation, that there is no choice in the selection of clients and that these women gamble with their own safety at an extreme level. The extent to which these women described screening clients has two interesting implications. The nature of screening implies an acute awareness of violence-related risks amongst these women. These screening strategies also suggest that to understand women who work on the streets as passive and poorly equipped to manage these risks would be a gross oversimplification. The ways in which these women reported screening clients in an attempt to approximate risk highlights how they employ agency in their work. The fact that all of these women described rejecting individuals they perceived as dangerous, even when this meant losing money, highlights how even in the context of economic pressure, women working on the streets engage in decision making processes in which their safety and wellbeing is prioritised.

These findings also revealed some interesting implications with regards to the legal framework surrounding the street-based sector in New Zealand. Specifically, it is possible that decriminalisation of the street sector has simplified the screening process. It was clear that the change in law had at least provided an environment in which sex workers could more freely complete these negotiations without worrying about either party being arrested. Personal safety could therefore be prioritised in this context.

The screening of those approaching as clients, however, only represented one aspect of violence risk management on the street. Whilst the process of screening was used to initially assess dynamics of power and control in negotiations with potential clients, it was acknowledged that this was not foolproof and as such could not eliminate the potential for risk. The risk of violence was therefore continually managed throughout encounters with clients, and this is explored in the next chapter. 


\section{Chapter Six: Boundaries, rules, and tensions: managing risks of violence in encounters with clients}

\section{Introduction}

In this chapter, I move beyond initial screening strategies to a more focused exploration of how these women managed and negotiated risks of violence during their encounters with clients. Chapter Five provided some initial discussion of the relevance of power and control dynamics in interactions with potential clients, exploring how the women strategised to evaluate this in the initial meeting. This underpinned the decision to accept or reject particular individuals as clients. The importance of monitoring power dynamics and retaining control continued after these decisions had been made and was reflected in these women's descriptions of the strategies they used in the sexual encounter. Specifically focusing on the management of violence-related risks with clients, this chapter provides an in-depth account of how power and control dynamics were managed in an attempt to lessen the potential for violence, and explores factors that may impact on this.

\section{Power, control and violence in sex work}

The dynamics of power and control are considered to relate to the incidence of violence in sex work (Barnard, 1993; McKeganey \& Barnard, 1996; Miller, 1993; Pyett \& Warr, 1997; Sanders, 2001; Sullivan, 2007). Retaining control in encounters with clients is therefore a priority for street-based sex workers and this is driven by concerns about the potential for violence (Barnard, 1993; Selby \& Canter, 2009; Simić \& Rhodes, 2009). As a consequence, sex workers have been found to practise 'client management', including a process by which sex workers train or educate clients about what can and cannot be expected when purchasing services (Jordan, 1991).

Power and control relate to the incidence of violence in the sexual encounter on several levels. The very idea that clients need to be managed perhaps points to an acute awareness of the risk of violence amongst some women. The potential for violence therefore results in a need to retain a sense of control in encounters with clients (Barnard, 1993). Heterosexual sex between two people rarely encompasses an even distribution of power (Jackson, 1983; Kane, 1991; Rhodes, 1997; Richardson, 
1990). It is expected that women will assume the submissive role, thus empowering the male partner (Barnard, 1993). It would be overly simplistic to argue that all sexual encounters between men and women comprise men as powerful and women as powerless (Wojcicki \& Malala, 2001). However, the normative expectation is that the male will be in a position of dominance. This relates to patriarchal constructions of sexuality, in which women are cast as passive recipients of sex and it is expected that they will be available to assist male sexual satisfaction. An awareness of this dynamic is reflected in how sex workers manage sexual encounters with clients. As Sanders (2005) notes, "The dominant ideology that claims that all women are passive during sexual negotiations is considered a risk in sex work, so to compensate bravado and assertiveness are implicit in the routine" (p. 87). Sex workers therefore strive to take control in encounters with clients to undermine these expectations of passivity that can create a power imbalance in heterosexual sexual encounters. In agreement with this, the women who took part in this research prioritised taking control in encounters with clients for safety reasons. The process of taking control began in the initial meeting after the women had undertaken the screening process described in chapter five, through which they had approximated the likelihood of the potential client complying with their rules. Whilst initial boundaries are established in these early negotiations, the potentially volatile nature of the sexual encounter necessitates the continual management of these rules. One central way of minimising risk in the sexual encounter was taking control of where it would take place. The experiences and perceptions of these women will now be explored.

\section{Controlling the location of the job}

Trotter (2002) argues that the amount of control a sex worker has over the location in which the job takes place; the less likely it is that violence will occur (Trotter, 2007). Perhaps in recognition of this, it has also been found that a key strategy to manage violence-related risks amongst female street-based sex workers is controlling the location of the job (Barnard, 1993; Dalla, 2002; Nixon et al., 2002 Pyett \& Warr, 1999; Sanders, 2005; Williamson \& Folaron, 2001). In order to minimise the potential for violence, the overwhelming majority of the women in this research described taking control of the location in encounters with clients. Lexi explained, "I think that's about taking control of the job. That's more or less where it starts". The 
majority of the women felt that it was important to have total control over where the sexual encounter took place. Kay explained:

Go to car parks you choose, not to car parks they choose or to their house. Yeah I don't really agree with people going to people's houses because they could have people there... be in charge and say 'right we're going to go to this car park, this is where we're going to go'. Don't get in the car and go 'do you know of any place?' Or if he goes 'oh, I've got this place', then go 'oh no I prefer to go here - this is where I'm known to go'. You just say to the client that you'd like to be safe and most clients are pretty understanding with that...I think it's best for the girl doing the work to actually decide because that shows you're in control and if you're going to leave it to him, you know, he could take you anywhere. He could take you where there's a set up, somewhere secluded, you know? It's best to go to somewhere you know and where you feel safe. (Kay, Christchurch)

Kay was particularly adamant that going to the home of a client was a risky practice, while there were varied perspectives on this overall. Sapphire explained that she was willing to go with clients to their homes, but only if it was within a particular area:

I make sure that I don't go too far from my corner... Girls sometimes go to their houses and motels and things and if I do that I make sure that the house is within the city square. Because if you do go outside of there and you do have a bad client and they want to kick you out of their car or kick you out of their house then you're stuck in the middle of nowhere and you've got no way to get back. (Sapphire, Christchurch)

Sydney was prepared to visit a client's home depending on the location, whether anyone else may be present at the address, and also her assessment of how the client responded to her queries. She explained:

If they're walkers I take them to a certain spot. If they're in the car I take them to a certain spot...If they want to go to their house, well where is it first and who else is there? And it depends on how they react to those questions...I just go with my gut [and] if I feel they're being honest I go with them. And, you know, ninety-five percent of the time it's all good. (Sydney, Christchurch)

By contrast, three of the women felt that being invited to a client's home was an indicator that the individual was very unlikely to be a risk. Shannon noted, "When you go back to their place you know that they're pretty much genuine”. Similarly Deltah noted:

I normally take the client to where I want...I've got a car park up there that I take my clients to...It's security camera'ed and it's just tucked away...I feel safe because I know the atmosphere... Um otherwise the ones that I pick up to go to hotels or they ask me 'do you mind if you come to my place?' Well I 
don't mind going to a clients place because at the end of the day he's trusting me to go to his place, whereas I can't bring clients back here because this is my kid's house. So yeah going to their place is more of an option than being in the car park or in the back of the car. (Deltah, Christchurch)

Bianca also felt positive about clients who were prepared to take her home with them to do the job. However, she was reluctant to take clients back to her own home, noting:

If he's a good client he takes me up to his place...And once again I ask them 'am I alright with you? Because you're alright with me. Am I safe with you? Because you're safe with me'...If I really, really trust them and I've known them for some time I take them to my place. (Bianca, Wellington)

Two of the younger women interviewed (aged 17 and 18) appeared to have less control over these decisions and were more likely to compromise with clients. Hollie explained:

I'm not from here I don't really know where I'm going so like that's really scary - like I don't know where I am...I tell them where I want to go and if they don't like that then I'll suggest another place. And if they don't like that then well I'll make a compromise and I'll text where we're going to someone, usually. But I don't always have someone looking after me. It's just a one off thing. (Hollie, Christchurch)

There were therefore diverse opinions about the locations in which it was safest to go with clients and women described a range of experiences managing these decisions. Whilst these women could attempt to control the location of the job, there was always a possibility that some individuals would not comply with this. This sort of behaviour was considered a sign of significant danger. Tessa explained that when clients tried to drive to alternative locations, "you know there's a game going on already". Amongst all of the women interviewed, fifty percent had experienced an attempt to do this at least once whilst they had been working on the street. All of the women said that if they did encounter this situation they would immediately attempt to stop the job, even if it meant that they had to jump from a moving vehicle. Alphadites described how she had reacted in this situation:

I've had one situation like that. He said he was going home and I said, "No - I told you I don't go out that way!" I pulled on the breaks.... I said, "No - I told you I'm not going there, I told you to turn off"... Because we usually go up to Mount Vic. But he didn't turn off so I just pulled up the handbrake and said "I told you no turn back now"... He kind of freaked out a little bit. But he listened. (Alphadites, Wellington) 
Justice described a similar situation in which she said she was prepared to risk crashing the vehicle because of her concern over the behaviour of this individual. She explained:

I grabbed the wheel...He kind of freaked out. But I was like 'you're not doing as I say [and] you're not going where I want to go.'...I pulled the wheel and he was kind of like [shocked expression] 'don't do that again'. And I'm like 'well pull over now.' And he's like 'no don't do that again.' And I'm like 'no pull over. I'll make you a deal. I won't do that if you pull over. [But] If you don't pull over the car I'm going to keep doing it and next time it'll be worse, I will hold the wheel.' And he goes 'Ok I'll pull over'...He didn't want to crash and at that point in time I didn't care. It was either crash and hope to live, or go with this dude and maybe not return home...He let me out. (Justice, Christchurch)

Similar findings documented by Barnard (1993) showed that a client deliberately ignoring these instructions was considered a particularly dangerous scenario by sex workers interviewed. This was also true for the women in this research - a client attempting to drive to a location not previously agreed on was considered a significant risk of violence. The sort of violence that could be encountered was not necessarily always explicit, but could also comprise subtler forms of coercion to provide more than the client had actually paid for. Again, those with more experience appeared to be most equipped to manage attempts by clients to go to locations in which they could become more vulnerable with fewer options to exit safely. Claire described an experience she had at the age of 16 with her first client in Christchurch:

Well he caught me off guard and he was kind of a good speaker so I was like getting into a conversation with him and then just talking and then the next minute he's turning all these corners...And then hello we're already parked up...And I'm like 'Oh shit. Where are we?'...I was scared for myself...I couldn't run off because I didn't know where I was. I couldn't say 'no' just in case he had done something. So I had to go with it [and] spend as much time as I could just so I could get back. It didn't matter just as long as I was alright and got back...I couldn't get out and walk just in case there was no main road for ages or something....There was no choices...I mean he was actually quite good in the end. You know, being a nice person...But he took me back and everything maybe an hour after I should have been... But I had to, you know. I was kind of scared being my first time in Christchurch, first client. (Claire, Christchurch)

Whilst Claire emphasised that this individual had not been explicitly violent towards her, the details of her experience suggest that the client intentionally took control to establish a position of dominance that would allow him to set the terms of the 
encounter. Claire later described feeling unprepared for this situation and that she wasn't entirely sure at this time how best to take control over the location of the job. She explained that she later learned this was a relatively common ploy. She noted:

It happens quite a lot when you get new girls out there...I wish I'd known that, you know?...Knowing how to persuade him to stay around the corner instead of taking off. (Claire, Christchurch)

Learning how best to control the location of the job, and to respond to clients who attempted to contravene this rule, was therefore constructed as critical to managing violence-related risks whilst working on the street. Controlling the location of the job was a means of establishing a position of power, whilst also representing a means of minimising risk for the duration of the job. Tied in with this was establishing the options for safely exiting the car in the event of conflict.

\section{Risk and trust: strategies to exit safely and inherent tensions}

During encounters with clients, it was considered important to be able to exit the vehicle should any difficulties arise in which remaining in the car was no longer considered a safe option. Some findings have shown that women working on the streets have occasionally encountered individuals who have intentionally set the car door to lock in order to limit possible escape routes (Kinnell, 2006a; Williamson \& Folaron, 2001). In this research, a few of the women expressed specific concerns with regards the use of central locking whilst inside the vehicle. Deltah noted, "I really hate cars with central locking...I'd rather not be locked in the car doing the job. I like to know I can open the door". It was clear that the use of automatic locks on cars was constructed as an attempt to take control of the encounter creating an inevitable feeling of being trapped and subsequently, a perception of increased risk. Tessa explained:

I hate getting into cars that have automatic locks...I really dislike it. It's something that you know as soon as the car pulls away and it goes 'ding'...I go 'can you open the window?' They go 'oh nah it's cold - I'll put the air conditioning on.' And I've had to say 'look I don't like it'...And that's just an instinctive thing. [I think to myself] - 'I can't get out of that car because he's got it on automatic lock'. (Tessa, Christchurch)

Sydney described how she would attempt to check for this when she initially got in the car to ensure she could get out of the car if necessary: 
When you initially sit in the car don't shut the door...Or if you do put the window down...If you do shut the door just try it and see if it opens because it could be a kiddie lock...I started telling others, you know,' just to check the door'. If you're going to shut the door just open it you know say 'oh my coat's caught' or something and just open it just to make sure you're not locked in. (Sydney, Christchurch)

It was clear the use of automatic locks on cars was a particular concern relating to personal safety since this essentially voided any opportunities to exit the situation if the individual became violent. A few women reported that if a client used automatic locking they would ask them to unlock the doors and any refusal to do so would be considered a sign of potential danger. Tessa described how she managed a client who was reluctant to undo the automatic locking on his car:

He said 'oh the car just does it'. But you can set your car to do it. I really don't like that and I had to be a wee bit cunning about it and said 'look I really need to get a drink' and as soon as I was out of the car I said 'piss off and go away. I asked you to unlock the doors and you wouldn't. I'm not getting back in'. And [he said] 'oh don't be like that'. And I said 'I'm being like that. I can be however I want to be. You haven't paid me yet'. (Tessa, Christchurch)

Having the option to exit the car safely in the event of violence was therefore prioritised as a means of minimising risk. One woman described coaxing the client out of the car to do the job if she felt at risk, feeling that this provided more options to exit the situation if violence were to eventuate.

Shania: If I'm feeling freaked out I'll get them out of the car so then I've got room to fight. If I'm [feeling] ok then I'm ok in the car, otherwise I'll draw them out of the car like from the start.

Lynzi: So how do you do that?

Shania: Well I just tell them shit like I want to move around and you know there's no room and we can rock and roll out there kind of stuff. So if I'm uneasy thinking 'oooh' then I'll do that. There's no way I will do them in the car. I'll get them out there because then I've got all that area to get the fuck away (laughs) And, you know he's none the wiser.

Intentionally drawing the client out of the car was therefore used as a means of minimising risk, without enlightening the client about these concerns. It was clear that there were some inherent tensions in the desires of some clients to have control in the encounter, and the prioritising of the women to have sufficient options to exit safely. For instance, whilst the use of automatic locks in cars was considered a potential risk 
to the safety and wellbeing of these sex workers, there was also a possibility that some clients were nervous about the possibility of being offended against themselves. A few women described clients who had been "rolled" in the past by other sex workers or their minders and were therefore nervous about the possibility they may be robbed. Their attempts to control the encounter in this way therefore related to their own perceptions of vulnerability as opposed to a desire to trap the women so they could perpetrate violence themselves. Nonetheless, differentiating between these individuals and those who genuinely were a risk would be highly problematic. The women, therefore, had to prioritise their own safety in these situations. Justice described how she would persuade these genuine but nervous clients to allow her to take control. She explained:

[They think] the money's there for you to get out and run because they had had that kind of experience. So it's like "look mate It's not going to happen. You respect me, I'll straight up respect you. We do things like they're meant to be done, then it's all good I will not do that to you...A bit of trust won't hurt I'm trusting you'. (Justice, Christchurch)

These examples highlight a tension between the prioritisation of personal safety amongst these women and the desire of some clients to take control of the encounter for a variety of reasons. Further tensions were highlighted in the management of power dynamics during and after the sexual encounter. These issues will now be explored.

\section{Managing sexual boundaries}

In chapter five, the ways in which the women strategised to establish sexual boundaries with clients were explored. However, whilst these boundaries are communicated to clients in the initial meeting, there remains a possibility that some men (bad or bogus clients who slip through the initial screening process) will choose to ignore these boundaries. Indeed there are some inherent tensions in how power and control dynamics function to minimise risk in the sexual encounter. In their research with clients of female street-based sex workers, McKeganey \& Barnard (1996) found that there was an expectation amongst some clients that as they were paying for the sex worker to provide services, they should therefore be in charge of the sexual encounter. Similarly, Monto (2004) found that some men engaged in sex with sex workers precisely because it gave them an increased sense of control. There are 
therefore some conflicts between the priorities of sex workers to take control and the desire of some clients to have control. Furthermore, it has been argued that as purchasers, clients are in an inevitable position of power since they represent income for sex workers (Barnard, 1993). However, it is also true that sex workers have something to offer clients. Therefore, the power balance in these interactions is highly complex and there are some inherent tensions within this. It has been argued that these conflicting priorities create friction that can result in some clients attempting to push the boundaries of sex workers (Barnard, 1993; Sanders, 2001). It is perhaps a consequence of these tensions that the sexual encounter has been considered to represent the most dangerous part of the transaction for sex workers (Sanders, 2005).

In this research, attempts to push sexual boundaries were considered a sign of potential danger and were taken very seriously. All of the women had experienced clients at some point in their working lives who attempted to breach these boundaries by pushing for services that were not agreed on in the initial negotiations. Again, this sort of behaviour was perceived as a considerable sign of danger. The women described initially reminding the client of the original agreement. For instance, Bianca recalled telling them, "hey, that wasn't part of the bargain when we first talked about what you wanted". In a few cases, women were prepared to compromise and offer the services if they were comfortable with this but only if the client was prepared to provide a suitable extra payment. Nevertheless, feeling comfortable about what services would be provided was prioritised above the possibility of any additional payment for the overwhelming majority of these women. Claire noted:

Even if they offer more money I'd be like "nah - sorry I don't feel comfortable with that". You just have to be straight otherwise they're just going to treat you like garbage and take advantage...I'd have a few, yeah, who'd offer more money, keep offering and you just have to say "no". You can't give in...I couldn't anyway, I couldn't give in...I mean I've never done, I won't do anything I'm uncomfortable with. And you have to tell them otherwise you're going to be in a lot of crap... Otherwise you're just going to be used [and] doing something you don't want to do. (Claire, Christchurch)

With individuals who did push for services not available, generally the women were prepared to give the client a warning that any further attempts would result in the termination of the job. Sydney stated:

I'll give them one chance and say 'look don't do that otherwise that's it'...I can walk back from where they park - that's why I have the car park I go to 
because it's close. Um yeah - if they keep trying to overstep it I just get out of there. It's just not worth it. (Sydney, Christchurch)

Amy described a similar system of warning individuals who tried to engage in sexual acts that had not been agreed to. She described using a particular manner to communicate this, explaining:

Oh I warn them, sometimes I warn them twice and the third time I just walk away...I tell them - 'no you can't do that'. And the second time I say 'if you do that again I'm out of here ', and if they do it again then I just leave...And I stick to it, I stick to exactly what I say I'll do... [I say] ... 'try that again and I'm out of here'. And if you sort of change your whole voice and be real firm they believe you. So you don't say 'oh don't do that' pussyfooting around cause that's when they'll try you more...If you go 'oi that's enough', you know and 'stop' and you are really strong, they're like 'uh, sorry about that'. (Amy, Christchurch)

The women also expressed frustration with individuals who would attempt to remove the condom during the job. This also represented an attempted violation of prenegotiated sexual boundaries. As such, the women demonstrated little tolerance for this sort of behaviour. All of the women had experienced clients who had attempted to remove the condom during sex. Although only a minority of clients attempted this, the women described a need to remain constantly aware throughout the encounter to ensure the condom was not removed or tampered with. Deltah explained, "At the end of the day when the condom's on and it's going up there it's not touched. Don't even let them go up there, they don't even touch there as far as I'm concerned". The older and more experienced women interviewed described specific strategies to retain control of the condom and to manage clients who made repeated requests for unprotected sex. Rose, for instance, described educating clients by emphasising the health risks of unprotected sex. She stated:

I just say "No darling - condom (laughs). You can't take it off"...I always say to clients "Darling - well you think about it, if you have been with those workers and they've sucked your cock without a condom, they've sucked everybody else's too"... But in a nice warm friendly manner...you can swing them around....they normally think "yuk" (laughs)...You know, that's your first option - to try and educate them. (Rose, Wellington)

Using an educative approach was a useful strategy to respond to clients who made requests for unprotected sex during the job and is a strategy that has been highlighted elsewhere, more so in relation to the indoor sector (Sanders, 2006d). In New Zealand, however, for those who go beyond requesting unsafe sexual practices and covertly 
remove the condom, sex workers also have the option of contacting the police. Under the PRA clients can be charged for covertly removing the condom and as a consequence it has been reported that the PRA has given sex workers more power to negotiate condom use with clients (Abel \& Fitzgerald, 2010a). Sex workers can now refer to 'the law' on the issue of condom use with clients. To date there has been one prosecution for this offence (New Zealand Herald, 2005). In this research, it was clear that there was some awareness that sex workers had the right to contact the police in this situation. Shannon explained how she would react to clients who covertly removed the condom during the job:

Oh yeah they've tried. You know when they pull out and especially if you're doing doggy style or even if it's just missionary you know I always stick my hand down there to make sure it's on and well if it's off I'll say "hop up for a minute". And because I never get fully undressed - so I'd get out of the car. And you know if they start yelling and abusing me I'd say "yell and abuse me all you like, I'm ringing the police”. (Shannon, Christchurch)

A further strategy described was to provide an alternative for the client that played on their sexual desires. Tessa explained:

Mm I've had that happen...I stood up, got another one out of the bag said 'that was obviously bothering you. If you want to carry on we'll put a fresh on...or the other option is you can have a wank'... [And he said] 'oh don't be like that'. I said 'oh well I'll have a wank as well and you can watch'. And actually some of them really like that, you know? So I just got round the situation like that.... Well two seconds later he came, you know? Well that was easy. (Tessa, Christchurch)

In this situation, this strategy functioned to alleviate the potential for conflict whilst educating the client of safer alternatives. It is important to acknowledge that not all clients who request unprotected sex would consider being explicitly violent towards a sex worker. Nevertheless, through this behaviour they threaten the boundaries and physical health of sex workers and therefore they need to be managed in recognition of these risks. Those considered more problematic were individuals who attempted to complain about services provided and enter into a dispute with the women. The next section considers strategies to manage these individuals.

\section{Managing disputes}

Previous research has highlighted how disputes initiated by clients over payment and services provided can in some cases result in violence (Sanders, 2005; Kinnell, 2008). 
In one study it was found that one third of street-based sex workers had experienced a client who refused to pay in the previous 12 months (Abel, 2010). Similar findings emerged in this research. Disputes were described as most likely to occur with individuals who did not wish to pay the full fee agreed in the initial negotiations. To manage the risk of these disputes, all of the women insisted on getting the money first so that the individual could not refuse to pay after services had been provided. LisaLou explained:

It's always good to get the money first because it's not good to get it after because they could always turn around and say 'well I haven't got any money'. And you've just gone off and wasted your time, and um they've just actually got their own way with you....that happened to me once and that's when I thought nah I'm going to get my money up first, cash up first! Yeah it was for a sex job and um, yeah he conned me. You know and I believed him and after I'd done my job that's when he turned around and told me he didn't have any money so I was just like 'I'm never going to do that again.' (LisaLou, Wellington)

Similarly, Kay noted:

Always get your money before you do a job, no matter what. If they've got to go to a credit machine you go straight to the ATM...I believe that no matter what don't ever do anything until you have the money. Yeah. (Kay, Christchurch)

Getting the money first was therefore a universal strategy to manage the risk of a dispute relating the refusal to pay for services. However, a few women suggested that some clients were resistant to this because they feared being victimised themselves. Amy noted, "Seventy percent of them would let us do that but because they're [other sex workers] typically ripping them off - they're too scared to...Some of them are too scared to give you the money in the first place". Other individuals may be resistant to this for different reasons which could result in violence, particularly in locations where there are few options to exit the situation. In such situations other strategies may be called upon. Sydney described how she had managed a client who had first of all driven her to a location that had not been agreed on, and had refused to pay up front:

This guy took me all the way out to an orchard down around Marshland Road area. But little did he know that when I was younger that's the Orchard we went to get our fruit... we used to get fruit out there and so I knew exactly where I was. But he didn't know that I knew that. And back then I used to carry a knife, not that I would ever use it, just in case. And I was so pissed off...We were arguing about 
the money and he finally gave me the money, I did the job and which I shouldn't have even done...I was so pissed off that there must be something in my eyes that changed because I don't get angry very often. But he did pay me and then he did take me back into town...Yeah. Very strange man. (Sydney, Christchurch)

A further possibility, however, was that an individual could attempt to covertly take back the money during or after the job. This was known as being 'ripped off' by a client. A few of the women had experienced this and described strategies to hide the money in order to prevent this situation from occurring. Kay explained:

Make sure you put your money away too in case they're going to grab it when they're trying to touch you. Don't put it in your pockets or in your bra you know. I've had mates who've put it in their bra and then they go get a job and, you know, 'oops there's my money gone'. (Kay, Christchurch)

Similarly, Sapphire noted:

I put it in my pocket. Um usually I've got one of those plastic snap lock bags in my pocket and I put it in one of them so that it's not losable for one...it's harder for them to get back off you if they want to. They can't just reach into your pocket and pull out a few notes and score, you know?...They're going to reach in and feel around and think "well where's the money, it's not there". Yeah. (Sapphire, Christchurch)

The most common situation described in which disputes could emerge, however, was a client requesting a full or partial refund if they could not 'come' by the end of the job. To minimise the likelihood of this, the women described avoiding clients who were visibly under the influence of alcohol, as described in chapter five. However, this situation could also be encountered with clients for other reasons relating to mental and physical health conditions. There was also the possibility that clients may be under the influence of illicit drugs, which may in some cases be more difficult to identify in the screening process. It should be noted that in this situation many clients would never consider requesting a refund and the situation may be easily managed. Deltah described a situation she had with a client who couldn't 'come' having taken ' $\mathrm{P}$ ' earlier in the evening:

Um he seemed to pre-ejaculate and go soft and get hard again and do the same thing. And I think he did that about four times and I said look mate if you're not going to come I'm going to have to terminate the job. We've been here too long. We've been sitting here for more than 25 minutes I said that's the longest tops...If I'm not back by that time my mates start getting worried.' Don't ever suggest to give the money back because at the end of the day you're a working girl, you can't give the money back. The guy was like "yeah I've been on the old fries ay so I'm probably not going to come". And I was 
just like "oh well take me back please mate"...Yeah he did more apologising than I did because I felt stink. I was like "well I didn't know you were on P mate but you just don't do that. You're wasting my time”. Yeah. (Deltah, Christchurch)

Indeed, such situations are inevitably managed more easily with individuals who do not already have violent tendencies or any intention to perpetrate violence. However it was clear that for some individuals who may already have a propensity for violence (and perhaps the intention to perpetrate violence regardless) this was a potentially volatile situation. In such situations, however, none of the women said they would be prepared to return money to a client for this reason. Hollie explained:

Nah rules are rules. You know, they pay for what they get and if they don't like it they don't get their money back. There is no refunds...Some of them if they can't get it up or something then they ask for the money back and I'm like "nah you don't get the money back". Once they've paid, they've paid. (Hollie, Christchurch)

Similarly, Kay also felt that she had a right to keep the money. She noted:

No if you go on a job with him even if he's not come that's not your fault - it's his fault. You've done the job - you've done your part [and] he has no right whatsoever to take it...If you've done the job there's no way a client can get his money back. Definitely. (Kay, Christchurch)

Sapphire described how she managed these situations:

Customers that aren't happy at the end of the job because they can't come some of those guys do get quite anti and either start demanding their money back or get quite agro. But generally if you're quite assertive and turn around and say "well look you didn't just pay for the service you pay for my time. And because you paid for my time I'm not giving you back your money." (Sapphire, Christchurch)

As sex work is decriminalised in New Zealand, the women had the option of approaching the police to assist in such disputes. Vixen described how she would respond if this situation were to eventuate: "I'd tell him to drive me to the police station and we'll deal with it in front of the police...I don't want to really go to the police station but I will". Whilst the overwhelming majority of the women felt confident managing clients who attempted to obtain refunds, one woman described having some difficulties with this. Shania admitted, "I don't know how to say 'no that wasn't the deal'...I still struggle a bit with that. I'm not real forceful...yeah I struggle a bit with that". 
Several strategies were therefore described to alleviate the possibility of disputes with individual clients. Learning how to manage such situations was clearly important whilst working on the street. Whilst these strategies were undoubtedly useful, it is important to acknowledge that in some situations it is impossible to avert disputes. Indeed, with individuals who are intent on perpetrating violence, controlling their behaviour is unlikely to be an option. However, in such situations sex workers continue to strategise against victimisation. I will now move on to consider strategies to manage in the event of violence.

\section{Managing violence}

This chapter has explored how these women managed power and control dynamics throughout encounters with clients as a risk management strategy. However, whilst the women could strategise against the possibility of violence, there was ultimately no way of preventing this if an individual was determined to attack them. Women who work on the streets use a number of skills to measure the potential for violence although every encounter involves an element of chance, and the true motivations of individuals who approach as clients can only be fully known once the transaction is complete (Williamson \& Folaron, 2001, 2003). Whilst most clients are genuine, there is an inherent risk that some are not and will not accept the terms of the encounter. Barnard (1993) notes:

There were a number of ways in which the women sought to manage their dealings with clients so as to minimise the likelihood of trouble erupting. However these strategies were not always successful. Some clients did not accept the women's conditions of business and would use physical intimidation to force them to accede to their demands, sexual or otherwise. (p. 684)

Indeed, whilst women could strategise against violence, there was always a possibility that bad or bogus clients could present exceptionally well and pass as genuine clients. Indeed, serial murderers of sex workers have effectively mimicked genuine client behaviour, encompassing 'good client' characteristics, such as Garry Ridgeway who murdered at least 48 women over a 22-year period (Levi-Minzi \& Shields, 2007) and Steve Wright who was a regular client but went on to murder five women in Ipswich in 2006 (Kinnell, 2008). All of the women in this research appeared acutely aware of this possibility and had considered how they may react if attacked. The next section 
explores reactive strategies to manage these risks, and what strategies the woman employed to respond in the event of violence.

\section{Carrying weapons}

The majority of the women reported carrying a weapon that they would use to defend themselves should an individual become violent towards them during a job. The carrying of weapons amongst street-based sex workers has been previously documented (Barnard, 1993; Dalla et al., 2003; Nixon et al., 2002; Sanders, 2004a; Williamson \& Folaron, 2003). All of the women stressed that they would never use the weapon against another person unless they were attacked first. A weapon was considered an option only in crisis situations. Kay for instance stated, "You know it's his life or mine and I'd rather take his. That's why I carry protection. I'd be carrying a knife with me". Some findings suggest that sex workers are sometimes prepared to react with physical violence if attacked at work (Harris et al., 2011). In this research, however, a few women had concerns about carrying a weapon at work. In some cases, carrying a weapon appeared to function more as a means of self-reassurance rather than something that would inevitably be used should they encounter a bad or bogus client. Tessa, for instance, described carrying a knife for this reason:

I do I have a little knife. It's just a very little knife...I know exactly where it is when I'm working...I think you have to be pretty careful when you start thinking about being prepared to use something like that because unless you can move really quickly afterwards...I mean I'm small, I'm not a big person and I mean I know a lot of the girls say if they've got high shoes on they can throw the shoes and the shoes might be off and they might just be able to run like crazy. But still, you can't run as fast as a car. If you're prepared to do something like that you have to really have it clear in your head because you might just make them angrier. So I think you have to be pretty bloody careful. But yeah I do like to know where my knife is when I'm working. (Tessa, Christchurch)

Sydney also felt that using a weapon in response to violence could prove risky. She explained, "you need to know how to use it as well because they can just easily get your wrist and that's it". Several women were concerned about the possibility of being caught in the possession of a weapon and charged for this. These concerns were clearly warranted, reflected in the experiences of a few women who had been charged with this offence in the past. Lexi explained: 
I got caught. I got caught with a warrant and they said 'empty your bag'. And I emptied it out and they go 'look we understand why you've got it but you're not allowed it'....It was a knife. Yeah so I don't carry one now. Yeah they says 'look we know why you've got it but we're going to have to charge you.' (Lexi, Christchurch)

To negotiate the possibility of being arrested for this reason, several of the women described carrying items that could be used as a weapon but were not officially classed as a weapon. Mobile phones, body spray, hair accessories, pens, reading glasses, nail files and high-heeled shoes were all described as items that could potentially be used as weapons in the event of violence, whilst they could also be legitimately carried on the street. Shania explained, "Yeah well if you call 'impulse' [deoderant] a weapon. I've sprayed it in a guy's face...It's good because you can have it out there". Carrying weapons was therefore a strategy to feel safer whilst working on the street, whilst also providing a means to respond to violence should this eventuate. Most of the women, however, did not carry items that would conventionally be understood as weapons since they could be charged for this. In addition, whilst many of the women carried weapons they were not necessarily always prepared to use these, recognising that in some situations this could escalate the situation rather than facilitating an escape. The next section explores experiences of women who had encountered violence at work.

\section{Responding to violence: fight, freeze or flight}

The experience of violence provokes wide-ranging responses from individuals. It is commonly assumed that when experiencing violence, particularly sexual violence, victims will and should employ physical resistance. However, empirical research with rape survivors suggests that women react to and resist this form of victimisation in a range of ways (Jordan, 2008). In this research, women who had experienced violence from individuals who had approached as clients described responding in several ways. Shania noted that there are typically three broad responses that may be experienced when offended against violently, explaining "what do they say? Like flight [or] fight. And they say that. And I think there is that freeze. Because, yeah, you just freeze”. All of the women had different perceptions of how they would manage should they encounter a violent client and this was often in contrast to the experiences recounted by those who had actually been in this situation. For instance, amongst a few women who had not experienced violence in this way, there was a perception that they would 
firstly respond with physical violence towards the offender. This, it can be argued, links to the common misconception that victims can effectively prevent their own victimisation if they respond in particular ways. Amy articulated this point. She explained, "you sort of think you've got that chance to confront them before they attack you? I don't know why we think that way but we do". Women who had encountered violence from clients described managing these experiences in ways that did not usually include fighting back physically. Most often this involved 'freeze' and 'flight' responses where the priority was usually finding a way of exiting the situation if at all possible. Justice, for instance, described a situation in which she had been attacked after refusing to provide particular services:

I was doing the job and he done something to me that I didn't like. And I told him not to do it and I said 'I will take what I have earned and I will leave'. So that's what I tried to do because he just wouldn't stop doing it and I didn't like it and he wanted to do something I'd never done before. And I kept telling him 'no' so I kind of grabbed my money that he had given me and I go out the car...He was hitting me and that I just kind of let him until he needed to breathe a bit... and I ran and I told the girls I was with. (Justice, Christchurch)

Lexi was attacked by an individual who claimed to be seeking revenge against other sex workers who he claimed had robbed him previously. Similar attacks where an offender claims to be avenging robbery by other sex workers have been highlighted elsewhere (Harris et al., 2011). Lexi described how she remained focused on getting out of the situation regardless of what was lost in the process:

He had a job and that but he wanted to sort of do it again sort of thing and all that without paying - shit like that. And ripped the condom off and sort of was forceful. But well I'm not strong but I did back myself up and I ended up getting out of the car...Yeah I ended up getting control but he did get my bag, my money and scared me a little bit...I was really scared and it was just more or less trying to keep my calm to get away, whether I lost my money or whatever it was just me getting away. So that was my main objective, which I did...It was it was freaky, and he had something sharp and fucking cut my finger and shit so it was just getting out that fucking car...you just don't think you're going to get out of that car. (Lexi, Christchurch)

Sapphire described how she had responded when she had encountered an individual who appeared intent on perpetrating violence. She explained:

He says to me "oh how much for a blow job?" And I says "sixty bucks". And he goes "ok sweet as". [We] went down to my normal spot. Everything was all good and then when we drove down there he leaps out of his car runs around my side of the car, rips open my door and gets his thing out and starts doing 
himself [laughs]. And I said "what are you doing?" You know, "where's the money? What do you want, you want a blow job or what?" [laughs] And he goes "oh here's the money", and hands me twenty bucks. And I says "this isn't sixty dollars, this is twenty - this is nothing". And he goes "yeah I'll just beat off". Um and I was like [thinking] "hmmm ok" and because he was in my way I didn't really have much choice of where to go...And I hadn't had that experience before so I sat there for a couple of minutes thinking - what am I meant to do here? Um, am I meant to try and get past him or go out the other side of the door or what? So my phone went off and I used that as a cue. I went "right that's it - times up. See you, gotta go", and I slipped past him quite quickly - as quickly as I could. I went to walk off and he ran up behind me and walked like about a centimetre away from me standing over me like this [demonstrates looking down]. And he looked quite angry and I think he was going to try and take his money back off me. And I turned around, I stopped and I went "what the fuck are you doing?" And because I sounded quite aggressive and I'd actually stopped and turned around and faced him he goes "oh, oh nothing". And took a step back and ran over to his car and slammed the doors closed. And as soon as he took off running back to his car, I took off running down the driveway because I thought "oh this is weird, this guy's going to try and take his money back off me or run me over or something" you know? And he did. He jumped in his car and he tried screaming up the driveway behind me but I was already out of the car park by that stage and he stopped at the end of the driveway [and] checked out that I was already in the open and so he didn't have a chance of getting to me at that stage and then he drove off all angry. (Sapphire, Christchurch)

Whilst getting out of the situation safely was always the priority, in some situations this was particularly challenging. Pania, for instance, described creating a distraction in order to facilitate her exit away from the offender. She recounted:

Down in Lyttleton a client took me down by the domain, the wharf end and he decided he was going to rape me. And he had central locking and he had his elbow on the central lock and he was smacking me around so I planted my foot on the horn. I planted my foot on the horn and he freaked out and threw me out of the car. (Pania, Christchurch)

In some situations, however, exiting the situation was not a safe option. Shania recounted a situation in which an offender had threatened her with a knife during the sexual encounter. She described how she had reacted in this situation by pretending she was a willing participant in the scenario. She explained:

I've had a client who flipped and put a knife on my throat and there was nothing I could do there, absolutely nothing. And so the only thing I could do was try and make out that I loved it like that too, you know?...And I don't know to this day whether he would have done that if I hadn't been able to do that. Would he have [killed me] or was it just something that got him off, you know what I mean?...He loosened up but I've often wondered what would have happened. (Shania, Christchurch) 
This example demonstrates how women manage these experiences in diverse and innovative ways. Women in this research used skill and agency in the ways in which they responded to violence, and in their considerations of the possibility of violence occurring. Tessa, for instance, reflected on how different situations could require less orthodox responses. She noted:

I know that you know there are situations that men really do get off on having power over and you know in that respect pretence can be really good. But I'm not necessarily going to be [pause] in my head I'm not going to be vulnerable or scared or powerless. Even if I have to pretend that I am. It's a strange one. It's a really multi-faceted thing. (Tessa, Christchurch)

Indeed, these responses indicate that reactive strategies are complex and situation dependent rather than something that can be predicted or planned for. Whilst physical self-defence may be lauded as the only option, it was clear that a few women strategised to read individual situations and respond as they considered it appropriate at the time. Shania explained:

I knew Karate and shit when I got attacked and I spent five years doing it and it was no good to me then you know? But I've learned just kind of like talking and stuff ...Because if they're having sex and they get violent like that it's something to do with the sex that you can kind of like try and talk it out...It's the violent sexual satisfaction. (Shania, Christchurch)

Whilst it is not always possible to prevent violence, these examples demonstrate how these women continued to strategise against violence in diverse ways. These examples also highlight the psychological skills that can be developed by sex workers, through extensive contact with people from wide ranging backgrounds in potentially sensitive situations. These skills are often downplayed in rhetoric through which female street sex workers are dismissed as hapless victims who are "hopelessly trapped in an endless cycle of victimisation" (Silbert \& Pines, 1981, p. 398). Greater recognition of these skills and the role they play in the management of violence-related risks is necessary to create more informed insights into the experience and incidence of violence in street-based sex work.

\section{Summary}

This chapter has demonstrated how the management of power and control dynamics is central to the management of violence-related risks in encounters with clients. Whilst some potentially problematic individuals may be screened out when initially 
approaching as clients, as shown in chapter five, it was considered important to continue to manage risk throughout the encounter. Specifically, the women prioritised taking control in encounters with clients by controlling the location of the job and strictly enforcing sexual boundaries. In general, clients were said to be respectful of individual boundaries and rules set in the encounter. However, all of the women had experienced clients who had attempted to push their sexual boundaries, which was considered an indicator of potential danger. The women therefore described using their working persona in response to clients who would attempt to push their boundaries. Nevertheless, whilst the women could attempt to stay in control and to manage clients who pushed their boundaries, enforcing this with those intent on perpetrating violence was impossible. Regardless of this, women who had been attacked described strategies aimed at retaining control either psychologically or physically in these situations.

These findings provide some evidence that the decriminalisation of sex work has had a positive impact on the management of violence-related risks with clients. For instance, a few of the women suggested that they would now be willing to involve the police in disputes over payment, whilst one woman said she would be prepared to contact the police if a client covertly removed a condom. However, those approaching as clients were not the only potential perpetrators. The women also managed risks of violence from passersby in the course of their work. The experience and management of this type of violence will be reviewed in the next chapter. 


\section{Chapter Seven: 'Who's the slut, who's the whore?': The experience and management of violence from passersby}

\section{Introduction}

This chapter moves beyond the risks of violence from bad and bogus clients to explore the experience and management of violence perpetrated against street-based sex workers by passersby. This chapter begins with a discussion of the legal, social and cultural factors that are supportive of the public harassment and abuse directed at female sex workers in the open space. The women's experiences of verbal abuse, physical violence and harassment whilst working on the street are then outlined, exploring how these risks were managed. This chapter concludes with a discussion of the significance of this pervasive violent behaviour towards street-based sex workers in the decriminalised context.

\section{The culture of street harassment}

Street-based sex workers are frequently portrayed as a social nuisance in the urban space (Hubbard, 1998; Kantola \& Squires, 2004; Sanders \& Campbell, 2007; Scoular et al., 2007). Historically, legal frameworks surrounding prostitution have supported these portrayals by prohibiting street-based sex work or significantly limiting the spaces in which sex workers are permitted to work. Even in contexts where there are more liberal frameworks in place, the practice of street-based sex work is negatively constructed, evidenced in the ghettoising of street-based sex workers into 'tolerance' zones (McKeganey, 2006). This has contributed to the construction of sex work as undesirable in the public space and implies that, as such, the removal of street-based sex workers would be of benefit to the rest of society (Lowman, 2000; Sanders \& Campbell, 2007). This framing of street-based sex work as an undesirable social phenomenon inevitably influences, at least to some extent, public perceptions of street-based sex workers and reinforces the stigma associated with sex work on the street. In a social and political context such as the UK, where the dominant discourse defines street-based sex work as a social nuisance, it has been found that sex workers manage the additional risk of encountering community protestors who aim to drive sex workers out of the area (Kinnell, 2008; Morgan Thomas, 2009; Sagar, 2005; Sanders, 2004a; Williams, 2008). Furthermore, support for such vigilante behaviour by authorities is invoked through public statements about street-based sex work. As 
Kinnell (2008) notes, "The rhetoric of 'cleaning the streets' and 'waging war' on sex workers and clients is also invoked in numerous anti-street prostitution announcements in the UK” (p. 90). Indeed, in the 2006 Coordinated Prostitution Strategy in the UK it was stated that street prostitution "is not an activity that we can tolerate in our towns and cities" (Home Office, 2006, p. 1), The behaviours of some residents living in areas of street-based sex work have reflected this message of zero tolerance and embarked on campaigns specifically directed against street-based sex workers (Sanders, 2004a). In one area street workers were found to wear sunglasses to protect against aerosol attacks by vigilantes (Kinnell, 2008). In public policy in the UK, community is defined as homogenous and separate to those engaged in the sale of sexual services (O’Neill, 2009). Sex workers are therefore constructed as outsiders. However, some findings suggest a split in community perceptions in the UK, with some expressing a willingness to 'coexist' with sex workers (Pitcher et al., 2006). Nevertheless, those with strongly opposing views are often the most vocal. Pitcher et al., note, "Such inclusive views were not shared by all residents. For some, sex workers were outside society and antithetical to community, defined as "despicable", referred to by one resident in Southside as 'it', (p. 18). Antipathy towards streetbased sex workers is also reflected in the experience of frequent abuse from passersby (Abel, 2010; Benoit \& Millar, 2001; Campbell \& Kinnell, 2000; Day et al., 2001; Kinnell, 2006a; Nixon et al., 2002; PLRC, 2008). As Kinnell (2008) notes:

Harassment, minor assaults and muggings of street-based sex workers by 'people in the vicinity' are so common in many areas that such incidents are often not even recorded as Ugly Mugs, even though the atmosphere of hostility and abuse provides the context and arguably the cause, for more serious attacks. (p. 89)

Similarly, Day et al. (2001) state that:

...women involved in street prostitution experience high levels of verbal (and physical) abuse from those who pass through the red light area. We observed for ourselves the seemingly endless hatred directed at street prostitutes from those who see them as an easy target. (p. 230)

The socially constructed status of street-based sex workers as undesirable women, combined with their historically defined status as law breakers, has created a context in which low level violence towards sex workers on the street is supported through discourse and, in some contexts, through legal frameworks surrounding prostitution. Whilst some community violence may be defined as 'lower level', the frequent abuse 
of street-based sex workers arguably creates an environment in which violence towards sex workers is normalised (Miller \& Schwartz, 1995).

Decriminalisation, it can be argued, represents at least a symbolic change in the way in which street-based sex workers are constructed in the public domain. The decriminalisation of street-based sex work, in theory, provides a context in which a commitment to the safety and wellbeing of street-based sex workers informs the dominant discourse as opposed to a commitment to ridding the streets of sex workers. However, in New Zealand despite the law change street-based sex workers continue to experience abuse and harassment from the general public (Abel, 2010; PLRC, 2008). The next section explores experiences of verbal abuse that were recounted by these women.

\section{Verbal abuse}

Verbal abuse against street-based sex workers is well documented both in New Zealand and elsewhere (Abel, 2010; Day et al., 2001; Miller \& Schwartz, 1995; Morgan Thomas, 2009; Nixon et al., 2002; Pitcher et al., 2006; Sharpe, 1998). In line with these previous findings, the women who took part in this research encountered verbal abuse on an almost nightly basis whilst at work. The content of the abuse was usually underpinned by misogynist ideas. For instance, Shannon noted that this typically involved "'oh show us your tits' and all that and call you a slut or they'll throw five cents at you". Despite the frequency of verbal abuse towards them on the street, the women employed considerable restraint in their reaction to this. Bianca, for instance, described how she responded to verbal abuse. She explained:

They're drunk, you know, and they're smart and when they get smart to me I go "well you should be at home with your mummy" [Laughs]....They know there's sex workers. And I think to myself "well, why do they drive around there when there's other ways they could drive around to get to where they want?" But they just drive around just to get smart. Because they're bored and there's no one else they can pick on. But then I just say "well, have a lovely night!" [laughs] (Bianca, Wellington)

Whilst the women experienced verbal abuse regularly, the most common reaction was to ignore this. It was felt that reacting to verbal abuse would impact negatively on work. Deltah explained: 
The ones that scream and yell at you at the side of the road, well I don't listen to that. You just hear a whole lot of yelling and you just block it out because at the end of the day if you let it get to you then you've just let them ruin your whole night of work. I just let it go in one ear and out the other. (Deltah, Christchurch)

Similarly, Lisa-Lou noted:

The good thing to do is just take control and just ignore them and try not to retaliate...Because you'll just get all worked up and then I can't work, it's like "oh nah I've got to go home, because I don't feel that I can work now because of that"... a few times. I've just thought "nah I'm going home". Because sometimes when it's a slow night you'll get, a lot of them that are going around abusing you and stuff like that. (Lisa-Lou, Wellington)

For the most part, the women ignored the verbal abuse they experienced because they felt that responding to it would result in increased stress and would be unlikely to resolve the situation. However, this also reflected a commitment to working discreetly so to not attract negative attention or deter potential clients from making contact. Claire noted:

I mean you're out there so you've got to keep the noise down...It's for the safety of you and the girls around you. It's just common sense. You don't go yelling out when you're trying to get work. (Claire, Christchurch)

The commitment to work quietly for these reasons contradicts portrayals of streetbased sex workers as always representing a nuisance in the public space. They are blamed for a range of issues such as noise and litter (Buckley, 2009). However, these findings suggest that significant noise in areas used for street-based sex work may relate in part to the harassment of the sex workers themselves. One key informant who lived and worked in the street sex work area reported regularly witnessing this abuse:

I still see the kind of low grade violence that it's easy for any member of the public to see. You know people yelling abuse out car windows and hurling things out of car windows and that sort of stuff. (Key informant, Church)

This key informant went on to suggest that the abuse directed at street-based sex workers created tensions amongst some local residents, explaining:

We have a reasonably good relationship with a number of people who live around here. But those tensions haven't gone away, there are some people who still live around here who are still pretty unhappy and who live with, you know, being woken at two, three, four o'clock in the morning with the screaming abuse from cars and all that sort of stuff. (Key informant, Church) 
Other key informants also expressed concerns over the frequency of verbal abuse experienced by street-based sex workers. Overwhelmingly it was understood that the women accepted this type of abuse as inevitable and ignored it, despite the fact they should not have to tolerate this behaviour. A key informant noted, "I guess a lot of the girls out there build a wall to it and they ignore it...It shouldn't be like that". Key informants from the police in Christchurch were also aware of the abuse experienced by women working on the streets. Whilst overall it was felt that this wasn't acceptable, there was also a perception that this was, to some extent inevitable. One police key informant explained:

Well I'm hearing that. Yeah they do [get harassed]....A Thursday night or a Friday night you get a lot of people just driving up and down the street just for the sake of looking at them. It's not surprising...drunks, young guys drunk going up there and giving them a bit of lip and a bit of stick and then there's always, there's always strange guys that just roam around and want to talk to them and approach them....I just think it's part of their business. Yes. I mean you know...some of the girls dress with the purpose of trying to attract clients and that's going to attract other attention. (Key informant, Police)

This example highlights how socially constructed ideas about women and sexuality can inform perceptions of what behaviour is considered acceptable towards streetbased sex workers. As women who may intentionally dress in ways that could be construed as sexually provocative, it is suggested that female street-based sex workers are likely to encounter street harassment as "part of their business". As such, they may be expected to put up with this as an inevitable part of their work. It is perhaps as a consequence of these deeply ingrained ideas that the overwhelming majority of the women ignored the verbal abuse they encountered since female sex workers have been afforded such low social status. However, a few women did describe resisting this, and challenged the perpetrators on the basis of the insults they had directed at them. Catherine explained:

Usually I don't react because that just encourages them. But sometimes...when they say something really stupid then I will yell out to them.... Well you know I had someone call out 'you fucking slut' and I was like 'prostitute actually'. 'Why don't you get a real job', 'well I'm at university actually' and they don't like that at all...And the fact is, even if we are out there because we want to have some fun or because we've got a drugs habit or whatever, it's our choice and they have no right to make that judgment. (Catherine, Christchurch) 
Several of the women reflected on the content of the verbal abuse, which was typically based on sexual stereotypes, and stigmatisation of sex workers. Vixen, for instance, recalled responding to the calling out of "whore" with the sarcastic reply "oh thanks for telling me, I forgot!". According to Goffman (1990) members of stigmatised groups internalise negative portrayals of their identity and are silenced by a fear of judgement, which is termed 'felt stigma'. However, consistent with other research findings it appeared that the women resisted internalising these underlying messages. Instead, they reflected on the ideas implicit in the insults directed at them (Abel \& Fitzgerald, 2010b; Sallmann, 2010). For instance Hollie explained:

I find it a crack up because, you know, the girls...they're just jealous because we can get our money out there and do what we do and make more money than them. And they just yell out and abuse us because they can't do it. You know, they'd have a big cry about it [doing sex work]...It's like "ok well if you're going to yell out that then you get out here and see how you go". You know, "you go and give it away for free - what do you get a couple of drinks out of it?" (Hollie, Christchurch)

Similarly, Sydney stated:

The worst is when a girl goes past within a car of guys and she's yelling out "slut" and "whore" and you think "you're the one with all these guys and you're probably rooting them without protection". So who's the slut, who's the whore? (Sydney, Christchurch)

Whilst most of the abuse that was described by the women was unimaginative, in the form of flippant insults typically used to disparage women, a few women described an even more brutal level of verbal abuse. This abuse involved passersby making light of the recent murder of a street-based sex worker in the city. Amy recalled:

These guys the other night there must have been about six of them and I know men when they get together have that sort of mob mentality...They were like 50/55 and all six of them had a different comment like "oh well you should be in the river" ...like one of them said "shouldn't you be in the river?"... They all said something different and I was thinking "you fucking filthy assholes" you know?... But we get that all the time. (Amy, Christchurch)

This example highlights the need to prioritise tackling the harassment of street-based sex workers in the public space and also the need to challenge stigma. This is particularly problematic, however, as it requires encouraging sex workers to report this violent harassment, ensuring police take these reports seriously, and educating the public so to reduce the stigma that is at the root of these incidents. This particular example illustrates how even what essentially equates to a threat to kill is considered 
an appropriate response to street sex workers amongst some members of the public. It is unlikely that this sort of abuse would be considered appropriate behaviour towards most other groups in society, and that individuals would feel entitled to deliver this type of abuse at, for example, police officers or charity collectors. Street-based sex workers should have equal protection from this abuse both in law and in the societal response to it.

Whilst most of the abuse was ignored or responded to liberally, a few of the women described responding to frequent verbal abuse more explicitly in some situations. However, it was clear that the perpetrators were generally unlikely to engage in any direct confrontation. Shannon recounted an experience:

I remember one night I was out there and there was these four girls in a car...driving up and down abusing the fucking shit out of me and...I says to them "what fucking wimps get out of the car and come over here". ... Well the lights at Tuam Street went red and the traffic was backed up and they were right on my corner and I went up to the car and you want to see how fast they locked their doors. You know, just mouth and too scared.... at the end of the day they're wimps, they're only doing it to show off. (Shannon, Christchurch)

This example suggests that whilst the perpetrators of verbal abuse wished to engage with sex workers from a distance, this enthusiasm did not extend to any direct or meaningful engagement. This may reflect the 'othering' of sex workers amongst some members of the public. Whilst verbal abuse was most frequently experienced, the women also experienced physical violence of varying degrees from passersby. This chapter will now move on to outline these experiences.

\section{Physical violence}

Whereas only some of the women had encountered physical abuse from individuals approaching as clients, from other sex workers and from minders, all of the women without exception had encountered physical abuse from passersby. Most commonly this involved eggs, bottles and other objects being thrown at the women from cars, typically accompanied by verbal abuse. However, a few women reported being shot at with pellet guns and a male passerby had physically and sexually assaulted one woman. Whilst, overall, verbal abuse was dismissed as relatively trivial, the physical abuse encountered was considered more concerning. Deltah noted, "I don't like the ones that throw things out the windows cause I've been hit by a few eggs and a lot of 
bottles...that's horrible ay". Similarly, Kay explained that whilst she would not generally respond to verbal abuse, she felt that physical abuse needed to be addressed: "I don't comment unless they're getting really smart and throwing shit...because that's not cool, throwing things at girls... They could seriously injure someone". Physical violence from passersby was occasionally more explicit than the throwing of objects, however. One woman recounted having been physically and sexually assaulted by a passerby in an opportunist attack. Contrasting with the portrayal of clients as violent abusers, a passing client had intervened in this attack so the woman could get away from the offender. Amy explained:

I said 'hello' to him and he didn't say 'hello' and I was like' oh that's weird' because normally people, you know, say 'hello'. And, yeah it was weird...He stopped...And then he crossed the road and was probably quite a bit away from me, still quite a good distance. And I turned around and asked if he was alright because it was like he was lost or something. And he just didn't answer me. And I turned around and he had me just like that... There was actually two clients that were driving round...It was only because the client stopped that I got away in the first place...He wasn't going to leave until he had put me down...And I ran across the road to the dairy and the guy...he stayed and waited with me until the police got there. (Amy, Christchurch)

Amy reported this incident to the police and the offender was subsequently jailed for two and half years. However, the extent to which women were prepared to report the more frequent lower level violence from passersby was variable. Deltah explained that whilst she would record the vehicle's details, she was reluctant to report these incidents to the police, feeling that this would have a detrimental impact on her work:

Yeah I normally just take their licence plate numbers if I can see them...Sometimes I won't go to the police because it just kills my night and I end up sitting at the police station when I could be out there making money. I just come home and get changed and go back out and make money instead of just going to the cop shop because there's not very much they can do. (Deltah, Christchurch)

Although only a few of the women said that they would report the individuals who threw missiles at them at work, in Christchurch the police were already well aware that sex workers were frequently abused by some members of the public. Indeed, all of the key informants commented on the extent and nature of abuse that was experienced by sex workers on the street. One police key informant reported making an effort to address this behaviour when possible: 
Oh I think they get harassed a lot. I mean I've seen people throw bottles at them, like get a drink bottle and throw water at them and I've stopped and had a go at people about that. And I think things like that they just put up with it. They don't really report that type of thing...I think they almost see that that's sort of part of their occupation...I mean I have actually seen, I've heard people yelling out to them and I mean I always stop and talk to people doing that sort of thing. (Key informant, Police)

Unfortunately, not all authorities had such a pro-active approach to responding to this abuse. Amongst some agencies, it was clear that there was a degree of apathy in addressing this sort of behaviour. A key informant from NZPC in Wellington recounted a discussion with an organisation that played a key role in public safety:

I was talking to one of the agencies who's charged with securities...you know on a local body contract to go around, walk around all the inner city streets. And when I was talking to her about missiles being thrown, you know the immediate reaction was "well that's life - what do you expect". It was an extraordinary reaction, so extraordinary that we knew that there was an ingrained problem with an authority. I thought "my gosh, we have to do something here and work to get that attitude turned around"...Even, when they realised how in the corner that they were in it wasn't acceptable for an authority to say it's normal for bottles to be thrown at street based workers. When they realised where they were sitting on the argument they tried to make a case that other groups had bottles thrown at them too...I've met lots of women who are non sex workers and not one of them in my long life would be able to tell me that they've had a bottle thrown at them and that that would be normal. (Key informant, NZPC Wellington)

The apathy towards addressing abusive behaviour towards street-based sex workers by passersby, perhaps links to widespread identification with the long legacy of criminalisation of street-based sex workers. A police key informant noted:

I know they do. They often do [get hassled]. And the ladies from the Prostitutes' Collective often report to us about people going past and throwing rotten fruit and shooting air guns and doing all sorts of things. So that is a legacy of their occupation I suppose. (Key informant, Police)

It was clear that some police were committed to supporting street-based sex workers to challenge the abuse and harassment they experienced whilst working on the street. One woman, Claire, recalled reporting an experience she had whilst working on the street:

A car went past me and they pulled out a rifle...Yeah and shot it. And I happened to be on the side and it just went past me - the bullet. And I had a friend with me who witnessed it as well. And the cameras and stuff had seen it...I reported it to [youth workers]...And they took me down to the police 
station and made some complaints which I'd never done before. And...it just felt good, I mean having them idiots going past and doing that. I mean they're probably one out of many who do that. And it's not only guns, it's bottles too...Everyone's got opinions on the police but yeah I did actually have a little respect for them after that. I mean at least those little boys can't go around shooting people. (Claire, Christchurch)

This example highlights how having a supportive experience reporting violence can have a significant impact not only in addressing violence on the street but also in increasing confidence in the police amongst some sex workers. It appeared that this was particularly important for younger people working on the street who tended to have less confidence in the extent to which the police could assist them in the event of any kind of violence. Whilst older sex workers either ignored verbal abuse and the throwing of missiles, or reported licence plates to the police, amongst some younger people there was a tendency to retaliate with violence towards abusive passersby. One key informant explained:

I think a lot of the older workers get a lot more hardened to it and they can ignore it a lot more. The young ones get really volatile. Sometimes they'll throw things back or so it can end up turning into just a big bloody mess especially when often you might have one person working behind the fence there's 15 of their friends. So you can imagine what can sometimes end up happening and the original perpetrator of the stupid behaviour ends up getting absolutely hammered. (Key informant, Youth)

In agreement with this, one woman who had originally become involved in sex work at the age of 16 described how her response to this type of violence had changed as she grew older. She explained:

Like at the beginning like when people were doing that we had like little glass beer bottles that were next to us and if someone got smart we would have threw a bottle and shattered their windows and stuff...But as you get older you sort of just brush it off, you know it's just like "oh it's another boy racer". Yeah [laughs]...you sort of get used to it and you sort of just brush things off. You sort of just zone out, ay. (Jane, Christchurch)

The more volatile or proactive responses by younger people could also, however, represent recognition by some of the new generation of post-law reform sex workers that they do not warrant this sort of abuse from passersby.

The data presented in the above paragraphs suggests that passersby rather than clients may represent the most common perpetrators of physical abuse towards street-based sex workers, however trivial this abuse is considered to be. This contradicts 
constructions of street-based sex workers as 'deviants' and other members of the public sharing spaces with street-based sex workers as 'victims'. This also contradicts portrayals of clients as the sole perpetrators of physical abuse towards sex workers. These examples are indicative of the stigma associated with street-based sex work that has continued to prevail since the passing of the PRA. However the abuse these women experienced appeared to come from opportunistic passersby rather than local residents specifically campaigning against street-based sex workers. The next section briefly considers the significance of this.

\section{Harassment from residents}

The harassment of street-based sex workers by vigilante groups of residents in the areas in which they work has been identified as a risk factor for street workers (Hubbard, 1998; Kinnell, 2008; Lowman, 2000; Sagar, 2005; Williams, 2008). As noted earlier in this chapter, this behaviour has arguably been supported by authorities in places such as the UK through policies that construct street-based sex workers as a social nuisance, supporting the dominant social perception that street-based sex workers are unwelcome in the public space.

In New Zealand, since the passing of the PRA there has been some resistance to street-based sex work, notably in areas of South Auckland where a vigilante group formed aiming to drive street-based sex workers out of a residential area (Buckley, 2009). In addition, this has been supported by attempts to reverse or amend the provisions of the PRA so that street-based sex workers are only permitted to work in specific areas (Manukau City Council, 2010). The response in Manukau has been framed around concern about street prostitution causing public nuisance and residents feeling unsafe in the area (Mossman and Mayhew, 2007). More recently, in Christchurch tensions between residents and sex workers have been reported after street-based sex workers were displaced to areas outside the central business district following the earthquake on February the $22^{\text {nd }}$ 2011. In an article entitled 'Homeowners enraged as sex 'skanks' move in' that appeared in a national newspaper, it was reported that residents "came charging out of their homes armed with torches and cameras" (Leask, 2011). Further, residents were reported to be photographing sex workers and their minders whilst ordering them to leave the area. One resident was quoted as saying: 
For the last 20 years the deal was that the skanks stayed in the area over Bealey Ave. We kind of accepted it. But now the skanks are hanging out here, they cross up and down the street and people are really nervous about them and the traffic and people they are attracting. Yes, it's legal but it doesn't make it right or acceptable near the homes of decent people. If you have one skank, other skanks will come. It just escalates. Where do you draw the line? (Resident, quoted in Leask, 2011)

This suggests that despite the change in law, there is still considerable resistance towards sex workers in the public domain, particularly when sex workers move into areas that have not historically been associated with sex work. This suggests that areas in which street-based sex work takes place are still considered as what Wagenaar \& Altink (2009) have termed "contested space” (p. 168). As Sanders and Hubbard (2003) argue, the marginalisation of sex workers into "streets of shame" creates a "moral geography" that dictates the areas in which it is considered appropriate for sex work to take place (p. 79). In moving from this location, sex workers in Christchurch transcended the boundaries of these informally defined areas of moral turpitude, into areas in which there is a constructing of sex work as a form of moral pollution. The continued influence of moral discourses is evident in this resident's assertion that decriminalisation does not make sex work "right or acceptable". In addition, the 'othering' and disdain for street sex workers is evident in the labelling of sex workers as "the skanks". However, the newspaper article detailed above also suggests that sex workers resist attempts to control their use of the public space, and construct this resistance around their rights under the PRA. In response to the harassment from residents one sex worker, Candice, was reported as saying:

There's no need for it. They have no right. We are all going through the same thing after the earthquake. It's like I'm being crucified. Shame on them...I'm just trying to earn a living, that's it. They are living back in the $18^{\text {th }}$ century. What I do is legal so what is the problem? I'm not bringing it into their area. I'm taking my clients well away. (Candice, quoted in Leask, 2011)

These events took place well after the timeframe in which the fieldwork was carried out. At the time of the fieldwork, very few of the women in Christchurch or Wellington reported being harassed specifically by residents. Although it is unclear whether the passersby who verbally abused the women and threw missiles at them could be counted as local residents, it appeared that there were few incidents of harassment perpetrated specifically by local residents with an aim of moving street- 
based sex workers out of these spaces. Only one woman, Tessa, described an incident of this sort:

I was up Bealey Ave end one night and, well there's a block of flats there and quite a few of the cars turn around there. And I was on my way home. I thought 'if I get a job in the next half an hour cool, if I don't you know I've got something in my pocket - I'll go home'. And this guy came out from the flats and he got really abusive - "I know what you're doing, just fuck off - I've got kids in there". I said "ok just ask me nicely". And he was "oh I'm going to smash your face into the footpath", you know he was getting nasty. And I said "ask me nicely I will gladly go somewhere else. I didn't realise when I stood here that it was going to bother anyone. But I'm not going to move because you're threatening to push my face into the footpath. Ask me nicely". And he goes [mumbling] "Oh can you please go somewhere else"...I said "easy ay", and walked off. So to a degree you can't allow people to intimidate you....If you show weakness someone will exploit it. (Tessa, Christchurch)

This experience demonstrates how sex workers can manage and negotiate such experiences and conflicts with the portrayal of sex workers as a social nuisance. The low levels of reported harassment in Christchurch and Wellington may relate to the fact that sex workers on the street have worked consistently in the same area for a considerable period of time. The tensions reported in Christchurch only appear to have emerged since sex workers have moved into a new area. This suggests that there is still a degree of intolerance towards sex workers on the street in areas not typically used for street sex work. However, there is also a possibility that the low levels of harassment during the fieldwork period reflected in part a more positive positioning of street-based sex workers in the public space since decriminalisation. A key informant who lived and worked in the street sex work area in Christchurch felt that in recent years there had been a change in the relationship between sex workers and other residents:

I don't know whether it's got anything to do with the change in laws to be honest but we used to have a lot of crap out there all the time. Every day began with a clean up operation. But these days the clean up operation is hardly anything at all. I mean and it's mostly actually to do with the Salvo van that comes past three nights a week and you know coffee cups and wrappers and what have you, but that's most of it...I mean the area is clean, that's certainly the case. There does seem to be a better attitude on the whole I think by many of the women towards their neighbourhood, put it that way. Neighbourliness. (Key informant, Church)

It is possible that there has been a positive change in the relationship between sex workers and other local residents since the law reform. Tessa's experience, however, 
combined with the verbal and physical abuse from passersby, the vigilante action towards street-based sex workers in South Auckland, and the reports of renewed tensions in Christchurch suggest that challenges remain in moving towards more positive acceptance of street-based sex workers in New Zealand society. The next section discusses the significance of violence from passersby, theorising on why this continues to exist in the decriminalised context.

\section{Discussion}

The nature and extent of violence and abuse from passersby suggests a need to prioritise ways of addressing this behaviour. Women in this research described frequent verbal abuse, having objects thrown at them from cars, being shot at, and being physically assaulted by passersby. The decriminalised context should, in theory, represent a more progressive context in which this sort of behaviour can be challenged. Arguably, the first step in challenging this is to understand the behaviour and the underlying ideas that inform the beliefs conveyed in these actions. Overwhelmingly, the women attributed the abuse from passersby to a lack of understanding about street-based sex workers. Zoe explained:

Oh yeah...you get shit every time man. You get eggs thrown at you, like glass bottles and stuff thrown at you ay...they don't know me they just think I'm some slut that works on the corner.... they just drive off ay they don't really come back. Too scared and stuff you know knowing "oh fuck I shouldn't have done that". There are idiots out there because they don't realise you're out there to do it for yourself. Like they don't realise how hard it is because their dad and mum's fucking rich and got jobs and they get what they want. But try doing something for yourself ay, and getting it your own way. Yeah. (Zoe, Christchurch)

Almost all of the women expressed an awareness of how they were negatively perceived by others outside of the sex industry. This awareness has been highlighted in other research, such as a UK study in which sex workers demonstrated familiarity with stereotypes of their work (Boynton, 2002). There was also a strong sense from key informants that ignorance, stigma, and entrenched privilege directly contributed to harassment and violence towards street-based sex workers from passersby. One key informant noted:

I think a lot of people in this city, in this country, probably just don't have a very mature understanding of sex and sexuality. And have an issue with somebody, with a female, who is having more sexual partners than one. And I 
think we're still living on the edge of a Victorian society...Praising words for men that have more than one sexual partner, derogatory ones for females and they're usually females out there. (Key informant, NZPC)

The continued influence of the Madonna/whore dichotomy was strongly reflected in the content of the verbal abuse experienced by street-based sex workers. Most frequently, the women recalled having words such as 'slut' and 'whore' shouted at them, reflecting the perception of the perpetrators that these are negative terms. Their use of these words specifically, reflects a perception that sex with multiple partners is abhorrent behaviour for women to engage in and as such these women are considered deserving of abuse. The fact that other women were frequent perpetrators is also significant. This type of verbal abuse from other women, it can be argued, highlights how despite the successes of feminism, the Madonna/whore dichotomy continues to prevail and is still internalised by some women. Challenging verbal abuse towards street-based sex workers, therefore, in part relies on continuing to challenge these deeply ingrained patriarchal ideas that create and support social divisions between groups of women. In addition, violence towards street-based sex workers by passersby was also thought to relate to the general character of the perpetrators, and was associated with their propensity to seek entertainment by harassing others. One key informant noted:

They get a thrill out of it. You know, "let's abuse them and see how they react. Let's see if they throw a bottle back at our car or let's pick a fight'. You know some people may not like them and they maybe want to get them off the street...But yeah I think in general it's more entertainment. (Key informant, NZPC)

This, it can be argued, also reflects a lack of understanding about sex work and the 'othering' of street-based sex workers since these individuals intentionally target street workers to observe how 'the other' will react. Perhaps at the root of this behaviour is curiosity about street-based sex workers that stems from this widespread ignorance. Raising awareness of the realities of street-based sex work and those involved in it may, therefore, go some way in addressing this. Further, the constructing of this type of abuse as unacceptable and defining this behaviour as a form of violence would also assist in addressing it. 


\section{Summary}

This chapter has demonstrated how street-based sex workers experience frequent violence, not primarily from clients, but from passersby. This contradicts portrayals of street-based sex workers as a social nuisance in the public space, highlighting how sex workers on the street often tolerate violence from passersby in the form of verbal and physical violence. This also contradicts the perception that clients are responsible for most of the violence experienced by sex workers. These findings also indicate how street-based sex workers manage and resist this form of victimisation. Although the women resisted this victimisation, as workers in a decriminalised sex industry, these women could be better supported in their management of this type of violence.

The law change at least represents a symbolic change in how street-based sex workers are perceived, and communicates publically a commitment to supporting their safety and wellbeing. However, it is important to question why, in this context, these women continued to experience this level of abuse from passersby. Specifically, it is important to consider why stigma continues to shape the experiences of street-based sex workers in public spaces. There are several linked explanations to these questions. One explanation relates to the long legacy of criminalised street-based sex work that has resulted in the 'othering' of street-based sex workers. A second possible explanation is that despite the law change, large sections of the public remain poorly informed about sex workers. Although the law has changed, there has been no specific attempt to educate members of the public about the street-based sex industry. The third explanation relates to broader ideas about women and sexuality that need to be challenged - specifically the convention that women who have multiple sexual partners are deserving of violence.

Challenging this type of violence against street-based sex workers therefore relies on counteracting the ideas that underpin stigmatisation and 'othering' of street sex workers, namely the idea that street sex workers are deviant and exist outside communities and society. Since the law change, sex workers continue to be targeted with violence by passersby, however the decriminalised context provides an appropriate environment to move forward by challenging the ideas that are supportive of this violence. The next chapter moves on from individual strategies to explore the 
ways in which these women worked collectively with others to manage violencerelated risks, exploring tensions and challenges that remain since the law change. 


\section{Chapter Eight: Beyond individual actions: collective strategies to manage risks of violence on the street}

\section{Introduction}

This chapter explores how street-based sex workers work with others to collectively strategise against and respond to the incidence of violence. First, the importance of peer support between sex workers is considered. This discussion is juxtaposed with an exploration of the conflicts and tensions that existed between sex workers and occasionally resulted in violence. The role of minders on the street is then considered, demonstrating how the women had complex views on the function and efficacy of minders in the street context. The extent to which minders can tangibly support sex workers to manage risks of violence is explored. The changing role of the police in the context of street-based sex work and violence risk management is then considered, highlighting positive changes in recent years, in addition to existing tensions and continued challenges. Finally, the role of support agencies is explored, considering the women's perceptions of strategies developed by agencies to support sex workers in their management of risk. The overall aim of this chapter is to move beyond an analysis of individual strategies to explore collective strategies to manage risks of violence on the street.

\section{Peer support and safety: friendship, conflict and the management of risk}

Social bonds between sex workers on the street represent a significant and tenuous means of managing risks of violence. Previous research has demonstrated how streetbased sex workers support co-workers on the street (Abel, 2010; Miller, 1993; Nixon et al., 2002; PLRC, 2008; Sanders, 2001). Some of this research has highlighted tensions within these peer relationships as a consequence of competing for clients for the purpose of financial success (Abel, 2010; Hoigard \& Finstad, 1992; Sharpe, 1998). In relation to this issue, Harris et al. (2011) note:

Sex work by definition implies competition between women for paying customers, and this tends not only to work against solidarity and a sense of collective practice, but toward increased risk of all kinds...In contrast though, the women seemed to rely on their fellow workers to manage some of the endemic risks of sex work. (p. 392)

In this research, the women described the relationships they had with other women on the street in contradictory ways. On the one hand, other women were constructed as a 
source of essential peer support. Almost all of the women had formed social bonds on the street with other women and felt confident that this support could be relied on to protect against specific types of violence. On the other hand tensions and conflicts were identified that link to economic pressures and hierarchies between the women that functioned to informally regulate the street environment. The ways in which the women provided support to protect each other from violence and the complexities within this will now be explored.

\section{Sharing information to prevent violence}

A key part of peer support as a risk management strategy was sharing information on potentially problematic clients. Previous findings have suggested that women on the street sometimes shared incorrect information to intentionally lead others to potentially dangerous men (Williamson \& Folaron, 2001). Such behaviour may be supported by other findings suggesting violence between sex workers as a consequence of competition and jealousy (Brewis \& Linstead, 2000; Nixon et al., 2002; O’Neill \& Barberet, 2000; Plumridge, 2001; Pyett \& Warr, 1997; Sharpe, 1998). Other findings have contradicted this suggesting that a safety code on the street meant that women would warn others on the street from going with certain men who they felt could be dangerous (Sanders, 2001; Miller, 1993). In this research, the overwhelming majority of women said that they received most information about potentially dangerous clients from other women working on the street. Deltah, for instance, explained that she learned of potentially dangerous clients "mainly from other ladies". All of the women recalled sharing information about clients who had pushed their boundaries or were violent towards them. Laura explained, "They [other workers] would tell you if they've been hurt by a person that looks like this and he's got a car like this and tell you to just keep a look out". Bianca explained how she would warn other workers telling them "don't go there with him, he's no good that guy”. Similarly Sapphire recalled telling others "oh, don't even bother talking to that one”. Sharing information with other women on potentially dangerous clients was an important strategy to manage risk. Shania emphasised how important she felt it was to communicate with other women. She explained:

Talking with the other girls because, you know, like they can tell you to "look out for this one"...It's that word of mouth thing... We need to be able to talk amongst ourselves to help keep each other safe...People who have been 
working on the street a lot longer have been telling me about different people who drive around and stuff and so I guess if you're talking to other working girls ...it minimises the violence and stuff. (Shania, Christchurch)

Key informants from agencies that provided outreach services also felt that positive relationships between sex workers helped support violence risk management on the street. One key informant noted:

Talking to other street sex workers is particularly important because it gives you that hands on experience of how to recognise what sort of car is likely to cause trouble... to talk to a client to see what he's like rather than just jumping in the car, all that sort of thing. So talking with other street based sex workers out there...being able to impart that knowledge also to others. (Key informant, NZPC)

Peer support therefore facilitated information sharing which assisted women in their management of risk. This included information about potentially dangerous clients in addition to encouraging safer working practices. A few of the women also described close friendships with other sex workers who closely monitored their safety together whilst working on the street.

\section{Peer minding}

A few of the women interviewed described informal systems of minding on the street to protect against violence from potential clients. This has been highlighted in other research that found some street-based sex workers watched out for other workers, and sometimes recorded licence plates of client cars (Abel, 2010; Barnard, 1993; O’Neill \& Barberet, 2000; Sanders, 2001). Deltah explained how she worked with another women to manage safety whilst working on the street. She explained, "I normally work side by side with someone or the corner away and they can always remember what licence plate number of the car that I get into. Or I text it to my mates phone”. One of the women interviewed, who had become involved in street prostitution at a young age, described how she had managed violence-related risks by working closely with a group of friends also involved in the street scene. This peer minding amongst younger people was highlighted in another New Zealand study where it was found that:

...they hung around in groups of young people on the street. Some of the members of the group would be engaged in sex work whilst others were 'minders', being paid a fee from the money their friends earned. (Abel and Fitzgerald, 2008, p. 365) 
Whilst younger people may experience hostility from older workers, these findings suggest that some young people manage these risks collectively within their own peer group. Justice described how her group of friends worked together closely, adhering to shared rules. She explained:

We had each other's numbers. We knew how long they took, how long they had to take, if they weren't back in what time they had to be back we were ringing or texting 'what's going on'...We'd certain car parks to go to. Um, we weren't allowed too far out of the four avenues because that was just too far. Um, yeah, we'd watch out for each other. (Justice, Christchurch)

Working closely with others also fostered an atmosphere in which safer working practices were encouraged amongst sex workers of all ages. As noted in chapter five, working heavily under the influence of drugs or alcohol was constructed as a risky work practice on the street. Peer support was considered important to ensure that excessive use of alcohol or drugs was discouraged. One key informant noted:

If you don't have a boss you might feel more able to work when you've been drinking or you might feel more able to work when you've been taking drugs when you shouldn't...If you're working in a situation with a peer group they might say 'oh you're out of it go home'. And so for street based sex workers that peer support is really important to make sure you're not out there when you shouldn't be. But if you don't have it that could be a vulnerability. (Key informant, NZPC)

It was clear that working on the street after excessive drug or alcohol use was strongly discouraged amongst the women. Licious described telling others in this situation "Man you should go home bro, look at you you're wasted". There was a definite culture of support between sex workers on the street that is reflected in the way in which these women described relationships with their co-workers. However, these relationships were also complex and amongst the ethos of peer support there was an undercurrent that was characterised by conflict and jealousy between women.

\section{Providing 'back up'? Challenges and contradictions}

All of the women interviewed described a strong ethos of support on the street to protect against violence from 'outsiders' such as potential clients and passersby. In Claire's words, "the back up's pretty good”. Whilst Shannon did not have any close friends on the street, she noted "if I seen any of them being hassled I'd be right there”. As long as good working relationships were maintained, the street was considered a relatively supportive environment. Kay explained: "If you're nice to 
them [other street workers], you know not rude and that then no matter what they're with you. You know they'll step in". Similarly, Sydney noted: "If you hear or see a girl being harassed by a guy on the corner you'll go up there and say, you know, 'what's happening?' and 'Fuck off she obviously doesn't want you here so move along”. A few key informants also highlighted the importance of "backing each other up" and peer support whilst working on the street. One key informant stated:

I think that the relationship between sex workers is really important. I think, you know, depending if they have peer support or not. I think working in an unsupportive environment without peer support would be a risk. I think, you know, the relationship of backing each other up. (Key informant, NZPC)

Sapphire described an experience with a violent client who had forced himself on her, highlighting the value of peer support and camaraderie between sex workers on the street. She explained:

I'm sure if he had more time and it wasn't such an open area he probably would have tried to get my pants off and stuff. But I says to him "what are you doing, get the fuck off me". And he goes "but I'm nearly finished". And I says "get the fuck off me". And he goes "nah I'm nearly there". And I says "get the fuck off me right fucking now". And I yelled it that time and one of the other girls called out "Oi are you alright?". And he jumped up and ran off. (Sapphire, Christchurch)

All of the women said that they would intervene if they became aware that another sex worker was in danger. However, a supportive peer environment was also reliant on the maintenance of positive working relationships between the women. It was apparent that the competitive environment resulted in jealousy and conflict between some sex workers. This appeared to be particularly the case for those who were new to the street. Cindy explained:

The girls are only just starting to warm to me now... I got bullied quite a lot when I first came on...just trying to intimidate me, basically to get me to leave... The girls are warming to me now they just know I'm genuine and, you know, I'm just out there to have fun and earn a living...I had one girl stick up for me the whole time, you know told them 'hey' you know 'leave her alone she's alright'...I stood on any corner and I was told to get off and I'm like 'no you go off', you know? (laughs)...I did stand my ground and I think that's why I got a lot of shit. (Cindy, Christchurch)

Conflict between sex workers in New Zealand was also highlighted in research conducted by Abel (2010) in which it was found that jealousy and profit making 
sometimes resulted in violence between sex workers. In line with these findings, hostility towards newer workers appeared to be linked to competition, jealousy, and a perception that some of these women represented a threat to the income of others. Lexi explained, "I've seen it out there recently with a pretty girl doing well and that and she's just got shoved right off the street and they've given her shit". In some cases, competition and jealousy resulted in some women standing over those who were new. Jane explained:

The new school girls get told to move on and stuff...we get pissed off at them because we've been out there for so long and some newbie comes along and she's taking all our clients...If we can see a new school making heaps of money we are going to go take new school's money. (Jane, Christchurch)

Other sex workers had a more pragmatic approach to this and very few of the women said they would respond with violence towards newer sex workers on the street. Bianca had worked on the street for several years and described how she would manage these situations to support other women who felt threatened. She explained:

Some girls try and compete against one another. Some of them go 'oh what's she doing on the corner?' And they expect me to go over there and tell them to go but I won't. I'll go 'nah well hello they're doing the same job as us'. Sometimes there's a bit of jealousy going on...like the medium age ones get jealous of the young ones or the ones that are new and have just come out here. They get out on the corner and get all the clients because they're the new face, you know? But I just tell them, you know, "good things come to those who wait”... You've just got to persevere. (Bianca, Wellington)

Arguably, an overly competitive atmosphere where some women are socially excluded could increase risk for some sex workers. Shania noted, "I think [pause] well it would be safer if girls weren't so bitchy to each other, you know? Like 'you took my client - oh he's mine'. Like that kind of shit". Conflicts between the women related not only to competition for clients but also to a desire to control and own areas of the public space in which to work. All of the women had experienced arguments when they had either inadvertently or intentionally stood on a particular corner. Licious explained:

You know who stands where so if you're going to go there and stand on their corner expect them to say to you "hey what are you up to approaching my shit". You know, you can't go doing that... Some of the men that drive around they drive around certain corners because they know what girls they want. And if a new girl's standing there and then that girl gets the client then the other girl's thinking 'Oh yeah? You come back here and I'll take your 
money'. (Licious, Christchurch)

However, a few of the women had a more relaxed attitude about others working next to them. Sapphire noted:

There can be two girls working on the same corner; it doesn't matter. And I don't mind. I have another girl that comes and stands with me every now and then and works and it's not an issue to me. So I don't see why it would be an issue to them. (Sapphire, Christchurch)

The possible exclusion of those who were newer to the street highlights a potential for increased vulnerability amongst this group since they may miss out on this peer support and information sharing at a time when they arguably most need this in place. It appeared that those who were new firstly needed to learn how to negotiate the street environment, which could undermine the development of other risk management strategies. However, a few of the women described strategies to manage conflict and violence between sex workers on the street. One woman, Sapphire, described how she had managed this type of violence whilst working on the street:

One girl that I had problems with I just pretty much told her to fuck off and that was the end of it because I stood up for myself. I said "fuck off; I'm not going anywhere. Don't you fucking tell me what to do". And just stood there and eyeballed them so they eventually left. They walked around for a couple of minutes around me making out that they were not losing face, you know, because I hadn't moved. And then they walked off and then came back and tried talking to me again about half an hour later acting all friendly like "oh Sapphire what have you done tonight, are you doing much work?" (Sapphire, Christchurch)

Amongst the women it was apparent that one strategy to manage this sort of violence was to stand strong against attempts to intimidate, harass, and control them. However this strategy was not effective in all situations. Catherine, a younger sex worker, explained how for her letting the incident go was best:

I remember feeling very upset and I guess afraid at the time...Down by the bridge I had one incident where a girl took my bag off me, like just ripped it off my shoulder and went around the corner and took half the money that was in my bag...I didn't really go back to that corner after that because it's just not worth the hassle, it's just a fucking corner. And while I feel that, you know, they don't have a right to charge rent on any corner because it's not theirs, um, ideals are all very well. But then there is the reality, right? (Catherine, Christchurch)

For a few women it was clear that managing this sort of violence was problematic, particularly for younger women and those with fewer supports. Key informants also 
expressed concern about the difficulties addressing this sort of violence between sex workers. One police key informant noted:

There is always intimidation between some girls. Some girls are in the wrong corner. Some girls look too nice to be a street girl. Some girls don't use drugs, therefore, how can you trust her? Who's she working for? Yeah you're always going to have those issues...It's a wee bit of a hit and miss approach because when you do find that individual who is intimidating the other girls, no one's going to court. What are you going to do? (Key informant, Police)

Managing violence from other sex workers was largely limited to careful negotiation of the street environment and, in some cases, a capacity to respond to intimidation verbally and physically. This presents difficulties for younger and less experienced sex workers who may have limited knowledge of the street scene. A few women suggested that to minimise the possibility of conflict, it was important that those who were new workers approached others for information on common work practices. Shania explained:

Let people know that you're new and also that you're nervous and find out the right prices and stuff. You don't want to go out there and start undercutting everybody because you're going to get your head kicked in. (Shania, Christchurch)

Relationships between these women were, therefore, complex and contradictory and could both support and threaten the safety and wellbeing of individual women. It is perhaps as a result of the complexities managing the street environment and the broad range of risks that some women worked with a minder on the street. However, this too was complex and this chapter will now move on to explore some of these issues.

\section{The role of minders on the street: supporting safety or supporting exploitation?}

The presence of minders or 'pimps' in the street environment has been well documented (Barry, 1995; Chapkis, 2000; Dalla et al., 2003; Faugier \& Sargeant, 1997; Hoigard \& Finstad, 1992; Nixon et al., 2002; Sanders, 2005; Silbert \& Pines, 1982; Sterk, 2000; Williamson \& Cluse-Tolar, 2002). Some studies found that all street-based sex workers work with a male minder or 'pimp' (Harris et al, 2011; Sterk, 2000). In one study it was noted that, "all streetwalkers ended up working with or for a male partner, whose main role was to protect them from the 'dangers of the street" (Sterk, 2000, p. 47). This contrasts with other studies in which none of the women claimed to have a pimp (Sharpe, 1998). In addition, the role of the minder or pimp is 
disparate. In the USA, for instance, pimps on the street may recruit women to work for them. According to Williamson and Cluse-Tolar, "A pimp is one who controls the actions and lives off the proceeds of one or more women who work on the street" (p. 1074). In this situation, female sex workers may be targeted by the pimp with violence should they, for instance, leave the street before making the required amount of money for the night or attempt to work independently (Williamson \& Cluse-Tolar, 2002). The presence of a 'pimp' may, however, have other meanings - to deter violence from individuals approaching as clients, and in some cases to provide vengeance where there are perceived to be few options for more formal recourse by reporting violence to the police. In some criminalised contexts, the use of minders as a protection strategy may be influenced by the pursuit of sex workers by police and the resulting absence of sufficient mainstream protection (Chapkis, 2000). Furthermore, Sanders (2005) notes:

Whether such an individual exists or not, the most frequently used deterrent is the threat of repercussions from a pimp or boyfriend...In prostitution there is a long history of an informal system of 'street justice' to punish male clients who have broken contracts, which may account for why this deterrent is a popular strategy (p. 81)

Theorising the significance of 'pimps' or 'minders' is complicated by the diversity in roles performed by these individuals in the street context. Some individuals, for instance, may form explicitly exploitative relationships with women working on the street (McLeod, 1982). In other contexts, such as Glasgow in Scotland, 'minders' have been said to represent a form of protection from violence. Barnard (1993) notes:

Another strategy used by the women was to have men acting as minders for them... Where women were using minders they were usually boyfriends or husbands. They would keep watch on women's interactions with clients, keep hold of the money and on occasion follow them into the alleyway as well. (p. 699).

In a study of street-based sex work in Oslo, Hoigard and Finstad found that women had diverse and complex definitions of how the term 'pimp' should be defined. Some women for instance, said they did not have a pimp but described exploitative relationships with partners who may otherwise be defined as 'pimps' (Hoigard \& Finstad, 1992). The role of these individuals is, therefore, problematised by the complex nature of their relationships with women on the street and the ways in which their role is defined by the women with whom they work. These findings suggest that 
'pimps' and 'minders' can be both protectors from and perpetrators of violence against women working on the street.

In this research, out of the 28 women interviewed, only 11 reported working with a male who they described as a 'minder'. All of these women worked in Christchurch, and several of these sex workers had only initially started to work with a minder in response to the murders of women working on the street in 2006 and 2008. Minders were usually male partners of the women, whilst some were family members and a few were casual acquaintances. The role of minders on the street in violence risk management was highly complex. The role of the minder was, in theory, to observe women leaving with clients, whilst recording licence plate information and the time the women left the street. If a woman had not returned within the expected timeframe, then the minder would raise the alarm by contacting the police. However, the actual role performed by minders appeared to vary significantly. The following sections explore some of this complexity.

For some women having a minder was intended to deter clients who could potentially be violent towards them. Kay explained, "I reckon the best thing is to always let your clients know you've got someone watching”. Other women, however, felt they could achieve this by simply implying to potential clients that they were being watched whilst working on the street. Fabricating the presence of a minder on the street as a strategy to deter potential perpetrators of violence has also been highlighted elsewhere (Sanders, 2005). Kay explained that she would tell clients she had a minder so that they would think "oh yeah, better not do anything". She explained that whilst she sometimes did not have someone watching her she would "just lie [and say] 'oh I've got a mate over in the bush watching just to look out for me'...Put it in there nicely" (laughs). Jackie described minders as "sort of a back up security thing". She explained that if she did not feel comfortable she would claim "oh I have to be back on my corner now cause my minder's waiting for me”. Similarly, Sydney explained how she had fooled bad clients who had been rough with her. She noted, "There has been a few times where guys have been a bit rough...and I've just yelled out some random name... like 'Bob, Fred, help!'”, Minders were at least in theory used as a strategy to deter violence from potential clients. However a few women described using a minder more to deter violence from other sex workers and their minders, rather than those approaching as clients. Justice explained why she always went out to 
work with her minder without exception.

Lynzi: So would you ever go out without them?

Justice: Nah.

Lynzi: Always with them?

Justice: I always went out with minders; I never went out alone. It wasn't just the clients it was other girls.

Lynzi: Oh, Ok.

Justice: Other girls with minders that thought "oh fuck they're doing better than me. How about I just piss around and watch them go on and off on and off on and off jobs and then just go and roll them"

It was evident that some minders could be protectors against violence on the street, whilst also being potential perpetrators working in partnership with other sex workers. The dual role of minders as protectors and potential perpetrators of violence has been acknowledged in earlier research (Hoigard \& Finstad, 1992; Nixon et al., 2002). The 'bodyguard' role of the minder or 'pimp' is questionable according to Hoigard and Finstad who note:

The guard role isn't particularly important either. The most important security precautions are taken before the trick is turned. The women screen their customers in advance on the basis of the customers' eyes, their body language and what they say. They also screen on the basis of information from other women. Once she is gone with a customer, there is not much the pimp can do. Violence happens quickly. (p. 165)

In this research, the role of the minder was far from clear-cut and it appeared that there was considerable variation within this. This complexity was evident in both sex worker and key informant interviews. This complex and varied role is reflected in the account below from one police key informant:

Oh well it's a safety thing isn't it...I do ask if someone's looking after them. I mean the thing is to be honest it's probably a waste of time most of them...But I think it's better often than on their own. And if things happen, I mean someone else can call the police if they get dragged off or anything. Like just recently a girl was attacked, no minder...Maybe if she'd had a minder they could have been on the phone straightaway. Yeah so I mean in my view I think it's a positive thing really. But obviously there's some pretty violent minders out there. There's minders that stand over. You know, you hear so many stories...A client picks them up and then they take them to the stop and then the minder corrals them...So some of the minders...they're just on drugs 
and they take all their money. So you know there's minders and there's 'minders' there. (Key informant, Police)

The perception that 'minding' could have vastly different meanings was expressed by almost all of the interviews. From the accounts of both key informants and sex workers, it was apparent that some 'minders' had little concern for the safety of sex workers, despite initially appearing on the street in the aftermath of a murder. One key informant explained:

They're a relatively newcomer to our streets. After we had our first murder they started appearing. People wanted safety - somebody looking out for them, especially when that person wasn't arrested for two weeks. And I have mixed reservations...In an ideal society on our streets I would like to see no need for minders. I'd like to see people being able to do whatever it is they do and keep their own money. Some of those people on the streets don't look very nice at all and some of them - there's a fine line between a minder and a pimp. And some of them are definitely pimps. And so we don't really have such a problem with minders if that's what the worker wants. But somebody out there taking a large amount of her money - I have a definite problem about that. And using her to make their drug money. (Key informant, NZPC)

Sex workers who did not work with minders raised similar issues. Several of these women were sceptical about efficacy of minders as a safety strategy. Amy explained:

I could have had a minder, but then I look at the minders and they don't do anything, they don't know where their missus's are. They're always like 'have you seen my missus? How long do you think she's been?' (sighs)...I mean, what the fuck are they doing? Fucking useless. I'd be gutted. (Amy, Christchurch)

Sydney shared this view. She described the minders currently on the street as 'absolutely pathetic'. Providing an example to support her low opinion of minders, Sydney noted, "One girl, her boyfriend was minding her, but when she got raped in the morning he was at the pub around the corner". Furthermore, Shania noted, "I look around and they're not there, they're never there, they're off!"

The perception that minders were often absent when women were working may indeed reflect the reality that some of these individuals did very little to support women's safety. However it is also possible that, whilst not being particularly visible, some minders were in fact still present. Whilst accompanying the Salvation Army outreach van, it was somewhat bizarre but not entirely unusual to observe men creeping out of bushes to get a hot drink. One minder was observed sitting on the roof of a building. This covertness perhaps in part relates to the possibility that some 
clients would feel intimidated by the presence of a minder, perhaps having been followed and stood over in the past. However, a few of the women were also concerned that some minders were on the street coercing women to work in order to support their own drug habit. Shannon explained:

I refuse to pay a minder. It's hard enough trying to make an earn out there let alone having to give a minder half of it...half of the minders are boyfriends and they have habits so it's the only reason they're out there and as soon as the girl gets back to the corner you see it. The boyfriends right on top of it, for the money so they can go and score drugs. (Shannon, Christchurch)

It was clear that in some situations minding did amount to blatant exploitation, whilst other situations were supportive relationships. Justice, for instance, had been 'minded' by members of a street gang when she was a young person. She then went out to work as an adult and had members of her family act as minders. She articulated the vast differences between these experiences. Although she referred to both groups as 'minders', it was clear that the first experience was highly exploitative due to the explicit coercion that was involved. She noted that her family members who minded here were not "going to stand out there and take my money after I've worked so hard". She explained, "At the end of the day if I said "no (I'm not going to work tonight)' then they're not going to go, 'that's not happening' and give me the bash for it. It's just going to be 'alright then,',

Exploitative minding relationships, however, did not exclusively involve male partners of sex workers or gang members. Whilst undertaking the fieldwork in Christchurch, two women were present on the street who self-identified as minders. However, none of the women interviewed accepted them as such, and there was a perception that these women formed exploitative relationships with younger and more vulnerable women in order to profit from their sex work. A few of the women interviewed had also been targeted, though demonstrated little tolerance for this behaviour. Shania explained:

Lynzi: When they've tried to get money what do they do?

Shania: Well she just fucking said, you know, that it's her street (laughs) and um every cunt pays her or else you're fucking out and you'll never be back on there again and so this is how much I had to give.

Lynzi: And what did you say?

Shania: Fuck off - no way mate. 
Lynzi: And how did she react?

Shania: Well she was going to smash me, but if you stand up to her she'll back down but if you freak she'll go hard...Yeah if you stand up and you tell her "fuck - no way" then, um, she won't.

The majority of women reported managing the risk of being robbed by these 'minders' by hiding their money in different locations. Shannon noted:

No it's never happened and it never would happen because they would never get a chance because my money's always kept in here (gestures). And if they take my bag off all they get is make up - that's it. And condoms. Good luck to them. (Shannon, Christchurch)

Minders (and individuals masquerading as minders), who aimed to profit from the sex work of others via coercion and violence, risk being charged under the PRA. An important provision of the PRA is that it is an offence to induce or compel an individual to provide or to continue to provide sexual services (Abel et al., 2010). Whilst it is not against the law to gain from the sex work of others, it is an offence to force people to work in the sex industry for personal profit. This therefore legislates against this sort of behaviour, providing rights for sex workers to resist this type of violence. One woman suggested that the law change had helped empower sex workers in the management of this type of risk. Claire explained:

Um back then it was more rougher as well. I mean everyone for themselves. I mean because it wasn't allowed you could go along and beat someone up and get away with because you can't go and tell the cops...Now you can go out there and stand your ground, you know, without someone telling you 'this is my corner and you have to work for me'. (Claire, Christchurch)

However, although Claire said that she felt more empowered to manage this type of risk, key informants suggested that it was difficult to tackle this sort of violence when some victims were reluctant to report these incidents. One key informant explained:

It's very, very difficult...You know, we might be out on the street and come across somebody who tells us about a particular person who said that she's not allowed to go on the street anymore because she's just going to get beaten up if she does. And, you know, her money was taken from her last night by this person...it's all very well [saying] "look you should go to the police." But they're scared of that person and they don't want to do that because they think there's going to be repercussions. (Key informant, NZPC) 
It was clear that challenging individuals, such as minders and others who attempt to control individual women or the entire street, was fraught with challenges. There was a definite risk of repercussions for some women, should they report this violence, particularly if in intimate relationships with the perpetrator. This highlights some remaining challenges in the aftermath of decriminalisation. Whilst the law change can empower sex workers in their management of risk, it cannot determine who will choose to associate themselves with the street sex work scene. The long legacy of criminalisation, which pushed street-based sex workers into the shadows, arguably created a dynamic on the street that allowed exploitation to flourish unchallenged. Whilst the law change has provided important rights to sex workers, it cannot be expected to change this dynamic overnight.

The complexity of the role of minders on the street means that it is impossible to provide solid conclusions on the extent to which this supports violence risk management. It may then be useful to consider minders on a spectrum with some existing to support the safety of women, whilst others are merely using the label 'minder' as a veil to disguise the exploitative relationships they have with women. However, this is not clear-cut and in some situations the minding relationship may be characterised by elements of support and elements of exploitation. Complexities were also observed in the changing relationship between the police and sex workers. These issues will now be explored.

\section{The role of the police in a decriminalised context}

The decriminalisation of street-based sex work arguably provides an opportunity for a shift in the relationship between police and street-based sex workers. Due to their visibility and social status, street-based sex workers are typically the most criminalised group of sex workers (Jeffrey \& Sullivan, 2009; Phoenix, 2006; Scoular \& O’Neill, 2010). In criminalised contexts, police may be tasked with moving sex workers and their clients out of the public space. According to Brooks-Gordon (2006):

Street-prostitution is usually policed solely to remove sex workers and their clients from public areas. These control policies increase sex workers' vulnerability by increasing levels of client anger and public hatred towards them, and by decreasing their ability to manage their own risks. (p. 209) 
As a consequence, in such contexts protection from he police may be considered "the luck of the draw" (Williamson \& Folaron, 2003, p. 279). Research carried out to evaluate the impacts of the PRA highlights positive change in how street-based sex workers perceived the police since the law change. Street-based sex workers were more likely to report that most police cared for their safety, compared with private and managed indoor workers, and they were significantly more likely than managed indoor workers to report that the police attitude towards them had improved since the law change (Abel, 2010). In agreement with this, the findings of this research suggest that since decriminalisation there has been a positive change in the relationship between the police and sex workers. However, the findings also suggest that some challenges remain. This section explores some of these remaining challenges but first considers the way in which the role of the police had shifted since the law change.

\section{From law enforcement to protection}

The extent to which the move towards decriminalisation had facilitated a changing relationship between police and sex workers was evident in the accounts of sex workers who had worked on the street before the law change. Shania, for instance, explained that although the relationship between police and sex workers could improve further, the police role had changed significantly for the better. She explained:

Some would just be pricks and take you in and I think the worst thing I found was that you'd get taken in and then you'd have to go to court in the morning in your working gear and you'd been up all night and, you know, you're crook or whatever. And as soon as you go out there everybody knows what you're doing, you know? And it was...just like degrading... Whereas now I think we're definitely treated better. There's definitely room for improvement but um definitely a lot treated a lot better now and not so stigmatised and not so, um, looked down upon now with them. Yeah. (Shania, Christchurch)

Most frequently referred to was the value in removing the risk of arrest for soliciting, which meant that sex workers felt more able to approach the police if they were offended against whilst working on the street. One key informant noted:

Truly you were not going to ring the police and expect equal treatment. You have that expectation prior to the law change. You knew that you were breaking the law, they would see you in that way. And that they might come and do a round up on you...That's a big change. (Key informant, NZPC) 
The women were in agreement with this, and felt that the role of the police had changed so that they were now more likely to look out for the safety of sex workers. Bianca explained:

I didn't used to call the police I would just call my friend...I think because it was the law then, you would get caught for it [working]. But now that it's changed and it's decriminalised and it's good because the police are watching out for the safety of us which is quite good. (Bianca, Wellington)

Jackie felt that the law change had facilitated a changed attitude amongst police towards street-based sex workers. She noted, "I think, um, the police have changed their attitude finally since it's legal. They're actually quite good. Yeah compared to five years ago it's totally different". Similarly, Lisa-Lou stated:

They are actually more caring for you now. Like asking 'are you alright' and stuff like that. You know back then, that's when they looked at you like you were a piece of shit, you know? But now I think that they just more fear for your safety. (Lisa Lou, Wellington)

It was clear that the law change had gone some way in removing some of the difficulties the women had engaging with the police before the law reform. Shania noted:

It builds a relationship I think with the police um in the fact that I feel confident enough now to go to them if need be, if anything you know went down whereas before you wouldn't. You would not because chances are you're going to be arrested...So I guess it's closed a bridge there...Sort of made each other approachable. (Shania, Christchurch)

Shania explained that before the law change she had been reluctant to report an attack she had experienced which was perpetrated by someone who had approached as a client, explaining:

I had a fear of what was going to happen to me...And I guess that's taken that stigma away with it being legal and stuff. If it happened now I would report it. I would definitely do that now but back then it was more out of fear of what they were going to me. What the police were going to do. What was going to happen to me and how I was going to be exposed. (Shania, Christchurch)

Shannon also experienced an attack before the law change and had received an unsatisfactory response from the police when she reported it. She explained that she felt this response would be different now that the law had changed:

Well, you know, I said to the police 'I want to take this further'. But then they turned around and says to me 'well because of what you are' - because I am a 
prostitute and if they did get him it would be very hard to prove in court that he did that, you know...So I just turned around and said 'well fuck the lot of yous' and just walked out. I thought they were there to help.... Well I think that was shit but now that the law's changed it's different... Yeah like if it had been decriminalised back then well it would have been different. (Shannon, Christchurch)

Sullivan (2004) has argued that the provision of legal rights for sex workers serves to increase recognition of the consensual capacity of those who sell sex, thus subsequently ensuring that non-consensual activity is more readily recognised and responded to in the criminal justice system. The responses above suggest that the change in law gave these women increased confidence that sexual violence would be more appropriately responded to in the decriminalised context. Furthermore, these responses suggest that the law change has had a positive impact in removing the threat of arrest, and thus better-supports sex worker safety by making the police more approachable. However, despite this the new role of the police in supporting the safety of street-based sex workers is still tenuous. Whilst it is clear there have been some benefits, it is also clear that there are some tensions in this new role. This chapter will now move on to explore some of these challenges, starting with an exploration of how sex workers and police perceived the police role since the passing of the PRA.

\section{The role of the police post-decriminalisation: police perceptions}

In order to better understand the nature of the police role since the law change it is useful to consider the ways in which the police and sex workers perceive this role. One police key informant described the role as related to 'trust' and 'responsibility' in addition to information sharing:

The positives around it for us is that there's a lot more information sharing. Um also the trust and the responsibility that falls on us with the prostitutes has been great - that's a criteria that we now live with. (Key informant, Police)

Overall it was clear that the police key informants interviewed now considered their role in the street sex industry to relate more to violence prevention and support. One key informant felt it would be beneficial to have a more focused role dedicated to supporting sex worker safety on the streets, explaining:

I mean we could be out there all the time. Like you know this was more core role and there was a team of people you know looking at them and looking at 
the violence. You know we could make a huge difference if that was our core role job. You know we could make that, we could just be working on it all the time but you know because we fill in a few roles, it's not our only role. If we had a team of people it would be fantastic so things like that would help. (Key informant, Police)

It was clear that the law change had, to some extent, altered the relationship between police and sex workers. Another factor that has clearly influenced this, however, is the three murder investigations that had taken place in Christchurch since 2005. It was clear that these investigations had acted as a catalyst in prompting the police towards more meaningful and positive engagement with sex workers. One police key informant noted that during the first murder investigation, "We then recognised that we actually needed to have a closer liaison with them and help them out a bit more because they were helping us. So it sort of just built up from there”. Thus, in Christchurch, the changing relationship between police and sex workers cannot be entirely attributed to the change in law since it was clear that the first murder investigation had also influenced this to some extent. However, had sex work not been decriminalised at this time, any attempts by the police to engage with sex workers on this level would have been seriously inhibited. The impact of zero tolerance policing of sex workers in criminalised contexts has been highlighted elsewhere; it has been suggested that such strategies prevent potential witnesses from coming forward (Brooks-Gordon, 2006). Thus, the law reform has clearly provided an environment in which more supportive relationships between police and sex workers on the street are possible. The dual influence of these factors was also apparent in interviews with sex workers in Christchurch who discussed their perceptions of the changing police role in practice.

\section{The role of the police: sex workers' perceptions}

All of the women interviewed observed a change in the role of the police in recent years. In Christchurch it appeared that police engagement with sex workers during a murder investigation had, in some respects, facilitated a more positive relationship, although there were some remaining challenges. Abel's (2010) $\mathrm{PhD}$ research found that street-based sex workers in Christchurch were more positive about the police than those based in Auckland and Wellington. This, perhaps, reflects efforts to engage with sex workers more positively in the context of the murders that have occurred in Christchurch. One key informant explained: 
I think that the rapport the police have with the girls is pretty good. You know I wouldn't say it would be great because there's generations of that stuff too but I think it's not too bad. And it was interesting going out just after Mel [was murdered]. A couple of girls who really, really didn't like the police said they're being amazing...yeah there was some sense that they were being treated okay, yep. (Key informant, Social Service)

Similarly, Shania explained:

I guess the Mellory thing has made the relationship a bit better with the working girls and the police. Like they talk to you, they look out for you... They just will [ask], you know, "are you ok? How's it been going?" You know ask "have you seen anything shady?"... That has made the relationship, um I don't know if you'd say better but getting towards working together. (Shania, Christchurch)

A few sex workers differentiated between police who had engaged with them in the course of the murder investigations and those who had not. Hollie explained that she preferred engaging with the detectives:

The detectives are different - to me they're a whole different situation, you know? Like there's the traffic and the patrol cops but the detectives are completely different. But I still don't trust them. I mean a cop's a cop. But yeah they try and talk to me and make sure I'm alright and I'm just like "yeah just leave me alone, I'm fine". (Hollie, Christchurch)

In general, the women suggested that the police now played a key role in the dissemination of information on violence in the local area that could impact on sex workers. Pania explained:

[I find out] through other workers and through the police... The Police quite often come out and let us know that they won't give us the name of the girl that's gone in to make the complaint but they've come out to let us know about it. Yeah. (Pania, Christchurch)

Similarly, Sapphire explained:

Yeah they come and check up on us... If there's something happening and they're looking for a certain person or they've had an incident happen with another girl or something they will come down and ask you if you've seen this person or if you've had any problems or anything like that. Um generally they're pretty good. They don't full on harass you. (Sapphire, Christchurch)

In Wellington, women also reported that the police warned them about incidents of violence in the local area. Lisa-Lou explained: 
...Some of them come past and they ask if we're alright and stuff like that and we go "yeah"...I think that they know that we're in danger as well. Because I remember one time this girl, she got dragged around the corner and she got raped. This was just where we were working. So a bunch of them came down and just said to us "Be aware because there's this fella walking around", and they gave us a photo. "Um just be aware because this fella's walking around and he's raping girls". So you know, that's really nice from that kind of perspective. (Lisa-Lou, Wellington)

The overwhelming majority of the women felt that the police role had changed since decriminalisation. In Christchurch, this changed role also related to the effort police had made to engage with sex workers during a murder investigation. However, it was clear that there were some remaining challenges. These challenges will now be explored to consider some of the difficulties with this changing relationship and to explore some of the complexities in addressing these issues.

\section{Managing disputes: the role of the police}

An interesting change since the PRA is that sex workers can now contact the police in disputes with clients over payment, which would have been problematic before decriminalisation. Jackie noted, "Now that it's legal we sort of have the right to do that. When it was illegal it would have been difficult". Sex workers on the street do have the right since the law change to contact the police for assistance in disputes with clients. However the experiences of some of these women who had involved the police in such situations, suggest some remaining challenges in ensuring sex workers are supported appropriately in these situations. Amy described a situation she had with a client:

I've had a few weird incidents where I thought I was right and I was wrong. Well the last client I had a fight with - he wouldn't pay me. I went to this house and when I went to leave his house he'd stolen the money off the table so I fought with him all the way to town. And when I got to town I was fucking angry and I was throwing stuff out of the car so I was trying to get him to just freak out and give me my money. And the policeman that turned up - I said, "it was a $\$ 100$ job" and the guy goes "no it was only sixty". Well the police believed him and told him just to give me \$60. Well they should never have done that. And the cop with me was going "oh you should be just happy you got some money out of him" ... I ended up doing everything four times and he complained about it and I end up with $\$ 60$ because a policeman says so...And they wonder why the clients are doing shit, [it's] because they're getting away with it - the coppers are on their side. (Amy, Christchurch)

This experience suggests some positive change in that Amy was empowered to 
challenge the client in front of the police, which would have been highly problematic before the PRA was passed. However, this situation also raises questions about the attitudes of some police towards sex workers. The inference that Amy should be satisfied to have received "some money out of him" implies that she is not entitled to a set payment, perhaps because it is assumed that street sex work is not real work. This experience also highlights a continued power imbalance between sex workers and clients. It is significant that the officer made the decision to side with the figure suggested by the client, as opposed to Amy. Such situations may not be easily resolved since it is essentially one individual's word against another. However, the officer could have agreed to a middle ground between the figures suggested by both parties. Whether or not intentional, in siding with the client, the officer reinforced to Amy that the police could not entirely be relied on.

Another woman, Vixen, described a similar situation in which she had contacted the police to remove a problematic client from her home. She explained:

One not so long ago actually - I had to ring the police to get rid of the guy off my premises. I was with him for an hour and a half and he was on $P$ and drunk and couldn't 'come'. And he started getting a bit rough because I said "look we're going to finish the job soon so you're going to have to 'come".' And he couldn't 'come'. So I finished the job and he wanted half his money back. And because he wouldn't leave the premises I had to ring the police, you know? And that was in my house... The police had to take him away. But the woman police, when I explained the situation the woman police wanted me to give him half his money back. (Vixen, Christchurch)

These experiences reinforce the importance of the rights provided under the PRA that mean sex workers can now involve the police in disputes without risking being arrested themselves. On the one hand, these experiences represent positive examples in that they demonstrate that some sex workers on the street genuinely feel that they can contact the police now in these situations. However, the outcomes of these women doing so are troubling and suggest a need to educate police on business practices relating to sex work. Given the lack of understanding about street sex work at a societal level, it is perhaps not surprising that the officers responded in this way. Some education about the realities of sex work, and those involved in it, would better equip officers to respond with fairness when assisting in disputes between sex workers and clients. There were several other challenges with regards to police engagement with sex workers on the street. One of these challenges relates to the 
tension between police supporting sex worker safety and the financial priorities of sex workers.

\section{Supporting sex worker safety: barriers and tensions}

As noted earlier in this chapter, it was clear that some police were making a significant effort to positively engage with sex workers on the street since the law change, and particularly during the murder investigation in Christchurch. The increased police presence on the street since the PRA has passed was documented in research reviewing the impacts of the PRA (Abel, 2010). In general, street workers were said to find this increased contact unproblematic. Abel notes:

The majority of street-based workers said that the police were just 'cruising' or passing by to check on things. This increased contact was talked about by many street-based workers in the qualitative interviews and the majority talked of more toleration shown by the police since law reform. (Abel, 2010: 238)

In Christchurch, however, women were concerned about the potential impact of the frequency and nature of this contact on their financial success. As the fieldwork for this research was carried out during an ongoing murder investigation, there was a particularly strong police presence on the street at that time. It was clear that in this context, the women sometimes found the extent of the police presence overbearing. This point was repeated several times by several women who appeared frustrated at the police presence on the street. Shania noted, 'It's so bloody dead out there and there's not a hell of a lot of traffic. And with the Police presence you know it's scaring off jobs and things like that'. Similarly, Jane explained:

Now they're out here more often that we need them to be. When we need them they're not here, when we don't need them they're here scaring off the clients. We see more cop cars going past us than clients and that scares the clients. (Jane, Christchurch)

These concerns related specifically to a perception that an overt police presence could result in a loss of income since some clients may be reluctant to approach sex workers in view of the police. Zoe explained:

They come up to you and annoy us because they ask us all these questions and drive my clients away. But I mean I guess in a way it's good because they are down monitoring that street because that street has been monitored since the end of last year when Mel left us and stuff. Since then they've monitored that street so badly like oh my god every single car you look at - it's a pig. And it 
drives clients away, which drives work away, drives money away. (Zoe, Christchurch)

However, Pania suggested that the police could be understanding of this:

I mean the cops are coming round every half and hour or so now... We see more of them than we see clients which is quite freaky because clients freak out...I mean they come round heaps but like they all know what I'm doing. And, you know, they see me and they'll just blabber or something. And I'm like' well can you go away now. You're going to stop a client from coming'. And they're all good about it. (Pania, Christchurch)

The fact that Pania could request police leave because they may 'stop a client from coming' is significant in that it suggests a shift in power between police and sex workers since the decriminalisation of street-based sex work. Making this request would have essentially been impossible before the law had changed, since Pania would have risked being arrested for soliciting. The concerns of these women about the potential impact of the police presence suggest a tension between supporting sex worker safety and monitoring ongoing safety concerns, whilst not negatively impacting on the business of sex workers. Importantly, these responses demonstrate a more equal power relationship in which sex workers can express concerns about these issues without risking arrest themselves. The law change can therefore be seen to have enabled more positive dialogue between police and sex workers. However, other issues were raised that represent challenges to relationship building between police and sex workers since the law change. These issues will now be explored.

\section{Additional challenges}

Whilst it was clear that some police had been making a significant effort to change the relationship with sex workers on the street, there were still barriers to achieving this. One existing challenge related to the difficulties engaging with women who had previous involvement in criminal offending and contact with police in this context. For a few women, negative perceptions of the police related not only to sex work and the stigma attached to it, but to wider life experiences that had shaped these perceptions. For instance Lexi explained, "I don't have a really good rapport with the police...Because I have been in trouble with the law before they don't give a fuck". Laura explained that she didn't trust the police as a consequence of her previous experiences, stating: 
I don't like them. They just don't like girls that are on the street...I don't have a very high opinion of the police. I've had some bad experiences with them too... I try to keep away from them...I hate getting pulled up by them. Even if I'm walking I just don't like the feeling it gives you. It makes you feel like you've actually done something wrong, you know, even when you haven't done anything wrong. I really hate it. (Laura, Christchurch)

Since the sex industry does not exist in social and legal isolation, there were broader issues that need to be considered with regards relationship building between police and some sex workers. Amongst those women who did express significant distrust in the police, these perceptions appeared to be influenced by these broader issues of social exclusion and oppression.

Another barrier is that some police continue to exploit their position of power over sex workers. This did not appear to reflect the approach of the police overall, but the actions of some individuals within the police. Hollie described an incident in which she claimed a police officer had paid for sex and then blackmailed her by requesting ongoing free services so he would not inform on her friends, explaining "Yeah. Like there's someone who's a cop in Christchurch who paid me and then blackmailed me and said [pause] you know, 'well I'll do over your fucking mates, raid their houses and stuff". A similar incident had occurred in Christchurch months prior to the fieldwork had taken place. The offending officer was subsequently jailed for two years (Steward, 2009). The propensity for some police to abuse their power in this way has been highlighted in contexts where sex work is criminalised and police arguably have increased scope to exploit sex workers (Hubbard, 2004; Nixon et al., 2002). In the USA, for instance, a study found that some sex workers reported being forced to provide sexual services for no payment and being beaten by the police (Silbert \& Pines, 1981). However, in removing the risk of arrest the shift to decriminalisation has at least partially shifted the power balance so that reporting incidents of this nature is a viable option for sex workers.

\section{Agencies supporting sex workers}

Whilst most of the women were, to some extent, sceptical about the role of the police in supporting their safety, it was clear that agencies supporting sex workers were respected by the women to a greater extent as a viable source of support. In terms of services available to support the safety of street-based sex workers, NZPC was 
mentioned on numerous occasions by other key informants and by the women. Deltah noted, "NZPC come out with the pamphlets to be aware of this person and a description of the bad people”. Similarly, Catherine explained:

The PC came round and they said this guy has just been released from jail and he's been done numerous time for assaults on sex workers...I'm pretty sure I saw him in a car and I avoided that job. And then later heard someone say 'oh that guy - he's a fucking rapist' and you know, 'I'd just avoid him'. (Catherine, Christchurch)

NZPC were also valued as peer educators with younger and less experienced sex workers. Claire described how she had learned how to say 'no' and had become more aware of her human rights as a sex worker whilst in contact with NZPC following an incident with a client:

I hadn't noticed until it finished and I was like freaked out and being me I just didn't know what to do. I was sort of ashamed as well. Didn't want to say anything to anyone, couldn't do anything about it. Yeah. It was just against the rules though, on the street, and it was just something you couldn't do [sex without a condom]. But once I got to PC and stuff I was alright. Yeah. They told me if they force it it's against the law...Actually I learned quite a bit there (NZPC)...um saying 'no', you know?...I mean when I started at the PC I never knew you didn't have to do stuff that you didn't want to...Like sometimes I felt real vulnerable. (Claire, Christchurch)

One key informant from NZPC felt it was now easier to engage with sex workers on the street since prostitution had been decriminalised and sex workers no longer had to remain vigilant about being approached whilst working on the street. She explained:

I believe that coming from my personal experience that it might actually be easier to engage now because I just think when I worked I was young and we'd hide because we were scared of getting in trouble, you know, and now it's decriminalised you don't have to hide. So people are willing to say 'hi' and talk to you as opposed to sort of jump the fence and hide behind the building because, you know, the sex police are coming along. (Key informant, NZPC)

Sex worker organisations globally focus their work extensively on harm reduction and commonly projects supporting sex worker run schemes to respond to and prevent violence, known as 'Ugly Mugs' (Kinnell, 2006a; Pitcher, 2006; Sanders, 2001). Ugly Mugs schemes are essentially warning systems whereby sex workers record details of encounters they have had with violent and abusive clients in a book, so that others can be aware and avoid these individuals. They therefore aim to facilitate information sharing about the incidence of violence with large numbers of sex workers. Due to a 
dispute over details that appeared in the Ugly Mugs book at NZPC, however, the scheme was discontinued in response to the threat of legal action. It was clear that amongst many of the women, particularly the older women interviewed, the Ugly Mugs book was a missed resource that had been very helpful to them in their working lives. Bianca explained, "I used to read it a lot though. Mugshots, yeah...they should bring it back in. They should". Similarly, Pania noted, "I thought it was really good. Yeah. I mean it was very informative of all the wankers (laughs)...I think they need to fucking get it back out". All of the women who had worked when the Ugly Mugs scheme operated expressed regret that the scheme was no longer in operation. LisaLou explained:

You know that ugly book? They should have kept that out. They had an ugly book and it was for, you took down the number plates and that, and you weren't allowed to do that anymore and it really helped us ay? Because it helps to track them down, you know, and they should actually get charged for what they've done. (Lisa-Lou, Wellington)

Although the Ugly Mugs book was unavoidably discontinued, in 2006 a youth worker in Christchurch, in consultation with NZPC and Telecom, developed a text messaging service, 'Protext'. The service was developed shortly after a woman had been murdered whilst working on the street in Christchurch. A few of the women particularly valued the Protext service. Justice explained:

I think that's cool. That's a good idea because you know, not all the girls get the same client and I might have this weird out client that's just really freaking me out. What about the poor next girl that he goes and picks up? If she doesn't know then she's going to get in that car and something worse might happen to her than what had happened to me. And how am I going to feel when I hear "oh yeah this girl, something happened to her and it was really bad" you know? [I'd think], well I wish I could have told her somehow...that this is the car and this is the person. So... if that's happened you can just text and it goes around (and) then other people can spread it by mouth... "we just got a text". So then they know, they're safe and they don't get in that car. Then I can hear good things and not hear, you know, "that creep got someone else". (Justice, Christchurch)

Similarly Kay noted:

It's pretty good because you get alerted about who the dodgy men are so you can keep a look out. It's pretty cool. Because you can't always hear it through ear, you know? So you can text it. It's helpful ay - for safety. (Kay, Christchurch) 
Police key informants were also supportive of the Protext service. One key informant from the police described how Protext had directly led to the arrest of an offender:

I get the message straight away and...I can activate certain areas, of control around, um, finding out who these particular people are... One as an example was through the Protext line there was a woman who had been taken through to... actually one of the hotels here in town. (She) remembered the room and number and the first name of the guy...As a result of that we found out who that particular person was and, um, he was locked up because he was a strange man indeed...really at the end of the day it's a safety issue having Protext. (Key informant, Police)

All of the women were supportive of the Protext scheme, however a few women admitted that they did not always have a phone with them when they were working. Catherine explained, "Someone kind of briefly explained it once but I guess at the time I didn't have a phone. It could be something useful'. Similarly, Tessa noted:

Well it's useful if you've got a phone that's working, you know, if you're phone hasn't gone flat because you've been away from home for two days and you didn't remember to take your charger... that thing would work well but um not everyone has phones or they're not always working. (Tessa, Christchurch)

Several key informants also raised this point. One key informant noted, "One would like to think so but the reality is sometimes people go out without a phone or they don't have any money on their phone, or it's got stolen, or they've lent it to somebody else". A few of the women, however, suggested that they could still benefit from the services since other women shared this information with them. Sydney stated, "Oh it's a great idea ay. Yeah. But there's a lot of girls that don't have phones, so yeah so if one girl has a phone they can pass that on".

Other key informants explained that concerns about privacy were additional barriers to sex workers signing up to the Protext service. One key informant explained, "We try and get them to join up. Generally they'll say "no" though because they don't want anything coming on their phone that links them to the industry".

The Protext service was a useful strategy to facilitate widespread safety related information sharing between sex workers and support agencies. Although there were some obvious limitations, overall the Protext service is an important resource in supporting sex workers in their management of violence-related risk. 


\section{Summary}

This chapter has explored collective strategies to manage risks of violence on the street. The findings reveal some inherent tensions and continued challenges in these strategies, in addition to positive changes. Relationships between the women were complex. On the one hand sex workers represent a key source of support. On the other hand, other sex workers were perceived as a threat and competition and jealousy sometimes resulted in violence between sex workers. To manage this, women had to learn to negotiate the street environment. This extra layer of violence is significant as it could serve to increase other risks on the street if women spend time and energy strategising to avoid conflict with other workers.

The importance of successfully negotiating the street environment was partly reflected in the decisions of a few women to work with minders on the street. The functions of minders in supporting the management of violence-related risks were also tenuous. The role of the minder was highly complex and numerous concerns were raised that some minders were only involved to benefit financially from the work of sex workers, whilst not fulfilling their intended role to support the women in their management of risk. There were few examples of minders preventing or addressing violence. A few of the women also suggested that minders were perpetrators themselves, sometimes complicit with other sex workers to carry out violence against other women. The actual efficacy of minders in violence risk management was, therefore, questionable.

The responses suggested that although there had been some significant positive change in police engagement with sex workers in recent years, there were some outstanding issues. The findings revealed some tensions in the relationship between police and sex workers. For instance, whilst sex workers appreciated police concern for their safety during a murder investigation, there were also concerns that the police presence could deter potential clients. Further, it was clear that whilst some police were making a significant effort to build relationships with sex workers, others were continuing to side with clients. The reluctance of some sex workers to engage with police, however, reflects previous experiences with the police and, in some cases, previous involvement in criminal activity. Addressing this is therefore complex when it relates to far broader social and cultural issues. Despite this, it was clear that since the law change there had been some considerable improvements in the relationship 
between police and some sex workers. Whilst there were some existing issues, the decriminalisation of street-based sex work had created an environment in which more productive relationships between police and sex workers were at least possible.

Interviews with sex workers and key informants revealed that support agencies, particularly NZPC, provided valuable support to work collectively with sex workers managing violence-related risks. The peer education work undertaken by NZPC was acknowledged as particularly valuable for those who were younger or less experienced working on the street. In addition, the Protext service developed in Christchurch and managed by NZPC was highlighted as a useful resource to support the information sharing practices of sex workers on risks relating to violence at work. Whilst not all sex workers used the service, overall, Protext was considered to be a useful resource by sex workers and key informants. It was also noted that since the law change engaging with sex workers on the street had become more straightforward since there was no necessity to hide from authorities. The PRA can therefore be considered to have provided an environment more conducive to supporting collective strategies between sex workers and others to manage violence-related risks.

This thesis has explored individual and collective strategies utilised by these streetbased sex workers to manage violence-related risks from potential clients, passersby, other sex workers, and minders on the street. The next chapter discusses the significance of these findings in the context of decriminalisation, exploring what more could change to better support street-based sex workers in their management of risk. 


\section{Chapter Nine: Moving forward: risk management strategies in context}

\section{Introduction}

The purpose of this chapter is to contextualise the findings discussed in this thesis on strategies to manage risks of violence, considering this specifically within the postPRA environment. This chapter brings together themes explored throughout this thesis to consider whether street-based sex workers safety strategies could be better supported in the decriminalised context. This chapter begins with a brief overview of some of the prevailing debates about street-based sex work post-decriminalisation, outlining the problematic nature of the arguments that continue to persist. In this chapter I also explore the lack of focus on perpetrators of violence against sex workers. Furthermore, this chapter considers the alternatives of environmental strategies such as zones, safe houses, and options for creating a safer environment for street sex workers in the decriminalised context. To finish, the continued impact of stigma in supporting violence against street-based sex workers is explored and barriers to challenging this stigma are discussed.

\section{Old arguments, new laws}

The decriminalisation of street-based sex work in New Zealand was a unique change. Based on the principles of harm minimisation, the law change was initiated in the interests of the health, safety, and human rights of sex workers. Whilst the law represents a new approach to sex work policy, old arguments have continued to be repeated by those who oppose the law. For instance, the National Director of the organisation 'Family First' has stated that decriminalisation has been "a community disaster" (McCoskrie, 2011). Others have suggested that street-based sex work in Auckland increased by $400 \%$ following the law change, and have called attention to the violence that sex workers continue to experience in the decriminalised context (Farley, 2008). Thus, some commentators have continued to portray street-based sex work as a morally threatening, dangerous social nuisance in need of eradication. Whilst there is a wealth of evidence contradicting these arguments, it is important to discuss this since these ideas link to broader debates about violence in street-based sex work. It has been argued that the violence sex workers continue to experience suggests that the law change has clearly not worked for street workers and as such 
those on the street should cease working, whilst street work should be re-criminalised as an unsafe and illegal activity (New Zealand Herald, 2009; The Christchurch Press, 2008). This section will explore these arguments in relation to the findings of this thesis.

Common stereotypes of street-based sex workers suggest they are forced to work on the street, which is why they locate themselves in what is considered to be the most risky sector of the industry (Sanders et al., 2009). Women who work on the streets have been portrayed as chaotic and with little control over their work. However, although some street workers may enter the sex industry as a forced choice (Abel et al., 2010; Harding \& Hamilton, 2008), it is clear the decision to work on the street specifically is strongly motivated by a desire to control working hours, to control which clients are accepted, and the ability to keep all of the money from the job (Abel, 2010; Benson \& Matthews, 1995; Brewis \& Linstead, 2002; Pyett \& Warr, 1999). The findings in chapter four of this thesis support this assertion and demonstrate how these women described their decision to work on the street using the concept of control. Thus, it is unlikely that street-based sex work will dwindle in a decriminalised context. Accordingly, Abel (2010) notes that:

...it is extremely unlikely that the street-based sector could be eliminated in a decriminalised environment which makes it easier to work indoors. There are motivations to work on the street and different perceptions of risk that will ensure that the size of this sector is unlikely to change significantly. (p. 244)

The diverse ways in which the women in this research constructed their participation in street-based sex work suggest that it is unrealistic to expect that street work will disappear post-law reform since their decisions to work on the street were often driven by a perception of it being of the most effective means of making money, and at the same time having control over the process. Working from the street provided an opportunity to work independently whilst also being surrounded by others. In this way, it provided the independence of private indoor sex work, and the peer support of managed indoor work. Although it is extremely positive that these women could choose to work indoors without being criminalised, it is equally important that they could continue to work on the street without the risk of arrest. It is particularly important that the disposability discourse that promote the eradication of street work is challenged, since the ideas implicit in these arguments are supportive of violence 
towards street-based sex workers (Lowman, 2000). Indeed, the findings of this thesis highlight the violence that these women continued to experience in the decriminalised context. The experience of violence, however, does not signal that the law change has failed. Accordingly, Abel (2010) states that:

Decriminalisation cannot prevent murder and people working in sex work, in particular street-based workers, continue to constitute a vulnerable population. Other occupational groups such as taxi drivers and security guards are also vulnerable to violence and so vulnerability cannot be argued as a case for criminalisation. Such arguments would be solely based on moral grounds which are transcended by the purposes of the PRA. What decriminalisation has provided for the sex worker population are human rights. (p. 321)

The decriminalisation of street-based sex work cannot be expected to eliminate violence since it is merely an important first step, rather than the ultimate solution to providing a safer environment for sex workers on the street. Violence against sex workers does not occur as a consequence of the sex industry, but because offenders make choices to perpetrate violence towards those engaged in the selling of sexual services. The findings of this thesis highlight how the change in law has, to some extent, simplified the screening process through which the women assessed the risk of violence from those who approached them as potential clients. This process involved taking time to carefully talk to those approaching as clients in order to gauge their mood and demeanour, looking closely at physical features and eye contact. In line with findings on risk management strategies internationally, some women described relying on instinct whilst others had individual rules regarding age, body type and ethnicity of clients, in addition to the type of vehicle driven. (Barnard, 1993; Dalla et al., 2003; Nixon et al., 2002; Sanders, 2004b; Williamson \& Folaron, 2001). The women also described assessing initial power dynamics in their negotiations with potential clients, again in an attempt to screen out individuals who could be problematic. Critically, in the decriminalised context, this process was possible without the risk of entrapment, meaning that the women could question potential clients openly. Further to the screening of the client, the women described screening the car before getting in to check for any weapons, any means of concealing weapons and features of the car that could make exiting difficult if necessary - such as central locking of doors and windows. Many of these strategies have been documented in places where sex work is criminalised (Barnard, 1993; Benson, 1998; Dalla et al., 
2003; Harris et al., 2011; Pyett \& Warr, 1999; Sanders, 2001, 2004a; Williamson \& Folaron, 2001). Significantly, in this study of a decriminalised environment, a few of the women described now feeling freer to conduct their negotiations with clients in open areas, and that they no longer had to spend time hiding from authorities. This suggests that the law change has better supported these women in their management of risk by removing the risk of arrest for soliciting.

A further way in which it appeared the law change has had some impact on the management of risk is in power and control dynamics employed in negotiations with clients. Some sex workers reported referring to the law when enforcing condom use with clients, which suggests that the law change has to some extent shifted the power balance in favour of sex workers. In line with the findings of other studies on violence risk management on the street, the women all preferred to control the location of the job (Barnard, 1993; Dalla, 2002; Miller, 1993; Pyett \& Warr, 1999; Sanders, 2004a, 2005; Williamson \& Folaron, 2001). Furthermore, strategies to retain control during the sexual encounter, specifically: setting sexual boundaries with clients, role-playing and manipulating clients' sexual fantasies were described by the women. This has been explored to a far lesser extent in previous studies with street-based sex workers and these findings illustrate the skill of managing power and control, particularly in potentially problematic situations. Therefore, these findings challenge some existing stereotypes about street-based sex workers and highlight that whilst the law change has not eliminated violence, it has provided a climate in which the women could more effectively strategise against the risk of violence in their work.

These findings support the contention that re-criminalising sex work would negate many of the positive impacts of the PRA (Abel, 2010). Overwhelmingly, all of the women interviewed for this research said that they would not stop working if sex work on the street was re-criminalised. For instance, Tessa, who had started working on the street after the law reform, felt that criminalising clients would be likely to increase violence against sex workers. She explained:

Oh it would have a huge impact. There would be much more trickiness going on. You know, and back to the kind of clients that you get the problems with anyway - you would just have a hell of a lot more and bigger problems with them. With those same individuals - If they made it illegal it would just give more power to those guys to go and take it for nothing...ones that have that little devious streak and think it's their right. The fact that it is legal and you 
can ask money for sex here is a huge protecting factor for women because you have the right to ask for money for it and there's no bullshit about it. (Tessa, Christchurch)

Progressive debates on street-based sex work and violence require a shift away from assumptions that sex workers should relocate from the streets. If the safety and rights of street-based sex workers are to be prioritised, it is important that street-based sex work remains decriminalised in New Zealand. The next sections explore options to support street-based sex workers in their management of violence-related risks in the context of decriminalisation, locating this discussion in the context of the findings of this thesis.

\section{Focusing on perpetrators}

The decriminalisation of sex work provides an opportunity to shift the focus of discussions on street-based sex work and violence away from the responsibility of sex workers to keep themselves safe, to an increased focus on understanding and reacting appropriately to the perpetrators of violence. Chapter two and chapter four of this thesis highlighted the problematic nature of the focus on risks of violence from 'clients', when those who attack sex workers are often not clients since they perpetrate violence rather than paying the agreed fee for a consensual sexual encounter. More nuanced understandings of who is responsible for perpetrating violence against sex workers are critical to ensure that global efforts to address violence focus on actual perpetrators, as opposed to promoting the blanket criminalisation of men who pay for sex. Moreover, it is imperative that these perpetrators are apprehended and brought to justice. In relation to this Barnard (1993) notes that:

Perhaps men who see prostitutes as easy targets would be discouraged from this perception if there were more successful convictions of other men who attack prostitutes. This could be achieved if the police made a concerted attempt firstly, to encourage women to report all such instances by taking them seriously and secondly, adopting a policy of vigorous pursuit of such men. (p. 702)

In this research, a few of the key informants felt that a more overt focus on the perpetrators of violence against sex workers would contribute to creating a safer street-based sector. One key informant from a harm minimisation project for drug users felt there needed to be "harsher penalties for the perpetrator". There was a 
perception that violence against sex workers is still not taken seriously enough, and although the law change had created a platform for change, there was still scope for further improvement. One key informant explained that whilst he felt that the law had improved the capacity to address violence, there was a need for a more robust approach to responding to violence against street-based sex workers, noting:

...the law has its place and I think the fact that the man can now be charged for, you know, forcing a woman to have sex without a condom and those sorts of things - that's got to be at least a plus...I think the book could probably be thrown a bit more. (Key informant, Church)

Another key informant highlighted the need for a concerted effort to respond to all forms of violence against sex workers on the street - including the 'lower level' violence outlined in chapter eight. It was noted that the first step was encouraging street-based sex workers to report these incidents, whilst the next step was ensuring these incidents are taken seriously in the criminal justice system:

If somebody gets charged for biffing something at somebody (and we always tell people to take down anything like that - registration numbers and that) and if somebody's brave enough to actually do it and go through the courts and that gets put into the media. You know, and [people] talk about it. That can make a change too. (Key informant, NZPC)

These responses raise an important issue in that regardless of the legal framework surrounding street-based sex work, if violence against sex workers is not responded to appropriately and perpetrators are not apprehended, it is unlikely to decrease. A more overt focus on the actual perpetrators of violence against sex workers in the decriminalised context would also help challenge the assumption that sex workers are solely responsible for ensuring their own safety, and would rightly locate the responsibility for violence with the perpetrators. However, to ensure this it is critical that sex workers are supported when reporting violence to the police. The findings in chapter eight of this thesis suggest that the change in law has had a considerable impact on how these women perceive the police and the utility of reporting violence. However it has also been found in previous research that there is still a reluctance to report violence amongst some sex workers (Abel, 2010). Furthermore, whilst the findings in chapter eight demonstrate a marked shift in the relationship between police and sex workers, it is clear that some challenges remain. One key challenge relates to the role of the police assisting in disputes between sex workers and clients. It is particularly encouraging that a few of these women recounted a willingness to involve 
the police in disputes with clients, however the experiences of those who did so suggest a lack of knowledge amongst some police with regards to the business practices intrinsic to sex work. This is hardly surprising given the low levels of understanding of sex work on a societal level, and the prevalence of myths regarding sex workers. These are also situations that the police would have seldom been involved in prior to the law reform. To address this challenge, training to familiarise police officers with the practicalities of sex work and the PRA would be beneficial to ensure that all police are equipped to respond appropriately when sex workers report violence. These findings are significant in highlighting the role that the police can play in supporting sex workers on the street, when the illegality of street-based sex work is removed. Further change in this regard would help ensure that more perpetrators of violence against sex workers are brought to justice.

\section{The management of street-based sex work?}

As noted in chapter one and chapter two, throughout history there has been a concerted effort to control and manage street-based sex work. Since the law change, street-based sex work in New Zealand is essentially deregulated and there are few formal controls over the locations in which street-based sex work takes place. The extent to which more regulation could have a positive or negative impact on supporting sex workers' safety strategies is worthy of further consideration. When asked about what more could change to improve safety in the street sector since decriminalisation, a few of the women and key informants suggested environmental strategies. These strategies will now be explored to highlight the challenge of providing safer environments in a decriminalised context.

\section{Zones}

In other research, it has been argued that managed zones can prove useful in providing greater opportunities for sex workers to work safely in non-isolated locations (Barnard, 1993; Van Doorninck \& Campbell, 2006; Morgan Thomas, 2009; O’Neill et al., 2004; Sanders \& Campbell, 2007). However, this generally relates more to legal contexts in which sex workers are criminalised for working on the street and thus the provision of zones is considered at least an improvement on zero tolerance. Indeed, discussion around zoning is often framed by the language of 'tolerance' to argue for areas in which sex workers can be 'tolerated' to work safely in 
the public space. Thus, it is acknowledged that the creation of zones may serve to reinforce the marginalised status of street-based sex workers (Hubbard, 1997). In this research, the possible efficacy of managed zones to support sex worker safety was raised in interviews with a few key informants, but was not suggested by sex workers themselves. The fact that none of the women suggested that specific areas to work in would be helpful to their safety is significant and, perhaps reflects one of the key strategies highlighted in chapter six to control the location of the job; taking clients to locations where they feel safe. It is therefore possible that if zones were created, few sex workers would choose to work in these zones. In research with street workers in Scotland McKeganey (2006) found that although tolerance zones were intended to support safety, some sex workers were reluctant to use them. This was because they were concerned that clients would be reluctant to approach them in crowded areas, that there were safer spaces to work in outside the zone and that working outside the zone increased their chances of being picked up by a client. Furthermore, it has been found that zones are typically proposed in areas that are away from busier public spaces, thus potentially increasing the vulnerability of street-based workers (Quadara, 2008). Thus, advocates from sex worker rights organisations have argued that compulsory zoning would threaten the safety of sex workers on the street (O'Neill et al., 2004). In line with these findings, a few key informants argued that zones would be used to limit sex workers' use of public space and would create unnecessary tensions between sex workers. One key informant explained:

Any changes would probably have negative effects on sex workers because it would be to create zones where street workers could operate from which would have negative effects on sex workers by cramming more of them into a smaller area and that would create friction and increase chances of violence. (Key informant, NZPC)

The possibility that zoning could create tensions between sex workers is supported by data in chapter eight that highlights the complex and at times, volatile relationships between individual women. The creation of specific sex work zones may heighten these tensions between sex workers and subsequently increase the vulnerability of some women. Compulsory zoning of sex workers into specific areas could, therefore, undermine existing safety strategies. 


\section{Safe houses}

Although none of the women suggested that a sex work zone would support their safety and wellbeing in the decriminalised context, a few suggested that the provision of a 'safe house' to work from could be useful in supporting safety on the street. Safe house brothels for street-based sex workers operate in East Sydney in Australia where street sex work is partially decriminalised. These facilities have been found to have a positive impact on the health and safety of street-based sex workers (Jeffrey \& Sullivan, 2009). Licious described a safe house as something that would be useful for her, suggesting that this could help deter violence since there would be surveillance in place. She explained:

If they opened up a house...if they had a house for us to go when you get a job to go and do the job at with say like people that are there, you know? Just a safe place for you to be and do your job, then that way you're not in a car in a car park and you're not going to get robbed. That's what I reckon anyway...just like someone there who's going to be there to know who's coming in the door. Put a camera in the hallway so that you can get videos of who you're with, you know? You could be in a bedroom and then get smacked up and the guys going to leave but you've always got their face on camera... We can walk in the door and not be accosted by anybody going in, get our job over and done with in the room, and then leave. You know? (Licious, Christchurch)

However, whilst a few of the women spoke positively of the idea of a safe house, several women said they would be unlikely to use these facilities if they were available. Lexi, for instance, explained that she would be keen to be involved in the management of such a facility:

Lexi: I'd love to run a house like that. Yeah. That could be an opportunity.

Lynzi: But would people who were bringing their clients there, would they have to pay?

Lexi: Room hire yeah just to cover rent and cleaning and stuff like that. Yeah.

Lynzi: So wouldn't it be like in a parlour?

Lexi: Just a room - do the job and go. Just toilet, shower, basic facilities. Yeah.

Whilst Lexi was supportive of this idea for others to make use of, she said that she would be unlikely to use this herself because she preferred to control where she took her clients: 
Lynzi: So if there was something like that, would you use it when you were working out on the street?

Lexi: Nah.

Lynzi: You wouldn't? Why not?

Lexi: Because I think I'm private too. I don't know. And I work for myself. I'm in control of that.... That was one of the reasons I went out to work.

The importance of having control and remaining independent was emphasised throughout the interviews with sex workers and is demonstrated through the findings of chapter four. Thus, although the idea of having a safe house seems to make sense from a safety perspective, it is likely that some sex workers would not make use of this even though they may appreciate the value of it for others. It is also possible that some women would be reluctant to pay a fee to use a safe house, particularly if they already have locations where they felt safe with clients. Holly, for instance, explained that whilst it would be useful to have somewhere to go that was monitored for safety reasons, she would be reluctant to pay a fee to use these facilities. She explained:

Maybe car parks where the workers can go that are monitored.... Well not car parks, something else. But like I say it's like a parlour, a place where you buy a room - you have to pay for that. (Holly, Christchurch)

A key informant also suggested that although a safe house could provide a safer environment for women, financial pressures would be likely to take priority meaning that women would be unlikely to use these facilities if this would mean a loss in earnings through having to pay a fee:

I would imagine though that there would be girls that would never use a safe house because the dollar's getting harder and harder to get. If you're doing an $\$ 80$ job and you're going to lose ten to a house or you get to keep the $\$ 10$ if you do it in the back of a car or whatever, that $\$ 10$ means there's the difference between your safety and not. (Key informant, Drug)

Thus, although a safe house may prove useful for some street-based sex workers, these findings suggest that this would have a limited impact since some women would be reluctant to use such a facility.

\section{Creating safer spaces}

A more productive way of supporting sex worker safety in the decriminalised context may involve ensuring that spaces associated with street-based sex work are designed 
to support sex workers strategies to manage risks of violence. The manipulation of space is a strategy used by sex workers on the street to manage risks of violence (Sanders, 2004a). In relation to this Sanders and Hubbard (2003) note:

Due to the extent of violence in the lives of many street sex workers, they seek to maintain control of the space of the red-light district to reduce risk. Standing under street-lamps, away from dead-ends that may hinder escape and working close enough to residential houses that may be called upon for assistance, are all ways in which sex workers manipulate the street environment within which they work in order to reduce the considerable risks. (p. 86).

The desire for safer working spaces was reflected in the suggestions offered by the women that changes to the public space could help better support their safety whilst working on the street. One such strategy related to the increased use of CCTV cameras on the street, consistent with other research findings (Sanders, 2004a). Claire felt that more cameras in areas in which street-based sex workers are located would help better support her safety, explaining "Um well I like the idea of a lot of cameras around the place. There should be more if anything”. Similarly Shania suggested "maybe they could put more cameras in", and Zoe stated "More cameras. I know that. Maybe corner on either side of the lights". Key informants agreed that the provision of more cameras would better support the safety of sex workers in the area. One key informant noted:

I know the council have just put more cameras in. I would like to see even more. I'd like to see cameras that pick up number plates rather than just the car whizzing by. (Key informant, NZPC)

A key informant from the Christchurch police agreed whilst the increase in cameras had been helpful, even more cameras would better support sex workers to work safely, noting, "I think that's a real positive thing that we've got cameras down there ...yeah cameras everywhere would be fantastic". All of the police key informants felt that the increased use of security cameras had been beneficial. However there were some concerns regarding how clients may respond to these cameras and the possibility that this could impact on sex workers. One police key informant explained:

Well I think, I think the realisation that we now have cameras on Manchester Street must be a real reassurance to the girls. That if something does happen they're going to get picked up. Now the reverse might go to punters that they don't want to pick up girls on Manchester Street because they may be identified and be spoken to. So it's going to be an interesting next six months 
to see what happens you know. I hope the girls are going to take on that as being a nice cloak over them as they continue to operate out of there for their protection. I'm sure you'll find that there may well be a movement of some out of sight of those cameras. (Key informant, Police)

However, none of the sex workers in this research expressed concerns over the cameras on this basis. But, suggestions of how the physical environment could be adapted to better support the safety of street-based sex workers were not limited to the provision of cameras. Sex workers and key informants also referred to the need for better lighting in some areas, and accessible public toilets for sex workers to use. Cindy suggested, "Yeah, more lighting...maybe a couple of portable toilets, you know?". The need for more public toilets may at first seem unrelated to supporting safety, however a key informant explained that this would mean sex workers did not have to leave the central area in which they work alongside others, noting, "Toilets. If there was toilets it might be a bit safer because women wouldn't have to walk to really odd places to try and pee. It would be a bit more pleasant". Whilst it was felt that more public toilets would be beneficial, most commonly mentioned was a need for better lighting in specific areas. One key informant noted:

A bit more lighting I think would be really good. I think that Latimer Square is terrible. I think that lots of violence happens in Latimer Square not just to workers, to the general public and no wonder [because] it's so bloody dark. And I think that our city council should know that is an area that's used for those type of purposes and light it up a bit more. (Key informant, Youth)

However, a key informant from the City Council had a very different view, explaining:

There have been calls from time to time for the council to do things like put more lighting up which seems to me an odd response because why the council would choose to facilitate or enable a really dangerous activity - there's a logic gap there for me. (Key informant, City Council)

This highlights the tensions that emerge from conflicting views on street-based sex work and the resistance in some corners to creating safer spaces for sex workers. Broad risks of violence managed by these women that have been outlined throughout this thesis suggest that supporting the safety of sex workers requires a more holistic societal commitment to supporting the right of street workers to work safely. It is clear that sex workers alone cannot change the culture of violence towards them. This 
chapter will now move on to consider how the safety of sex workers on the street may be better supported at a societal level.

\section{Changing attitudes}

The stigma attached to street-based sex work is supportive of violence against sex workers and, accordingly, renders this group more vulnerable (Lowman, 2000; O'Neill, 2008). It has been argued that decriminalisation is likely to do very little to address stigma (Sharpe, 1998). Indeed, it is clear that since the law change in New Zealand sex workers continue to be stigmatised (Abel, 2010). However, it can be argued that when sex work is decriminalised there is increased scope to challenge the stigma that promotes violence against sex workers. The continued impact of stigma was evident in this research, and the findings of chapter seven highlight how this translates into the frequent abuse and harassment directed at the women whilst they worked on the street. Moving forward to better support the safety of street-based sex workers therefore requires changing attitudes that are supportive of violence towards sex workers on the street. As Barnard (1993) notes:

In many senses prostitutes are easy targets for men who have violent inclinations. This is not only because it is in the nature of their work to go with strangers to oftentimes dark and lonely places. It is also the case that prostitutes are treated as second class citizens because the work they do is considered to many to be immoral...there remains a need for a sea change in the public perception of prostitutes as second class citizens who do not qualify for the same civil liberties as the rest of the population. (p. 702)

When asked about what more could change to support sex workers to work safely on the street since the shift to decriminalisation, the women overwhelmingly referred to the need to change negative attitudes towards them amongst the general public. Shania felt that the law change had gone some way in challenging stigma that is supportive of violence towards street-based sex workers, but she also felt that some challenges remained. She noted:

I mean how do you educate ignorance and small mindedness? I mean you really can't but the fact that it is accepted now whether people like it or not has definitely made it that bit safer too... We're never going to have the whole of society on our side...There will always be people [who] look down...But talking about it and bringing it out into the open is definitely making it safer...like the law change and stuff...people are aware we're there, we're not out there on our own, you know what I mean? (Shania, Christchurch) 
A few key informants also felt that in order to better support sex worker safety postdecriminalisation, a priority should be to change attitudes in society towards streetbased sex workers. This point was emphasised particularly amongst key informants from NZPC, perhaps reflecting the extent of their experience and awareness of the wide-ranging impacts of whore stigma, and how this relates specifically to the vulnerability of street-based sex workers. As noted in chapter two, the link between stigma and violence against sex workers is well established (Lowman, 2000). One key informant referred to this link between 'othering' and violence, stating that:

There's this rite of passage thing with young men in our society where 'the other' is definitely the street based sex worker...so to young men perhaps of certain mindset...they could feel that their rite of passage has to involve some kind of interaction that isn't safe for the sex worker. It might be hurling abuse or throwing missiles or hassling. (Key informant, NZPC)

The 'othering' of street-based sex workers has been supported by media portrayals of this group as deviants or victims (Hallgrimsdottir, Phillips, Benoit \& Walby, 2008). Furthermore, Bennachie and Marie (2010) suggest that the vulnerability of streetbased sex workers is perpetuated by the language used by abolitionists who are described as using a "discourse of hate" (p. 24). One key informant commented on the potential impact of media coverage that reinforces negative ideas about streetbased sex workers. It was felt that those with an abolitionist perspective (described below as the 'anti lot') reinforced dangerous ideas about street-based sex work in the media, which could subsequently support the views of individuals who wish to harm sex workers:

Well I think we've got to stop the 'anti lot' from continuing to produce negative headlines. We've got to counteract that because that builds on that stigma and that entitlement to deal to street based sex workers. The young man, the thug with his mates - that kind of marketing of messages to them saying that street based sex workers are problems and they're scum and they're cancer and they should be removed. (Key informant, NZPC)

The need to prioritise challenging attitudes that are supportive of violence towards sex workers was reflected in the experiences of these women. For instance, in chapter seven, one of the women recounted a passerby making abhorrent comments about the recent murder of a woman who had been working in the vicinity. This public indifference towards violence against street-based sex workers was also evident in an 
experience recounted by one sex worker, Sydney, who recalled a colleague being raped in a public place and offered no assistance by passersby:

I told you about um [worker] getting raped in the morning when everyone was walking to work they could hear her, you know, they could see her being raped and they all had a quick look and then kept going. (Sydney, Christchurch)

In addition, one key informant felt that the violence perpetrated against street-based sex workers was directly linked to, "the moral abhorrence of women who are having sex with multiple partners. And in particular, sex workers - You know that kind of 'she only got what she deserved and she was only a whore'”. The propensity to blame street-based sex workers for the violence they experience is considered to be related to the patriarchal legacy that equates female sexuality with deviance and shame, and this was highlighted in chapter one and two of this thesis. It is clear that victimblaming attitudes towards street-based sex workers continue to prevail. For instance, referring to the trial of Steve Wright, who murdered five women in Ipswich, Kinnell (2008) notes that:

The view that sex workers themselves generate the violence they suffer, their very existence provoking murderous rage and encouraging sadistic tendencies in men who would otherwise behave themselves, was stressed at Wright's trial. The prosecution claimed his behaviour was precipitated by his move into the soliciting area of Ipswich and his alleged switch from indoor to street workers, the implication being that it was drug-using street workers...which elicited his murderous response. (p. 246)

Prevalent discourses that stigmatise street-based sex workers therefore threaten the safety of these women and are supportive of violence towards them. Whilst the decriminalisation of street-based sex work cannot eliminate these discourses, it provides a context in which oppressive and violent ideas about street-based sex workers are at least unsupported through the laws and policies on sex work, since the PRA was enacted in the interest of sex worker safety. Thus, the decriminalised context is more conducive to challenging these discourses to change negative attitudes towards street-based sex workers. However, even in the decriminalised environment this represents a challenging task.

\section{Barriers to changing attitudes}

In relation to the struggle to address violence against lesbian, gay bisexual and transgender (LGBT) communities, it has been noted that several barriers exist such as 
moral panic about the AIDS epidemic, stigma, social invisibility and insufficient human rights (Richardson and May, 1999). Sex workers and key informants in this research suggested that a similar set of barriers negate efforts to challenge violence against sex workers. One key informant explained that the stigma attached to the very concept of sex work was still so deeply ingrained that changing negative attitudes is fraught with challenges, stating, "I think that sex workers and their very being aggravates some people”. Another key informant from NZPC reflected further on this point, explaining:

You know people just seem to pick on prostitutes and it would take a lot to change the views. A lot of people don't see it as being right to sell your body for sex, you know, 'how could you do that? That's disgusting, that's really low'... They see that as being a really low thing to do. (Key informant, NZPC)

As noted in the first two chapters of this thesis, the negative positioning of streetbased sex workers in society links to moral judgments about female sexual behaviour that have prevailed for centuries. Accordingly, it is not surprising that these ideas are so deeply ingrained. One key informant felt that positive change relied on challenging "preconceived negative attitudes" that have fuelled stigma against sex workers. However, it was recognised that this was a hugely problematic task because some people believe so strongly in the validity of their preconceptions about street-based sex workers. One woman echoed this idea, alluding to her own negative attitudes about sex work as a young adult. Tessa recognised the difficulties in changing attitudes when these ideas are so deeply ingrained. She explained:

Some people are just flat out, you know? But no amount of bloody trying to convince me when I was 20 that I would be doing it when I was 47, you know...there's no way I would have ever believed it in a million years that my attitude would have changed enough and no amount of talking about it would have changed that. So to a degree I'm aware of that if I was to talk with someone else who thought that way [shrugs]. (Tessa, Christchurch)

Negative ideas about sex workers on the street were linked by one key informant to a lack of knowledge and understanding in mainstream society, as a result of not being familiar with any real people working on the street:

The point I'm making is that there isn't a point where people can empathise because they simply don't know. And so it's easier to just look at some of the traits that they imagine street based sex workers to have like drug use and being unpredictable... and speaking to passersby and being outrageously 
demonstrative sexually. And not really see around the corner from that kind of image to the person. (Key informant, NZPC)

Negative and poorly informed perceptions of street-based sex workers are sometimes reinforced by prominent public figures who promote hateful attitudes towards sex workers. One key informant noted, "When you've got people like the mayor [and] councillors who are standing up and saying well, you know, "these are the scum of the earth" - you've got to actually change that".

It was clear that barriers continue to exist in changing attitudes towards street-based sex workers since decriminalisation. This is to be expected since these attitudes have been supported historically, not only through laws that criminalised sex workers, but also through patriarchal expectations of female sexual behaviour. Changing attitudes that are supportive of violence towards street workers therefore requires eroding the remnants of the patriarchal legacy that continues to lend itself to victim blaming discourses and judgements towards women who have multiple sexual partners. The next section of this chapter explores strategies to move forward to decrease the marginalisation of street-based sex workers in the decriminalised context, so that the safety of sex workers on the street is better supported at a societal level.

\section{Moving forward}

In order to create a safer environment for street-based sex workers in the decriminalised context, it is essential to change attitudes that are supportive of violence towards those working in this sector. The findings of this thesis demonstrate how women continued to strategise against violence in the decriminalised context. Whilst the PRA provided an essential platform for change, challenges remain in addressing violence against sex workers. The findings of chapter one and two outlined how sex workers on the street have been stigmatised and dehumanised, through dominant discourses that have permeated media coverage and public debates focused on the 'problem' of street-based sex work. A key theme that emerged in this research was a need to work towards increasing public familiarity with street-based sex work in order to decrease their marginalisation, and subsequently erode attitudes that are supportive of violence towards sex workers. One key informant from NZPC explained that effecting this change relied on "the establishing of human faces of sex workers and particularly human faces of street- based sex workers". Thus, one key informant 
noted that this required somehow reaching those in society who are unfamiliar with street-based sex work to portray street sex workers as people, as opposed to caricatures of stigma laden ideas who are open to undisputed condemnation from others. It was noted that:

We have to be able to show the mothers that they are the daughter that they are, the real people that they are. Not just a 'thing' standing on the side of the road...In doing that it challenges the perceptions that people have and allows them to realise eventually that the ideas that they have been formed were not necessarily accurate and as a result it humanises sex workers. (Key informant, NZPC)

Although the media has undoubtedly reinforced negative portrayals of street workers, two key informants explained that the media could also represent a useful tool to tackle these negative attitudes, and referred to a television series run several years earlier based on the lives of street-based sex workers. One key informant explained:

Did you ever see the series that came out of England called Band of Gold? I think a series like that gave people for the first time a realisation that these people are actually human beings as well. They were mothers and you know they had lives they weren't just having sex 24/7 and I think that was a really wonderful piece of television that came through...I mean obviously you can't have a television series going all the time but you just need to get into people's lives - they're people, they're human beings. (Key informant, NZPC)

The findings of chapter seven clearly showed how street-based sex workers have been perceived and responded to negatively in their work by some passersby and residents. This suggests a need for a more positive acceptance of street workers in the communities they work in. One key informant reflected on this, explaining that more positive engagement with those working on the street could decrease the marginalisation of sex workers:

I think, you know, the first part of that is humanising [sex workers] - people living in the inner city walking past street workers that they know and, you know, the coffee table chats that occur where people say "well you know I actually stop and talk to them. I know a few and they're very friendly to me". And so that becomes a kind of social game - adopt a street worker in my hood...It's familiarity and people relating, acknowledge that this is part and parcel of their neighbourhood... So the humanising the feeling positive about integrating sex workers into your neighbourhood. (Key informant, NZPC)

Interviews with the women revealed that a few sex workers were actively engaged in challenging negative attitudes and ideas that dehumanise and disparage those who 
work on the street. Tessa described an interaction she had with a young woman one evening on her way home from work:

I had a situation the other night. I met this young woman on the way, well I was on the way home but she was going out partying. And she got out of the taxi on Manchester Street and she was wearing the little dress, you know the high shoes. She looked great. She was going to a party and her friends had given her slightly the wrong directions. Within two minutes of getting out of the taxi she'd been stopped twice and asked "how much" and she was horrified. She was bawling her eyes out. And I said "look, you've got to take it as a compliment". This is what I said to her - you have to take it as a compliment. "Don't be offended because I tell you full well that those men will be far more embarrassed about having asked you when you're not working than you are about having been asked"...So I said to her about that and we walked past a couple of other girls who were working and one of them called out to her "oh you look really great!" And she went [sigh] "Oh I don't know whether to be offended". And I said, "Don't be offended. You know, these [street workers] are just normal people". I mean I'd actually changed my shoes. I'd decided that's it, I'm finished work and, you know, I put on my sneakers so I was 'off duty' so to speak and I don't think she clicked that I'd been out working as well. And I thought oh I'm not going to make a fuss, I'll get her to where she's going. But I did say to her "these are just normal people. You know, they're just providing a service”. (Tessa, Christchurch)

This narrative demonstrates how interactions between sex workers and others using the public space can make a positive contribution to challenging stigma. However, preconceived negative ideas about street-based sex workers continue to prevent this by 'othering' street workers to such an extent. The impact of this 'othering' was outlined in chapter seven, which showed that the women were regularly abused and harassed by passersby. It is clear that those who work on the street are the most stigmatised group of sex workers, and this is reflected in the treatment they receive whilst working in the open space. Women who work on the streets have been associated with particular characteristics and behaviours, such as drug use, and have been represented as the ultimate 'bad woman' who openly flaunts her rejection of female sexual norms in exchange for personal gain. One key informant suggested that the tendency to use particular images of street-based sex workers to form arguments about the legitimacy of sex work has resulted in a disowning of some sex workers, who are subsequently seen as representing the negative stereotype:

Street-based sex workers are criticised by all almost it seems to me and sadly even within the sex industry you have a quick distancing and you hear it from the most liberal minds where people are quick to say "oh the stereotype". And that's almost like a disowning of street-based sex workers in that one word. 
You know - "we're not all wearing fishnets". Well what if we were? You know what is wrong with that if we were all wearing fishnets and stilettos? And what if we all fitted the stereotype - so what? (Key informant, NZPC)

This highlights a particularly salient point that directly relates to the broader safety and wellbeing of street-based sex workers. If the safety and wellbeing of all sex workers is to be prioritised then it is critical that particular images and behaviours are de-stigmatised as opposed to being used to illustrate what represents 'the stereotype' and thus, the 'bad' whore. Whilst undertaking the data analysis, it occurred to me that amidst all the discussion on who is not the stereotype, exists some women whose lives do reflect some aspects of this image. Whilst distancing from the image that encompasses drug use, poverty, mental health issues and particular ways of dressing for work, may raise the profile and status of some sex workers, it defines other sex workers as the bad example. Positioning street workers as 'the stereotype' subsequently reinforces discourses discussed throughout this thesis that promote violence against this group by suggesting that they are deviant, dirty and need to be eradicated. Better supporting the safety and wellbeing of street-based sex workers therefore requires a paradigm shift away from the divisions drawn between groups of women, to break down problematic distinctions between 'good' and 'bad' whores.

It is, therefore, essential to look towards ways to bridge gaps between street-based sex workers and others in the community. The decriminalisation of street-based sex work is significant in providing an environment in which the stigma that promotes violence against street-based sex workers can be challenged by creating new understandings of sex work in contemporary society. One way in which this may be achieved is through Participatory Action Research with sex workers and others in the communities in which they work (O’Neill \& Campbell, 2002). Research conducted in the UK in an area where tensions existed between street sex workers and others in the community utilised this methodology. Through qualitative interviews, focus groups, and art workshops with sex workers and other residents this research ensured that all of those involved were "engaging in a process that makes the social relations of power associated with the organisation of neighbourhood space visible" (O'Neill et al., 2004 , p. 222). Future research using this methodology would be useful to explore the possibilities for working towards a more positive positioning of sex workers in the open space. Furthermore, it has been noted that visual methods can have a much more powerful effect in creating new understandings than words alone (O'Neill et al., 
2004). A photography exhibition that aimed to challenge public perceptions of streetbased sex workers in the UK city of Norwich provides a useful example of a project that proactively challenges the 'othering' of those who work on the street through the use of visual methods (Briscoe, 2011). ${ }^{7}$ Future initiatives of a similar nature would prove useful in challenging discourse that promotes stigma, which could subsequently help alleviate attitudes that are supportive of violence towards street-based sex workers.

\section{Summary}

This chapter has reviewed the strategies to manage the risks of violence amongst women working in the context of decriminalised street-based sex work. The decriminalisation of the sex industry in New Zealand was a unique change that set New Zealand apart from other countries in representing the most liberal approach to street-based sex work globally. In exploring the management of risk in this context, this chapter has demonstrated how, in the context of decriminalisation, street-based sex workers continued to strategise against risks of violence. Whilst this continued strategising does highlight agency amongst these women, this also represents a long legacy of criminalisation that has placed responsibility on sex workers to manage their own safety on the street. Decriminalisation, it has been argued, provides an opportunity to better support street-based sex workers in their management of risk. This chapter has explored potential options for future change to better support the safety strategies of street-based sex workers in the context of decriminalisation.

In this chapter I have argued that there are barriers to creating safer spaces for streetbased sex workers. If the safety of street workers is to be prioritised, it is important that they remain free to work in the public space rather than imposing controls on the street sector. Control was a key theme highlighted in this thesis, as it was clear that central to these women's decision to base their work on the street was a desire for control. Whilst the street sector is portrayed as haphazard and out of control, a perception of increased control was fundamental to the ways in which these women described not only their decisions to work on the street but also their interactions with

\footnotetext{
${ }^{7}$ For further information on this project see: http://www.ffatsatina.com/index.php? $p=4$
} 
clients. Thus, efforts to manage the street sex industry could conflict with the control strategies these women described.

The provision of safe houses and the creation of zones may seem like a common sense approach to supporting safety, however the prerogative to make sufficient money and to work in spaces individually defined as safer means that some women would not use these spaces. In addition, the creation of zones could increase tensions on the street and paradoxically increase the vulnerability of some sex workers. Whilst street-based sex work has been decriminalised in New Zealand, the areas in which street work is practised can still be understood as disputed spaces due to enduring stigma attached to street workers. The decriminalisation of sex work provides an opportunity for redefining street-based sex workers positively in public spaces, rather than continuing to support ideas that they are a group that is undesirable and needs to be removed. Supporting the safety of street-based sex workers requires a commitment to creating safer spaces for sex workers in the areas they choose to work in, through the provision of security cameras and better lighting. Achieving this requires a paradigm shift away from the perspective that sex workers should be solely responsible for managing their own safety, to an understanding that they deserve protection from violence that is comparable to those working in other occupations defined as 'high risk'.

The biggest barrier to achieving a more supportive environment for sex workers in the decriminalised context was identified as the persistence of negative ideas about streetbased sex work. Sex workers and key informants highlighted this as a significant issue that continued to threaten the wellbeing of street-based sex workers since the law change. Negative attitudes towards street-based sex workers were considered to be at the root of violence from people approaching as clients, and from passersby. It was clear that there was a need to tackle discourses explicitly supportive of violence towards street-based sex workers. For instance, victim-blaming discourses that construct street workers as the ultimate example of 'asking for it' need to be challenged. Furthermore, there are more subtle ideas that could change to better support sex worker safety. This includes the presumption that women should be removed from the streets for their own safety, and that street-based sex work is always inherently negative for women involved. The widely accepted idea that streetbased sex workers should move to indoor settings fails to acknowledge the positive 
aspects of working on the street, as stressed by many of the women in this research, and reinforces the idea that sex work is unacceptable and as such should be hidden from the public.

In order to challenge negative attitudes that are supportive of violence, it is critical to find ways of humanising street-based sex workers to decrease stigma. One potential option to achieve this is through utilising the media to disseminate more balanced and realistic information about street-based sex workers. Further to this it is important to de-stigmatise images that have been said to represent the negative stereotype of sex work. The provision of a more supportive environment for those working on the street relies partly on raising the profile and status of all sex workers, regardless of judgments about the choices they have made and their lifestyles.

The decriminalisation of street-based sex work provided a framework that better supports the safety strategies utilised by sex workers on the street. The safety strategies identified in this thesis are similar to those found in other contexts, though the data suggests that sex workers in the decriminalised context can spend more time screening clients and are more empowered in negotiations with clients. The strategising of these women also suggested that they continue to manage significant risks of violence in their work and that whilst decriminalisation was an important first step in better supporting the safety of street-based sex work, a broader shift is required. Moving beyond decriminalisation to support the safety of street-based sex workers requires greater acknowledgement of the skills of sex workers in the management of risk on the street, and a more positive positioning of sex worker rights in the public spaces.

The next chapter concludes on the overall findings of this thesis, outlining the significance of these findings in the context of international sex work policy and violence against street-based sex workers. 


\section{Chapter Ten: Conclusion}

In 2003 the Prostitution Reform Act was passed in New Zealand, decriminalising sex work. Throughout history the patriarchal structure of society has ensured female sex workers remain marginalised both in law and in their social status. Those working on the streets have been the most stigmatised and most criminalised group (Hubbard \& Sanders, 2003; Kantola \& Squires, 2004; O’Neill, 2008). Moreover it has been found that street-based sex workers are most vulnerable to experiencing violence in their work, whilst they have been denied basic labour rights, and have been expected to assume responsibility for their own safety (Sanders \& Campbell, 2007). Criminalisation is thought to undermine the ways in which those working on the street can strategise against risks of violence (Kinnell, 2006a; Sanders, 2004a). Furthermore, it has been argued that decriminalisation would provide a framework that better supports the safety of sex workers (Brooks-Gordon, 2008; Day \& Ward, 1997). Research undertaken to review the PRA five years after its enactment found broad positive impacts for the health and safety of sex workers in the indoor and outdoor sectors (Abel et al., 2007). This thesis builds on these existing findings by exploring strategies used by 28 women to manage risks of violence whilst working in the decriminalised context. The specific aims of this thesis outlined in chapter one were:

- To consider perceptions of the risks of violence amongst women working on the streets as sex workers.

- To explore strategies to manage risks of violence amongst these women.

- To provide an analysis that locates these findings in the context of decriminalised street-based sex work, and;

- To consider what more could change to better support these women in their management of violence-related risks.

The aim of this chapter is to discuss the significance of the research findings in relation to previous research on street-based sex work, legal frameworks, and the management of violence-related risks.

One of the central aims of this research was to explore perceptions of the risks of violence with women working in the street context. Clients are typically understood to 
be the main perpetrators of violence against sex workers (Benoit and Millar, 2001; Matthews, 2008). However, on the street, sex workers manage risks of violence from a range of potential perpetrators (Day et al., 2001; Kinnell, 2008; Sanders, 2004a). The findings of chapter four highlight the diverse risks managed by the women interviewed for this research. Whilst the women prioritised strategising against risks of violence from those who approached as clients, the experiences they recounted revealed that they managed risks of violence from passersby, minders, and other sex workers, in addition to risks from potential clients. Moreover, violence described which was perpetrated by 'clients' generally involved non-payment in addition to other violence. This finding supports the argument proposed by Kinnell (2008) that those who attack sex workers often do not pay, and as such, should not be described as clients, even through they may have effectively mimicked client behaviour (Sanders, 2005).

These findings, therefore, suggest a need for a more nuanced conceptualising of violence in research with street-based sex workers that takes into account the broad risks of violence and the diverse, and often misleading identities of perpetrators. The social construction of clients as violent abusers has gained precedence in recent years, reflecting the influence of abolitionist feminist ideology that simplistically depicts female sex workers as victims and male clients as offenders (Barry, 1984, Farley et al., 1998; Jeffreys; 1997; Raymond, 1998). The portrayal of male clients as offenders has several implications. Firstly, the suggestion that violence is intrinsic to the purchase of sexual services essentially invalidates and directs attention away from the actual violence that is perpetrated against sex workers. The stigma associated with buying sexual services provides a convenient veil for the real perpetrators of violence against sex workers, including individuals who approach as clients, other sex workers, minders, and passersby. Thus, the defining of male clients as the sole perpetrators of violence absolves wider society from responsibility for the endorsement of violent attitudes towards those who work from the street that is reflected in the frequent abuse sex workers experience from passersby whilst working in the open space. Furthermore, such portrayals misrepresent the diversity amongst the sellers and purchasers of sex, which perpetuates the stigma that is supportive of violence towards sex workers. 
The findings of this thesis demonstrate strategies used by these women to manage risks, particularly from potential clients, that have been outlined in previous research on violence risk management (Barnard, 1993; Miller, 1993; Pyett \& Warr, 1999; Sanders, 2004a). However, it is clear that the decriminalisation of street-based sex work has provided an environment in which these women had sufficient time to screen clients without the additional concern of the risk of arrest. Power and control are central themes in this thesis, since these dynamics were integral to the strategies these women used to manage risks of violence on the street. The research findings highlight how in the decriminalised context these women openly negotiated with potential clients throughout the encounter. Such open and detailed negotiations with potential clients would have been fraught with difficulty before the law change, since there was a possibility of entrapment. The decriminalised framework had, therefore, empowered these women in their work allowing for straightforward negotiations with potential clients, which better supports screening strategies.

The increased sense of freedom that these women described in their work since the law change is particularly significant in supporting the management of violencerelated risks. In addition to simplifying the screening process, not having to 'hide' whilst working on the street appeared to have improved the relationship between sex workers and police, and had made the engagement of other organisations such as NZPC more straightforward. In Christchurch it was clear that increased partnership working between organisations supporting sex workers and the police had emerged following the murders of three women who had been working on the street. Such relationships between these organisations were problematised before the law change by the inevitable tensions that exist when the police continue to arrest and charge sex workers. The freedom sex workers now have to work on the street openly without having to avoid authorities is therefore critical to ensuring risks of violence can be managed as far as possible and responded to in partnership with sex workers. Thus, it is paramount that street-based sex work remains decriminalised for sex workers and clients. When street-based sex workers and clients are criminalised, sex workers must be covert in carrying out their work in order to ensure financial success whilst avoiding detection by authorities (Chapkis, 2000; Kinnell, 2006a; Hubbard \& Sanders, 2003). The findings of this thesis clearly illustrate the significant benefits of ensuring sex workers do not need to be covert when meeting clients. 
The decriminalisation of street-based sex work in New Zealand was a unique change. The change in law in New Zealand can be conceptualised as the first step towards eroding discourses that are integral to the maintenance of patriarchal society, within which female street workers are portrayed as deviant and 'fallen' women. Decriminalising sex work on the street is therefore a critical step towards righting the wrongs that have been perpetrated against street-based sex workers throughout history. Moving forward from this point requires a paradigm shift away from discourses that stigmatise female street workers, towards a positive repositioning of sex work in contemporary society.

This thesis has provided the first in-depth insight into the experiences of street-based sex workers specifically managing risks of violence in a decriminalised context. The findings signal that the law change in New Zealand provided a framework in which the safety strategies commonly used by street workers to manage risks of violence are better supported. These findings are significant not only in the New Zealand context, but on a global scale in light of ongoing debates regarding prostitution law reform, particularly in the UK. In the decriminalised context they continued to manage significant ongoing risks of violence. However it is precisely because of these risks that the decriminalised framework is so important. In enabling these women to work out of shadows, the PRA provided a context in which these women could more effectively strategise against risks of violence not only on an individual level but also collectively with police and support agencies. In addition, decriminalisation opened up new possibilities for further strengthening this collective strategising, and to work towards promoting discourse that prioritises the rights of sex workers and challenges the attitudes that are violent towards them. In the pursuit of a framework that genuinely prioritises the safety and wellbeing of street-based sex workers, other countries should consider the New Zealand model as an alternative to criminalising sex workers and clients. However, decriminalisation should not be seen as the final solution but merely a crucial starting point towards proactively addressing violence against sex workers. 


\section{References}

Abel, G. (2010). Decriminalisation: A harm minimisation and human rights approach to regulating sex work. Unpublished doctoral dissertation, University of Otago, Dunedin.

Abel, G. (2011). Different stage, different performance: The protective strategies of role play on emotional health in sex work. Social Science Medicine, 72, 1177-1184.

Abel, G., \& Fitzgerald, L. (2008). On a fast-track into adulthood: An exploration of transitions into adulthood for street-based sex workers in New Zealand. Journal of Youth Studies, 11(4), 361-376.

Abel, G., \& Fitzgerald, L. (2010a). Risk and risk management in sex work postProstitution Reform Act: a public health perspective. In G. Abel., L. Fitzgerald., \& C. Healy (Eds.), Taking the crime out of sex work: New Zealand sex workers' fight for decriminalisation (pp. 217-238). Bristol: Policy Press.

Abel, G., \& Fitzgerald, L. (2010b). Decriminalisation and Stigma. In G. Abel., L. Fitzgerald., \& C. Healy (Eds.), Taking the crime out of sex work: New Zealand sex workers' fight for decriminalisation (pp. 239-259). Bristol: Policy Press.

Abel, G., Fitzgerald, L., \& Brunton, C. (2007). The Impact of the Prostitution Reform Act on the Health and Safety Practices of Sex Workers. Christchurch: Department of Public Health and General Practice, University of Otago.

Abel, G., Fitzgerald, L., \& Brunton, C. (2009). The Impact of Decriminalisation on the Number of Sex Workers in New Zealand. Journal of Social Policy, 38(03), 515531.

Abel, G., Healy, C., Bennachie, C., \& Reed, A. (2010). The Prostitution Reform Act. In G. Abel., L. Fitzgerald., \& C. Healy (Eds.), Taking the crime out of sex work: New Zealand sex workers' fight for decriminalisation (pp. 75-84). Bristol: Policy Press.

Alice, L. (2003). Power, experience, and process in feminist research. In C. Davidson \& M. Tolich (Eds.), Social Science Research in New Zealand: Many Paths to Understanding (pp. 62-68). Auckland: Pearson Education New Zealand Limited.

Angrosino, M. V., \& Mays de Perez, K. A. (2000). Rethinking Observation: From Method to Context. In D. K. Denzin., \& Y. S. Lincoln (Eds.), Handbook of Qualitative Research (pp. 673-702). London: Sage.

Barnard, (1992). Working in the dark: Researching female prostitution. In H. Roberts (Ed.), Women's Health Matters (pp. 141-156). London: Routledge. 
Barnard, M. (1993). Violence and vulnerability: conditions of work for streetworking prostitutes. Sociology of Health and Illness, 15(5), 683-705.

Barnard, M., Hart, G., \& Church, S. (2002). Client Violence Against Prostitute Women Working from Street and Off-street Locations: A Three City Comparison. Violence Research Programme: Research Findings. Swindon: Economic and Social Research Council.

Barnett, T., Healy, C., Reed, A., \& Bennachie, C. (2010). Lobbying for decriminalisation. In G. Abel., L. Fitzgerald., \& C. Healy (Eds.), Taking the crime out of sex work: New Zealand sex workers' fight for decriminalisation (pp. 217-238). Bristol: Policy Press.

Barry, K. (1984). Female Sexual Slavery. New York: New York University Press.

Barry, K. (1995). The Prostitution of Sexuality. New York: New York University Press.

Bartley, P. (2000). Prostitution : prevention and reform in England, 1860-1914. London: Routledge.

Basu, A., \& Dutta, M. (2008). Participatory change in a campaign led by sex workers: Connecting resistance to action-orientated agency. Qualitative Health Research, 18, $106-119$.

Becker, H.S. (1963). Outsiders: Studies in the Sociology of Deviance. New York: The Free Press.

Bennachie, C., \& Marie, J. (2010) 'Their words are killing us': Violent language of anti-sex work groups. Research for Sex Work, 12, 24-25.

Benoit, C., \& Millar, A. (2001). Dispelling myths and understanding realities: working conditions, health status and exiting experiences of sex workers. British Columbia: University of Victoria.

Benoit, C., \& Shaver, F. (2006). Critical issues and new directions in sex work research. The Canadian Review of Sociology and Anthropology, 43(2), 243-252.

Benson, C. (1998). Violence Against Female Prostitutes: Experiences of Violence, Safety Strategies and the Role of Agencies. Leicestershire: Department of Social Sciences, Loughborough University.

Benson, C., \& Matthews, R. (1995). Street prostitution: Ten facts in search of a policy. International Journal of the Sociology of Law 23(4), 395-415.

Benson, C., \& Matthews, R. (2000). Police and prostitution: vice squads in Britain. In R. Weitzer (Ed.), Sex for sale: prostitution, pornography, and the sex industry (pp. 245-264). New York: Routledge. 
Bland, L. (1992). The case of the Yorkshire Ripper: mad, bad, beast or male? In J. Radford., \& D.E.H. Russell (Eds.), Femicide : the politics of woman killing. (pp. 233252). New York: Maxwell Macmillan International.

Bondi, L. (1998). Sexing the City. In R. Fincher., \& J.M. Jacobs (Eds.), Cities of Difference (pp. 177-200). New York: The Guilford Press.

Boynton, P. (2002). Life on the streets: the experiences of community researchers in a study of prostitution. Journal of Community \& Applied Social Psychology, 12, 1-12.

Boynton, P., \& Cusick, L. (2006). Sex workers to pay the price. British Medical Journal, 332, 190-191.

Brents, B., \& Sanders, T. (2010). Mainstreaming the Sex Industry: Economic Inclusion and Social Ambivalence. Journal of Law and Society, 37(1), 40-60.

Brewis, J., \& Linstead, S. (2000). 'The Worst Thing is the Screwing' (1):

Consumption and the Management of Identity in Sex Work. Gender, Work \& Organization, 7(2), 84-97.

Brewis, J., \& Linstead, S. (2002). Managing the sex industry. Culture and Organisation, 8(4), 307-326.

Briscoe, K. (2011, May 2). Photographic exhibition to challenge perceptions of Norfolk street workers. Norwich Evening News 24. Retrieved May 30, 2011, from http://www.eveningnews24.co.uk/news/photographic_exhibition_to_challenge_perce ptions_of_norfolk_street_workers_1_880975

Brooks, A. (2007). Feminist standpoint epistemology: Building knowledge and empowerment through women's lived experience. In S. N. Hesse-Biber \& P. Leavy (Eds.), Feminist research practice : a primer (pp 53-82). Thousand Oaks: Sage Publications.

Brooks-Gordon, B. (2006). The price of sex: prostitution, policy and society. Cullompton: Willan Publishing.

Brooks-Gordon, B. (2008), State violence towards sex workers: Police power should be reduced and sex workers' autonomy and status raised. British Medical Journal, 337 , a908.

Brooks-Gordon, B. (2010). Bellwether citizens: The regulation of male clients of sex workers. Journal of Law and Society, 37(1), 145-70.

Buckley, T. (2009, April 19). Locals sweep sex workers off the streets. Sunday News. Retrieved May 1, 2009, from http://www.stuff.co.nz/national/2345076/Locals-sweepsex-workers-off-streets 
Bullough, V., \& Bullough, B. (1987). Women and prostitution : a social history. Buffalo, N.Y: Prometheus Books.

Busch, N.B., Bell, H., Hotaling, N., \& Monto, M.A. (2002). Male customers of prostituted women: Exploring the perceptions of entitlement to power and control and implications for violent behavior Toward Women. Violence Against Women, 8(9), 1093-1112.

Campbell, R. \& Kinnell, H. (2000). "We Shouldn't Have to Put Up with This": Street Sex Work and Violence. Criminal Justice Matters, 42(1), 12-13.

Canter, D., Ioannou, M., \& Youngs, D. (2009). Sex and violence: The experience and management of street prostitution. In D. Canter., M. Ioannou., \& D. Youngs (Eds), Safer sex in the city: The experience and management of street prostitution (pp. 1-10). Surrey: Ashgate.

Carmody, M. (2006). Preventing adult sexual victimisation through education? Current Issues in Criminal Justice, 18(2), 342-356.

Chapkis, W. (1997). Live Sex Acts : Women Performing Erotic Labor. New York: Routledge.

Chapkis, W. (2000). Power and control in the commercial sex trade. In R. Weitzer. (Ed.), Sex for sale: Prostitution, pornography and the sex industry (pp. 181-201). New York: Routledge.

Chase, S. E. (2005). Narrative enquiry: Multiple lenses, approaches, voices. In N. K. Denzin., \& Y. S. Lincoln. (Eds.), The SAGE handbook of qualitative research (pp. 651-680). Thousand Oaks: Sage Publications.

Church, S., Henderson, M., Barnard, M., \& Hart, G. (2001). Violence by clients towards female prostitutes in different work settings: questionnaire survey, British Medical Journal, 322, 524-525.

Code, L. (1991). What can she know? : feminist theory and the construction of knowledge. Ithaca: Cornell University Press.

Code, L. (1995). How do we know? Questions of method in feminist practice. In S. Burt., \& L. Code (Eds.), Changing methods : feminist transforming practice (pp. 1344). New York: Broadview Press.

Cotterill, P. (1992). Interviewing women : Issues of friendship, vulnerability and power. Women's Studies International Forum, 15(5-6), 593-606.

Dalla, R. (2002). Night moves: A qualitative investigation of street-level sex work. Psychology of Women Quarterly, 26, 63-73. 
Dalla, R. L., Xia, Y., \& Kennedy, H. (2003). "You just give them what they want and pray they don't kill you": Street-level sex workers' reports of victimization, personal resources, and coping strategies. Violence Against Women, 9(11), 1367-1394.

Day, S. (2007). On the game. London: Pluto Press.

Day, S., \& Ward, H. (2007). British policy makes sex workers vulnerable. British Medical Journal, 334, 187.

Day, S., Ward, H., \& Boynton, P.M. (2001). Violence towards female prostitutes. British Medical Journal, 323(7306), 230.

Delacoste, F. and Alexander, P. (1988). Sex work: Writings by women in the sex industry. London: Virago Press

Denzin, D. K., \& Lincoln, Y. S. (2003). Introduction: The discipline and practice of qualitative research. In D.K. Denzin., \& Y.S. Lincoln (Eds.), Collecting and interpreting qualitative materials (Vol. 2) (pp.1-45). London: Sage.

DeVault, M. (1990). Talking and listening from women's standpoint: Feminist strategies for interviewing and analysis. Social Problems, 37(1), 96-115.

Douglas, M. (1985). Risk acceptability according to the social sciences. London: Routledge.

Downe, P. J. (1999). Laughing when it hurts: Humor and violence in the lives of Costa Rican prostitutes. Women's Studies International Forum, 22(1), 63-78.

Dworkin, A. (1997). Life and death. New York: Free Press.

Eden, P. (1997). 'Sex industry' worlds: massage parlours, escort agencies, and the social organisation of sex work in Christchurch. Unpublished doctoral dissertation, Christchurch: Canterbury University.

Edwards, S. (1997). The legal regulation of prostitution: a human rights issue. In G. Scrambler \& A. Scrambler (Eds.), Rethinking prostitution: Purchasing sex in the 1990s (pp. 57-82). London: Routledge.

Efthimiou-Mordaunt, A. (2002). Sex-working drug users: out of the shadows at last. Feminist Review, 72, 82-94.

Ekberg, G. (2004). The Swedish law that prohibits the purchase of sexual services: Best practices for prevention of prostitution and trafficking in human beings. Violence Against Women, 10(10), 1187-1218.

El-Bassel, N., Witte, S.S., Wada, T., Gilbert, L., \& Wallace, J. (2001). Correlates of partner violence among female street-based sex workers: Substance abuse, history of childhood abuse, and HIV Risks. AIDS Patient Care \& STDs, 15(1), 41-51. 
Eldred-Grigg, S. (1984). Pleasures of the flesh: sex \& drugs in colonial New Zealand, 1840-1915. Wellington: Reed.

Eldred-Grigg, S. (2008). Diggers, hatters \& whores: The story of the New Zealand gold rushes. Auckland: Random House.

Espiner, C. (2005, April 15). Number of prostitutes rises 40\%. The Christchurch Press.

Erickson, P.G., Butters, J., McGillicuddy, P., \& Hallgren, A. (2000). Crack and prostitution: Gender, myths, and experiences. Journal of Drug Issues, 30(4), 767-788.

Farley, M. (2004). Bad for the body, bad for the heart': Prostitution harms women even if legalised or decriminalised. Violence Against Women, 10, 1087-1125.

Farley, M. (2008). What really happened in New Zealand after prostitution was decriminalised in 2003? Retrieved January 5 2009, from http://www.prostitutionresearch.com/Report\%20on\%20NZ\%2010-29-2008.pdf.

Farley, M., Baral, I., Merab, K., \& Sezgin, U. (1998). Prostitution in five countries: Violence and post-traumatic stress disorder. Feminism Psychology 8(4), 405-426.

Farley, M., \& Barkan, H. (1998). Prostitution, violence and post-traumatic stress disorder. Women \& Health, 27(3), 37-49.

Farley, M., \& Kelly, V. (2000). Prostitution: a critical review of the medical and social sciences literature. Women \& Criminal Justice, 11(4), 29-64.

Faugier, J., \& Sargeant, M. (1997). Boyfriends, 'pimps' and clients. In G. Scrambler., \& A. Scrambler (Eds.), Rethinking prostitution: Purchasing sex in the 1990s (pp. 121136). London: Routledge.

Fawkes, J. (2005). Sex working feminists and the politics of exclusion. Social Alternatives, 24(2), 22-23.

Fitzgerald, L. \& Abel, G. (2010). The media and the Prostitution Reform Act. In G. Abel., L. Fitzgerald., \& C. Healy (Eds.), Taking the crime out of sex work: New Zealand sex workers' fight for decriminalisation (pp. 197-215). Bristol: Policy Press.

Frances, R. \& Gray, A. (2007). Unsatisfactory, discriminatory, unjust and inviting corruption: Feminists and the decriminalisation of street prostitution in New South Wales. Australian Feminist Studies, 22(53), 307-324.

Glucksman, M. (1994). The Work of Knowledge and the Knowledge of Women's Work. In M. Maynard., \& J. Purvis. (Eds.), Researching women's lives from a feminist perspective (pp. 149-165). London: Taylor \& Francis.

Goffman, E. (1990). Stigma: Notes on the management of a spoiled identity. London: Penguin Books. 
Goodyear, M. (2008). Remembering Ipswich, The case for decriminalisation of prostitution: A human rights and public health perspective. Retrieved 15 June 2009, from myweb.dal.ca/mgoodyea/files/rememberingipswich.doc.

Goodyear, M., \& Cusick, L. (2007). Protection of sex workers. BMJ, 334 (7584), 5253.

Gorry, J., Roen, K., \& Reily, J. (2010). Selling your self? The psychological impact of street sex work and factors affecting support seeking. Health and Social Care in the Community, 18(3), 492-499.

Gould, A. (2001). The criminalisation of buying sex: The Politics of prostitution in Sweden. Journal of Social Policy, 30(3), 437-456.

Gray, D. E. (2004). Doing research in the real world. London: Sage.

Gysels., M., Pool, R., \& Nnalusiba, B. (2002). Women who sell sex in a Ugandan trading town: life histories, survival strategies and risk. Social Science \& Medicine, 54(2), 179-192.

Hammond, N. (2010). Tackling taboos: Men who pay for sex and the emotional researcher. In K. Hardy, S. Kingston \& T. Sanders (Eds.), New sociologies of sex Work (pp. 59-74). Surrey: Ashgate.

Hallgrimsdottir, H. K., Phillips, R., \& Benoit, C. (2006). Fallen women and rescued girls: Social stigma and media narratives of the sex industry in Victoria, B.C., from 1980 to 2005. The Canadian Review of Sociology and Anthropology, 43(3), 265 - 280.

Hallgrimsdottir, H. K., Phillips, R., Benoit, C., \& Walby. (2008). Sporting girls, streetwalkers, and inmates of houses of ill repute: Media narratives and the historical mutability of prostitution stigmas. Sociological Perspectives, 51(1), 119-138

Harding, R.. \& Hamilton, P. (2008). Working girls: Abuse or choice in street-level sex work? A study of homeless women in Nottingham. British Journal of Social Work, 39(6), 1-20.

Harding, S. (1993). Rethinking standpoint epistemology: What is "strong objectivity?". In L. Alcoff., \& E. Potter., (Eds.), Feminist epistemologies (pp. 49-82). New York: Routledge.

Harding, S. (1998). Is there a feminist method? In S. Kemp., \& J. Squires., (Eds.), Feminisms (pp. 160-170). Oxford: Oxford University Press.

Harris, M., Nilan, P., \& Kirby, E. (2011). Risk and risk management for Australian sex workers. Qualitative Health Research, 21(3), 386-398. 
Hawkes, G. (2005). Naughty but nice, or never on Sundays? Sex and sin, past and present. In G. Hawkes., and J. Scott (Eds.), Perspectives in human sexuality (pp. 155165). South Melbourne: Oxford University Press.

Hemynge, B. (1967). Prostitution in London. In H. Mayhew (Ed.), London labour and London poor (pp. 210-226). London: Frank Cass and Co.

Hoigard, C., \& Finstad, L. (1992). Backstreets : prostitution, money, and love. Cambridge: Polity.

Home Office. (2004). Paying the Price: A consultation document. London: Home Office.

Home Office. (2006). A coordinated prostitution strategy. London: Home Office

Hubbard, P. (1997). Red light districts and toleration zones: geographies of female street prostitution in England and Wales. Area, 29(2), 129-140.

Hubbard, P. (1998). Community action and the displacement of street prostitution: Evidence from British cities. Geoforum, 29(3), 269-286.

Hubbard, P. (1999). Researching female sex work: Reflections on geographical exclusion, critical methodologies and "useful" knowledge. Area, 31(3), 229-237.

Hubbard, P. (2004). Cleansing the metropolis: sex work and the politics of zero tolerance. Urban Studies, 41(9), 1687-1702.

Hubbard, P. (2006). Out of touch and out of time? The contemporary policing of sex work. In R. Campbell., \& M. O’Neill (Eds.), Sex work now (pp. 1-32). Cullompton: Willan.

Hubbard, P., \& Sanders, T. (2003). Making space for sex work: female street prostitution and the production of urban space. International Journal of Urban and Regional Research, 27(1), 73-87.

Hubbard, P., \& Scoular, J. (2009). Making the vulnerable more vulnerable? The contradictions of British street prostitution policy. In D. Canter., M. Ioannou., and D. Youngs (Eds.), Safer Sex in the City: The experience and management of street prostitution (pp. 135-153). Surrey: Ashgate.

Jackson, S. (1983). Childhood and sexuality. Oxford: Basil Blackwell.

Jeffrey, L.A., \& Sullivan, B. (2009). Canadian sex work Policy for the $21^{\text {st }}$ century: Enhancing rights and safety, lessons from Australia. Canadian Political Science Review, 3(1), 57-76.

Jeffreys, E. (2005). In defence of prostitution. Social Alternatives, 24(2), 20.

Jeffreys, S. (1997). The idea of prostitution. North Melbourne: Spinifex. 
Jones, A. (2011, May 4). Sex-trade workers say Ottawa trivializing their serious claims in appeal. The Canadian Press. Retrieved June 1, 2011, from http://www.albertalocalnews.com/reddeeradvocate/news/national/Sextrade_workers_say_Ottawa_trivializing_their_claims_121276884.html.

Jordan, J. (1991). Working girls - women in the New Zealand sex industry talk to Jan Jordan. Auckland: Penguin.

Jordan, J. (2005). The Sex industry in New Zealand: A literature review. Wellington: The Ministry of Justice.

Jordan, J. (2008). Serial survivors: Women's narratives of surviving rape. Sydney: The Federation Press.

Kane, S. (1991). HIV, heroin, and heterosexual relations. Social Science Medicine, 32(9), 1037-50.

Kantola, J., \& Squires, J. (2004). Discourses surrounding prostitution policy in the UK. European Journal of Women's Studies, 11(1), 77-101.

Kelly, L., Burton, S., \& Regan, L. (1994). Researching women's lives or studying women's oppression? Reflections on what constitutes feminist research. In M. Maynard \& J. Purvis (Eds.), Researching women's lives from a feminist perspective (pp. 27-48). London: Taylor \& Francis.

Kesler, K. (2002). Is a feminist stance in support of prostitution possible? An exploration of current trends. Sexualities, 5(2), 219-235.

Kempadoo., K. and Doezema, J. (1998). Global sex workers: rights, resistance and redefinition. Routledge: New York.

Kingston, S. (2009). Demonising desire: Men who buy sex and prostitution policy in the UK. Research for sex work, 11, 13-14.

Kingston, S. (2010). Intent to criminalize: Men who buy sex and prostitution policy in the UK. In K. Hardy, S. Kingston \& T. Sanders (Eds.), New sociologies of sex work (pp. 23-38). Surrey: Ashgate.

Kinnell, H. (2006a). Murder made easy: the final solution to prostitution? In R.

Campbell., \& M. O’Neill (Eds.), Sex work now (pp. 141-168). Cullompton: Willan.

Kinnell, H. (2006b). Clients of female sex workers: men or monsters? In R.

Campbell., \& M. O’Neill (Eds.), Sex work now (pp. 212-234). Cullompton: Willan.

Kinnell, H. (2008). Violence and sex work in Britain. Cullompton: Willan.

Kitzinger, C. (2004). Feminist approaches. In C. Seale., G. Giampietro., J. F. Gubrium., \& D. Silverman (Eds.), Qualitative research practice (pp. 125-141).

London: Sage. 
Kurtz, S. P., Surratt, H.L., Inciardi, J.A., \& Kiley, M.C. (2004). Sex work and "date" violence. Violence Against Women, 10(4), 357-385.

Leask, A. (2011, March 11). Homeowners enraged as sex 'skanks' move in. New Zealand Herald. Retrieved March 13, 2011, from

http://www.nzherald.co.nz/nz/news/article.cfm?c_id=1\&objectid=10711562

Lees, S. (1997). Ruling passions: Sexual violence, reputation and the law. Open University Press: Buckingham.

Lee-Treweek, G., \& Linkogle, S. (2000). Danger in the field: Risk and ethics in Social Research. New York: Routledge.

Leigh, C. (1997). Inventing sex work. In J.Nagle. (Ed.), Whores and other feminists. London: Routledge. 225-231

Letherby, G. (2003). Feminist research in theory and practice. Buckingham: Open University Press.

Levi-Minzi, M., \& Shields, M. (2007). Serial sexual murderers and prostitutes as their victims: Difficulty profiling perpetrators and victim vulnerability as illustrated by the Green River case. Brief Treatment and Crisis Intervention, 7(1), 77-89.

Liamputtong, P. (2007). Researching the vulnerable. London: Sage.

Littlejohn, R. (2006, December 18). Spare us the 'people's prostitute' routine. Mail Online. Retrieved August 4, 2010, from

http://www.dailymail.co.uk/debate/columnists/article-423549/LittlejohnSparePeoples-Prostitute-routine-.html

Lopes, A. (2006). Sex workers and the labour movement in the UK. In R. Campbell., \& M. O’Neill (Eds.), Sex work now (pp. 263-289). Cullompton: Willan.

Lowman, J. (2000). Violence and the outlaw status of (street) prostitution in Canada. Violence Against Women, 6(9), 987-1011.

Lupton, D. (2006). Sociology and risk. In G. Mythen \& S. Walklate (Eds.), Beyond the risk society: Critical reflections on risk and human security (pp. 11-24).

Maidenhead: Open University Press.

Maher, L. (1997). Sexed work: gender, race and resistance in a Brooklyn drug market. Oxford: Clarendon Press.

Mahood, L. (1990). The Magdalenes: prostitution in the nineteenth century. London: Routledge.

Malloch, M.S. (2004). 'Risky' women, sexual consent and criminal 'justice'. In M. Cowling., \& P. Reynolds (Eds.), Making sense of sexual consent (pp. 127-139).

Aldershot: Ashgate. 
Manukau City Council. (2010). Manukau City Council (Regulation of Prostitution in Specified Places) Bill.

Marrin, M. (2006, December 17). Now end the hypocrisy on Prostitution. The Sunday Times. Retrieved August 2, 2010, from

http://www.timesonline.co.uk/tol/comment/columnists/minette_marrin/article756147. ece

Matthews, R. (2008). Prostitution, politics and policy. Oxon: Routledge-Cavendish.

Matthews, R., \& O’Neill, M. (2003). Prostitution. Hants: Routledge.

Maynard, M. (1994). Methods, practice and epistemology: The debate about feminism and research. In M. Maynard., \& J. Purvis. (Eds.), Researching women's lives from a feminist perspective (pp. 10-27). London: Taylor \& Francis.

McLeod, E. (1982). Women working: Prostitution now. London: Croom Helm

McCroskrie, B. (2011, March 11). Christchurch families now victims of prostitution law. Family First Press Release. Retrieved April 2, 2011, from

http://www.scoop.co.nz/stories/PO1103/S00090/christchurch-families-now-victimsof-prostitution-law.htm

McClure, L. K. (2005). Introduction. In L. K., McClure \& C. A. Faraone (Eds.), Prostitutes and courtesans in the ancient world (pp. 3-18). Madison: University of Wisconsin Press.

McGinn, T. (2004). The economy of prostitution in the Roman world: A Study of Social History and the Brothel. Ann Abor: University of Michigan Press.

McKeganey, N. (2006). Street prostitutes in Scotland: The views of working women. Drugs, education, prevention and policy, 13(2), 151-166.

McKeganey, N., \& Barnard, M. (1992). AIDS, drugs and sexual risk. Buckingham: Open University Press.

McKeganey, N., \& Barnard, M. (1996). Sex work on the street: prostitutes and their clients. Bristol: Open University Press.

McKinnon, C. A. (1993). Prostitution and civil rights. Michigan Journal of Gender and Law, 1, 13-31.

Melrose, M. (2002). Labour pains: Some considerations on the difficulties of researching juvenile prostitution. International Journal of Social Research Methodology, 5(4), 333-351

Melrose, M. (2007). The government's new prostitution strategy: A cheap fix for drug-using sex workers? Community Safety Journal, 6(1),18-26. 
Melrose, M. (2009). Out on the streets and out of control? Drug-using sex workers and the prostitution strategy. In J. Phoenix (Ed.), Regulating sex for sale: Prostitution policy reform in the UK (pp. 83-97). Bristol: The Policy Press.

Miller, J. (1993). "Your life is on the line every night you're on the streets": Victimization and the resistance among street prostitutes. Humanity and Society, 17(4), 422-446.

Miller, J. (1995). Gender and power on the streets: street prostitution in the era of crack cocaine. Journal of Contemporary Ethnography, 23(4), 427-452.

Miller, J. (1997). Researching violence against street prostitutes. In M. Schwartz (Ed.), Researching Violence Against Women (pp. 144-156). Thousand Oaks: Sage.

Miller, J., \& Schwartz, M.D. (1995). Rape myths and violence against street prostitutes. Deviant Behaviour, 16(1), 1-23.

Monto, M. (2000). Why men seek out prostitutes. In R. Weitzer (Ed.), Sex for sale: Prostitution, pornography, and the sex industry (pp. 67-83). New York: Routledge.

Monto, M. A. (2004). Female prostitution, customers, and violence. Violence Against Women, 10(2), 160-188.

Morgan Thomas, R. (2009). From 'toleration' to zero tolerance: a view from the ground in Scotland. In J. Phoenix (Ed.), Regulating sex for sale: Prostitution policy reform in the UK (pp. 137-158). Bristol: The Policy Press.

Mossman, E. (2008). International approaches to decriminalising or legalising Prostitution. Wellington: Ministry of Justice.

Mossman, E., and Mayhew, P. (2007). Central government aims and local government responses: The Prostitution Reform Act 2003. Wellington: Ministry of Justice.

Mossman, E., \& Mayhew, P. (2008). Key informant interviews review of the Prostitution Reform Act 2003. Wellington, Ministry of Justice.

Mullins, C. (2008). Negotiating the streets: Women, power and resistance in streetlife social networks. In T. Anderson (Ed.), Neither villain nor victim: empowerment and agency among female substance abusers (pp. 65-83), London: Rutgers University Press.

Nagle, J. (1997). Whores and other feminists. Routledge: London

New Zealand Herald. (2005, July 13). Man fined for endangering prostitute. New Zealand Herald. Retrieved August 2, 2010, from http://www.nzherald.co.nz/prostitution/news/article.cfm?c_id=612\&objectid=103355 76 
New Zealand Herald. (2009, April 19). Community group squares off with street prostitutes. Retrieved May 1, 2009, from

http://www.nzherald.co.nz/prostitution/news/article.cfm?c_id $=612 \&$ objectid $=105674$ 03

Nixon, K., Tutty, L., Downe, P., Gorkoff, K., \& Ursel, J. (2002). The everyday occurrence: Violence in the lives of girls exploited through prostitution." Violence Against Women, 8(9), 1016-104

Oakley, A. (1981). Interviewing women: a contradiction in terms. In H. Roberts (Ed.), Doing feminist research (pp. 30-61). London: Routledge.

O'Connell Davidson, J. (1998). Prostitution, power and freedom. Cambridge: Polity Press.

O’Neill, M. (1996). Researching prostitution and violence: towards a feminist praxis. In M. Hester., L. Kelly., \& J. Radford (Eds.), Women, violence and male power: feminist activism, research and practice (pp. 130-147). Buckingham: Open University Press.

O’Neill, M. (1997). Prostitute women now. In G. Scrambler., \& A. Scrambler (Eds.), Rethinking prostitution: purchasing sex in the 1990s (pp. 3-28). London: Routledge.

O’Neill, M. (2001). Prostitution and feminism : towards a politics of feeling. Cambridge: Blackwell Publishers.

O'Neill, M. (2008). Sex, violence and work: transgressing binaries and the vital role of services to sex workers in public policy reform. In G. Letherby., K. Williams., P.Birch., \& M.Cain (Eds.), Sex as crime? (pp. 80-98). Cullompton: Willan.

O'Neill, M. (2009). Community safety, rights, redistribution and recognition: towards a coordinated prostitution strategy. In J. Phoenix (Ed.), Regulating sex for sale: Prostitution policy reform in the UK (pp. 47-65). Bristol: The Policy Press.

O'Neill. (2010). Cultural criminology and sex work: Resisting regulation through radical democracy and participatory action research (PAR). Journal of Law and Society, 37(1), 210-232.

O'Neill, M., \& Barberet, R. (2000). Victimisation and the social organisation of prostitution in England and Spain. In R. Weitzer (Ed.), Sex for sale: prostitution, pornography and the sex industry (pp. 123-137). London: Routledge.

O'Neill, M., \& Campbell, R. (2002). Working together to create change. Walsall prostitution consultation research. A participatory action research project. Staffordshire University and Liverpool Hope University College. 
O’Neill, M., Campbell, R., Hubbard, P., Pitcher, J., \& Scoular, J. (2008). Living with the other: Street sex work, contingent communities and degrees of tolerance. Crime, Media and Culture, 4(1), 73-93.

O'Neill, M., Campbell, R., James, A., Webster, M., Green, K., \& Patel, J., et al. (2004). Red Lights and Safety Zones. In D. Bell., \& M. Jayne (Eds.), City of quarters: Urban villages in the contemporary city (206-223). Aldershot: Ashgate.

O’Neill, M,. \& Pitcher, J. (2010). Sex work, communities, and public policy in the UK, In M. Ditmore., A.Levy., \& A. Willman (Eds.), Sex work matters: Exploring money, power and intimacy in the sex industry (pp. 203-218). New York: Zed Books.

Östergren, P. (2004). Sex workers critique of Swedish prostitution policy. Retrieved March 15 2009, from http://www.petraostergren.com/pages.aspx?r_id=40716.

Pauw, I., \& Brener, L. (2003). "You are just whores, you can't be raped" : barriers to safer sex practices among women street sex workers in Cape Town. Culture, Health \& Sexuality 5(6), $465-481$.

Pearce, J. J. (1999). Selling sex, doing drugs and keeping safe. In A. Marlow and G. Pearson (Eds.), Young people, drugs and community safety (pp. 118-127). London: Russell House.

Perkins, R. (1991). Working girls: Prostitutes, their life and social control. Canberra: Australian Institute of Criminology.

Perkins, R. (1993). Street prostitution and its manipulation by law in New South Wales. In P. Easteal., \& S. McKillop (Eds.) Women and the law: Proceedings of a conference held 24-26 September 1991. Canberra: Australian Institute of Criminology.

Perkins, R., and Bennett, G. (1985). Being a prostitute. Sydney: Allen and Unwin. Pheterson, G. (1987). The social consequences of unchastity. In F. Delacoste., \& P. Alexander (Eds.), Sex Work: writings by women in the sex industry (pp. 231-246). Pittsburgh: Cleis Press.

Pheterson, G. (1989). A vindication of the rights of whores. Seattle: Seal Press.

Pheterson, G. (1996). The prostitution prism. Amsterdam: Amsterdam University Press.

Phoenix, J. (1999). Making sense of prostitution. New York: St Martin's Press.

Phoenix, J. (2000). Prostitute identities: Men, money and violence. The British Journal of Criminology, 40(1), 37-55. 
Phoenix, J. (2006). Regulating prostitution: Controlling women's lives. In F. Heidensohn (Ed.), Gender and justice: New concepts and approaches (pp. 76-95). Cullompton: Willan.

Phoenix, J. (2008a). Reinventing the wheel: contemporary contours of prostitution regulation. In G. Letherby., K. Williams., P. Birch., \& M. Cain (Eds.), Sex as crime? (pp. 27-46). Cullompton: Willan.

Phoenix, J. (2008b). Be helped or else! Economic exploitation, male violence and prostitution policy in the UK. In V.E Munro., \& D.G Marina (Eds.), Demanding sex: Critical reflections on the regulation of prostitution (pp. 35-50). Aldershot: Ashgate.

Phoenix, J. (2009). Regulating sex for sale: Prostitution policy reform in the UK. Bristol: Policy Press.

Philip, N. (1991). Working girls: An illustrated history of the oldest profession. London: Bloomsbury Publishing.

Pitcher, J. (2006). Support services for women working in the sex industry. In R. Campbell., \& M. O’Neill (Eds.), Sex work now (pp. 235-262). Cullompton: Willan.

Pitcher, J., Campbell, R., Hubbard, P., O'Neill, M., \& Scoular, J. (2006). Living and working in areas of street sex work: from conflict to coexistence. Bristol: Joseph Rowntree Foundation

Plumridge, E. (2001). Rhetoric, reality and risk outcomes in sex work. Health, Risk and Society, 3(2), 199-215.

Plumridge, E., \& Abel, G. (2001). A 'segmented' sex industry in New Zealand: sexual and personal safety of female sex workers. Australia and New Zealand Journal of Public Health, 25(1), 78-83.

Prestage, G., \& Perkins, R. (1994). Introduction. In R. Perkins., G. Prestage., R. Sharp., \& F. Lovejoy (Eds.), Sex work and sex workers in Australia (pp. 6-21). Sydney: University of New South Wales Press.

Prostitution Law Review Committee. (2008). Report of the Prostitution Law Review Committee on the operation of the Prostitution Reform Act 2003. Wellington:

Ministry of Justice.

Prostitution Reform Act (2003).

http://www.legislation.govt.nz/act/public/2003/0028/latest/whole.html\#DLM197821.

Pyett, P., \& Warr, D. (1997). Vulnerability on the streets: Female sex workers and HIV risk. AIDS Care, 9(5), 539.

Pyett, P., \& Warr, D. (1999). Women at risk in sex work: strategies for survival. Journal of Sociology, 35(2), 183-197. 
Quadara, A. (2008). Sex workers and sexual assault in Australia: prevalence, risk and safety. Melbourne: Australian Centre for the Study of Sexual Assault.

Queen, C. (1997). Sex radical politics, sex-positive feminist thought and whore stigma. In J. Nagle (Ed.), Whores and other feminists (pp. 125-135). London: Routledge.

Raphael, J., \& Shapiro, D.L. (2004). Violence in indoor and outdoor prostitution venues. Violence Against Women, 10(2), 126-139.

Raymond, J. G. (1998). Prostitution as violence against women: NGO stonewalling in Beijing and elsewhere. Women's Studies International Forum, 21(1), 1-9.

Raymond, J. G. (2004). Prostitution on Demand: Legalizing the Buyers as Sexual Consumers. Violence Against Women, 10(10), 1156-1186.

Rhodes, T. (1997). Risk theory in epidemic times: sex, drugs and the social organisation of 'risk behaviour'. Sociology of Health \& Illness, 19(2), 208-227.

Rhodes, T., Simić M., Baroš, S., Platt, L., \& Žikić, B. (2008). Police violence and sexual risk among female and transvestite sex workers in Serbia: qualitative study. British Medical Journal, 337, a811.

Richards, L. (1999). Using Nvivo in Qualitative Research. Melbourne: Qualitative Solutions and Research Pty.

Richardson, D. (1990). AIDS education and women: sexual and reproductive issues. In P. Aggleton, P., Davies., \& G. Hart. AIDS: Individual, cultural and policy dimensions (pp. 169-179). Brighton: Falmer press.

Richardson, D., \& May, H. (1999). Deserving victims?: Sexual status and the social construction of violence. The Sociological Review, 47(2), 308-331.

Ringdal, N. (2004). Love for sale: A global history of prostitution. London: Atlantic Books.

Roberts, N. (1992). Whores in history : prostitution in western society. London: Harper Collins.

Robinson, J. (1983). Of diverse persons, men and women and whores: women and crime in nineteenth century Canterbury. Unpublished Masters dissertation. University of Canterbury: Christchurch.

Robinson, J. (1987). The Oldest Profession. In S. Cox (Ed.), Public \& Private Worlds: women in contemporary New Zealand (pp. 177-191). Wellington: Allen \& Unwin in association with the Port Nicholson Press. 
Roche, B., Neaigus, A., \& Miller, M. (2005). Street smarts and urban myths: women, sex work, and the role of storytelling in risk reduction and rationalization. Medical Anthropology Quarterly, 19(2), 149-170.

Rosen, E., and Venkatesh, S.A. (2008). A "Perversion" of choice: Sex work offers just enough in Chicago's urban ghetto. Journal of Contemporary Ethnography, 37(4), 417441 .

Roth, M. T. (2005). Marriage, divorce and the prostitute in ancient Mesopotamia. In C. A. Faraone., \& K.L. McClure (Eds.), Prostitutes and courtesans in the ancient world (pp. 21-39). Madison: University of Wisconsin Press.

Russell, D. (1984). Sexual exploitation, rape, child sexual abuse and workplace harassment. London: Sage.

Ryan, A. (2005). From dangerous sexualities to risky sex: Regulating sexuality in the name of public health. In G. Hawkes., \& J. Scott (Eds.), Perspectives in human sexuality (pp. 203-216). South Melbourne: Oxford University Press.

Sagar, T. (2005). Street Watch: Concept and Practice, Civilian participation in street prostitution control. British Journal of Criminology, 45(1), 98-112.

Sagar, T. (2007). Tackling on-street sex work: Anti-social behaviour orders, sex workers and inclusive inter-agency initiatives. Criminology and Criminal Justice, $7(2), 153-168$.

Salfati, C. G., James, A.R., \& Ferguson, L. (2008). Prostitute homicides: A descriptive study. Journal of Interpersonal Violence, 23(4), 505-543.

Sallmann, J. (2010). Living with stigma: Women's experiences of prostitution and substance use. Affilia, 25 (2), 146-159.

Sanders, T. (2001). Female street sex workers, sexual violence, and protection strategies. Journal of Sexual Aggression, 7(1), 5 -18.

Sanders, T. (2004a). The risks of street prostitution: Punters, police and protesters. Urban Studies, 41(9), 1703-1717.

Sanders, T. (2004b). A continuum of risk? The management of health, physical and emotional risks by female sex workers. Sociology of Health \& Illness, 26(5), 557-574.

Sanders, T. (2005). Sex Work: A risky business. Cullompton: Willan.

Sanders, T. (2006a). Researching sex work : dynamics, difficulties, and decisions. In D. Hobbs., \& R. Wright. The SAGE handbook of fieldwork (pp. 201-221). London: Thousand Oaks.

Sanders, T. (2006b). Sexing Up the subject: Methodological nuances in researching the female sex industry. Sexualities, 9(4), 449-468. 
Sanders, T. (2006c). Sexuality and risk. In Beyond the risk society: Critical reflections on risk and human sexuality. In G. Mythen \& S. Walklate (Eds.), Beyond the Risk Society: Critical Reflections on Risk and Human Security (pp. 96-113). Maidenhead: Open University Press.

Sanders, T. (2006d). Female sex workers as health educators with men who buy sex: Utilising narratives of rationalisations. Social Science and Medicine, 62(10), 24342444.

Sanders, T. (2007). Protecting the health and safety of female sex workers: The responsibility of all. BJOG An International Journal of Obstetrics and Gynaecology. 114(7), 791-793.

Sanders, T. (2009). Controlling the 'anti sexual' city: Sexual citizenship and the disciplining of female street sex workers. Criminology and Criminal Justice, 9(4), 507-525.

Sanders, T., \& Campbell, R. (2007). Designing out vulnerability, building in respect: violence, safety and sex work policy. The British Journal of Sociology, 58(1), 1-19.

Sanders, T., O’Neill, M., \& Pitcher, J. (2009). Prostitution: sex work, policy and politics. London: Thousand Oaks.

Schwandt, T. A. (2000). Three epistemological stances for narrative enquiry: Interpretivism, hermeneutics, and social constructivism. In D. K. Denzin., \& Y. S. Lincoln (Eds.), Handbook of qualitative research (189-214). London: Sage.

Scotpep. (2007). 17 $7^{\text {th }}$ December 2007. Retrieved 04 July 2008, from http://www.scotpep.org.uk/

Scott, J. (2005). A labour of sex? Female and male prostitution. In G. Hawkes., \& J. Scott (Ed), Perspectives in human sexuality (pp. 233-251). South Melbourne: Oxford University Press.

Scoular, J. (2004). The 'subject' of prostitution: Interpreting the discursive, symbolic and material position of sex/work in feminist theory. Feminist Theory, 5 (3), p. 343355 .

Scoular, J. (2010). What's law got to do with it? How and why law matters in the regulation of sex work. Journal of Law and Society, 37(1), 12-39.

Scoular, J. \& O'Neill, M. (2008). Legal incursions into supply/demand: Criminalising and responsibilising the buyers and sellers of sex in the UK. In V.E Munro., \& D.G Maria (Eds.), Demanding sex: Critical reflections on the regulation of prostitution (pp. 13-33). Aldershot: Ashgate. 
Scoular, J. \& O'Neill, M. (2010). Regulating prostitution: Social inclusion, responsibilitisation and the politics of prostitution reform. British Journal of Criminology, 47, 764-778.

Scoular, J., Pitcher, J., Campbell, R., Hubbard, P., \& O'Neill, M. (2007). What's antisocial about sex work? The changing representation of prostitution's incivility. Community Safety Journal, 6(1), 11-17.

Scoular, J. \& O'Neill, M. (2010). Regulating prostitution: Social inclusion, responsibilitisation and the politics of prostitution reform. British Journal of Criminology, 47, 764-778.

Scrambler, G. (1997). Conspicuous and inconspicuous sex work: the neglect of the ordinary and the mundane. In G. Scrambler., \& A. Scrambler (Eds.), Rethinking prostitution: purchasing sex in the 1990s (pp. 105-120). London: Routledge.

Scrambler, G., \& Scrambler, A. (1997). Afterword. In G. Scrambler., \& A. Scrambler (Eds.), Rethinking prostitution: purchasing sex in the 1990s (pp. 180-188). London: Routledge.

Scutt, J. (1993). Judicial vision: rape, prostitution and the 'chaste woman'. Women's Studies International Forum, 17 (4), 345-456.

Selby, H., \& Canter, D. (2009). The relationship between control strategies employed by street prostitutes and levels and varieties of client violence. In D. Canter., M. Ioannou., \& D. Youngs (Eds), Safer sex in the city: The experience and management of street prostitution (pp. 13-29). Surrey: Ashgate.

Shannon, K., Kerr, T., Strathdee, S., Shoveller, J., Montaner, J., \& Tyndall, M. (2009). Prevalence and structural correlates of gender based violence among a prospective cohort of female sex workers. British Medical Journal, 339, b2939.

Sharpe, K. (1998). Red light, blue light: Prostitutes, punters and the police. Aldershot: Ashgate.

Silbert, M. (1981). Sexual assault of prostitutes. San Francisco: Delancey Street Foundation.

Silbert, M.H., \& Pines, A.M. (1981). Occupational hazards of street prostitutes. Criminal Justice and Behaviour, 8, 395-399.

Silbert, M.H., \& Pines, A.M. (1982). Victimisation of street prostitutes. Victimology: an international journal 7, 122-133.

Simić , M., \& Rhodes, T. (2009), Violence, dignity and HIV vulnerability: Street sex work in Serbia. Sociology of Health \& Illness, 31(1), 1-16

Silverman, D. (1993). Interpreting qualitative data. London: Sage Publications. 
Skeggs, B. (1994). Situating the production of feminist ethnography. In M. Maynard., \& J. Purvis (Eds.), Researching women's lives from a feminist perspective (pp. 72-91). New York: Taylor \& Francis.

Skinner, M. B. (2005). Sexuality in Greek and Roman culture. Malden: Blackwell.

Smyth, L. (2000). Making sense of qualitative research. Kai Taikii Nursing New Zealand: Auckland.

Snook, L. (2003). The ethics and politics of social research. In C. Davidson., \& M. Tolich (Eds.), Social science research in New Zealand: Many paths to understanding (pp. 71-87). Auckland: Pearson Education New Zealand Limited.

Stanko, E. (1985). Intimate intrusions: Women's experiences of male violence, rape, child sexual abuse and sexual harassment. London: Routledge

Stanley, L., \& Wise, S. (1983). Breaking out: feminist consciousness and feminist research. London: Routledge.

Sterk, C. (2000). Tricking and tripping: Prostitution in the era of AIDS. New York: Social Change Press.

Steward, I. (2009, December 17). Ex-cop jailed for sex with prostitute. The Christchurch Press. Retrieved January 12, 2010, from http://www.nzherald.co.nz/nz/news/article.cfm?c_id=1\&objectid=10616073

St James, M. (1979, April 29). San Francisco Examiner, Retrieved June 21, 2011, from http://maggiemcneill.wordpress.com/quotes/

Sullivan, B. (1991). Feminist approaches to the sex industry. In S. Gerull., \& B. Halstead (Eds.), Sex industry and public policy (pp. 7-14). Canberra: Australian Institute of Criminology.

Sullivan, B. (2004). Prostitution and consent: Beyond the liberal dichotomy of 'free or forced'. In Cowling, M., and Reynolds, P (Eds.), Making sense of sexual consent (pp. 127-139). Aldershot: Ashgate.

Sullivan, B. (2007). Rape, prostitution and consent. The Australia and New Zealand Journal of Criminology, 40(2), 127-142.

Sullivan, B. (2008). Working in the sex industry in Australia: The reorganisation of sex work in Queensland in the wake of law reform, Labour \& Industry, 18(3), 73-92.

Sullivan, B. (2010). When (some) prostitution is legal: The impact of law reform on sex work in Australia. Journal of Law and Society 37(1), 85-104.

Sullivan, M. L. (2007). Making Sex Work: a failed experiment with legalised prostitution. North Melbourne: Spinefex. 
The Christchurch Press (2008, December 12). More street sex control sought. The Christchurch Press. Retrieved January 12, 2009, from http://www.stuff.co.nz/thepress/772108/More-street-sex-control-sought

Trotter, H. (2007). Navigating risk: Lessons from the dockside sex trade for reducing violence in South Africa's prostitution industry. Sexuality Research \& Social Policy Journal of NSRC 4(4), 106-119.

Valera, R., Sawyer, R.G., \& Schiraldi, G.R. (2001). Perceived health needs of innercity street prostitutes: a preliminary study. Journal of Health Behaviour, 25(1), 50-59.

Van Doorninck, M., \& Campbell, R. (2006). 'Zoning' street sex work: the way forward? In R. Campbell., \& M. O’Neill (Eds.), Sex work now (pp. 62-91). Cullompton: Willan.

Vanwesenbeeck, I. (2001). Another decade of social scientific work on sex work: A review of research 1990-2000. Annual Review of Sex Research, 12, 242-289

Wagenaar, H. and S. Altink (2009). To toe the line: Streetwalking as contested space. In D. Canter., M. Ioannou., \& D. Youngs (Eds), Safer sex in the city: The experience and management of street prostitution (pp. 155-168). Surrey: Ashgate.

Wahab, S. (2003). Creating knowledge collaboratively with female sex workers: Insights from a qualitative, feminist, and participatory study. Qualitative Inquiry, $9(4), 625-642$.

Wahab, S., \& Sloan, L. (2004). Ethical dilemmas in sex work research. Research for sex work, 7, 3-4.

Walklate, S. (1997). Risk and criminal victimisation: A modernist dilemma? British Journal of Criminology. 37 (1), 35-45

Walkowitz, J. (1977). The Making of an outcast group: Prostitutes and working women in nineteenth century Plymouth and Southampton. In M. Vicinus (Ed.), $A$ widening sphere: Changing roles of Victorian women (pp. 72-93), Bloomington: Indiana University Press.

Walkowitz, J. (1980). Prostitution and Victorian Society: women, class, and the state. Cambridge: Cambridge University Press.

Warr, D. J. (2004). Stories in the flesh and voices in the head: Reflections on the context and impact of research With disadvantaged populations. Qualitative Health Research, 14(4), 578-587.

Weitzer, R. (2000). Sex for Sale: prostitution, pornography and the sex industry. London: Routledge. 
Weitzer, R. (2005a). Flawed theory and method in studies of prostitution. Violence Against Women 11(7), 934-949.

Weitzer, R. (2005b). New directions in research on prostitution. Crime, Law and Social Change, 43(4-5), 211-235.

Weitzer, R. (2006). Moral crusade against prostitution. Society, 43(3), 33-38.

Weitzer, R. (2007). Prostitution: facts and fiction. Contexts, 6(4), 28-33.

Weitzer, R. (2010). The mythology of prostitution: Advocacy research and public policy. Sexuality Research and Social Policy, 7, 15-29.

West (2000). Prostitution: collectives and the politics of regulation. Gender, Work and Organisation, 7(2), 106-118.

Whittaker, D. and G. Hart (1996). Research note: Managing risks - the social organisation of indoor sex work. Sociology of Health \& Illness 18(3), 399-414.

Williams, K. (2008). From the oblivious to the vigilante: the views, experiences and responses of residents living in areas of street sex work. In G. Letherby., K. Williams., P.Birch., \& M.Cain (Eds.), Sex as crime? (pp. 172-189). Cullompton: Willan.

Williamson, C. and T. Cluse-Tolar (2002). Pimp-controlled prostitution: Still an integral part of street life. Violence Against Women 8(9), 1074-1092.

Williamson, C. \& Folaron, G. (2001). Violence, risk, and survival strategies of street prostitution. Western Journal of Nursing Research, 23(5), 463-475.

Williamson, C. \& Folaron, G. (2003). Understanding the experiences of street level prostitutes. Qualitative Social Work, 2, 271- 287.

Willis, J. W. (2007). Foundations of qualitative research: Interpretive and critical approaches. Thousand Oaks: Sage.

Wojcicki, J. M., \& Malala, J. (2001). Condom use, power and HIV/AIDS risk: sexworkers bargain for survival in Hillbrow/Joubert Park/Berea, Johannesburg. Social Science \& Medicine 53(1), 99-121.

Woodward, C., Fischer, J., Najman, J.M., \& Dunne, M. (2004). Selling sex in Queensland. Brisbane: Prostitution Licensing Authority.

Wotton, R. (2005). The Relationship between street-based sex workers and the police in the effectiveness of HIV prevention strategies, Research for sex work, 8, 11-13. 


\section{Appendices}

\section{Appendix A: Street based sex worker interview guide}

First off, it would be good to hear about how you started working and around about when this was.

(a) Thinking back to before you started working, what did you imagine sex work would be like?

(b) How did you end up getting into it? How long have been working on street? How old were you when you started?

(c) What led to you working on the street?

(d) How much did you know about street work before you started working?

(d) Looking back, is there anything that you wish you had known before you started working?

\section{Perceptions of risk}

I'd like to try and understand more about how you feel about your work and the next questions are about this.

(a) What do you like about your work? (Why/why not?)

(b) Are there any bad things about your work? What are they?

(c) What are the advantages of working from the street?

(d) Is there anything bad about working from the street?

(e) How do you feel about your safety out there in general?

(f) When you are working do you take any risks? (In what circumstances/why? Can also lead into how the risks are managed)

\section{Perceptions of vulnerability}

(a) Have you felt anxious or afraid when you've been working on the street? When/why/what did you do to cope?

(b) How do you feel about the safety of other workers you know are out there?

(Prompt around how they feel about younger people (if they are older) 
(c) Do you think that other workers worry about you when you are out there? What about other people who aren't sex workers?

(d) What would you say to people who say that sex work is not safe?

\section{Feelings of safety}

I'm really keen to learn about how you feel when you are working and whether or not you feel safe. The next questions are on this. If you have any experiences that you want to share you are welcome to but you don't have to talk about anything that you are not comfortable with.

(a) Before you go out and work, how do you feel and what do you think about?

(b) Is there anything that would stop you going out to work on a particular night? What?

(c) How do you feel generally when you are out working?

(d) What makes you feel safe when you are working? (Why/in what circumstances?)

(e) What makes you feel unsafe?

(f) How confident do you feel when you are working?

(g) How confident do you feel when you are not working?

(h) How much control do you feel you have when you are working? (What factors does this depend on, i.e. client, mood, drugs/alcohol, support of others)

(i) How much hassle do you get from people when you are working?

(j) How much is violence something that you worry about when you are working?

(k) I'm going to read out some violent situations and it would be really useful if you could let me know if these are things that you think about when you are out working.

(1) Being robbed, (2) being forced to stay with a client, or taken away somewhere you don't want to go (3) being bashed by a client (4) being raped or sexually assaulted, (5) client ripping off a condom, (6) being forcibly drugged (7) being murdered, (8) being 'stood over', (9) Being attacked by someone who isn't a client (who?), (10) Being insulted by passers by.

What is most worrying to you when you are working? What is least worrying to you? Is there anything on the list that doesn't worry you at all? Why? If nothing worries you, why?

(1) If any of these things happened to you would you report it to the police? Would you tell anyone else? Why? 
(m) I heard about the two women who were murdered whilst working on the street in 2005 and the woman who was murdered in December last year. Are you willing to talk about this?

If yes: When you heard about this, how did you feel? Did it make you think twice about working oin the street? Did others try to stop you? Did you do anything differently to protect yourself?

If no: Move on to next question

(n) Have you ever been in a situation that could have potentially been really dangerous if you hadn't got out of it? What happened, and what did you do?

\section{Strategies}

Thinking about how safe you feel when you are working on the street, it would be really useful for me to understand any things that you might do to look after yourself when you're out there. The next questions are about that. Any information and examples would be really helpful but if I ask about something that you think is too private just tell me you want to skip that part and we'll move on.

The first questions in this part are about how you decide whether or not to do a client.

- Experience and 'sixth sense'

(a) When a client approaches you and you are deciding whether or not to do the job, what are you thinking about?

(b) For what reasons might you refuse to do a client?

(c) What do you look out for as signs a client might not be safe?

- Screening and control

(a) At what point do you ask the client what service he wants and what the price will be? Is this always the same with every client?

(b) Who decides where you go for sex? How do you feel about this?

(c) Would you ever get in the car with more than one person? Why/why not?

- Regulars

(a) Do you have regular clients? Do you think it is good to have regular clients? Why?

(b) How do you deal with clients who get too full on? Can you think of any clients who have become a problem for you?

The next questions are about your contact with other workers in the area, and anyone else you might work with. 
- Peer support/working together

(a) Do you work alone or do you actually go out with another worker? What do you do to watch out for each other when you are working?

(b) How friendly is it on your corner?

(c) How much competition is there where you work for clients? What is this like?

(d) Who gives you advice on how to keep safe? What sort of advice have you been given? How important do you think this has been?

(e) Are there any circumstances where you wouldn't help another worker, or warn about a bad client?

- Pressure, coercion and the threat of being 'outed'

(a) Apart from other workers, have you ever asked someone else to watch out for you when you are working? Who was this person? How did you feel about this?

(b) Have you ever felt pressured into working on the street? How did this make you feel?

(c) Can you work on any corner you like? Why/why not?

(c) What would you do if a friend or family member said that they didn't want you to work anymore?

(d) How much do you worry about people finding out that you are working? Who do you not want to find out?

You probably know some people from PC and other places who come out at night and chat to workers. I want to talk to you about some of the things that they might do to try and support workers to stay safe.

- Agency provided resources

(a) A few years back, the PC in Christchurch made up a safety kit for street workers with a little book, a whistle, a notebook and pen, condom, lube etc. Did you get one? If yes did it help you? How did it help? If no do you think it sounds useful?

(b) Have you heard of the protext system that the PC run to warn about dodgy clients? What do you think of this?

(c) Have you heard of 'Ugly Mugs' books? Is protext better than these books? Why?

(d) Is there any other way that you find out about dodgy clients? 
(e) How much do you think the Police in Christchurch can help if things go wrong when you are working?

-Alcohol/drugs

(a) Do you drink or use at all socially? Would you work after drinking or using? Why/why not?

Thinking again about working in difficult situations, it would be really helpful to hear some more about how you manage when things get tough. This time I would like to hear more about how you manage bad clients. The first questions are based on potential situations and are quite personal. If any of the questions are too personal you don't have to answer them.

- Resisting coercion and sexual violence

(a) If you had agreed a location for sex and the client started driving somewhere else, what would you do? Or what would do if he locked the car doors without asking?

(b) Imagine you are about to do a client and he all of a sudden announces he isn't going to wear a condom. He uses every excuse under the sun, offers to pay you three times what you agreed and becomes really pushy about it. What would you do in this situation?

(c) If you were doing a client and he ripped the condom off while you were having sex what would you do?

(d) What would you do if a client tried to have anal sex and you hadn't agreed to it at the start?

(e) Would you be happy to kiss a client on the lips? If no, what would you do if a client started full on trying to kiss you while you were having sex?

(f) What would you do if a client tried to shove his fingers somewhere you didn't want them and was really forceful?

(g) You said earlier that you decide the price and take the money at (X) stage. What would you do if a client asked for his money back at the end?

- Remedial protection strategies

(a) If a client became really violent do you think you could defend yourself physically? What sort of things would have to happen for you to consider this?

(b) Do you carry any weapons to defend yourself with if a client gets violent? Have you ever had to use them? What happened?

(c) If a client got violent and you couldn't get away, what might you do in this situation? 
Everything you have told me has been really helpful. I just want to finish off with a couple of more general questions and get your views overall on anything you think might make street work safer.

\section{Improving safety}

(a) Thinking about all the things that you have told me about staying safe when you are working - what is the most important thing that you do? Is there anything that you feel you can really rely on?

(b) Can you think of any time where things have gone badly when you have been working where there is something you feel you could have done differently? What?

(c) As you mentioned earlier you have a lot of experience working in this part of the industry. Since sex work has been legal, do you feel safer? If yes, what has made you feel safer? (Note - only for people working prior to 2003)

(d) If street work was made illegal, would you stop working in the street? Would you have to do things differently?

(e) Imagine the police were given powers to arrest your clients for paying for services. What would this mean for your work?

(f) What would you tell people who say they want sex workers off the street?

(d) Is there anything that you think needs to change to make you feel safer in your work? What?

(e) If you knew someone who was thinking about starting out as a street based sex worker what advice would you give them to keep safe?

Thank you for taking part in this research 


\section{Appendix B: Socio-demographic questionnaire}

Day and Date:

Time:

\begin{tabular}{|l|l|}
\hline Place of Interview: & \\
\hline Drop in & 2 \\
\hline Home & 3 \\
\hline NZPC & 4 \\
\hline YCD & 5 \\
\hline Other (write in) & 7 \\
\hline
\end{tabular}

1. Within what age range are you now?

\begin{tabular}{|l|l|}
\hline Under 16 years & 1 \\
\hline $16-17$ years & 2 \\
\hline $18-21$ years & 3 \\
\hline $22-29$ years & 4 \\
\hline $30-45$ years & 5 \\
\hline Over 45 years & 6 \\
\hline Didn't answer & \\
\hline
\end{tabular}

2. Which ethnic group do you belong to?

\begin{tabular}{|l|l|}
\hline NZ European & 1 \\
\hline Māori & 2 \\
\hline Samoan & 3 \\
\hline Cook Island Māori & 4 \\
\hline Tongan & 5 \\
\hline
\end{tabular}




\begin{tabular}{|l|l|}
\hline Niuean & 6 \\
\hline Chinese & 7 \\
\hline Indian & 8 \\
\hline Other & \\
Please state: b) ...................................... & 97 \\
\hline
\end{tabular}

3, What education have you had?

\begin{tabular}{|l|c|}
\hline Primary school & 1 \\
\hline Secondary school (1-2 years) & 2 \\
\hline Secondary school (3 years or more) & 3 \\
\hline University, Waananga or other tertiary & 4 \\
\hline Don't know & 8 \\
\hline Didn't answer & 9 \\
\hline
\end{tabular}

4. How long in total have you been working in the sex industry?

5. Were you working in the sex industry before June 2003 when the law changed?

\begin{tabular}{|l|l|l|}
\hline Yes & 1 \\
\hline No & 2 \\
\hline Don't know & 8 \\
\hline Didn't answer & 9 \\
\hline
\end{tabular}

6. Have you been working in the sex industry continuously since you started?

\begin{tabular}{|l|l|l|}
\hline Yes & 1 \\
\hline No & 2 \\
\hline
\end{tabular}


Don't know

Didn't answer

8. How long do you think that you will stay in sex work?

\begin{tabular}{|l|l|}
\hline Less than 1 year & 1 \\
\hline $1-2$ years & 2 \\
\hline $3-5$ years & 3 \\
\hline More than 5 years & 4 \\
\hline Don't know & 8 \\
\hline Didn't answer & 9 \\
\hline
\end{tabular}

9. At present, are you doing any of the following activities outside of the sex industry?

\begin{tabular}{|l|l|l|l|l|}
\hline & Yes & No & Don't know & Didn't answer \\
\hline a) No other work & 1 & 2 & 8 & 9 \\
\hline b) Studying & 1 & 2 & 8 & 9 \\
\hline c) Paid work part-time & 1 & 2 & 8 & 9 \\
\hline d) Paid work full-time & 1 & 2 & 8 & 9 \\
\hline e) Training courses & 1 & 2 & 8 & 9 \\
\hline f) Caregiving & 1 & 2 & 8 & 9 \\
\hline g) Volunteer work & 1 & 2 & 8 & 9 \\
\hline
\end{tabular}

10. Within what age range were you when you started working?

\begin{tabular}{|l|l|l|}
\hline Under 16 years & & 1 \\
\hline $16-17$ years & 2 \\
\hline $18-21$ years & 3 \\
\hline $22-29$ years & 4 \\
\hline $30-45$ years & 5 \\
\hline
\end{tabular}




\begin{tabular}{|l|l|l|}
\hline Over 45 years & 6 \\
\hline Didn't answer & 9 \\
\hline
\end{tabular}

11a. Do you have any children?

\begin{tabular}{|l|l|}
\hline Yes (go to $11 \mathrm{~b})$ & 1 \\
\hline No (go to 12$)$ & 2 \\
\hline Don't know & 8 \\
\hline Didn't answer & 9 \\
\hline
\end{tabular}

11b. How many children at the moment depend on you financially? 


\section{Appendix C: Key Informant Interview Guide}

\section{Background}

(a) Can I ask you to please describe your role within this organisation / business?

(b) How long have you been in this role?

(c) Could you please tell me about the nature of your involvement / working relationship with the sex workers and the sex industry? (e.g., outreach, health provider, manager)

\section{Position on street work}

(a) What is your overall opinion of sex work?

(b) Some people hoped that one impact of the PRA would be that street workers would relocate to indoor working environments. Recent research suggests this doesn't appear to have happened. Why do you think some women continue to work on the street?

(c) Would it be better for street workers to move indoors? Why?

(d) What is your view on indoor sex work - is that safer than outdoor?

(d) How much do you agree that street based workers are 'vulnerable'? Why do you think this?

(e) Do you think street work should be made illegal? Why/why not?

\section{The risk of violence}

(a) What in your view are the main risks for women involved in street based sex work?

(b) How much do you think street sex workers in this area experience harassment from other local people? Why do you think this is? What impact does this have?

(c) Why do you think street sex workers sometimes get harassed by other members of the public? 
(d) A wide range of research suggests that only a small proportion of individuals are extremely violent towards street sex workers. Why do you think some people are violent towards street based sex workers? Who is violent and what relationship do they have with street workers?

(e) How much do you think we should be particularly concerned about female street based sex workers experiencing violence? Is this really such a unique risk? Why/why not?

(f) Thinking about the workers you have been in contact with, do you think workers are worried about being attacked when they are working? If yes, what impact does this have on their personal wellbeing? If no, what consequences does this have?

(g) How do you think street based workers cope with the risk of violence?

(h) In your view, are street based workers likely to report experiences of violence encountered in their work? If not, do you think they deal with it another way?

\section{Specific questions for Police}

What are the barriers to reporting violence for street-based sex workers? What are the barriers to sex workers engaging in discussions with the police?

Can you describe your approach to engaging with street-based sex workers?

What was the police relationship with street-based sex workers like before the law change? Has this changed? How?

How much is violence against sex workers a problem in Christchurch?

How much is gang involvement a characteristic of the street-based sex industry in Christchurch?

From your perspective, how much are stand over tactics and issue in Christchurch?

\section{Harnessing safety}

(a) How do you think street-based workers learn to avoid dangerous situations?

(b) How do you think street-based workers can keep themselves safe when they are working?

(c) What do you think are the most important sources of information for women who are new to street-based sex work to work safely? 
(d) Some workers might employ a minder to watch in the background while they are working and take down details of cars they get into in case something goes wrong. What do you think of this?

(e) Does your organisation/service do anything in particular to influence levels of safety in the street-based industry? How do workers respond to this?

(f) A couple of years ok, the PC in Christchurch distributed a safety kit amongst street workers. Were you aware of this?

(g) The PC in Christchurch have also been operating a service called 'Protext' for street based workers that they can register for and receive alerts to their mobile if a dodgy client has been around. They can also make reports to the service if they are worried about a client. What do you think of this?

(h) Thinking about decriminalisation, do you think it is now safer to work on the street as a sex worker?

\section{Future change}

(a) Is there anything that you think would make street based workers safer?

(b) Any other comments?

Thank you for taking part in this research 


\begin{tabular}{l|l}
\hline TO & Lynzi Armstrong \\
\hline COPY TO & Monica Lichti \\
\hline FROM & Dr Rhonda Shaw, Convener, Human Ethics Committee \\
\hline
\end{tabular}

\begin{tabular}{l|l}
\hline DATE & 11 August 2008 \\
\hline PAGES & 1 \\
\hline
\end{tabular}

\begin{tabular}{l|l}
\hline SUBJECT & $\begin{array}{l}\text { Ethics Approval: No } 15554 \\
\text { Title: Survival and Resistance: Risk management } \\
\text { strategies to negotiate violence amongst female street- } \\
\text { based sex workers }\end{array}$ \\
\hline
\end{tabular}

Dear Lynzi,

Thank you for your application for ethical approval, which has now been considered by the Social and Cultural Studies Human Ethics Sub-Committee.

Your application has been approved as of May $26^{\text {th }} 2008$. If your data collection is not completed by the approved completion date please apply to the Human Ethics Committee for an extension to this approval.

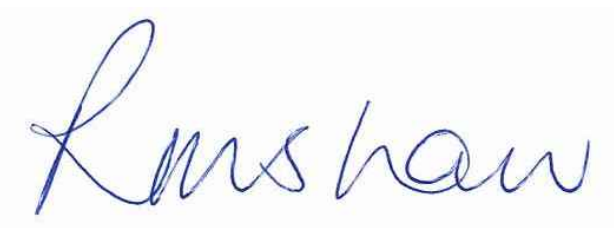

Convener 


\section{Appendix E: Sex Worker Participant Information Sheet}

\section{Street based sex work risk management research}

\section{Information for sex workers}

I am undertaking a research project at Victoria University of Wellington for my $\mathrm{PhD}$ degree in Criminology. This project aims to explore the ways in which female street based sex workers try to avoid violence when working, and how they feel about the risk of violence in their work.

You are invited to participate in this study. Your involvement in this project will be to agree to take part in an interview of around 1 hour with the researcher, Lynzi Armstrong. It would be very useful if you could take part in more than one interview, but this is your decision. Your contribution is valued highly as a professional working in the sex industry.

You will be asked a series of questions based on your experiences as a sex worker. The interview is flexible and you do not have to answer any questions that you do not feel comfortable with. You can talk about any aspect of your work that you think is important to this research and you should not feel restricted by the questions.

I will provide a summary of the results of the research when it is finished to NZPC so you can ask to see the copy at their office. You can also phone me directly if you would like your own copy sent by email or post.

Responses collected in the interviews will form the basis of this project and will be anonymously put into a written report. All material collected will be kept confidential - no one will have access to your personal information. The results of this project may be published, but your name (real or working) will never be used in the research.

However if you tell me anything in the interview that suggests you or someone else is in a situation where you might be seriously harmed, then confidentiality could be broken. I would discuss this with you in advance.

To confirm that you want to take part in the interview I need to you to sign a consent form. This form will be kept in a safe place so no-one has access to it and it will be destroyed when the project is finished. Even if you do sign the consent form you can still change your mind about taking part at any time. Your participation in this project is voluntary. 
If you have any questions about the research at any time you are welcome to contact me on 04463 5032, or either of my supervisors - Dr. Jan Jordan on 044635811 or Dr Elaine Mossman on 044635371.

This project has been reviewed by the Victoria University of Wellington Human Ethics Committee

Lynzi Armstrong 


\section{Appendix F: Key Informant Participant Information Sheet}

\section{Street based sex work risk management research}

\section{Information for key informants}

I am undertaking a research project at Victoria University of Wellington for my $\mathrm{PhD}$ degree in Criminology. This project aims to explore the ways in which female street based sex workers try to avoid violence when working, and how they feel about the risk of violence in their work. The intended outcome of the research is to consider how the risk of violence might be further minimised, to protect the right of female street workers to work safely in the industry.

You are invited to participate in this study. Your involvement in this project will be to agree to take part in an interview based on your experiences working with street based sex workers, or work closely related to this sector of the sex industry.

The interview is flexible and you do not have to answer any questions that you do not feel comfortable with. You can talk about any issues that you think are important to this research and you should not feel restricted by the questions. You are welcome to review the transcript of your interview at any time and make changes to anything you have said.

The results of this project may be published, but your name will never be used in the research and your participation will always be kept strictly private. We may want to quote what you say to illustrate various points in the research reports, but your words will definitely not be attributed to you personally. However, I may link the quote to the organisation you represent (i.e. NZPC, NZ Police, Salvation Army). I will provide you with a summary of the results when the project is finished.

Responses collected in the interviews will form the basis of this project and will be anonymously put into a written report. All material collected will be kept confidential - no one will have access to your personal information. However if you tell me 
anything in the interview that suggests someone is in a situation where they might be seriously harmed, then confidentiality could be broken. I would discuss this with you in advance.

To confirm that you want to take part in the interview I need to you to sign a consent form. This form will be kept in a safe place so no-one has access to it and it will be destroyed when the project is finished. Even if you do sign the consent form you still have the right to withdraw at any time.

If you have any questions about the research at any time you are welcome to contact me on 0275188941 or lynzi.armstrong@vuw.ac.nz. Alternatively you are welcome to contact either of my supervisors - Dr. Jan Jordan on 04463 5811, or Dr Elaine Mossman on 044635371.

This project has been reviewed by the Victoria University of Wellington Human Ethics Committee

Lynzi Armstrong 


\section{Appendix G: Participant Consent For}

\section{Participant Consent Form}

The researcher has explained to me the purpose of the research.

I know that I don't have to take part in the research if I don't want to.

I know I can choose which questions I want to answer and I can leave the discussion at any time.

I understand that all information will be kept confidential. What I say may be included in a research report, but not my name or anything that can identify me. However, with my agreement, my views could be linked to the organisation (or type of organisation) that I work for.

I understand that the only exception to this is if they thought that I or someone else was at risk of serious harm and they will discuss this with me first. 
